MARCOS GUANDALINI

\begin{abstract}
ANÁLISE METODOLÓGICA DO POSICIONAMENTO RELATIVO ATRAVÉS DO GNSS E SUAS APLICAÇÕES NA ENGENHARIA: USO DA TÉCNICA RTK/GSM
\end{abstract}


MARCOS GUANDALINI

\section{ANÁLISE METODOLÓGICA DO POSICIONAMENTO RELATIVO ATRAVÉS DO GNSS E SUAS APLICAÇÕES NA ENGENHARIA: USO DA TÉCNICA RTK/GSM}

\footnotetext{
Dissertação de mestrado apresentada à Escola Politécnica da Universidade de São Paulo, para obtenção do título de Mestre em Engenharia de Transportes.
} 
MARCOS GUANDALINI

\section{ANÁLISE METODOLÓGICA DO POSICIONAMENTO RELATIVO ATRAVÉS DO GNSS E SUAS APLICAÇÕES NA ENGENHARIA: USO DA TÉCNICA RTK/GSM}

Dissertação de mestrado apresentada à Escola Politécnica da Universidade de São Paulo, para obtenção do título de Mestre em Engenharia de Transportes.

Área de concentração:

Engenharia de Transportes

Orientador:

Prof. Dr. Denizar Blitzkow 
Este exemplar foi revisado e alterado em relação à versão original, sob responsabilidade única do autor e com a anuência de seu orientador.

São Paulo, 07 de agosto de 2012.

Assinatura do autor

Assinatura do orientador

Guandalini, Marcos

Análise metodológica do posicionamento relativo através do GNSS e suas aplicações na engenharia: uso da técnica RTK/ GSM / M. Guandalini. -- ed.rev. -- São Paulo, 2012.

$211 \mathrm{p}$.

Dissertação (Mestrado) - Escola Politécnica da Universidade de São Paulo. Departamento de Engenharia de Transportes.

1. Geodésia 2. Geodésia espacial 3. Sistema de posiciona mento global I. Universidade de São Paulo. Escola Politécnica. Departamento de Engenharia de Transportes II. t. 
Aos meus pais, Adolfo e Maria Luiza, pelo exemplo de integridade, honestidade e pela oportunidade de realizar este trabalho.

À minha amada esposa, Fernanda, pela dedicação, compreensão e, mais do que tudo, pela motivação para enfrentar este desafio. 


\section{AGRADECIMENTOS}

Ao meu orientador e amigo, Prof. Dr. Denizar Blitzkow, pela confiança, paciência e exemplo de profissional que guardarei para o resto da minha vida.

Aos professores Dr Edvaldo Simões e Dra. Ilce de Oliveira Campos, que contribuíram substancialmente para minha qualificação.

Aos amigos Danilo Rodrigues e Marcelo Nero, pelo constante apoio e colaboração no desenvolver desta dissertação.

A todos colaboradores da Alezi Teodolini, que contribuíram direta e indiretamente na elaboração deste trabalho.

À amiga Lilian Pontes, que colaborou durante todo o projeto.

Ao amigo Joe Sass, da ASHTECH, que contribuiu com informações importantíssimas.

Aos meus irmãos, Fernando, Gustavo e Rafael Guandalini e minha cunhada Amanda Frasson, pelo apoio e confiança.

Ao Prof. Antonio Moacir Rodrigues Nogueira, que colaborou em minha graduação de forma marcante.

Aos amigos Leandro Falavigna, Odilo Siqueira, Andre Toledo e Henrique Martins pelo constante apoio e incentivo.

A todos os colegas e professores do Laboratório de Topografia e Geodésia do Departamento de Transportes da Escola Politécnica da USP. 
A vitória e o fracasso estão tão próximos, que só a força do querer pode fazer a diferença...

Marcos Guandalini 


\section{RESUMO}

A utilização dos sistemas de navegação global por satélite, conhecidos pela sigla GNSS (Global Navigation Satellite System), cresceu vertiginosamente durante a última década. Atualmente, os receptores GNSS são ferramentas seguras, eficientes e altamente produtivas para a realização de observações aos satélites, possibilitando determinar coordenadas geodésicas sobre a superfície terrestre. As ferramentas e tecnologias disponíveis no mercado são de essencial importância no desenvolvimento eficiente dos projetos de engenharia. No entanto, o domínio das técnicas de trabalho e o conhecimento profundo de todos os métodos de execução são os principais obstáculos para a introdução de uma nova metodologia em projetos de engenharia. Este trabalho tem por objetivo esclarecer e testar a associação dessa tecnologia com o uso da telefonia celular, em especial com a utilização da conexão GSM (Global System for Mobile Communication)/GPRS (General Packet Radio Service), disponíveis no Brasil. O posicionamento preciso em tempo real tradicionalmente envia as observações de fase da onda portadora entre o receptor GNSS base e móvel através de frequências de rádio. Isso possibilita a determinação de coordenadas geodésicas e topográficas instantaneamente. Entretanto, obstáculos como áreas de relevo acidentado, edificações ou a baixa potência do rádio que envia os sinais fazem com que a comunicação entre os equipamentos seja interrompida com a perda frequente da solução instantânea. Apesar disso, este método de trabalho está consagrado como o mais produtivo, mantendo precisões topográficas, sendo que superar as restrições citadas seria uma inovação na área de Geodésia e Topografia. Com o avanço de tecnologias correlatas, criou-se uma nova maneira de enviar as observações de fase utilizando a conexão GSM através do pacote de dados GPRS. A conexão GSM é aplicada na tecnologia móvel padrão, que se tornou a mais popular para telefones celulares, de fácil acesso a qualquer usuário. Adequando o tradicional protocolo RTCM (Radio Technical Commission for Maritime Services) em um formato capaz de ser transmitido por GPRS, desenvolveu-se assim o serviço NTRIP (Network Transport of RTCM via Internet Protocol). Com esta nova concepção da conexão GSM/GPRS é possível realizar levantamentos com a técnica RTK (Real Time Kinematic) com 
vetores de até $100 \mathrm{~km}$, mantendo as precisões atingidas com a metodologia atual de pós-processamento. Os tipos de equipamentos, os limites de distâncias e a qualidade dos dados obtidos estão sendo discutidos nesta pesquisa e analisados de forma a verificar os resultados atingidos em termos de precisão e acurácia.

Palavras-chave: Geodésia. Posicionamento global. Satélites artificiais. Conexão GSM. Técnica RTK. Serviço NTRIP. 


\section{ABSTRACT}

The use of Global Navigation Satellite System has dramatically grown over the last decade. Currently, GNSS receivers are secure, efficient and highly productive for carrying out observations for the geodetic coordinates determination on the Earth's surface. The tools and technologies available on the market are essential in the establishment of engineering projects. However, the total knowledge of the techniques and the total domain of the execution methods are the first obstacles to the full incorporation of the technology in the engineering projects. This work is to clarify and to testethe technology described in this dissertation related to the facilities of cell phone coverage, particularly the GSM/GPRS connection able to be used in Brazil. The precise positioning in real-time traditionally involves the transmission of phase measurements between base and rover GNSS receivers; this is traditionally carried out through radio frequencies. This allows determining geodetic and topographic coordinates instantaneously. However, obstacles like accident topography terrain, buildings or low power of radio basis transmission, provoke constant interruptions in the communication among the radios and the consequent losing of the instant solution. Nevertheless, this methodology is the most productive for a centimetric accuracy; so the major challenge in geodetic positioning is to overcome the mentioned difficulties. With the high development of technologies related to mobile phone, a new way to transmit the observations using the GSM/GPRS connection was created. The GSM connection is a standard mobile technology, the most popular for cell phones, which became of easy access to any person. The traditional RTCM protocol in a convenient format can be transmitted by GSM/GPRS connection which is known as NTRIP service, becoming a full digital communication system. As of this new concept, it is possible to note vectors up to $100 \mathrm{~km}$ in RTK technique employment with the same high quality measurement. The equipment characteristics, distance limits and quality of the data recorded have been discussed and analyzed here in order to verify whether the results can achieve the necessary precision and accuracy. 
Keywords: Geodesy. Global positioning. Satellite geodesy. GSM connection. RTK technique. NTRIP service. 


\section{LISTA DE ILUSTRAÇÕES}

Figura 1 - Visibilidade dos satélites com o GNSS. .........................40

Figura 2 - Esquema geral do projeto GNSS.....................................40

Figura 3 - Interoperabilidade do SBAS. ......................................... 42

Figura 4 - Conceito de pseudossatélite ...........................................44

Figura 5 - Esquema operacional do LAAS. ..................................... 44

Figura 6 - Estrutura dos sinais GPS-2F após a modernização. ...... 46

Figura 7 - Arquitetura do sistema GALILEO................................... 49

Figura 8 - Intervalos de frequências do GPS, GLONASS e GALILEO.

Figura 9 - Par de Receptores GPS ProMark3 RTK L1....................51

Figura 10 - Par de Receptores GNSS ProMark 500 RTK L1L2. ....... 52

Figura 11 - Tela de informações do Receptor GNSS ProMark 500. 55

Figura 12 - Técnica RTK/UHF. .....................................................57

Figura 13 - Técnica RTK/GSM......................................................58

Figura 14 - Cobertura da rede com conexão GSM realizada por várias células vizinhas. Esquema hexagonal teórico utilizado como primeira aproximação.

Figura 15 - Cobertura da rede com conexão GSM realizada por 3 célulasvizinhas. Esquema circular realista utilizado como segunda aproximação.

Figura 16 - Borda de cobertura de 2 células vizinhas numa terceira aproximação onde existe a influência do relevo.

Figura 17- Destaque para as interfaces de ligação dos elementos de rede.

Figura 18 - Arquitetura de rede com conexão GSM mostrandoo

SEB e na parte superior, o SC.........................................................66

Figura 19 - Quadro com 8 slots da padronização FDMA/TDMA......67 
Figura 20 - Componentes do serviço NTRIP e a integração entre eles.

Figura 21 - Operação de configuração do software NtripServer. ...75 Figura 22 - Exemplo de Informações visualizadas no NtripCaster. 76

Figura 23 - Configuração do software NtripClient. 76

Figura 24 - Exemplo de aplicativo utilizando o software NtripClient dentro da interface própria de um fabricante específico. .77

Figura 25 - Opções de uso da conexão GSM/GPRS em aplicações utilizando a técnica RTK/GSM.....................................................78

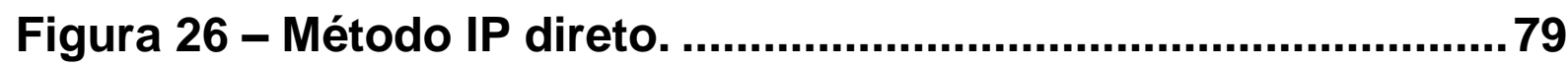

Figura 27 - Configuração do Método conexão GSM Direta.............. 80

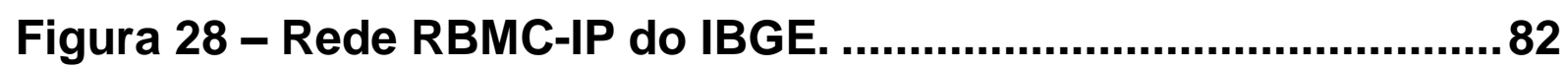

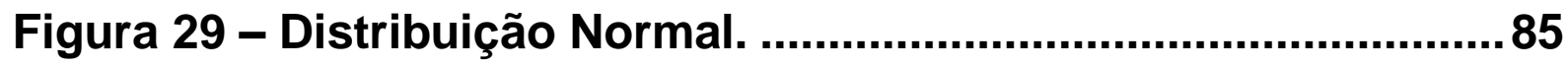

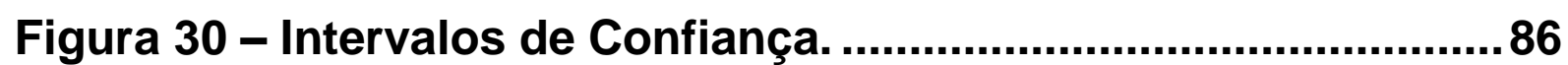

Figura 31 - Receptor GNSS ProMark 500.......................................90

Figura 32 - Receptor GPS ProMark3. .............................................

Figura 33 - Receptor GPS L1 com celular conectado via Bluetooth.

Figura 34 - Receptor GNSS L1/L2 com modem de conexão GSM integrado.

Figura 35 - Configuração dos parâmetros de conexão GSM/GPRS do receptor móvel

Figura 36 - Conectando ao software NtripCaster e selecionando a ERA IP POLI.

Figura 37 - Armazenando Coordenada com o emprego da técnica RTK/GSM. 96

Figura 38 - Dados e foto do vértice SAT 91607 ................................98

Figura 39 - Dados e foto do vértice V2295......................................98

Figura 40 - Dados e foto do vértice V2296.....................................98 
Figura 41 - Dados e foto do vértice V2009........................................99

Figura 42 - Dados e foto do vértice V2837......................................99

Figura 43 - Dados e foto do vértice V2510.................................... 99

Figura 44 - Dados e foto do vértice SAT93814............................... 100

Figura 45 - Dados e foto do vértice SAT93794. ............................. 100

Figura 46 - Dados e foto do vértice SAT96035............................. 100

Figura 47 - Dados e foto do vértice SAT93504.............................. 101

Figura 48 - Vértices utilizados da Rede Geodésica da Prefeitura de

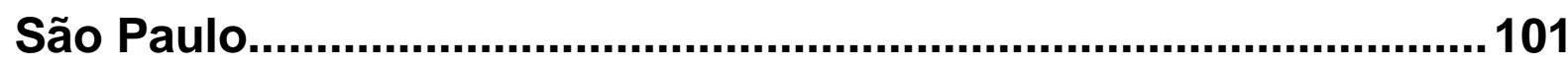

Figura 49 - Vértices utilizados do Sistema Geodésico Brasileiro. 102

Figura 50 - Dispersão dos pontos ao redor do valor oficial, no exp. 1 106

Figura 52 - Histograma Referente a E, no exp. 1........................106

Figura 51 - Incidência da coordenada E, no exp. 1 ........................ 106

Figura 54 - Histograma Referente a N, no exp. 1. ......................... 107

Figura 53 - Incidência da Coordenada N, no exp. 1......................107

Figura 56 - Histograma Referente a $h$, no exp. 1.......................... 107

Figura 55 - Incidência da Coordenada h, no exp. 1........................ 107

Figura 57 - Dispersão dos pontos ao redor do valor oficial, no exp.

2. 108

Figura 58 - Incidência da Coordenada E, no exp. 2 ...................... 109

Figura 59 - Histograma referente a E, no exp. 2............................ 109

Figura 60 - Histograma referente a N, no exp. 2............................ 109

Figura 61 - Incidência da Coordenada N, no exp. 2. ..................... 109

Figura 63 - Histograma referente a $h$, no exp. 2 . ..........................110

Figura 62 - Incidência da Coordenada h, no exp. 2.......................110

Figura 64 - Dispersão dos pontos ao redor do valor médio, exp. 3.

Figura 65 - Histograma referente a E, o exp. 3. 
Figura 66 - Incidência da Coordenada E, no exp. 3. ......................112

Figura 67 - Histograma referente a $\mathrm{N}$, no exp. 3...........................112

Figura 68 - Incidência da Coordenada N, no exp. 3. .....................112

Figura 69 - Incidência da Coordenada h, no exp. 3........................112

Figura 70 - Histograma referente a $h$, o exp. 3. ........................... 112

Figura 71 - Dispersão dos pontos ao redor do valor médio, exp. 4.

Figura 72- Histograma referente a E, no exp. 4............................ 114

Figura 73 - Incidência da Coordenada E, no exp. 4. ......................114

Figura 74 - Histograma referente a $\mathrm{N}$, no exp. 4.............................115

Figura 75 - Incidência da Coordenada N, no exp. 4. ...................... 115

Figura 76 - Histograma referente a $h$, no exp. 4............................115

Figura 77 - Incidência da Coordenada $h$, no exp. 4......................115

Figura 78 - Dispersão dos pontos ao redor do valor oficial, exp. 5.

Figura 79 - Histograma referente a E, no exp. 5.........................117

Figura 80 - Incidência da Coordenada E, no exp. 5. .....................117

Figura 81 - Incidência da Coordenada N, no exp. 5.......................117

Figura 82 - Histograma referente a N, no exp. 5. ..........................117

Figura 83- Incidência da Coordenada $h$, no exp. 5.........................118

Figura 84 - Histograma referente a $h$, no exp. 5...........................118

Figura 85 - Dispersão dos pontos ao redor do valor oficial, exp. 6.

Figura 86 - Incidência da Coordenada E, no exp. 6. .....................119

Figura 87 - Histograma referente a E, no exp. 6..........................119

Figura 88 - Incidência da Coordenada N, no exp. 6......................120

Figura 89 - Histograma referente a $\mathrm{N}$, no exp. 6........................... 120

Figura 90 - Incidência da Coordenada h, no exp. 6.......................120

Figura 91 - Histograma referente a $h$, no exp. 6.........................120 
Figura 92 - Dispersão dos pontos ao redor do valor oficial, exp. 7a.

Figura 93 - Incidência da Coordenada E, no exp. 7a. ..................... 122

Figura 94 - Histograma referente a E, no exp. 7a.......................... 122

Figura 95 - Incidência da Coordenada N, no exp. 7a.................... 123

Figura 96 - Histograma referente a N, no exp. 7a...........................123

Figura 97 - Incidência de Coordenada $h$, no exp. 7a......................123

Figura 98 - Histograma referente a h, no exp. 7a.......................... 123

Figura 99 - Dispersão dos pontos ao redor do valor oficial, exp. 7b.

Figura 100 - Incidência da Coordenada E,..................................125

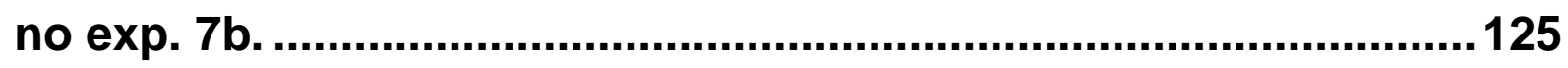

Figura 101 - Histograma Referente a E, no exp. 7b....................... 125

Figura 102- Incidência da Coordenada N, no exp. 7b..................... 125

Figura 103 - Histograma Referente a N, no exp. 7b. ......................125

Figura 104 - Incidência da coordenada $h$, no exp. 7b.................... 125

Figura 105 - Histograma Referente a h, no exp. 7b. ..................... 125

Figura 106 - Dispersão dos pontos ao redor do valor oficial, exp.8a.

Figura 107 - Incidência da Coordenada E, no exp. 8a. ...................127

Figura 108 - Histograma referente a E, no exp. 8a........................ 127

Figura 109 - Incidência da Coordenada N, no exp. 8a. ................. 128

Figura 110 - Histograma referente a N, no exp. 8a........................ 128

Figura 111 - Incidência da Coordenada h, no exp. 8a....................128

Figura 112 - Histograma referente a $h$, no exp. 8a........................128

Figura 113 - Dispersão dos pontos ao redor do valor oficial, exp. 8b.

Figura 114 - Incidência da Coordenada E, no exp. 8b. .................. 130

Figura 115 - Histograma referente a E, no exp. 8b........................ 130 
Figura 116 - Incidência da Coordenada N, no exp. 8b................... 130

Figura 117- Histograma referente a $\mathrm{N}$, no exp. 8b. ........................130

Figura 118 - Incidência da Coordenada $h$, no exp. 8b. ..................130

Figura 119 - Histograma referente a h, no exp. 8b. .......................130

Figura 120 - Dispersão dos pontos ao redor do valor oficial, exp.

9a.

Figura 121 - Incidência da Coordenada E, no exp. 9a. ..................132

Figura 122 - Histograma Referente a E, no exp. 9a....................... 132

Figura 123- Incidência da Coordenada N, no exp. 9a.....................133

Figura 124 - Histograma Referente a N, no exp. 9a.....................133

Figura 125 - Incidência da Coordenada h, no exp. 9a.................... 133

Figura 126 - Histograma Referente a h, no exp. 9a....................... 133

Figura 127 - Dispersão dos pontos ao redor do valor oficial, exp.

9b. 134

Figura 128 - Incidência da Coordenada E, no exp. 9b. .................. 135

Figura 129 - Histograma Referente a E, no exp. 9b....................... 135

Figura 130 - Incidência da Coordenada N, no exp. 9b.................. 135

Figura 131 - Histograma Referente a N, no exp. 9b. .......................135

Figura 132 - Incidência da Coordenada h, no exp. 9b. ................... 135

Figura 133 - Histograma referente a $h$, no exp. 9b........................ 135

Figura 134 - Dispersão dos pontos ao redor do valor oficial, exp.

10

Figura 135 - Incidência da Coordenada E, no exp. 10. .................. 137

Figura 136 - Histograma Referente a E, no exp. 10......................137

Figura 137 - Incidência da Coordenada N, no exp. 10................. 138

Figura 138 - Histograma Referente a N, no exp. 10....................... 138

Figura 139 - Incidência da Coordenada $h$, no exp. 10....................138

Figura 140 - Histograma Referente a h, no exp. 10..................... 138 
Figura 141 - Dispersão dos pontos ao redor do valor oficial, exp.

11 139

Figura 142 - Incidência da Coordenada E,no exp. 11. ....................140

Figura 143 - Histograma referente a E, no exp. 11........................ 140

Figura 144 - Incidência da Coordenada N, no exp. 11 ...................140

Figura 145 - Histograma Referente a N, no exp. 11........................ 140

Figura 146 - Incidência da Coordenada h, no exp. 11.................... 141

Figura 147 - Histograma Referente a h, no exp. 11 ........................141

Figura 148 - Dispersão dos pontos ao redor do valor oficial, exp.

12a.

Figura 149 - Incidência da Coordenada e_no exp. 12a................... 142

Figura 150 - Histograma Referente a E, no exp. 12a..................... 142

Figura 151 - Incidência da Coordenada N,no exp. 12a. ..................143

Figura 152 - Histograma Referente a N, no exp. 12a...................... 143

Figura 153 - Incidência da Coordenada h, no exp. 12a...................143

Figura 154 - Histograma Referente a h, no exp. 12a...................... 143

Figura 155 - Dispersão dos pontos ao redor do valor oficial, exp. 12b.

Figura 156 - Incidência da Coordenada E, no exp. 12b. 145

Figura 157 - Histograma Referente a E, no exp. 12b...................... 145

Figura 158 - Incidência da Coordenada N, no exp. 12b................. 145

Figura 159 - Histograma Referente a N, no exp. 12b. ................... 145

Figura 160 - Incidência da Coordenada h, no exp. 12b. ................145

Figura 161 - Histograma Referente a h, no exp. 12b...................... 145

Figura 162 - Dispersão dos pontos ao redor do valor oficial, exp.

13. 147

Figura 163 - Incidência da coordenada E, no exp. 13....................147

Figura 164 - Histograma referente a E, no exp. 13....................... 147

Figura 165- Incidência da Coordenada N, no exp. 13..................... 148 
Figura 166 - Histograma referente a N, no exp. 13.........................148

Figura 167 - Incidência da Coordenada h, no exp. 13.................... 148

Figura 168 - Histograma referente a $h$, no exp. 13......................... 148

Figura 169 - Dispersão dos pontos ao redor do valor oficial, exp.

14 149

Figura 170 - Incidência da Coordenada E, no exp. 14................. 150

Figura 171 - Histograma Referente a E, no exp. 14...................... 150

Figura 172 - Incidência da Coordenada N, no exp. 14.................. 150

Figura 173- Histograma referente a $\mathrm{N}$, no exp. 14. .........................150

Figura 174- Incidência da Coordenada $h$, no exp. 14. ................... 150

Figura 175 - Histograma Referente a h, no exp. 14...................... 150

Figura 176 - Dispersão do ponto no exp. 15...................................151

Figura 177 - Incidência da Coordenada E, no exp. 15. .................. 152

Figura 178 - Histograma Referente a E, no exp. 15...................... 152

Figura 179 - Incidência da Coordenada N, no exp. 15.................. 152

Figura 180 - Histograma Referente a N, no exp. 15....................... 152

Figura 181- Incidência da Coordenada $h$, no exp. 15.................... 152

Figura 182 - Histograma Referente a h, no exp. 15....................... 152

Figura 183 - Dispersão do ponto no exp. 16...................................153

Figura 184 - Incidência da Coordenada E, no exp. 16. .................. 154

Figura 185 - Histograma Referente a E, no exp. 16...................... 154

Figura 186 - Incidência da Coordenada N, no exp. 16................. 154

Figura 187- Histograma Referente a N, no exp. 16. ....................... 154

Figura 188- Incidência da Coordenada $h$, no exp. 16................... 154

Figura 189 - Histograma referente a h, no exp. 16...................... 154 


\section{LISTA DE TABELAS}

Tabela 1 - Resumo da modernização do GLONASS .......................47

Tabela 2 - Estrutura de sinais do projeto GALILEO ..........................48

Tabela 3 - Sinais disponíveis com a integração das constelações de satélites no projeto GNSS .......................................................50

Tabela 4 - Formato RTCM 3.0 e 3.1 e os tipos de mensagens que existem nessas versões são listados de 1001 a 1029.

Tabela 5 - Comparação das vantagens e desvantagens das

técnicas RTK/UHF x RTK/GSM........................................................59

Tabela 6 - Divisão da banda de 900 MHz na conexão GSM.............64 64

Tabela 7 - Esquemas de codificação por meio da padronização

GPRS

Tabela 8 - Níveis de conexão e número de slots no sistema com

conexão GSM/GPRS ......................................................................68

Tabela 9 - Tabela Físico X Lógico ...................................................73

Tabela 10 - Precisões nominais .................................................... 87

Tabela 11 - Coordenadas Oficiais da ERA IP POLI ..........................96

Tabela 12 - Informações dos vértices usados nos experimentos.103

Tabela 13 - Resultado para o Teste T Student no exp. 1...............156

Tabela 14 - Resultado do Teste Qui-Quadrado para o exp. 1........156

Tabela 15 - Discrepâncias das coordenadas obtidas no exp. 1....157

Tabela 16 - Resultado para o Teste T Student no exp. 2...............157

Tabela 17 - Resultado para o Teste Qui-Quadrado para o exp. 2. 158

Tabela 18 - Discrepâncias das coordenadas obtidas no exp. 2....158

Tabela 19 - Resultado para o Teste T Student no exp. 3...............159

Tabela 20 - Resultado para o Teste Qui-Quadrado para o exp. 3. 159

Tabela 21 - Discrepâncias das coordenadas obtidas no exp. 3.... 160 
Tabela 22 - Resultado para o Teste T Student no exp. 4...............160

Tabela 23 - Resultado para o Teste Qui-Quadrado para o exp. 4.161

Tabela 24 - Discrepâncias das coordenadas obtidas no exp. 4....161

Tabela 25 - Resultado para o Teste T Student no exp. 5............... 162

Tabela 26 - Resultado para o Teste Qui-Quadrado para o exp. 5.162

Tabela 27 - Discrepâncias das coordenadas obtidas no exp. 5....163

Tabela 28 - Resultado para o Teste T Student no exp. 6...............163

Tabela 29 - Resultado para o Teste Qui-Quadrado para o exp. 6.164

Tabela 30 - Discrepâncias das coordenadas obtidas no exp. 6....164

Tabela 31 - Resultado para o Teste T Student no exp. 7a.............165

Tabela 32 - Resultado para o Teste Qui-Quadrado para o exp. 7a.

Tabela 33- Discrepâncias das coordenadas obtidas no exp. 7a...166

Tabela 34- Resultado para o Teste T Student no exp. 7b..............166

Tabela 35 - Resultado para o Teste Qui-Quadrado para o exp. 7b.

Tabela 36 - Discrepâncias das coordenadas obtidas no exp. 7b.. 167 Tabela 37 - Resultado para o Teste T Student no exp. 8a.............168

Tabela 38 - Resultado para o Teste Qui-Quadrado para o exp. 8a. 168

Tabela 39 - Discrepâncias das coordenadas obtidas no exp. 8a.. 169

Tabela 40 - Resultado para o Teste T Student no exp. 8b.............169

Tabela 41- Resultado para o Teste Qui-Quadrado para o exp. 8b. 170 Tabela 42 - Discrepâncias das coordenadas obtidas no exp. 8b..170 Tabela 43 - Resultado para o Teste T Student no exp. 9a.............171

Tabela 44 - Resultado para o Teste Qui-Quadrado para o exp. 9a.

Tabela 45 - Discrepâncias das coordenadas obtidas no exp. 9a..172

Tabela 46 - Resultado para o Teste T Student no exp. 9b. 172 
Tabela 47 - Resultado para o Teste Qui-Quadrado para o exp. 9b. 173

Tabela 48 - Discrepâncias das coordenadas obtidas no exp. 9b.. 173

Tabela 49 - Resultado para o Teste T Student no exp. 10..............174

Tabela 50 - Resultado para o Teste Qui-Quadrado para o exp. 10.

Tabela 51 - Discrepâncias das coordenadas obtidas no exp. 10.. 175

Tabela 52 - Resultado para o Teste T Student no exp. 11.............175

Tabela 53 - Resultado para o Teste Qui-Quadrado para o exp. 11.

Tabela 54 - Discrepâncias das coordenadas obtidas no exp. 11..176

Tabela 55 - Resultado para Teste de T Student no exp. 12a. .........177

Tabela 56 - Resultado para o Teste Qui-Quadrado para o exp. 12a.

Tabela 57 - Discrepâncias das coordenadas obtidas no exp. 12a.

Tabela 58 - Resultado para Teste de T Student no exp. 12b..........178 Tabela 59 - Resultado para o Teste Qui-Quadrado para o exp. 12b.

Tabela 60 - Discrepâncias das coordenadas obtidas no exp. 12b.

Tabela 61 - Resultado para o Teste T Student no exp. 13..............179

Tabela 62 - Resultado para o Teste Qui-Quadrado para o exp. 13.

Tabela 63 - Discrepâncias das coordenadas obtidas no exp. 13.. 180

Tabela 64 - Resultado para o Teste T Student no exp. 14. 181

Tabela 65 - Resultado para o Teste Qui-Quadrado para o exp. 14.

Tabela 66 - Discrepâncias das coordenadas obtidas no exp. 14.. 182 
Tabela 67 - Resultado para o Teste T Student no exp. 15.

Tabela 68 - Resultado para o Teste Qui-Quadrado para o exp. 15.

Tabela 69 - Discrepâncias das coordenadas obtidas no exp. 15.. 183

Tabela 70 - Resultado para o Teste T Student no exp. 16. 184

Tabela 71 - Resultado para o Teste Qui-Quadrado para o exp. 16.

Tabela 72 - Discrepâncias das coordenadas obtidas no exp. 16.. 185 Tabela 73 - Resumo dos resultados dos exp. 1, 2, 3, 4, 5 e 6 (solução Fixa).

Tabela 74 - Resumo dos resultados do exp. 7a, 8a, 9a, 11 e 12 a (solução Fixa).

Tabela 75 - Resumo dos resultados do exp. 7b, 8b, 9b, 10 e $12 b$ (solução flutuante). 189

Tabela 76 - Resumo dos resultados do exp. 13, 14, 15 e 16 (solução flutuante). 191

Tabela 77 - Aplicação x Precisão Esperada - Técnicas tradicionais.

Tabela 78 - Média das diferenças máxima de acordo com a distância, tipo solução da ambiguidade e equipamento utilizado.194 Tabela 79 - Diferença padrão máxima de acordo com a distância, tipo de solução da ambiguidade e equipamento utilizado. 194

Tabela 80- Classificação e finalidade dos vértices padrão INCRA e respectiva precisão exigid.

Tabela 81 -Aplicação x Precisão Esperada - técnicas propostas.196 


\section{LISTA DE ABREVIATURAS E SIGLAS}

$\begin{array}{ll}\text { AAF } & \text { American Air Force } \\ \text { ABAS } & \text { Aircraft-Based Augmentation System } \\ \text { ARP } & \text { Antenna Reference Point Parameter } \\ \text { AUC } & \text { Autentification Center } \\ \text { BINEX } & \text { Bynary Independent Exchange Format } \\ \text { BKG } & \text { Bundesamt für Kartographie und Geodäsie } \\ \text { BLADE } & \text { Base Line Accurate Determination Engine } \\ \text { CEGAT } & \text { Centro Geodésico da Alezi Teodolini } \\ \text { CERB } & \text { Controladora de Estação de Rádio Base } \\ \text { CORS } & \text { Continuously Operating Reference Station } \\ \text { CWAAS } & \text { Canadian Wide Area Augmentation System } \\ \text { DD } & \text { Duplas diferenças de fase } \\ \text { DoD } & \text { Departamento de Defesa Norte-Americano } \\ \text { DGNSS } & \text { Differential GNSS } \\ \text { DGPS } & \text { Differential GPS } \\ \text { EBC } & \text { Estação Base de Comutação } \\ \text { EDGE } & \text { Enhanced Data rates for GSM Evolution } \\ \text { EGNOS } & \text { European Geostationary Navigation Overlay Service } \\ \text { EM } & \text { Estação Móvel } \\ \text { EIR } & \text { Equipment Identity Recorder } \\ \text { EPN } & \text { European Permanent Network } \\ \text { ERA } & \text { Estação de Referência Ativa } \\ \text { ERAs } & \text { Estações de Referência Ativa } \\ \text { ERA IP } & \text { Estação de Referência Ativa com IP fixo } \\ \text { ERAs IP } & \text { Estações de Referência Ativa com IP fixo } \\ \text { ERB } & \text { Estação Rádio Base } \\ \text { FAA } & \text { Federal Aviation Administration } \\ \text { FDE } & \text { Fault Detection Excluding } \\ \text { FDMA } & \text { Frequency Division Multiple Acess } \\ \text { FIG } & \text { Fédération Internationale des Géomètres } \\ & \end{array}$




$\begin{array}{ll}\text { FTP } & \text { Format Transfer Protocol } \\ \text { FKP } & \text { Flacenkorretturparameter } \\ \text { GAGAN } & \text { GPS Aided Geo Augmented Navigation } \\ \text { GCC } & \text { GALILEO Control Center } \\ \text { GIS } & \text { Geographic Information System } \\ \text { GBAS } & \text { Ground Based Augmentation System } \\ \text { GDP } & \text { Geometric Dilution of Precision } \\ \text { GLONASS } & \text { Global'naya Navigatstonnaya Sputnikowaya Sistema } \\ \text { GPSFD } & \text { Global Position System Fix Data } \\ \text { GPS } & \text { Global Positioning System } \\ \text { GPRS } & \text { General Packet Radio Service } \\ \text { GNSS } & \text { Global Navigation Satellite System } \\ \text { GSM } & \text { Global System for Mobile Communication } \\ \text { HDP } & \text { Horizontal Dilution of Precision } \\ \text { HLR } & \text { Home Location Recorder } \\ \text { HTPIH } & \text { Hypertext Transfer Protocol Internet Host } \\ \text { HTTP } & \text { Hypertext Transfer Protocol } \\ \text { IGS } & \text { International GPS Service } \\ \text { IH } & \text { Internet Host } \\ \text { IMSI } & \text { International Mobile Subscriber Identity } \\ \text { INS } & \text { Inertial Navigation System } \\ \text { IP } & \text { Internet Protocol } \\ \text { LAAS } & \text { Local Area Augmentation System } \\ \text { LAN } & \text { Local Area Network } \\ \text { LBS } & \text { Location Based System } \\ \text { L1 } & \text { Receptores GPS/GNSS de simples frequência. } \\ \text { L1 e L2 } & \text { Receptores GPS/GNSS de dupla frequência } \\ \text { MEO } & \text { Medium Earth Orbits } \\ \text { MSAS } & \text { Multi-functional Satellite Augmentation System(Japão) } \\ \text { NGA } & \text { National Geospacial Intelligence Agency } \\ \text { SC } & \text { Sistema de Comutação } \\ \text { SMC } & \text { Serviço Móvel de Comutação } \\ \text { SNAS } & \text { Satellite Navigation Augmentation System(China) } \\ \text { NTRIP } & \text { Networked Transport of RTCM via Internet Protocol } \\ & \end{array}$




\begin{tabular}{ll} 
NMEA & National Marine Electronics Association \\
OMC & Operation and Monitoring Center \\
OTF & On-the-fly \\
PCM & Pulse Code Modulation \\
PDOP & Positional Dilution of Precision \\
QZSS & Quasi Zenith Satellite System \\
RAIM & Receiver Autonomous Integrity Monitoring \\
RBMC & Rede Brasileira de Monitoramento Contínuo \\
RBMC-IP & Rede Brasileira de Monitoramento Contínuo com Proxy de Internet \\
RINEX & Receiver Independent Exchange Format \\
RTCA & Radon Testing Corporation of America \\
RTCM & Radio Technical Commission for Maritime Services \\
RTK & Real Time Kinematic \\
RTN & Real Time Network \\
SBAS & Satellite Based Augmentation System(s) \\
SCC & Sistema Central de Comutação \\
SEB & Sistema de Estação Base \\
SD & Selective Denial \\
SIM & Subscriber Identity Module Card \\
SOC & System-on-a-chip \\
SMS & Short Message System \\
TBC & To Be Confirmed \\
TBD & To Be Defined \\
TCP & Transmission Control Protocol \\
TDMA & Time-Division Multiplex Access \\
TRXs & Transmissores \\
TTFF & Time to First Fix \\
UCP & Universal Control Protocol \\
UERE & User Equivalent Range Error \\
UHF & Ultra High Frequency \\
UMTS & Universal Mobile Telecommunications System \\
VDP & Vertical Dilution of Precision \\
VLR & Visitor Location Recorder \\
VPN & Virtual Reference Station \\
\hline
\end{tabular}


WAAS Wide Area Augmentation System

WAD Wide Area Differential

WAN Wide Area Network 


\section{SUMÁRIO}

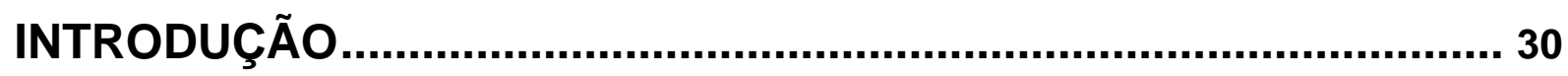

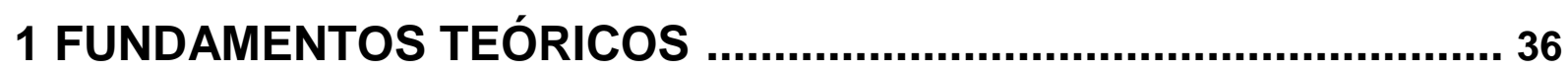

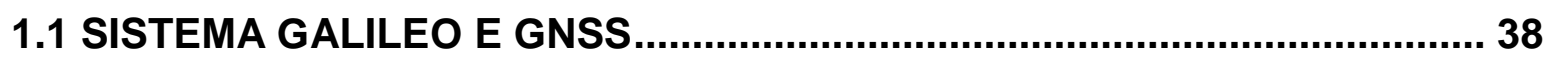

1.2 UTILIZAÇÃO DE RECEPTORES GNSS L1 E L1/L2, NA TÉCNICA RTK .... 50

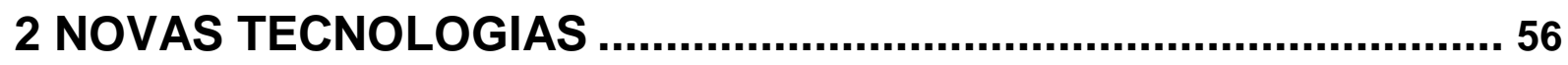

2.1 MÉTODOS DE POSICIONAMENTO GNSS COM ÊNFASE NA TÉCNICA RTK

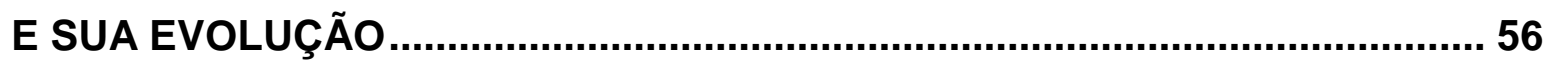

2.2 UTILIZAÇÃO DE SISTEMAS DE TRANSMISSÃO DE DADOS VIA

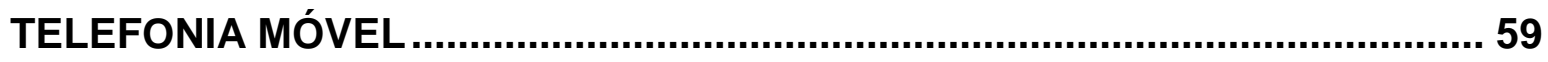

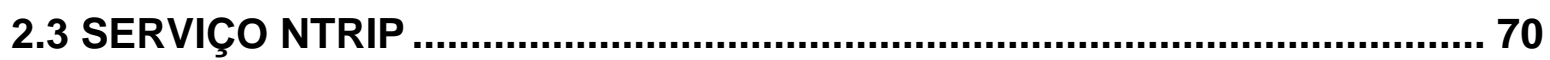

3 METODOLOGIA DA ANÁLISE DOS DADOS ................................. 83

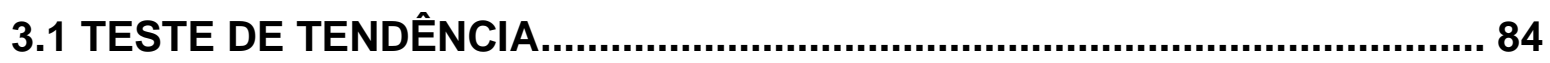

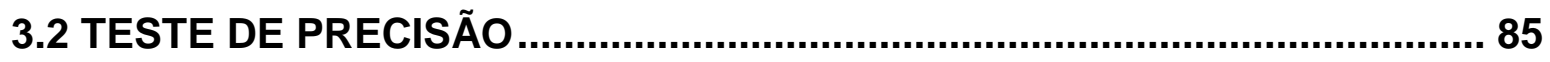

4 MATERIAIS E MÉTODOS ............................................................90 90

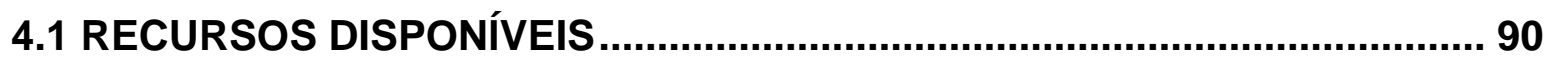

4.2 METODOLOGIA UTILIZADA PARA EXECUÇÃO DO LEVANTAMENTO.... 93

4.3 ESTAÇÃO DE REFERÊNCIA E VÉRTICES LEVANTADOS ....................... 95

5 DADOS COLETADOS ....................................................................104

5.1 DESCRIÇÃO DOS RESULTADOS OBTIDOS ........................................... 104

5.2 APRESENTAÇÃO DOS DADOS COLETADOS NOS EXPERIMENTOS.... 104

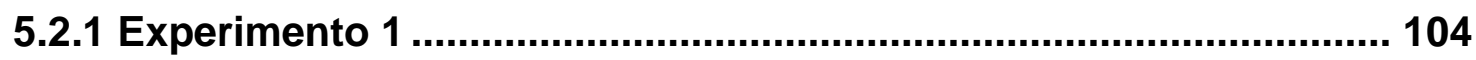

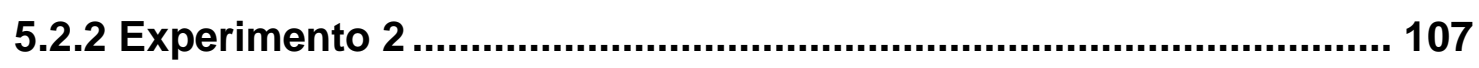

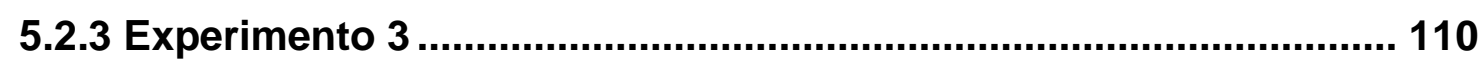

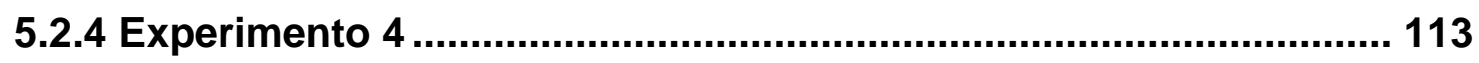

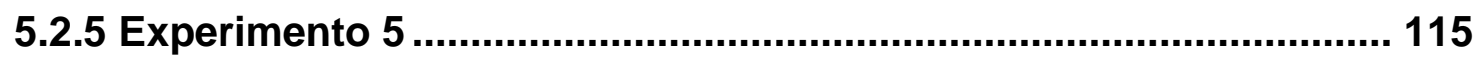

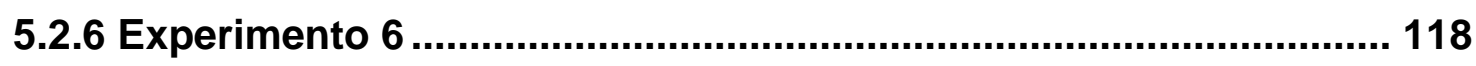

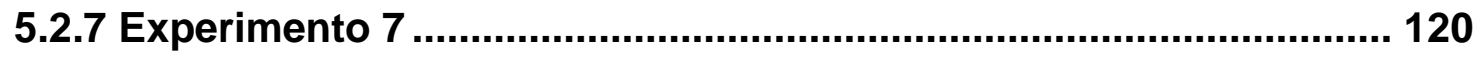

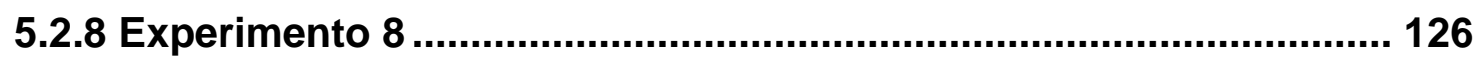

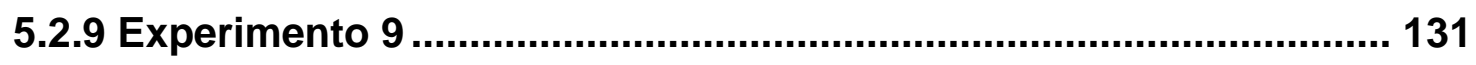

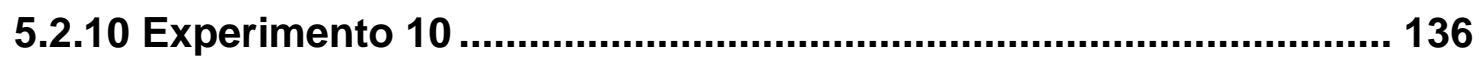




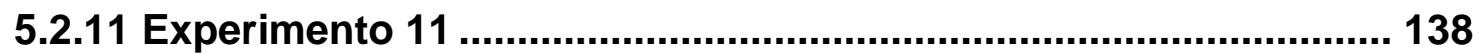

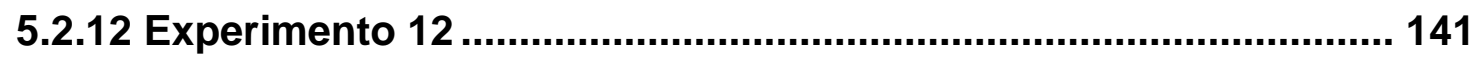

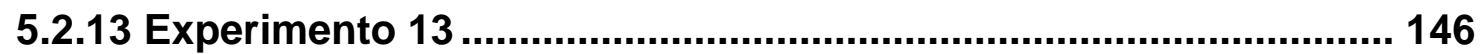

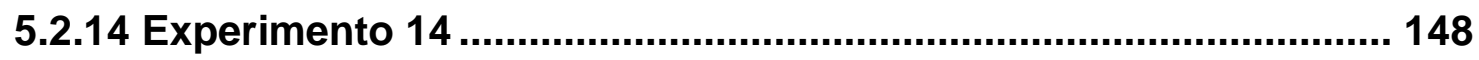

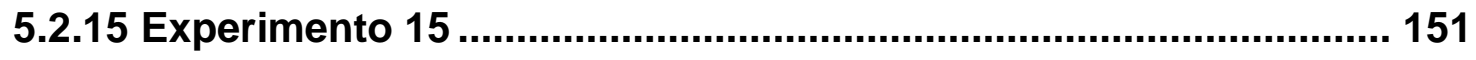

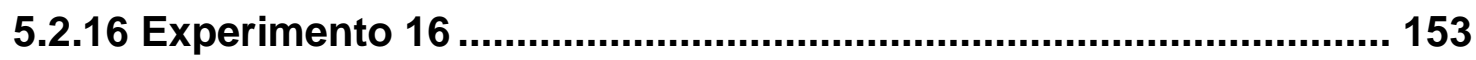

6 RESULTADOS OBTIDOS ...........................................................155

6.1 METODOLOGIA DE ANÁLISE DOS RESULTADOS ................................. 155

6.2 RESULTADOS OBTIDOS NOS EXPERIMENTOS .................................... 155

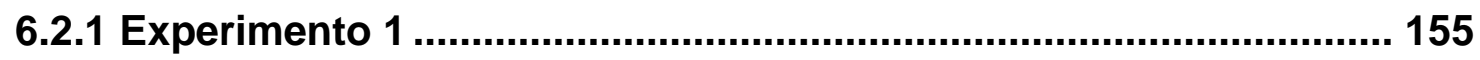

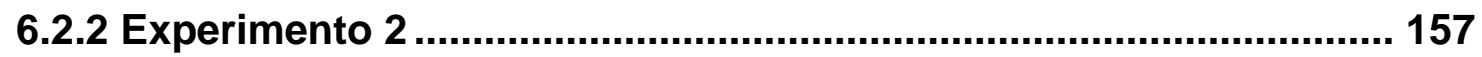

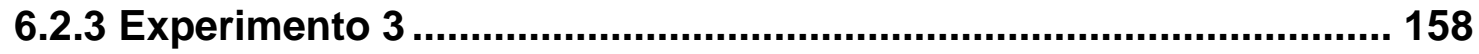

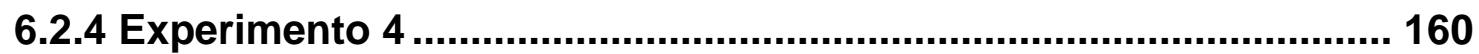

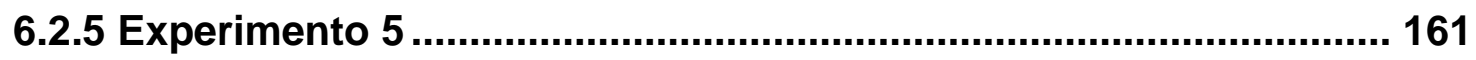

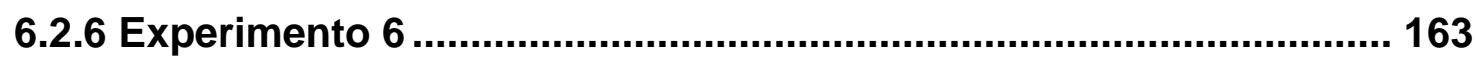

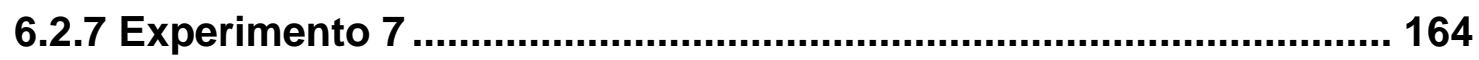

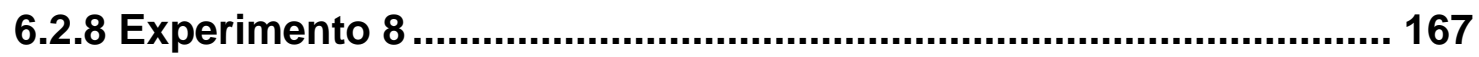

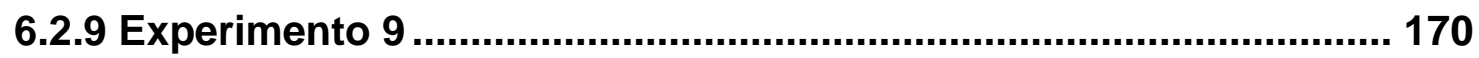

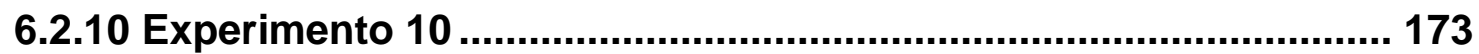

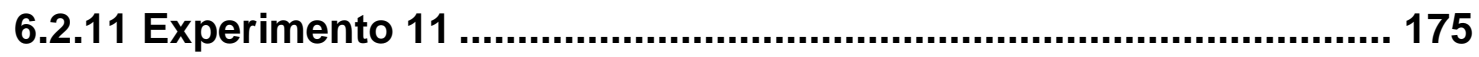

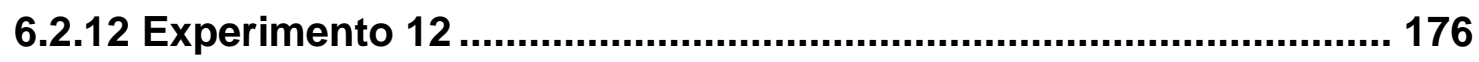

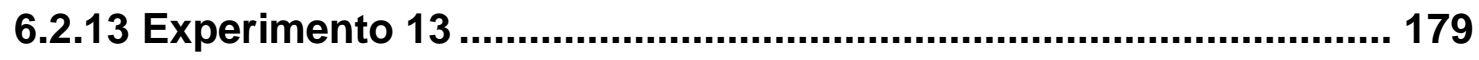

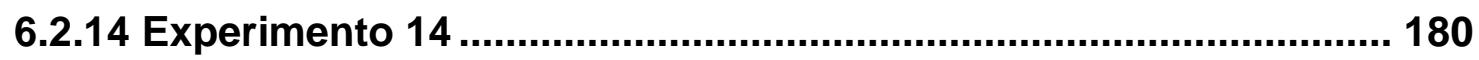

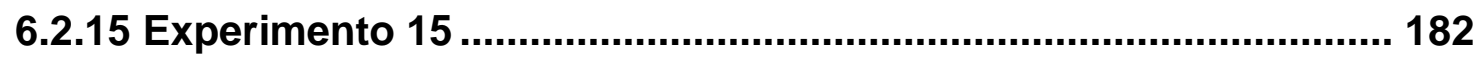

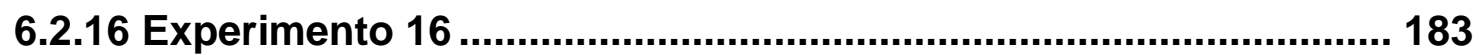

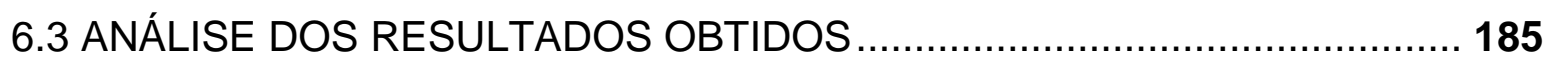

6.3.1 Comentários e resumo do trabalho de campo ................................ 185

6.3.2 Análise técnica dos resultados obtidos e suas aplicações ............ 192

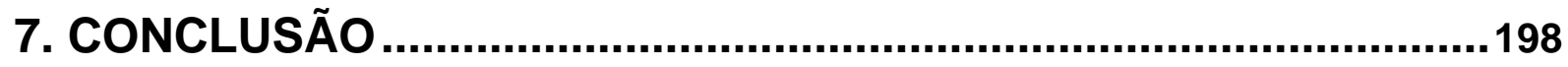

7.1 VANTAGENS DA TÉCNICA RTK/GSM EM COMPARAÇÃO A TÉCNICA

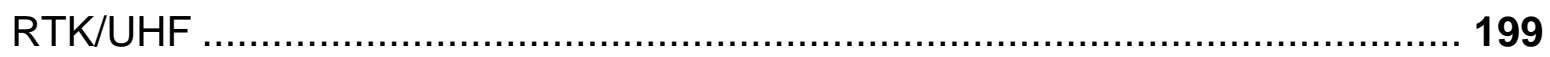

7.2 VIABILIDADE E UTILIZAÇÃO DA TÉCNICA RTK/GSM................................ 199

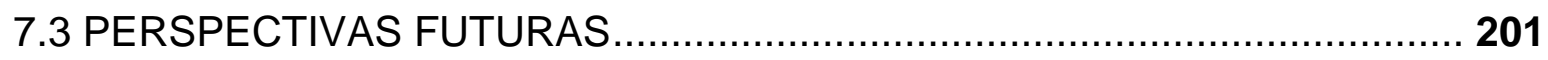


REFERÊNCIAS

203

GLOSSÁRIO

209 


\section{INTRODUÇÃO}

\section{Considerações iniciais}

A necessidade de determinar posições, limites, alinhamentos, áreas e implantar projetos vêm desafiando o homem há muito tempo. Recentemente, houve uma grande evolução nas técnicas de posicionamento, concomitantemente com o avanço das diferentes tecnologias que surgiram na era industrial e espacial.

Por séculos, paradigmas de técnicas de posicionamento foram superados e inovações implantadas nos projetos de engenharia, cada uma delas inovando e aumentando a produtividade e, em alguns casos, até aperfeiçoando o método tradicional.

Nas últimas duas décadas, a geodésia deixou de observar astros verdadeiros e passou a observar satélites artificiais, fazendo com que a execução de parte dos serviços de topografia clássica passasse a utilizar o sistema GNSS. Desde então, tem ocorrido um contínuo crescimento no número de usuários dessa tecnologia para a obtenção de dados espaciais em pontos da superfície terrestre ou próximos a ela. Essa tecnologia tem se mostrado indispensável na atualização de banco de dados geográficos e em trabalhos convencionais de levantamentos topográficos. A migração de grande parte dos serviços de topografia clássica para o emprego do sistema GNSS na técnica RTK ocorreu com o avanço da tecnologia de transmissão de dados.

Com a observação de satélites artificiais, fez-se necessária a criação de novos métodos de posicionamento, assim, é necessário definir, antes de ir a campo, a técnica de levantamento GNSS (método absoluto, método relativo na técnica pósprocessado ou RTK), a precisão e acurácia necessárias, compatíveis com a aplicação do projeto a ser executado. Os métodos de posicionamento relativo dependem ainda diretamente da distância entre os receptores, base e móvel.

No caso dos levantamentos topográficos, as metodologias espaciais com 0 GNSS já substituem o método tradicional, através do pós-processamento, auxiliando 
na produção de cartas topográficas com mais agilidade e com a mesma ou até melhor precisão do que as técnicas tradicionais.

No mapeamento cadastral, a metodologia com sistema GNSS/GPS (Global Positioning System) viabilizou a coleta de coordenadas geodésicas em campo no mesmo instante da coleta e criação do banco de dados cadastrais, elaborando mapas temáticos. Isto é possível devido à associação das posições coletadas com informações cadastrais.

Com respeito ao uso generalizado do posicionamento, a inovação é o sistema GNSS, o qual corresponde a um projeto de integração do sistema GLONASS (Global'naya Navigatstonnaya Sputnikowaya Sistema), do sistema SBAS (Satellite Based Augmentation System), do sistema de posicionamento europeu GALILEO com o uso de diferentes sinais e códigos e outros sistemas que virão a ser estabelecidos. Esforços dos fabricantes em apresentar ao mercado novos receptores que associem diferentes sistemas têm proporcionado uma revolução nas aplicações. Esta combinação de mudança no mercado e o surgimento de novas tecnologias representam importantes avanços para os usuários, principalmente em termos de produtividade e melhoria em acurácia e precisão dos resultados finais.

Algumas das vantagens da utilização de novas tecnologias de posicionamento se referem à praticidade e à rapidez quando comparadas aos métodos clássicos. Outro aspecto relevante é a precisão obtida e a distância alcançada entre as estações levantadas com o sistema GNSS, dependendo do receptor utilizado. Neste último aspecto, podem-se atingir distâncias de algumas centenas de quilômetros (500 km) com precisão melhor que $10 \mathrm{~cm}$.

A popularização e desenvolvimento do sistema GNSS foi proporcional à redução de custo dos receptores. Tal situação tem criado novas oportunidades de investimentos na engenharia, na construção civil, nos levantamentos topográficos, na implantação de projetos e no mapeamento.

O método de levantamento atual com maior produtividade e acurácia é a técnica RTK, o que significa cinemático em tempo real. Representa a inovação tecnológica que favorece o aumento de produtividade em campo, seja nos levantamentos topográficos ou nos trabalhos de implantação de pontos em obras de infraestrutura. Essa evolução se justifica pelo fato de que nesse método de levantamento se obtêm coordenadas com precisão centimétrica em tempo real. 
O início da utilização da técnica RTK se deu com a possibilidade de transmissão das observações da medida de fase da onda portadora (tratado daqui em diante neste trabalho apenas como observações de fase) a partir de um receptor base com coordenadas conhecidas. No processamento em tempo real, o envio das observações de fase do receptor base para o móvel, através de frequência de rádio (denominado neste trabalho de RTK/UHF), permite ao receptor móvel obter as coordenadas instantaneamente. Elas podem ser visualizadas no software instalado no coletor de dados, possibilitando a execução de tarefas de campo com maior eficácia. Recentemente, passou-se realizar essa tarefa por meio da transmissão via conexão GSM/GPRS, denominado aqui de técnica RTK/GSM.

A conexão GSM é empregada na telefonia móvel de comunicação padrão totalmente digital, mais usada em telefones celulares. A nova facilidade da técnica RTK, através da conexão GSM, permite ampliar a área de trabalho a partir da estação de referência, tornando mais fácil a inicialização do sistema em campo e permitindo maior produtividade nos projetos. Essa é a grande vantagem da transmissão das observações de fase pela técnica RTK/GSM com relação à técnica RTK/UHF.

A transmissão das observações de fase por meio da conexão GSM pode ser realizado de quatro formas distintas: a primeira opção é viabilizada a partir da configuração dos receptores GNSS base e móvel com conexão GSM, obtida pela inserção do dispositivo microeletrônico chip SIM (Subscriber Identity Module). Estes poderão se comunicar diretamente entre si utilizando a conexão GSM, quando disponível, possibilitando a sua instalação em qualquer local ou ponto de coordenada conhecida ou a ser determinada. A comunicação entre os receptores base e móvel será estabelecida através de ligação telefônica feita a partir do número identificador do SIM do receptor base; a segunda é a comunicação entre uma única estação de referência que disponibiliza o RTCM diretamente em um IP (Internet Protocol) sem nenhum controle de acesso dos receptores móveis; a terceira opção é a conexão entre o receptor móvel e conjunto de estações de referência denominado de Rede NTRIP (\$2.6) através de um software de gerenciamento que recebe os dados e controla os acessos. Neste método é utilizado apenas um chip SIM introduzido no receptor móvel para conexão com a estação de referência mais próxima para a obtenção das observações de fase; a quarta é um conjunto de no mínimo 3 estações de referência ligadas a um servidor, que gerencia correções RTK 
dentro de uma área de trabalho. Este método é o RTK em REDE e um de seus formatos é conhecido como VRS (Virtual Reference Station).

Os receptores devem ter a capacidade de gerar e/ou interpretar o protocolo RTCM 3.0, o qual compacta as observações de fase em um formato e tamanho adequados para o envio. A conexão GSM usa a mesma rede repetidora da telefonia celular, portanto, com maior área de cobertura e com a possibilidade de aumento da distância entre os receptores base e móvel, sem as restrições das transmissões via radio. Em síntese, utiliza-se um receptor GNSS móvel (L1 ou L1/L2) com um chip SIM para a conexão GSM, recebendo as observações de fase em tempo real da estação de referência mais próxima; esta é a tendência dos levantamentos topográficos.

O objetivo geral deste trabalho é a análise da viabilidade e da confiabilidade da conexão GSM nas técnicas de levantamento GNSS/GPS. Já o objetivo específico é analisar a viabilidade e confiabilidade, assim, foram realizados testes com a utilização de diferentes receptores do sistema GNSS na técnica RTK/GSM (simples e dupla frequência), com diferentes distâncias entre receptores base e móvel. Isso proporcionou a avaliação da acurácia e da precisão, sendo que as técnicas propostas e avaliadas foram as seguintes:

- Técnica RTK/GSM L1L2 com solução fixa;

- Técnica RTK/GSM L1L2 com solução flutuante;

- Técnica RTK/GPS L1 com solução fixa;

- Técnica RTK/GPS L1 com solução flutuante.

Outros objetivos se referem ao estudo das limitações e recomendações no emprego da técnica RTK/GSM, bem como estabelecer onde podem ser utilizadas as novas técnicas de trabalho.

O conceito do tema tratado, num primeiro momento, corresponde à integração entre os sistemas de transmissão de dados com emprego da conexão GSM/GPRS e da Internet com a tecnologia dos sistemas de navegação por satélite o GNSS. Este conceito abrange o posicionamento utilizando os receptores GNSS, que se comunicam por meio da conexão GSM/GPRS para enviar e receber a observação de fase através do serviço NTRIP. 
A transmissão da observação de fase via rádio vem sendo substituída por esse novo serviço NTRIP em conjunto com a nova conexão GSM/GPRS, reduzindo as limitações do antigo sistema de transmissão de forma significativa, principalmente nas regiões mais desenvolvidas do país onde a cobertura da conexão GSM/GPRS atende de forma satisfatória.

Ainda, deve-se ressaltar que existem variantes de uso dessa tecnologia, as quais são o IP direto e a conexão GSM direta, que serão também tratados nesse trabalho. Para tanto, é importante definir procedimentos práticos e parâmetros quantitativos para trabalhos realizados com o sistema GNSS na técnica RTK e na sua integração com as novas tecnologias, principalmente com a utilização do serviço NTRIP. Por se tratar de um novo conceito, existem poucos estudos.

Assim, essa pesquisa se justifica por apresentar resultados qualitativos e quantitativos deste novo tema para a comunidade geodésica internacional e brasileira.

Neste sentido, torna-se necessário abordar vários aspectos, tais como a degradação da precisão e da acurácia do posicionamento na técnica RTK/GSM, considerando a distância do receptor base para o móvel, a latência, a estabilidade da conexão GSM/GPRS, a solução fixa ou flutuante e a qualidade do posicionamento GNSS/GPS na área a ser trabalhada.

Espera-se que os resultados obtidos nessa pesquisa sejam de grande valia para diversos setores, a saber: topografia, construção civil, distribuição de energia, água e telefonia, órgãos públicos e meios de transporte; aplica-se, ainda, no monitoramento de estruturas, controle de erosão e controle de tráfego aéreo.

\section{Estrutura do trabalho}

No capítulo 1, é apresentada toda a revisão bibliográfica.

No capítulo 2, é apresentada a atualização de conceitos aplicados nessa pesquisa.

No capítulo 3, é apresentado o método estatístico aplicado na análise dos resultados obtidos para cada um dos experimentos realizados.

O capítulo 4 trata da descrição detalhada da metodologia aplicada, considerando os recursos disponíveis e o trabalho de campo. 
O capítulo 5 apresenta os dados coletados em cada um dos experimentos.

O capítulo 6 apresenta os resultados obtidos em cada um dos experimentos de campo. Além disso, é realizada a análise geral das técnicas aplicadas.

Finalmente, no capítulo 7, se apresentam as conclusões e recomendações, abordando as vantagens da utilização das novas técnicas e as perspectivas futuras para realizações de novos trabalhos que possam utilizar como modelo o estudo desenvolvido nessa dissertação. 


\section{FUNDAMENTOS TEÓRICOS}

O marco inicial dos projetos de navegação por satélites artificiais se deu na década de 1960, com a ideia da criação de um sistema comum de rádio navegação para as Forças Armadas dos Estados Unidos. Este projeto foi resultado da junção de dois projetos, o primeiro da Força Aérea, denominado 621B Project (Projeto 621B) e o segundo da Marinha, denominado de TIMATION Program (MONICO, 2008).

A partir do ano de 1970, tanto os Estados Unidos como a ex-União Soviética proporcionaram grande avanço tecnológico através do desenvolvimento independente dos seus próprios sistemas de navegação global por satélite denominados, respectivamente, GPS e GLONASS. Ambos os sistemas foram inicialmente concebidos para uso militar, conforme Afonso (2006); Monico (2008).

Enquanto o GLONASS passou por um período de grande decadência e carência de manutenção, decorrente do fim da guerra fria, o GPS se tornou operacional em 27 de abril de 1985, contendo uma constelação formada por 25 satélites em órbita (MONICO, 2000; LEICK, 2004; MONICO, 2008). No entanto, por volta do final da década de 1990, com a possibilidade de integração com a constelação GPS, o GLONASS passou a ser recuperado (LEICK, 2004).

O projeto Europeu, denominado GALILEO, prevê a integração com as constelações GLONASS e GPS com o objetivo de atingir a acurácia de $20 \mathrm{~cm}$ para posicionamento absoluto (TORAN-MARTI; VENTURA-TRAVESET, 2004).

Monico (2008) relata o Beidou/Compass, sistema de navegação e posicionamento chinês por meio de satélites artificiais, com o primeiro satélite lançado em 2000 e previsão de operacionalidade para navegação em território chinês nos próximos anos e posterior abrangência global. O sistema difere dos demais pelo fato de posicionar cinco de seus satélites em órbitas geoestacionárias. No entanto, tem a previsão de incluir no sistema espacial 30 satélites em órbitas similares aos dos sistemas já existentes.

Todos os sistemas de navegação possuem, basicamente, três segmentos: espacial, de controle e do usuário. O segmento espacial corresponde à constelação de satélites artificiais, dotados de uma sofisticada eletrônica para transmissão de sinais em determinadas frequências. Estes satélites são distribuídos em órbitas ao 
redor da Terra, em distintos planos e altura específica (a partir de $20.000 \mathrm{~km}$ aproximadamente). As constelações são projetadas de modo a possibilitar, em condições normais, a visibilidade mínima de 4 satélites simultaneamente. $O$ segmento de controle é responsável por gerenciar e armazenar todas as informações e dados recebidos dos satélites. Com as informações é possível o acompanhamento e controle de tudo o que se passa diariamente com os veículos. Isso é realizado por meio de estações fixas espalhadas pelo globo terrestre. A tarefa básica delas é de coletar os dados provenientes de todos os satélites sendo, posteriormente, transmitidos para uma estação central de controle. A partir daí é realizado o processamento das observações coletadas, possibilitando aos controladores do sistema calcular e armazenar parâmetros orbitais de cada satélite. As informações obtidas são utilizadas para a modelagem da ionosfera, a correção da não sincronização do relógio dos satélites e para a geração das efemérides operacionais. Esses novos parâmetros orbitais são então transmitidos novamente aos satélites por meio da estação central de controle. O segmento de usuários é composto por todos os profissionais das mais diversas áreas que utilizam o sistema para o posicionamento. Tal segmento tem sofrido grande expansão nos últimos anos, devido, principalmente, à popularização dessa tecnologia, aliada à redução de custos e às aplicações nas mais diversas áreas e setores como o apoio para mapeamento, projetos de SIG (Sistemas de Informação Geográfica), navegadores veiculares, entre outros.

Os receptores coletam as observáveis, distância ou fase da onda portadora, as quais são afetadas por erros aleatórios, sistemáticos e grosseiros, os dois últimos passíveis de eliminação e parametrização, conforme relata MONICO (2000). Entretanto, os erros aleatórios não são vinculados à causa conhecida e são quantificados após eliminação dos erros sistemáticos e grosseiros. Assim, dependendo da fonte, têm-se os erros relacionados ao próprio satélite, à propagação do sinal, ao receptor/antena e à estação, tratados com detalhes por Leick (1995), Monico (2000), Leick (2004), Segantine (2005) e Monico (2008).

O posicionamento pode ser realizado pelo método absoluto e pelo método relativo, sendo que o de maior importância nesse trabalho é o método relativo pela técnica RTK. Outros aspectos relevantes que têm afetado continuamente a evolução dos receptores dizem respeito ao uso de frequência simples na técnica RTK, 
associado a novos algoritmos de solução da ambiguidade e à facilidade de transmissão das observações de fase do receptor base para o móvel.

\subsection{SISTEMA GALILEO E GNSS}

De acordo com Monico (2000), mesmo a integração GPS-GLONASS - que significa um grande avanço em termos de ampliação da constelação -, não atende aos requisitos de acurácia para aplicações mais críticas. Portanto, tornou-se importante também a ampliação e atualização desses dois sistemas de posicionamento. Adicionalmente, os europeus passaram a desenvolver seu próprio programa, denominado GALILEO, que tem por objetivo atender à maioria das aplicações de forma mais aperfeiçoada. No entanto, dentro de um conceito mais amplo ainda se considera a integração de todos esses conjuntos de satélites, ou seja, do GPS, do GLONASS, do GALILEO e de outros, bem como a modernização dos mesmos com a inclusão de novos satélites e de maior diversidade de sinais. Todo esse contexto está inserido dentro do conceito GNSS.

Zhang et al. (2005) afirmam que o GNSS corresponde à tecnologia de posicionamento para grande gama de aplicações críticas, tais como LBS (Location Based System), pesquisa, emergência, agricultura, levantamento, estratégias militares, aplicações contra terrorismo e segurança. Os mesmos autores relatam ainda que a primeira era dessa tecnologia foi o GPS e que no futuro serão incorporados os sistemas de navegação por satélite da Europa, Japão, China e Índia, que proporcionarão melhor integridade, acurácia e viabilidade nas soluções de posicionamento, particularmente em tempo real.

De acordo com Rizos et al. (2005), o GNSS corresponde à integração e à modernização de praticamente todos os sistemas de navegação de satélites do mundo, desde o GPS, O GLONASS, O QZSS (Quasi-Zenith Satellite System), desenvolvido pelo Japão (detalhes em Tsujine, 2005), e o GALILEO. Neste contexto, estará disponível uma constelação de cerca de 80 satélites, permitindo uma grande combinação de sinais (GPS e QZSS - L1, L2, L5; GLONASS - L1, L2, L3; GALILEO - L1, E5, E6;), o que está exigindo a adequação dos receptores GPS para GNSS compatíveis com a recepção dos novos sinais e com o desenvolvimento de 
tecnologias inovadoras. Assim, poderá ser observado simultaneamente um número maior de satélites do que os disponíveis com o GPS, com máscara de elevação de 15 graus. Um comparativo dessa evolução pode ser observado na figura 1.

Rizos et al. (2005) comentam sobre vários benefícios que a implantação do GNSS oferecerá, tais como a melhora considerável da acurácia em aplicações em tempo real, a maior facilidade na correção dos efeitos da ionosfera devido à maior diversidade de sinais, a possibilidade de levantamento com precisão em corredores urbanos (áreas edificadas) e as aplicações de posicionamento em ambientes fechados.

Considerando a evolução do desenvolvimento do projeto GNSS, Legat e Hofmann-Wellenhof (1999); Monico (2000), mencionam que o projeto GNSS é composto por duas principais etapas. A primeira, denominada GNSS-1, representa a fase inicial de desenvolvimento do mesmo, onde se prevê a ampliação do GPS e do GLONASS, além da reestruturação do mesmo no que é denominado GLONASS-M (LEICK, 2004, POLISCHUCK et al. 2006). Inclui ainda, a integração desses com os sistemas ampliados (SBAS, GBAS, ABAS) (TORAN-MARTI; VENTURA-TRAVESET, 2004).

A segunda etapa, chamada de GNSS-2, corresponde à fase em que está prevista a modernização do GPS (GPS-2F) e do GLONASS (GLONASS-K) e a integração com a constelação do GALILEO, bem como o desenvolvimento de novas tecnologias para satélites e meios de comunicação, num sistema completamente novo, com controle civil internacional e com atendimento de todos os requisitos exigidos para os diferentes tipos de posicionamento. Um resumo esquemático do projeto GNSS pode ser observado na figura 2. 


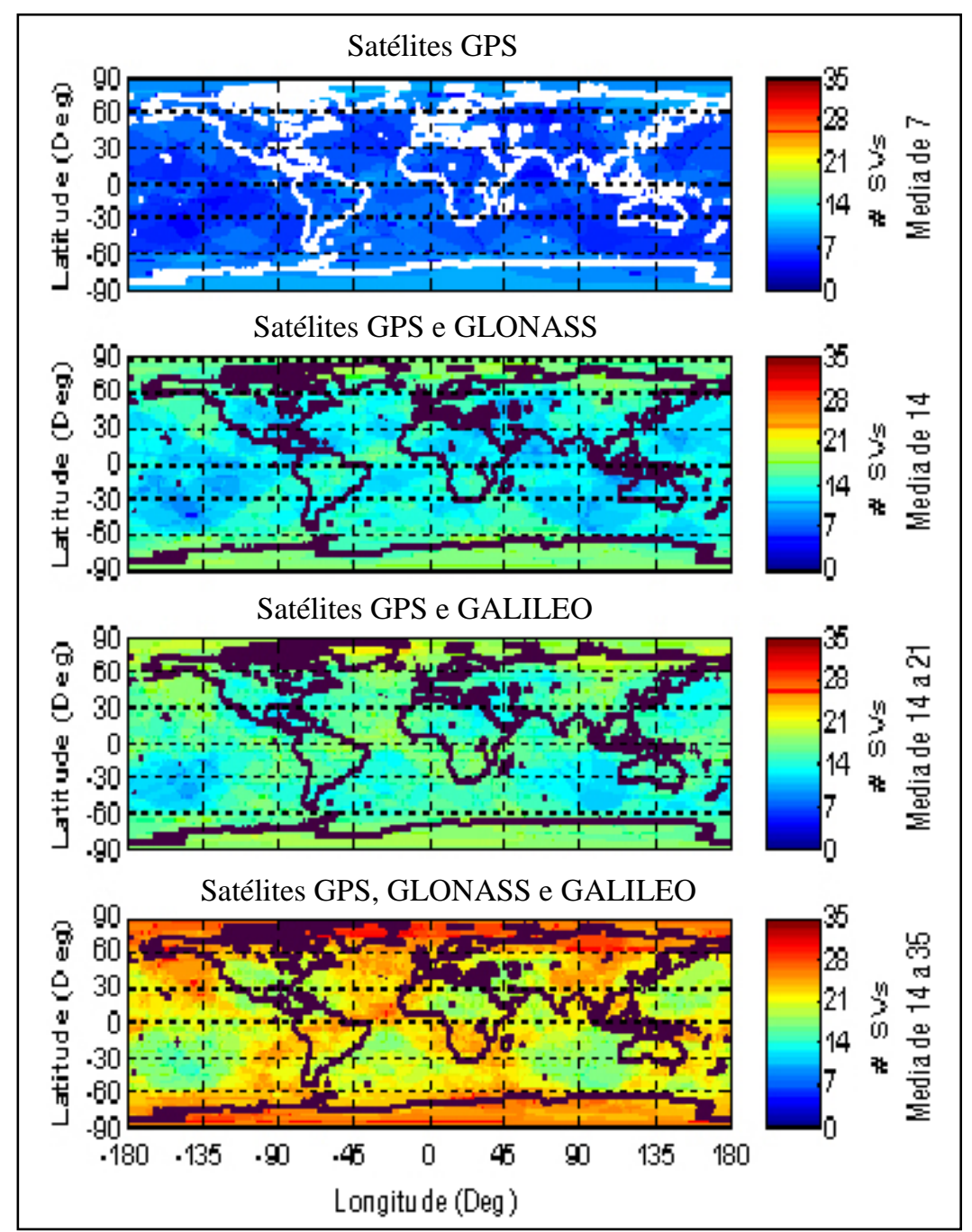

Figura 1 - Visibilidade dos satélites com o GNSS.

Fonte: Rizos et al. (2005).

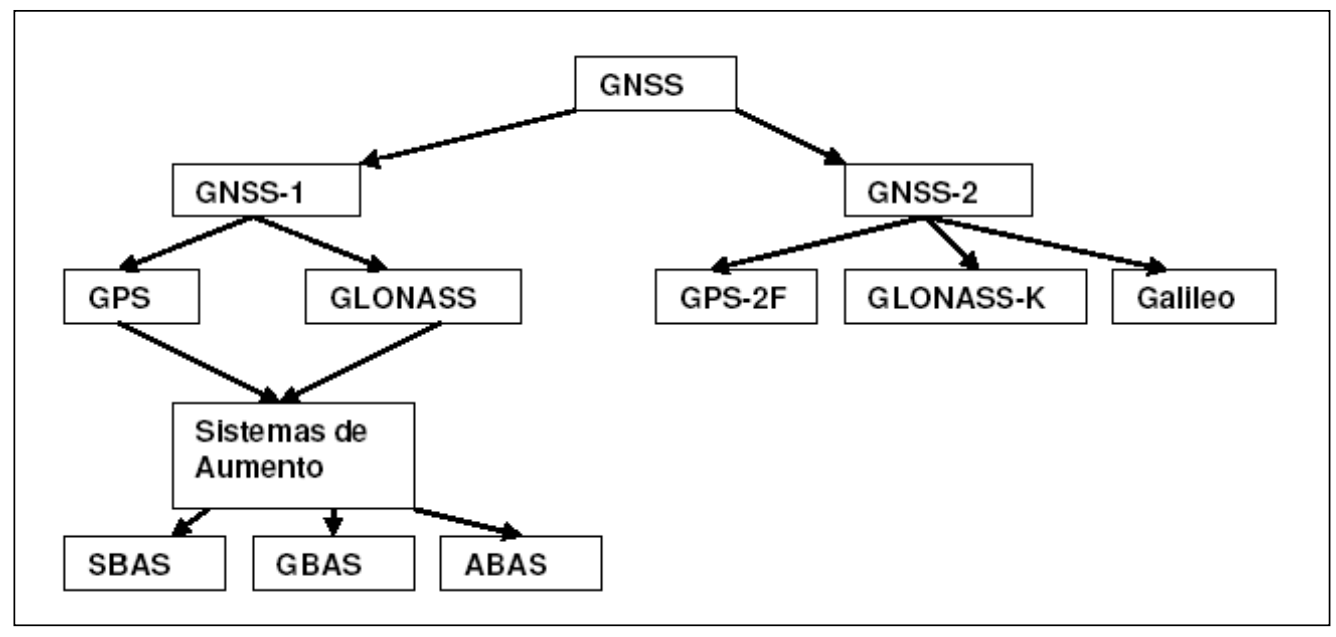

Figura 2 - Esquema geral do projeto GNSS.

Fonte: Garcia (2008). 
Os satélites da geração GLONASS-M (18 satélites), fazem parte do projeto GNSS-1, com avanços tecnológicos significativos, tais como a estrutura de sinais, o relógio de bordo, a melhoria na acurácia de navegação (melhora na razão de 2 vezes), aumento da vida útil do satélite, cujas especificações detalhadas são relatadas por Leick (2004); Polischuck et al. (2006).

Adicionalmente, como já mencionado, foi realizada a integração com sistemas de ampliação no projeto GNSS-1, para a melhoria do posicionamento absoluto. Estes sistemas são descritos a seguir.

O sistema SBAS, conforme descreve Paiva (2004), é constituído de estações de referência, que fornecem dados de posicionamento dos satélites GPS e relativos à troposfera, ionosfera, multipercurso, ruído e interferência. Essas informações da rede de estações de referência são enviadas às estações mestras, onde são aplicados algoritmos de correção, sendo os resultados enviados via satélite para os usuários do sistema, contendo correções relativas: à troposfera, à ionosfera, ao tempo do sistema e à localização dos satélites GPS, visando maior precisão no posicionamento. De acordo com Chujo (2007), o SBAS utiliza satélites geoestacionários para o envio de mensagens de correção de posição ao usuário, com grande área de cobertura. Em suma, dessa maneira, trata-se de sistemas regionais ampliados do GPS e do GLONASS com objetivo de corrigir erros inerentes aos efeitos de propagação dos sinais, a partir de satélites geoestacionários. Este sistema foi criado inicialmente com o objetivo de dar suporte à aviação civil e militar em todas as operações de voo. A acurácia do SBAS varia de 1,0 a 7,7 m, dependendo das características do sistema local.

De acordo com Monico (2000), no SBAS são oferecidos três serviços: 1) medidas de distâncias da antena do receptor até os satélites GEOs (tem sinais transmitidos iguais ao da portadora L1 do GPS); 2) determinação e transmissão de informações sobre a integridade dos satélites GPS, GLONASS e GEOs; 3) determinação e transmissão das correções WAD (Wide Area Differential) dos satélites GPS, GLONASS e GEOs, que melhoram a acurácia no posicionamento absoluto, derivado a partir das observações da distância.

Paiva (2004) relata que o SBAS é recomendado em operações de posicionamento terrestre, marítimo ou aéreo. Nas aplicações aéreas, pode-se citar o monitoramento de rotas aéreas, a otimização do espaço aéreo nos terminais aeroportuários, bem como o controle de decolagens e de pousos. Assim, as 
categorias de operação no SBAS podem ser caracterizadas em função do tipo de aplicação: a) orientação: nas proximidades de pouso e decolagem de aeronaves (3D); b) navegação: nas proximidades dos aeroportos (2D). Além disso, cada uma dessas categorias exige especificações sobre limites de integridade e de disponibilidade relacionadas com a área de cobertura ou o volume de serviços. $O$ mesmo autor afirma que existem disponíveis gratuitamente os serviços de SBAS em várias regiões do Mundo, tal como o WAAS (nos Estados Unidos da América), o EGNOS (na Europa) e o MSAS (no Japão). Iniciativas semelhantes são o GAGAN (na Índia), o SNAS (na China) e CWAAS (no Canadá), citadas por Toran-Marti; Ventura-Traveset (2004).

Uma visão geral da cobertura gratuita do SBAS ao redor do mundo bem como dos sistemas ampliados por satélite podem ser observados na figura 3 (TORANMARTI; VENTURA-TRAVESET 2004; GARCÍA, 2008).

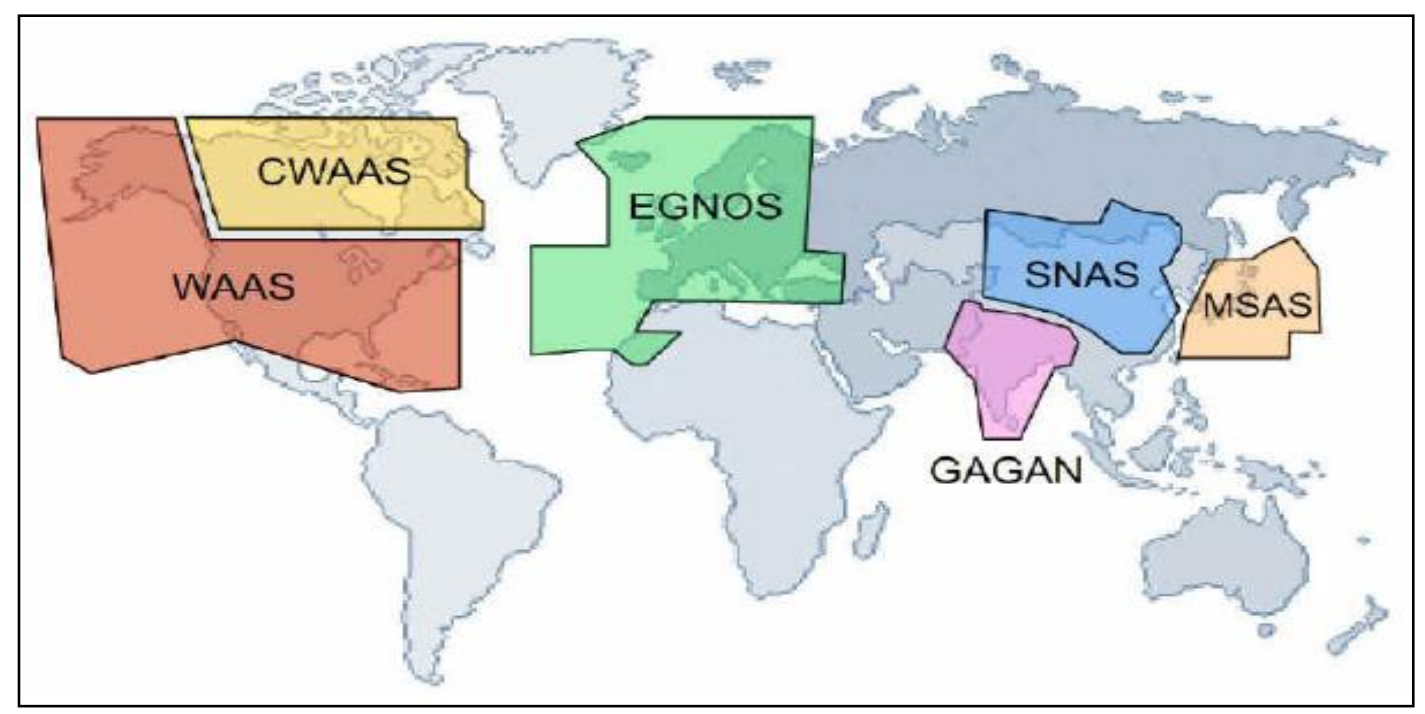

Figura 3 - Interoperabilidade do SBAS.

Fonte: Garcia Álvarez (2008) baseada em Toran-Marti e Ventura-Traveset (2004).

A inclusão do EGNOS em operação com o GPS e o GLONASS no GNSS-1, segundo Toran-Marti; Ventura-Traveset (2004), provocou uma melhora significativa na acurácia do posicionamento absoluto em sua área de cobertura (basicamente a Europa), de 10 a $15 \mathrm{~m}$ (apenas com o GPS) para 1 a $3 \mathrm{~m}$ com a associação dos sistemas. Além disso, está prevista uma área de cobertura mais ampla, abrangendo outras regiões, tais como a África, as Américas Central e do Sul, a Rússia e países orientais. 
O GBAS (Ground Based Augmentation System) é outro sistema de ampliação do GNSS-1, mas com área bem mais limitada que o SBAS. De acordo com Holderle et al. (2006), trata-se de um sistema de ampliação composto por um conjunto de estações de referência com receptores GPS instalados num raio de 32 a $48 \mathrm{~km}$. A estação de controle principal do GBAS gera correções e integridade dos dados e estes são enviados aos pseudossatélites (estações de transmissão VHF). Os mesmos atuam como fonte adicional para medida de distâncias e transmitem as correções diferenciais recebidas da estação de referência aos usuários localizados na sua área de abrangência, por exemplo, (figura 4) nas aproximações aeroportuárias (ZANDONADI JUNIOR; WALTER, 2003). Como a área de cobertura do GBAS é limitada pela distribuição das estações de referência e pela capacidade de transmissão VHF, o sistema pode ser utilizado apenas em áreas restritas, tal como em terminais aeroviários.

O resultado é o fornecimento da correção e da integridade de dados mais acurados, o que possibilita o alerta de falhas de maneira mais rápida do que o SBAS, para mesma área de abrangência (HOLDERLE et al., 2006). Dessa maneira, conforme Monico (2000), os GBAS estão sendo instalados próximo aos aeroportos, com o objetivo de dar suporte às operações de pouso e de decolagem, incluindo a Categoria III (onde os valores de acurácia exigidos são de 4,1 m na horizontal e 0,6 m na vertical, com nível de confiança de $95 \%$, informado pelo mesmo autor). Para tanto, adotam-se técnicas de posicionamento pelo método relativo com uso da fase da portadora.

O ABAS (Aircraft-Based Augmentation System, vide figura 4), de acordo com Garcia (2008), utiliza mais de quatro satélites para o posicionamento, além de detectar falhas no envio de informações. Nesse sistema de ampliação se utiliza o próprio receptor GPS em conjunto com outros equipamentos, tais como os INS (Inertial Navigation System). Esse tipo de sistema opera com dois outros subsistemas (Garcia, 2008):

O LAAS (Local Area Augmentation System) é o nome dado pela FAA (Federal Aviation Administration) ao GBAS e pode ser visualizado na figura 5 (CARROLL, 2004). 


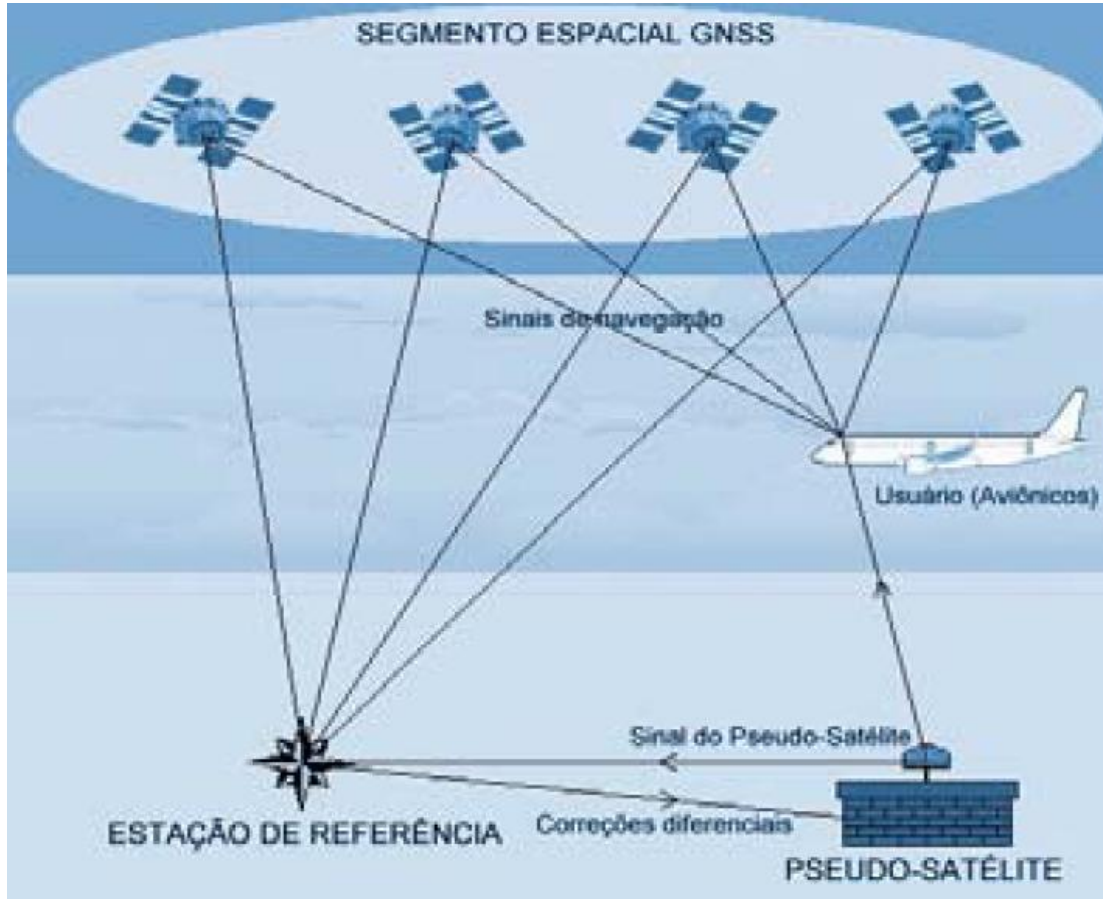

Figura 4 - Conceito de pseudossatélite

Fonte: Zandonadi Junior; Walter (2003).

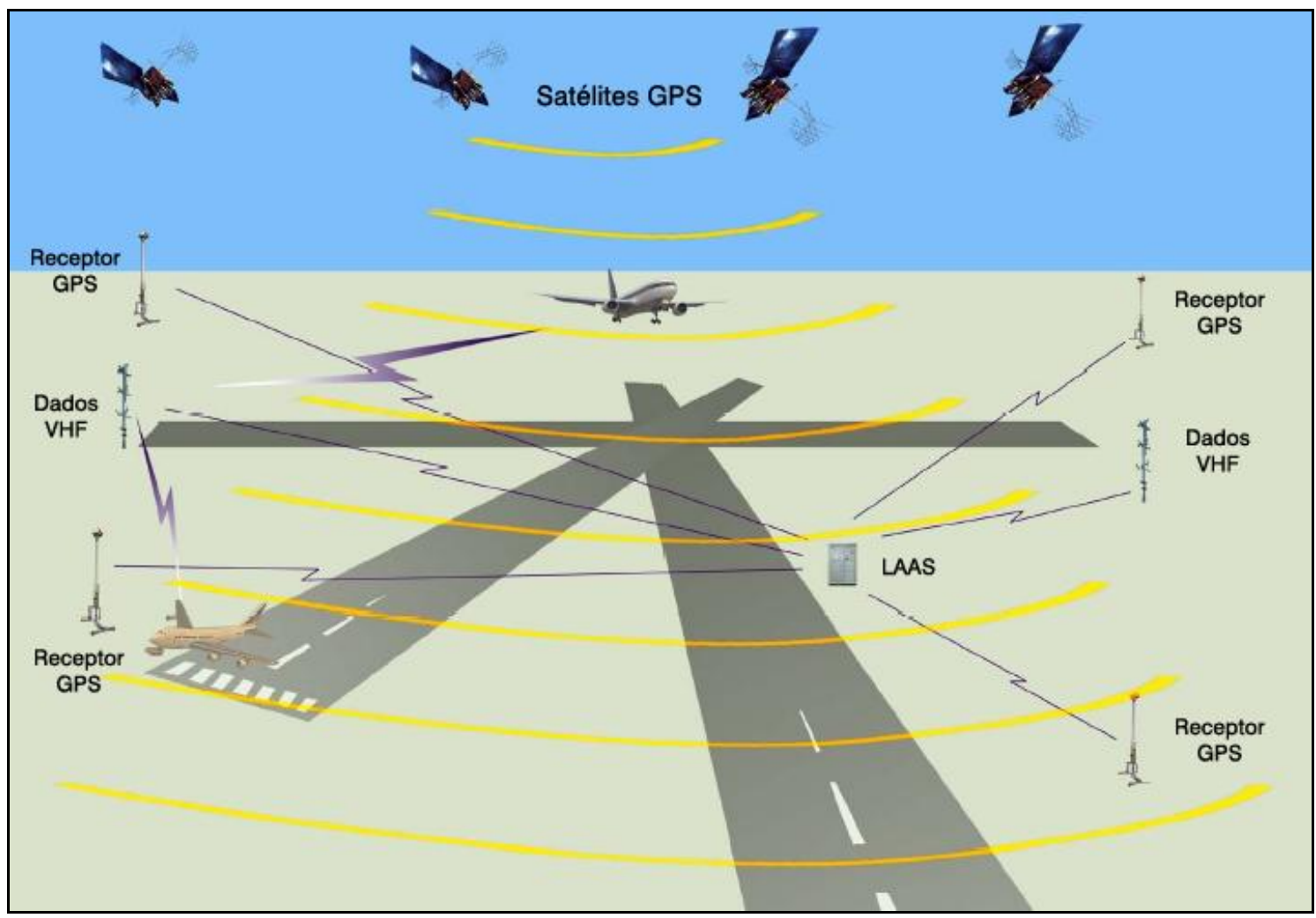

Figura 5 - Esquema operacional do LAAS.

Fonte: Carroll (2004). 
RAIM (Receiver Autonomous Integrity Monitoring): calcula a posição com a combinação de quatro satélites sobre cinco ou seis visíveis, de forma alternada tornando possível identificar qual o satélite que pode estar com sinal defeituoso.

FDE (Fault Detection Excluding): esta funcionalidade permite excluir o satélite defeituoso, de modo a utilizar o GNSS normalmente. Está instalado na maioria das aeronaves que operam na aviação civil.

No que se refere à segunda etapa de desenvolvimento do projeto GNSS, o GNSS-2, o objetivo significativo não se restringe apenas ao aumento das constelações (GPS-2F, GLONASS-K e GALILEO), mas também à inclusão de novos sinais.

Leick (2004) relata que a modernização do GPS (GPS-2F) abrange os avanços tecnológicos tanto dos satélites como dos receptores.

Em termos do segmento de controle do GPS-2F, conforme relata Monico (2000), está prevista a introdução do SD (Selective Denial); a criação de grupo executivo sobre assuntos GPS, com a participação de membros da sociedade civil; a integração de 14 estações de monitoramento do NGA (National GeospatialIntelligence Agency) para a melhoria das órbitas e das correções dos relógios dos satélites; a introdução de navegação autônoma para os satélites dos blocos IIR e IIF.

Em termos do segmento espacial, a constelação será composta pelos satélites dos blocos IIR e IIF, aumentando de modo significativo a capacidade do sistema, considerando nova proposta de estrutura de sinal (MONICO, 2000). A mesma implica na modulação do código C/A sobre a portadora L2 (esta tem disponível atualmente apenas o código P) e na criação da nova portadora L5 (frequência de $1176,45 \mathrm{MHz}$ ). Esta última está programada dentro do chamado domínio espacial do ARNSs (Aeronautical Radio Navigation Services). Essa situação implica igualmente na coerência entre os osciladores dos satélites GPS, o que tornará possível o rastreamento mais acurado da portadora e medidas mais precisas de fase (MACDONALD, 1999). Maiores detalhes quanto a esses novos sinais, bem como as suas estruturas, foram descritas por Leick (2004), sendo o esquema que resume e que proporciona melhor entendimento apresentado na figura 6 (MONICO, 2000). 


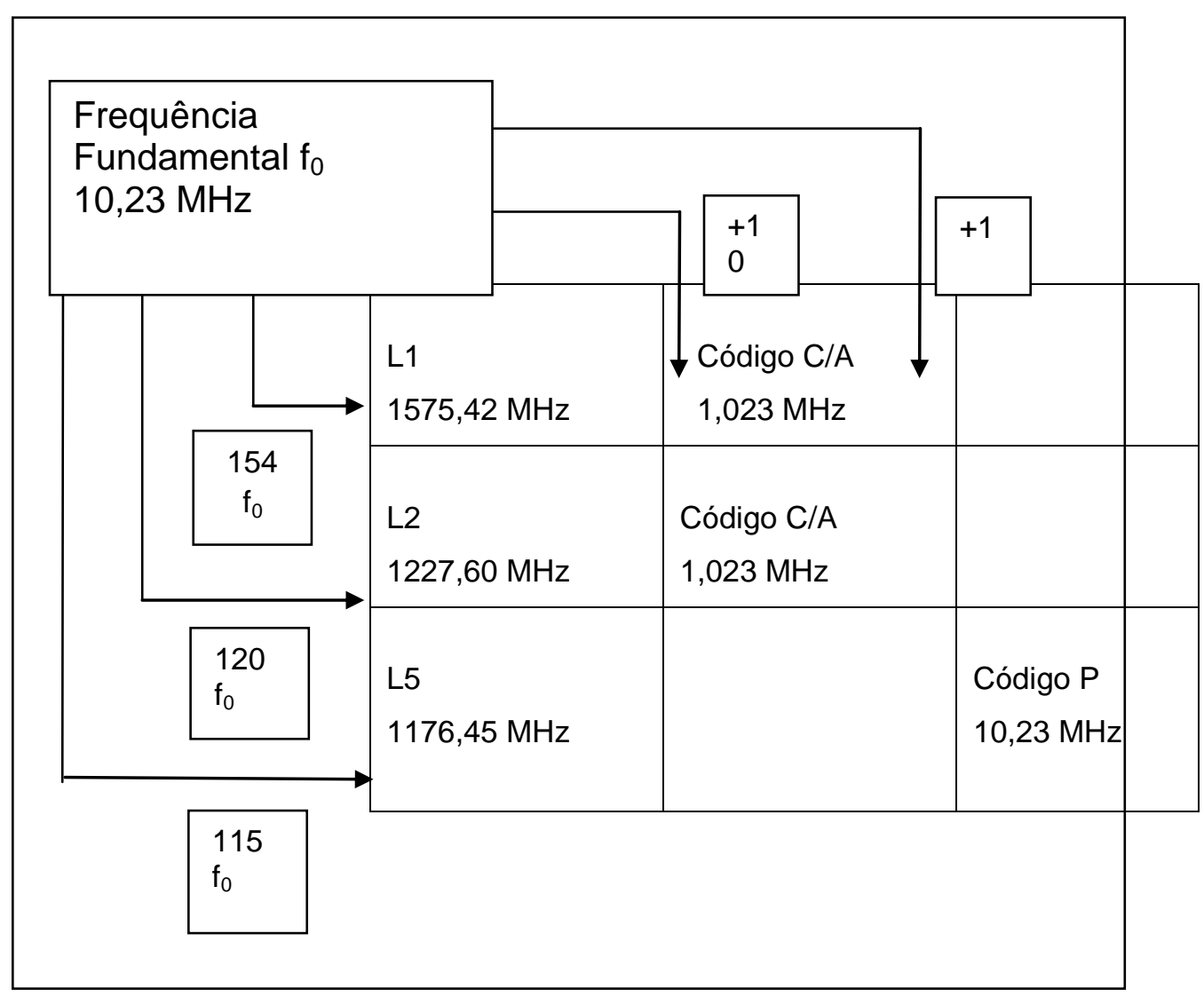

Figura 6 - Estrutura dos sinais GPS-2F após a modernização.

Fonte: Adaptado de Monico (2000).

O GLONASS-K corresponde à fase 3 de desenvolvimento daquele sistema, apresentando as seguintes mudanças com respeito ao GLONASS-M: introdução da banda $L$ (transmissão do protocolo RTCM para o posicionamento DGPS) que representa melhoria no posicionamento absoluto; aumento do tempo de vida útil dos satélites para 10 anos; diminuição do peso dos satélites pela metade; aumento da constelação para 24 satélites; melhoria nos relógios de bordo bem como a sincronia desses com as estações de controle, entre outros. Um resumo quantitativo da modernização do GLONASS, em todas as fases, pode ser observado na tabela 1 (POLISCHUCK et al., 2006).

Vale ressaltar que a tendência do projeto de modernização do GLONASS é que se concretize em curto prazo e que seja integrado ao GALILEO. Este é similar ao GPS, contendo o segmento de controle, o segmento espacial e o segmento de usuário. Estes segmentos são apresentados a seguir, com base em Monico (2000), Benedicto; Ludwig (2001), Eissfeller (2002), Leick (2004) e Segantini (2005). 
Tabela 1 - Resumo da modernização do GLONASS

\begin{tabular}{|c|c|c|c|c|}
\hline & Glonass & Glonass-M & Glonass-K & Glonass-KM \\
\hline Primeira etapa & & 2003 & 2005 & após 2011 \\
\hline Tempo de operação & 3 anos & 7 anos & $10-12$ anos & indefinido \\
\hline Peso do satélite: & $1415 \mathrm{~kg}$ & $1415 \mathrm{~kg}$ & $750 \mathrm{~kg}$ & (TBD) \\
\hline PROTON & 3 & 3 & 6 & $6(\mathrm{TBC})$ \\
\hline SOYUZ & - & 1 & 2 & 2 (TBC) \\
\hline $\begin{array}{l}\text { Energia. Fonte Subsistema. Fonte } \\
\text { de saída }\end{array}$ & $1000 \mathrm{~W}$ & $1600 \mathrm{~W}$ & 1270 (TBC) & TBD \\
\hline $\begin{array}{c}\text { Acurácia vertical de navegação em } \\
\text { tempo real }(95 \%)\end{array}$ & $60 \mathrm{~m}$ & $30 m$ & $\begin{array}{c}\text { 5-8m (TBC) }(40-60 \mathrm{~cm} \text {, } \\
\text { utilizando sistema } \\
\text { diferencial }\end{array}$ & TBD \\
\hline Quantidade de sinais civis & 1 & 2 & $3(\mathrm{TBC})$ & $3(\mathrm{TBC})$ \\
\hline Quantidade de sinais especiais & 2 & 2 & $3(\mathrm{TBC})$ & TBD \\
\hline Estabilidade dos relógios de bordo & $5 \times 10^{-15}$ & $1 \times 10^{-19}$ & $1 \times 10^{-15}$ & TBD \\
\hline $\begin{array}{l}\text { Erro médio quadrático considerando } \\
\text { a sincronização e navegação }\end{array}$ & $15 \mathrm{~ns}$ & $8 n s$ & $3-4 n s$ & TBD \\
\hline Funções suplementares & - & - & $\begin{array}{l}\text { Diferentes } \\
\text { integridades de sinal } \\
\text { (TBC). Correções } \\
\text { (TBC) Busca e } \\
\text { Recuperação (TBC) }\end{array}$ & TBD \\
\hline
\end{tabular}

Fonte: Adaptado de Polischuck et al. (2006).

O segmento de controle do GALILEO, conforme Hein et al. (2001), aproveita a estrutura do EGNOS, adicionado de 12 estações terrestres para atingir a abrangência global. Estas estações dão suporte na determinação de órbitas e na sincronização do tempo. Dentre elas, duas são centros de controle, denominadas GCC (GALILEO Control Center). Além disso, o projeto inclui uma rede de comunicação com duas cadeias independentes e com operação quase autônoma. Esta situação garante a integridade interna e operações de alta qualidade. Adicionalmente, prevê-se a implantação de 30 estações de monitoramento contínuo, as quais também enviam dados para as estações GCC.

Já o segmento espacial, consiste em 30 satélites, sendo 27 operacionais e 3 reservas, distribuídos em três planos orbitais circulares MEO (Medium Earth Orbits), inclinados de $56^{\circ}$ em relação ao plano equatorial com altura de $23.616 \mathrm{~km}$ (MONICO,2000). O período orbital é de 14 horas e 4 minutos e os satélites retornam na mesma posição em relação à superfície terrestre a cada 10 dias. Essa configuração garante cobertura, ou seja, visibilidade, de ao menos quatro satélites 
para todos os países da Comunidade Europeia, Norte da África e regiões limitadas pela latitude de $75^{\circ}$ norte. Quanto à estrutura dos sinais é semelhante ao GPS, incluindo as portadora L1 e L5 (mencionada anteriormente). No entanto, contêm outras duas portadoras, denominadas de E5b (frequência de 1207,14 MHz) e E6 (frequência de 1278,75 MHz). Um resumo da estrutura dos sinais do GALILEO, com a sigla dos mesmos e as respectivas frequências é apresentado na tabela 2.

\begin{tabular}{|c|c|c|}
\hline 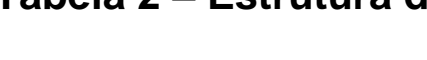 & Fase (sinal) & Frequência (MHz) \\
\hline & E5a (L5) & 1176.45 \\
\hline & E5b & (1196.91-1207.14) \\
\hline & E6 & 1.278 .750 \\
\hline & E2-L1-E1 & 1575.42 \\
\hline
\end{tabular}

Fonte: adaptado de Hein et al. (2001).

Quanto ao segmento de usuário, o sistema GALILEO, em função do GNSS, fará com que seja necessária a fabricação de receptores compatíveis não apenas aos sinais GPS e GLONASS, mas também às 4 frequências apresentadas na tabela 2. A figura 7 representa a arquitetura do GALILEO (BENEDICTO; LUDWIG, 2001).

Levando em conta os avanços da tecnologia de posicionamento por satélite que estão sendo estabelecidos no projeto GNSS, vale ressaltar as simulações realizadas por O'Keefe et al. (2002) onde foram analisados os valores dos diferentes fatores GDOP (Geometric Dilution of Precision), como o HDOP (Horizontal Dilution of Precision) e o VDOP (Vertical Dilution of Precision). Os valores obtidos indicaram melhoras significativas, com a redução dos valores desses indicativos, apontando para a viabilidade do emprego de posicionamento por sistemas de satélites também em regiões e áreas mais urbanizadas e com cobertura de vegetação. 


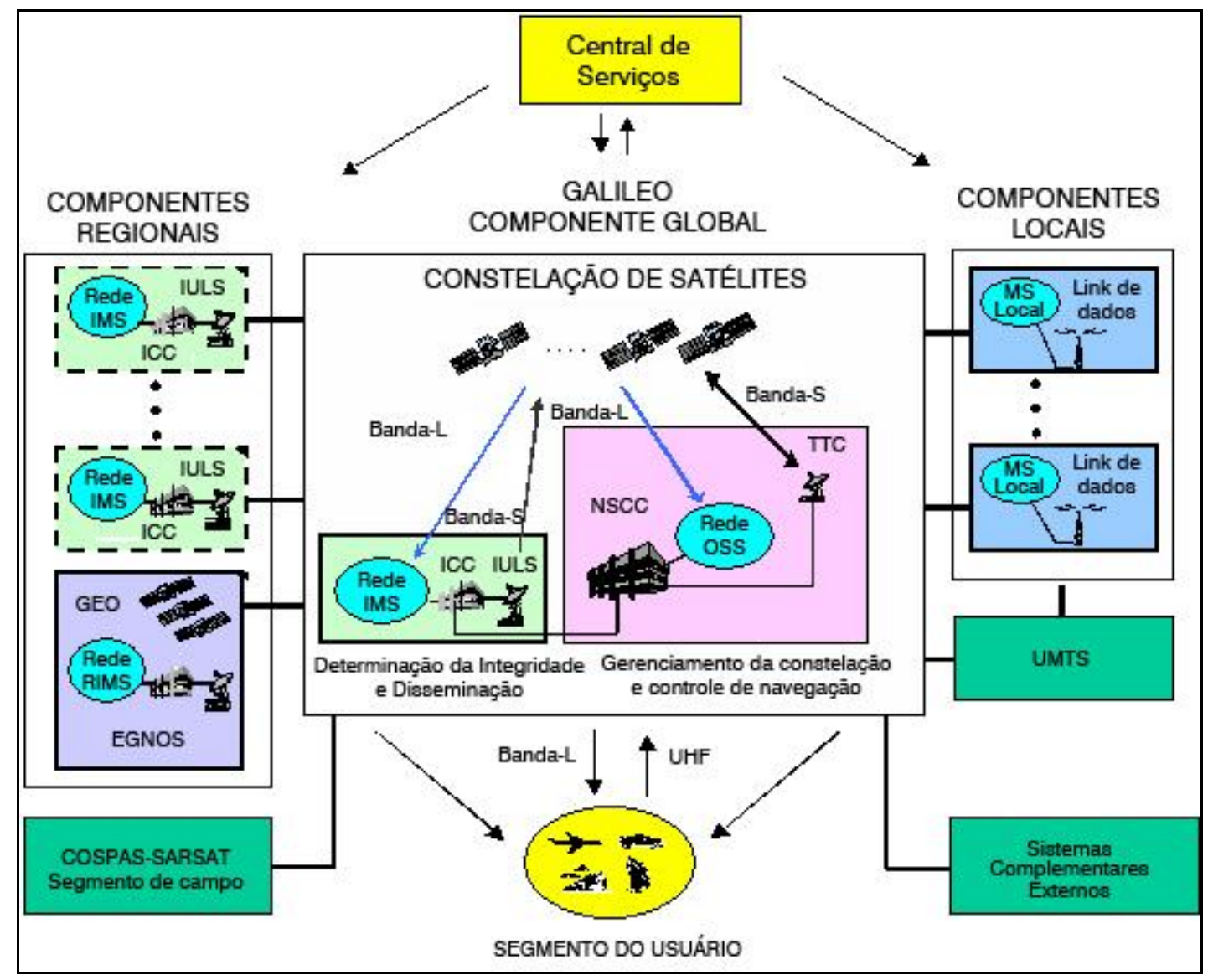

Figura 7 - Arquitetura do sistema GALILEO.

Fonte: Benedicto; Ludwig, (2001).

No projeto GNSS está prevista a integração e interoperabilidade entre o GPS, - GLONASS e o GALILEO. A tabela 3 (adaptada de LEICK, 2004) apresenta um resumo geral com a apresentação dos códigos dos sinais, o fator em relação à frequência fundamental de $10,23 \mathrm{MHz}$ e frequências finais. Um esquema no qual se podem visualizar essas frequências em conjunto está na figura 8.

Considerando tudo que foi descrito com relação ao GNSS, pode-se afirmar que ocorrerá ou está ocorrendo uma melhora em termos de rendimento global para o posicionamento por satélite. Entre os impactos previstos, conforme relatam vários autores, estão a redução dos efeitos da ionosfera e a melhoria na solução das ambiguidades (JOOSTEN; IRSIGLER, 2001; FENG, 2003). Na prática, em termos de aplicações, podem-se destacar os resultados positivos na determinação do vapor d'água na troposfera, na viabilidade do posicionamento geodésico, entre outros. Além disso, estão as aplicações que seriam inviáveis apenas com as constelações do GPS e do GLONASS, tais como as voltadas para as finalidades da aviação civil, 
se consideradas as exigências de acurácia da categoria III (MONICO, 2000 e 2008; SEGANTINI, 2005).

Tabela 3 - Sinais disponíveis com a integração das constelações de satélites no projeto GNSS

\begin{tabular}{|c|c|c|}
\hline Sinal/fase & Múltiplo de 10.23 & Frequência (MHz) \\
\hline L5 \& E5a & 115 & 1176.45 \\
\hline E5b & 117.5 & 1.202 .025 \\
\hline L2 & 120 & 1227.025 \\
\hline G2 & $\begin{array}{c}\text { Ver item (3.92, } \\
\text { Leick, 2004) }\end{array}$ & Por satélite \\
\hline E6 & 125 & 1.278 .750 \\
\hline L1, E1-L1-E2 & 154 & 1574.42 \\
\hline G1 & $\begin{array}{c}\text { Ver item (3.91, } \\
\text { Leick, 2004) }\end{array}$ & Por satélite \\
\hline
\end{tabular}

Fonte: adaptado de Leick (2004).

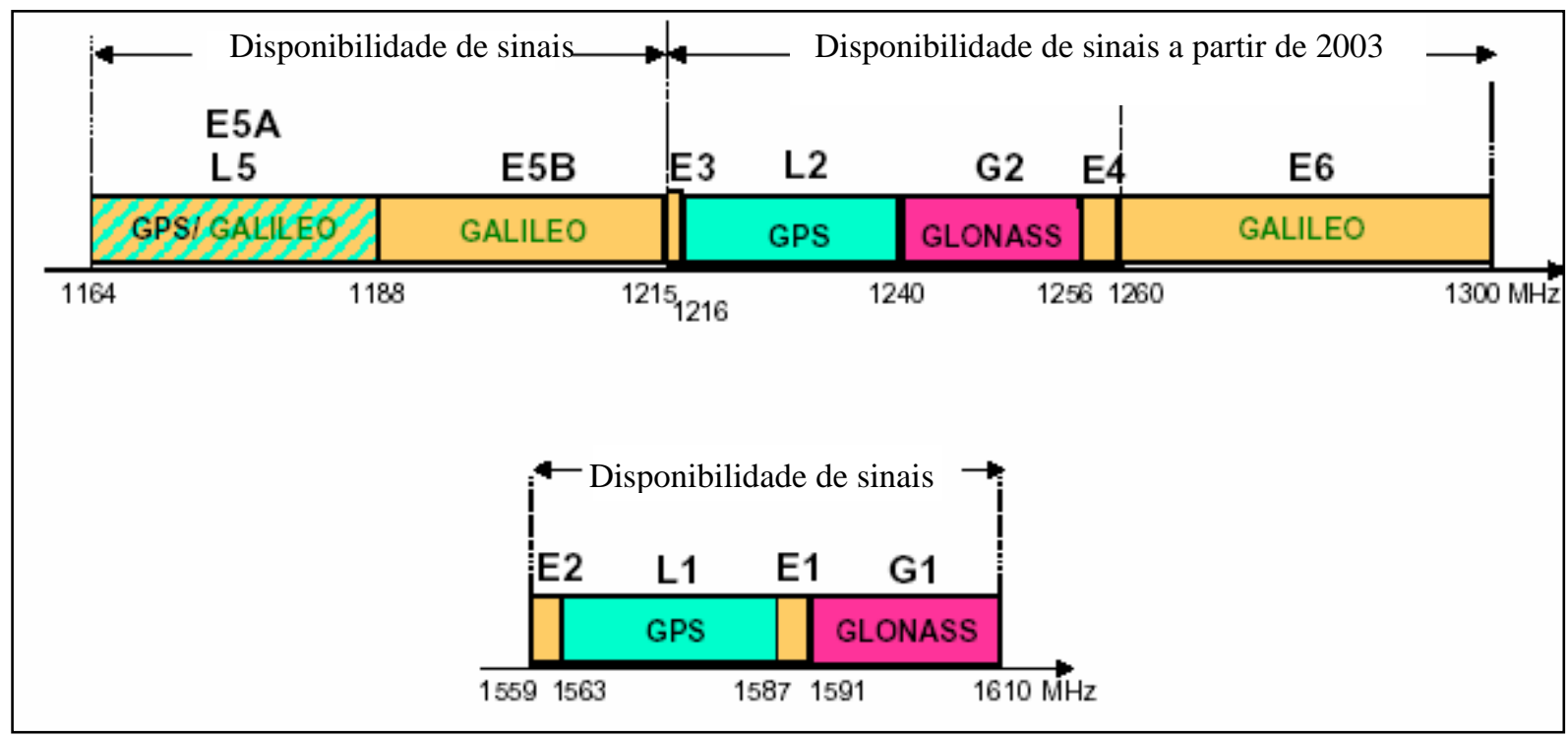

Figura 8 - Intervalos de frequências do GPS, GLONASS e GALILEO.

Fonte: adaptado de Hein et al. (2001).

1.2 UTILIZAÇÃO DE RECEPTORES GNSS L1 E L1/L2, NA TÉCNICA RTK

Os receptores GNSS de dupla frequência, oferecidos atualmente ao mercado, vêm apresentando redução no custo de aquisição e proporcionando maior produtividade em muitas situações. 
A possibilidade de executar levantamento na técnica RTK foi de domínio restrito aos receptores de dupla frequência até recentemente. No entanto, vale destacar a tecnologia BLADE (Base Line Accurate Determination Engine), (ASHTECH, 2008), utilizada pelos receptores GPS ProMark3 e ProMark100 RTK L1.

A utilização de receptores de simples frequência na técnica RTK é dificultada pelo tempo mais elevado na fixação da ambiguidade no momento inicial TTFF (Time to First Fix), podendo atingir vários minutos. Já para os receptores de dupla frequência, o procedimento leva apenas alguns segundos. No entanto, pesquisas recentes de inovação tecnológica realizada pela empresa $\mathrm{ASHTECH}$, em termos de envio de observações de fase do receptor base para o móvel, utilizando apenas a portadora $\mathrm{L} 1$, levaram ao desenvolvimento de um novo algoritmo de processamento de sinal de satélite. Tal algoritmo, denominado BLADE, de sigilo da ASHTECH (2008), é capaz de reduzir drasticamente o TTFF para receptores GPS de simples frequência. Além disso, é possível o cálculo de posições com acurácia na ordem de centímetros ou decímetros, combinando informações de distância do GNSS/GPS e do SBAS, o que resulta no fornecimento de solução das ambiguidades em receptores de simples frequência em tempo real com alta confiabilidade (ASHTECH, 2008). A figura 9 ilustra a composição do conjunto de receptores GPS L1 na técnica RTK.

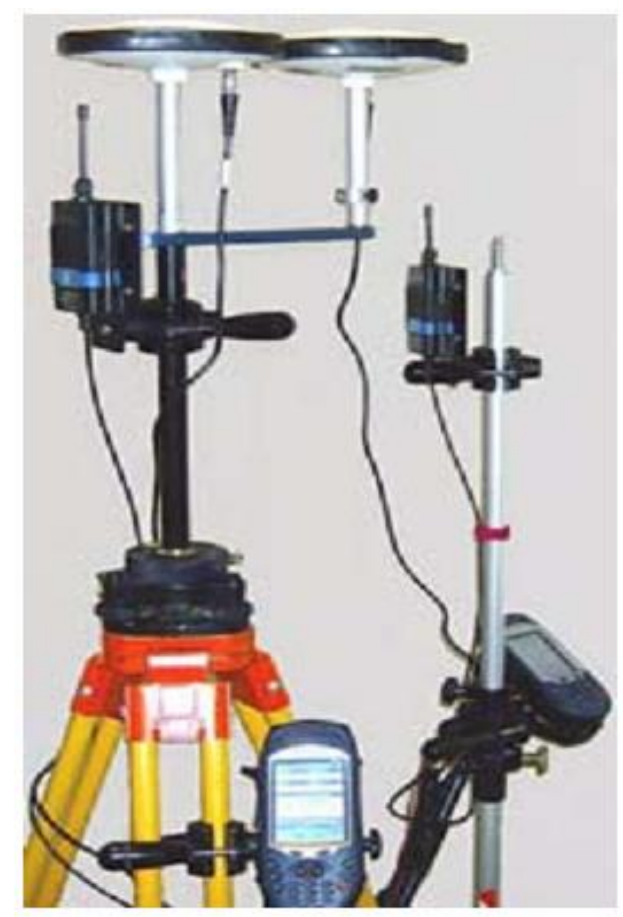

Figura 9 - Par de Receptores GPS ProMark3 RTK L1.

Fonte: ASHTECH(2008). 
O receptor GNSS é um equipamento com capacidade para o rastreamento simultâneo dos satélites, atualmente variando entre 12 a 120 canais. A necessidade de um número maior ou menor de canais será definida na determinação de quais frequências disponíveis serão utilizadas nas constelações GPS, GLONASS e GALILEO. Em algumas tecnologias podem ser utilizados três canais adicionais para rastrear os satélites geoestacionários e auxiliar o posicionamento. Desta maneira, o usuário GNSS rastreará em campo uma média de 16 satélites, o que permitirá um PDOP melhor em situações adversas e rastreará um maior número de observáveis GNSS facilitando o calculo das duplas diferenças de fase, até onde o aumento do número de satélites permita uma melhor geometria. No posicionamento relativo serão considerados apenas os satélites com uma boa relação sinal/ruído (ou seja, melhor sinal e com menos ruído) e a perda de ciclo será improvável, o que significa um avanço considerável no uso do GNSS. A figura 10 demonstra a composição do conjunto de receptores GNSS L1L2 na técnica RTK/UHF.

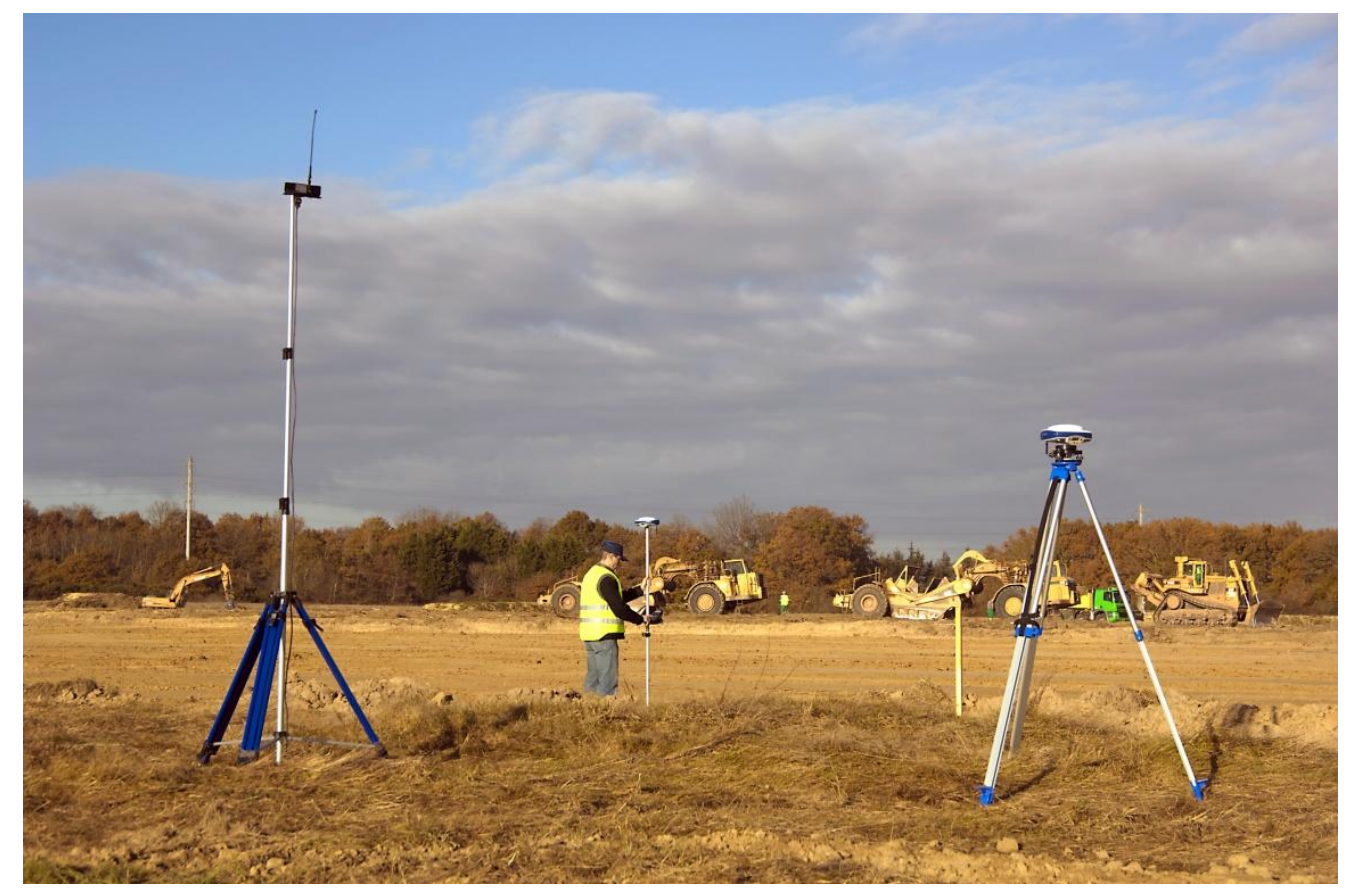

Figura 10 - Par de Receptores GNSS ProMark 500 RTK L1L2.

Fonte: ASHTECH (2008).

As diferenças de desempenho entre os receptores de simples e de dupla frequência e dos novos métodos de conexão podem ser influenciados por fatores, a saber: 
- Capacidade física: os receptores GNSS precisam rastrear o maior número possível de satélites (mínimo de cinco até oito satélites, principalmente no caso de receptores L1); quanto mais satélites visíveis melhor será o desempenho. Esta melhoria é caracterizada por mais segurança na coleta de dados, melhor precisão e níveis mais altos de confiabilidade.

- Tempo para primeira fixação - TTFF: alguns receptores GNSS de dupla frequência existentes no mercado podem executar esta tarefa em poucos segundos, ao passo que os receptores GPS de simples frequência podem requerer trinta minutos ou mais para essa mesma operação. Claro que, dependendo das exigências do trabalho a ser executado, isto pode ou não ser relevante. Por exemplo, se o receptor estiver funcionando continuamente e tiver a maior visibilidade possível de satélites, o tempo necessário para resolver a primeira ambiguidade é trivial, desde que o receptor mantenha sua posição fixa por um longo período de tempo. Porém, se o receptor tiver perda de sinais muito frequentes (perda de ciclo), acarretará perda da posição fixa. Dessa maneira, o tempo requerido para resolver novamente a ambiguidade e coletar posições com precisão na técnica RTK tornar-se-á importante.

- Linhas de base: é a distância entre o receptor base e o móvel. Na técnica RTK, o comprimento médio da linha de base para trabalhos topográficos é de $2 \mathrm{~km}$, viabilizando perfeitamente o sistema de simples frequência para esta aplicação. Alguns receptores RTK de dupla frequência têm a habilidade de medir linhas de base de até 40 quilômetros, com um sistema de rádio de alta potência, mantendo a precisão na ordem de centímetros. Com o emprego da conexão GSM/GPRS, associada ao GNSS/GPS, estima-se que o envio da observação de fase e correção em tempo real com o emprego da técnica RTK/GSM poderá atingir um raio de até $90 \mathrm{~km}$ mantendo as resultados atingidos com a técnica RTK/UHF.

- Latência: as medições de fase da onda portadora são realizadas com certa frequência e são transmitidas instantaneamente no instante $t_{0}$. $O$ receptor móvel receberá os dados com certo atraso havendo ainda um certo intervalo de tempo para o cálculo. Isso resulta em uma posição no instante $t_{1}$. A diferença $t_{1}-t_{0}$ é denominada latência.

- Protocolo RTCM: o formato de dados transmitidos, formulado pelos padrões recomendados, sendo o protocolo RTCM composto pelas informações 
apresentadas na tabela 4. Corresponde à comunicação efetuada com o uso de rádios transmissor e receptor que normalmente operam nas faixas de frequência VHF/UHF para este tipo de aplicação.

\section{Tabela 4 - Formato RTCM 3.0 e 3.1 e os tipos de mensagens que existem nessas versões são listados de 1001 a 1029.}

\begin{tabular}{|c|c|}
\hline Tipo de Mensagem & Descrição \\
\hline 1001 & Observáveis L1 de GPS RTK \\
\hline 1002 & Observáveis L1 amplificadas de GPS RTK \\
\hline 1003 & Observáveis L1L2 de GPS RTK \\
\hline 1004 & Observáveis L1L2 amplificadas de GPS RTK \\
\hline 1005 & Estação de referência estática RTK - ARP \\
\hline 1006 & Base ARP com a altura da Antena \\
\hline 1007 & Descrição da antena \\
\hline 1008 & Descrição da antena e número serial \\
\hline 1009 & Observáveis L1 RTK GPS \\
\hline 1010 & Observáveis L1 RTK GLONASS \\
\hline 1011 & Observáveis L1\&L2 amplificados GPS \\
\hline 1012 & Observáveis L1\&L2 amplificados GLONASS \\
\hline 1013 & Parâmetro do sistema \\
\hline 1019 & Dados de efemérides GPS \\
\hline 1020 & Dados de efemérides GLONASS \\
\hline 1029 & Sequencia de texto de um código \\
\hline 1033 & Descrições do receptor e antena \\
\hline
\end{tabular}

Fonte: Ashtech (2008).

- PDOP: considerando-se condições ideais, tais como número elevado de satélites com PDOP (Positioning Dilution of Precision) baixo (melhor geometria para o cálculo da posição), o tempo para a resolução das ambiguidades pode ser inferior a 10 segundos.

- Extrapolação: há uma tendência de se obter somente os dados referentes ao instante simultâneo de observação no receptor base e móvel e a possibilidade de uma extrapolação quando o receptor base efetua e envia os dados numa 
frequência inferior ao móvel. A extrapolação é o processo através do qual o receptor móvel pode continuar a obter posição precisa mediante uma estimativa a partir da última medição de fase da onda portadora recebida da base.

Um aspecto relevante é o efeito da latência, bem como a sua correção. Assim, é fundamental considerar os termos época ("epoch") e extrapolação ("extrapolation"). O termo época corresponde a um instante em particular quando um conjunto completo e inteiro de dados da fase da onda portadora é enviado do receptor base. Isto é, como o tempo para a disponibilidade dos dados é cíclico, cada ocorrência desse instante particular é chamada época.

Sendo assim, a extrapolação é o processo através do qual o receptor móvel pode continuar a obter posição precisa obtida da última medição de fase da onda portadora recebida da base.

Os novos receptores GNSS já estão preparados para exibir informações de extrema importância, tais como a latência, a conexão GSM ativa e o tipo de solução da ambiguidade (ver figura 11).

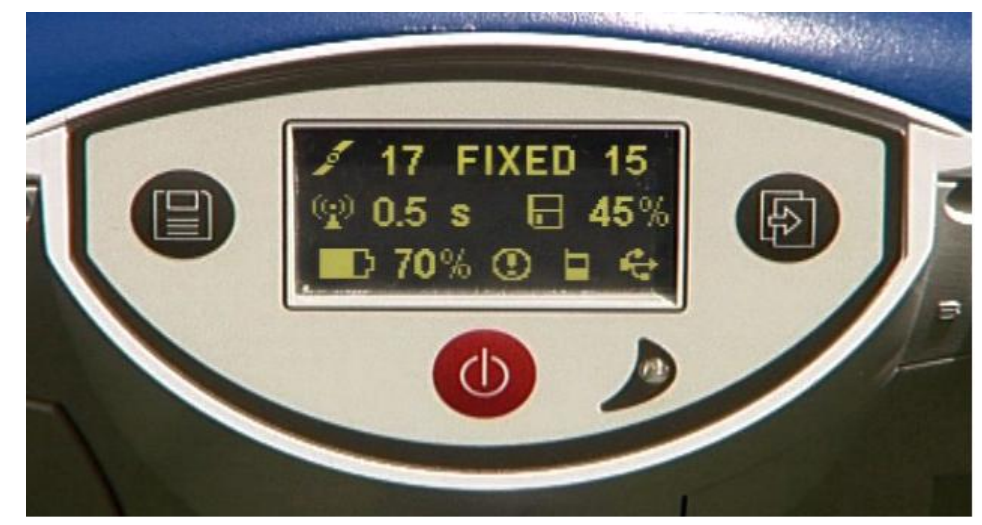

Figura 11 - Tela de informações do Receptor GNSS ProMark 500. Fonte: ASHTECH (2008). 


\section{NOVAS TECNOLOGIAS}

\subsection{MÉTODOS DE POSICIONAMENTO GNSS COM ÊNFASE NA TÉCNICA RTK E SUA EVOLUÇÃO}

Monico (2008) afirma que posicionamento é a determinação da posição de objetos com relação a um referencial específico. Corresponde ao posicionamento absoluto quando as coordenadas são determinadas diretamente por um único receptor. No entanto, quando as coordenadas são determinadas com relação a um ou mais vértices materializados e com coordenadas conhecidas, o posicionamento é denominado relativo. O emprego da tecnologia de posicionamento GNSS, (MONICO; 2000, 2008) apresenta a seguinte classificação:

- Posicionamento pelo método absoluto: simples ou preciso;

- Posicionamento pelo método relativo: estático, estático rápido, semicinemático, cinemático e cinemático em tempo real.

Todos esses métodos são descritos com detalhe por vários autores, tais como Monico (2000, 2008), Seeber (1993, 2003), Leick (2004) e Segantini (2005).

O posicionamento relativo pode ser pós-processado ou em tempo real; este último é conhecido pela sigla RTK, interesse maior deste trabalho. O mesmo se baseia no conhecimento das coordenadas de um ponto de referência onde é instalado o receptor base. Este recebe as observações dos satélites, sendo simultaneamente coletadas informações dos mesmos satélites no receptor móvel. A partir da solução das ambiguidades instantaneamente (destaque-se o método denominado OTF - on-the-fly, ver Leick, 2004; Monico, 2008) passa-se a obter as posições dos pontos de interesse, percorridos pelo receptor móvel, com precisões centimétricas. Ou seja, utilizam-se dois receptores (de dupla ou simples frequência) dotados de rádio, que possibilitam a transferência de dados entre os mesmos. Isto permite o cálculo das coordenadas em tempo real, existindo uma latência inerente ao tempo de transmissão dos dados de um receptor para outro. 
Com respeito às principais vantagens da técnica RTK, pode-se listar: obtenção instantânea das coordenadas, da solução da ambiguidade e do erro do relógio em tempo real; alta produtividade; possibilidade da locação de pontos e da divisão de áreas com acurácia centimétrica; utilização de vários equipamentos móveis tendo como referência um único receptor base. Quanto às desvantagens, pode-se dizer que a principal se refere ao custo da maioria dos equipamentos disponíveis no mercado para a utilização desse método de posicionamento. A análise da maior produtividade da técnica RTK frente aos métodos tradicionais será o fator de decisão na utilização e consolidação deste novo método de posicionamento. A introdução dos receptores de simples frequência na técnica RTK, a consagração da técnica RTK/UHF e a nova da técnica RTK/GSM, permitirá opções para atender a necessidade do aumento de produtividade nos trabalhos topográficos. Resumidamente, a técnica RTK é baseada na utilização de um receptor base que envia as observações de fase do receptor móvel que realiza o processamento em tempo real, calculando as coordenadas instantaneamente.

Assim, a técnica RTK pode ser viabilizada de dois modos:

a) Pela transmissão em UHF das observações de fase do receptor base para o móvel utilizando um enlace de rádios; denominada RTK/UHF. A figura 12 esquematiza a utilização de rádios para o envio da observação de fase.

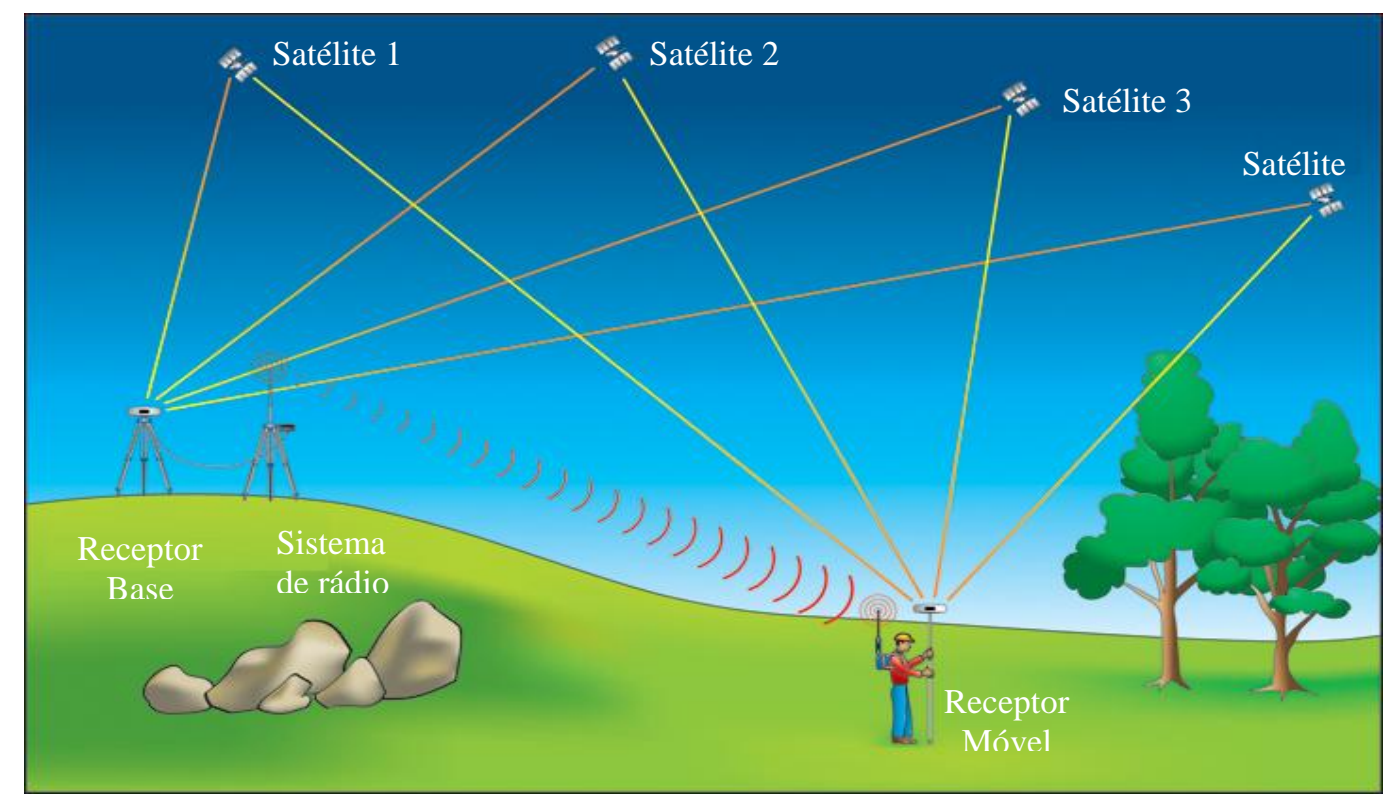

Figura 12 - Técnica RTK/UHF.

Fonte: Pacificcrest (2009). 
b) Pela disponibilização das observações de fase do receptor base para 0 móvel através da conexão GSM/GPRS, denominada RTK/GSM. A figura 13, ilustra a utilização da infraestrutura existente da conexão GSM/GPRS, realizando a comunicação entre o receptor base para o móvel.
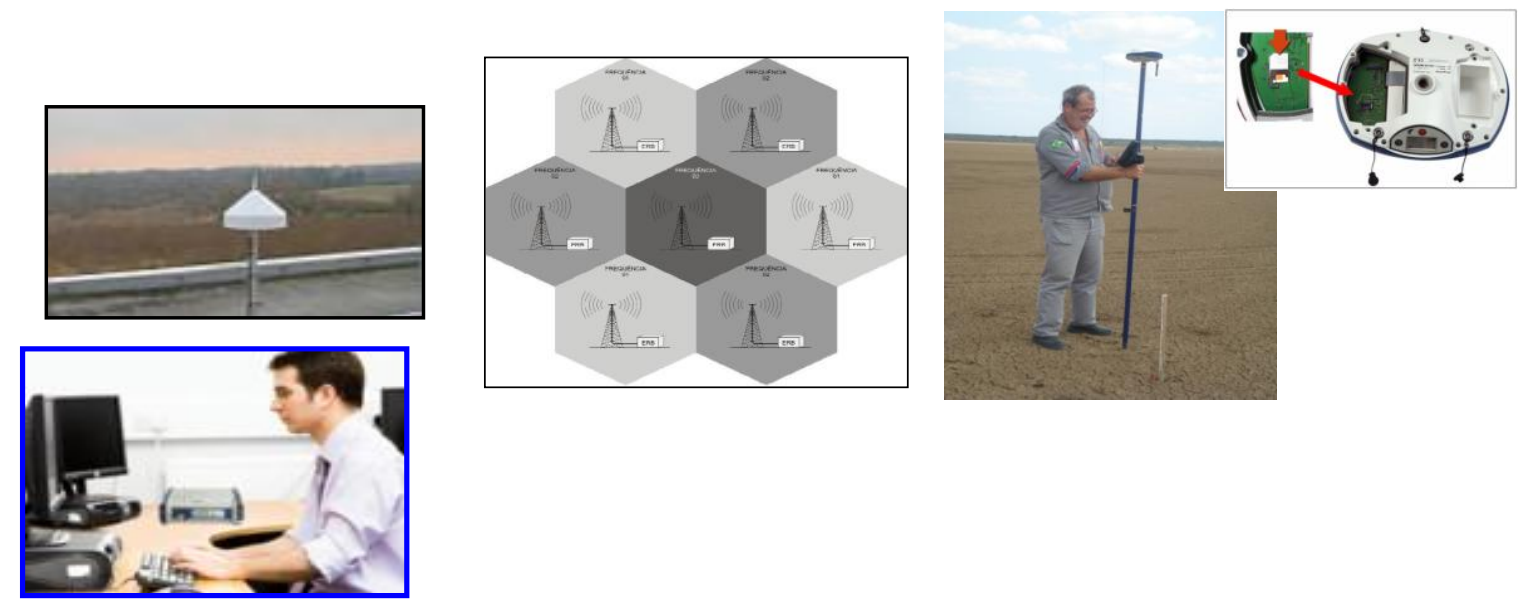

Figura 13 - Técnica RTK/GSM.

A tabela 5 demonstra as principais diferenças entre as técnicas mencionadas acima. Na união europeia estima-se que o uso da técnica RTK/GSM é de $95 \%$ enquanto que a técnica RTK/UHF apenas $5 \%$. O mercado americano chegará nesta proporção no final de 2013; no Brasil o uso da técnica RTK/GSM não é superior a $1 \%$ quando comparado ao uso da técnica RTK/UHF. Esta vem sendo utilizada devido a não dependência de nenhum serviço adicional, exceto seus próprios equipamentos. Entretanto, necessita-se de um número maior de profissionais em campo para o funcionamento da técnica RTK/UHF.

A implantação da técnica RTK/GSM dependerá diretamente do número de ERAs (Estações de Referência Ativa) GNSS estabelecidas numa determinada área, bem como a necessidade da cobertura da conexão GSM nesta área. Estes são os principais desafios para a consagração desta técnica no território brasileiro devido ao seu tamanho e a parcial cobertura da conexão GSM que hoje se restringe apenas aos principais centros urbanos.

Não restam dúvidas das vantagens da técnica RTK/GSM quando comparada à RTK/UHF; entretanto, o investimento necessário em ERA (Estação de Referência Ativa) e garantia de que a conexão GSM venha a estar disponível por todo o 
território brasileiro, tornam a substituição de uma técnica pela outra lenta. Isto ocorrerá primeiro nos grandes centros urbanos e posteriormente em ambientes rurais.

Tabela 5 - Comparação das vantagens e desvantagens das técnicas RTK/UHF x RTK/GSM.

\begin{tabular}{|c|c|c|}
\hline & Técnica RTK/UHF & Técnica RTK/GSM \\
\hline \multirow{2}{*}{ Vantagens } & $\begin{array}{l}\text { Sistema de Trabalho Independente da coberura } \\
\text { GSM }\end{array}$ & $\begin{array}{l}\text { Custo baixo do sistema completo } \\
\text { Equipe de campo com apenas } 1 \\
\text { profissional }\end{array}$ \\
\hline & $\begin{array}{c}\text { Envio das Observaçôes de Fase sem custo } \\
\text { Adicional }\end{array}$ & $\begin{array}{l}\text { Não há limitações topográficas para o } \\
\text { envio da observação de fase } \\
\text { Aumento na produtividade dos projetos } \\
\text { realizados }\end{array}$ \\
\hline \multirow{4}{*}{ Desvantagens } & $\begin{array}{l}\text { Custo elevado do sistema completo } \\
\text { Limitações de alcance dos rádios devido a } \\
\text { obstaculos Topográficos }\end{array}$ & $\begin{array}{c}\text { Necessidade da cobertura GSM na área } \\
\text { de trabalho }\end{array}$ \\
\hline & $\begin{array}{l}\text { Receptor Base com grande número de } \\
\text { periféricos em campo }\end{array}$ & \multirow{3}{*}{$\begin{array}{l}\text { Usuário torna-se sucetivel a problemas } \\
\text { com a rede GSM }\end{array}$} \\
\hline & $\begin{array}{l}\text { Necessita trocar a posição do receptor base } \\
\text { conforme o trabalho de campo }\end{array}$ & \\
\hline & Equipe de campo de no mínimo 2 profissionais & \\
\hline
\end{tabular}

\subsection{UTILIZAÇÃO DE SISTEMAS DE TRANSMISSÃO DE DADOS VIA TELEFONIA MÓVEL}

A tentativa de padronização das tecnologias de codificação e de transmissão TDMA (Time Division Multiple Access) e FDMA (Frequency Division Multiple Access), ocorrida na Europa visando a criação de uma homogeneidade no uso da comunicação sem fio, é conhecida pela sigla GSM; ela tem sido adotada pelas operadoras no Brasil. Timo et al. (2002) apud Queiroz (2008), afirmam que a conexão GSM começou a ser amplamente utilizada no início dos anos 90, quando o oferecimento dos serviços de telefonia móvel de segunda geração (2G) apresentou grande crescimento em várias regiões do mundo. O princípio dessa padronização foi a possibilidade de arquitetura aberta que permitisse o uso de equipamentos de 
vários fabricantes (utilização de um pequeno chip em diferentes equipamentos), de modo a provocar a redução de custos na aquisição e na manutenção.

As inovações tecnológicas na área de telecomunicações têm causado grande impacto na utilização dos sistemas de posicionamento por satélite (GPS e GNSS), conforme é relatado por Yan (2005). Isso se deve, principalmente, à grande expansão dos serviços de comunicação na última década, com maior área de cobertura e com o aumento da velocidade de transmissão de dados. A conexão GSM está dentro desse contexto.

Um sistema com a conexão GSM, de acordo com Pivaro (2008), é composto pelos seguintes elementos: EM (Estação Móvel), ERB (Estação Rádio Base), CERB (Controladora de Estações Rádio Base) e SC (Sistemas de Comutação), descritos a seguir.

A EM é a junção entre um aparelho celular e o módulo do assinante (SIM Card), sendo a única componente da rede móvel de conexão GSM diretamente ligada ao assinante. Possibilita que o usuário utilize a rede operadora para enviar ou receber chamadas de voz ou dados (mensagens de texto, acesso à Internet, fotos, vídeos, entre outros). Existem diversos modelos de EM, segundo a sua classe de potência e de sensibilidade.

O cartão identificador do assinante, SIM card, é um microchip que funciona principalmente como base de dados (HEINE, 1999), ou seja, tem como principal função armazenar dados e identificar o assinante. Os dados são de duas categorias: referentes à assinatura e ao assinante. Os dados da assinatura, necessários para o uso da rede com conexão GSM, referem-se ao número telefônico do assinante, o identificador de assinante internacional IMSI (International Mobile Subscriber Identity), único para cada usuário no mundo, os códigos de segurança do cartão SIM e os dados da operadora. Os dados do assinante correspondem às informações da agenda de contatos e outras informações que podem ser armazenadas no cartão SIM.

A ERB é responsável pelo controle do enlace de rádio, ou seja, o canal utilizado pela EM para troca de informações com a rede. Uma ERB é composta por diversos equipamentos, sendo que os mais importantes são os TRXs (transmissores) que estabelecem enlace entre EM, ERB e antenas, realizando a transmissão e a recepção de sinais eletromagnéticos. Além disso, em sua maioria, possuem estrutura metálica com suas antenas em posições mais altas possíveis 
(torres, edifícios, postes de concreto), de maneira a permitir a propagação mais eficiente do sinal. Nos equipamentos mais modernos, a conexão entre os TRXs e as antenas é feita por meio de cabos de fibra ótica. Adicionalmente, são instalados amplificadores para melhorar o sinal que é recebido pela antena antes que esse seja enviado aos TRXs.

No projeto de implantação de uma ERB, conforme relata Pivaro (2008), existem diversos fatores físicos que influenciam na capacidade de tráfego e no desempenho da transmissão. São eles: o número de portadoras, a potência máxima de transmissão, a sensibilidade mínima do receptor, o ganho de recepção (melhora do sinal que é recebido por meio de amplificadores instalados nas torres) e de transmissão das antenas (facilidade de propagação das ondas eletromagnéticas das antenas), a diversidade de recepção (conceito segundo o qual todo caminho de recepção é dotado de equipamentos duplicados, de acordo com Heine (1999), ou seja, ERB com duas antenas de recepção, dois cabos, dois amplificadores instalados na torre e outros equipamentos envolvidos na recepção do sinal), a altura das antenas em relação ao solo, o distanciamento entre antenas e o tipo de cabos metálicos (atenuação, perda).

$A$ área de cobertura de uma ERB é denominada de célula. No projeto, quanto maior for à área de cobertura com a menor quantidade de ERBs, mais baixo será o custo. Assim, a rede com conexão GSM é composta por uma série de células agrupadas, por isso o nome de sistema de telefonia móvel celular. A figura 14 apresenta uma área de cobertura de uma operadora, onde a mesma é dividida em hexágonos, os quais correspondem às células, numa primeira aproximação.

Numa segunda aproximação é apresentada a figura 15, onde existem 3 ERBs, cada uma com uma célula. Assim, uma EM que estiver nessa região recebe sinal de 1, 2 ou das 3 ERBs (área mais escura). No entanto, é possível uma terceira aproximação, mais realista ainda, conforme observado na figura 13 , onde as bordas de duas células são bastante irregulares devido ao relevo da região. $O$ cálculo dessas áreas de cobertura é realizado por meio dos métodos de Okumura-Hata e COST 231-Wlafish-Ikegami (ERICSON, 2004 apud PIVARO, 2008). 


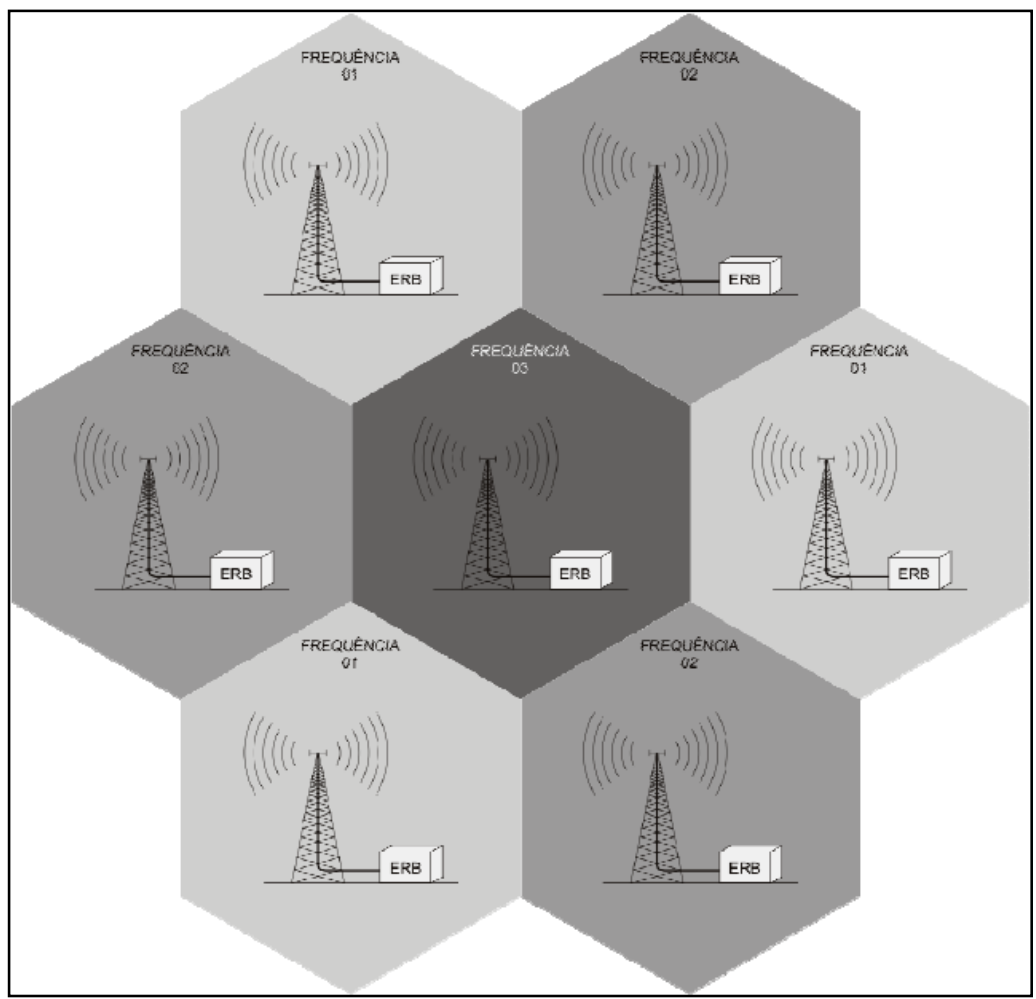

Figura 14 - Cobertura da rede com conexão GSM realizada por várias células vizinhas. Esquema hexagonal teórico utilizado como primeira aproximação. Fonte: Pivaro (2008)

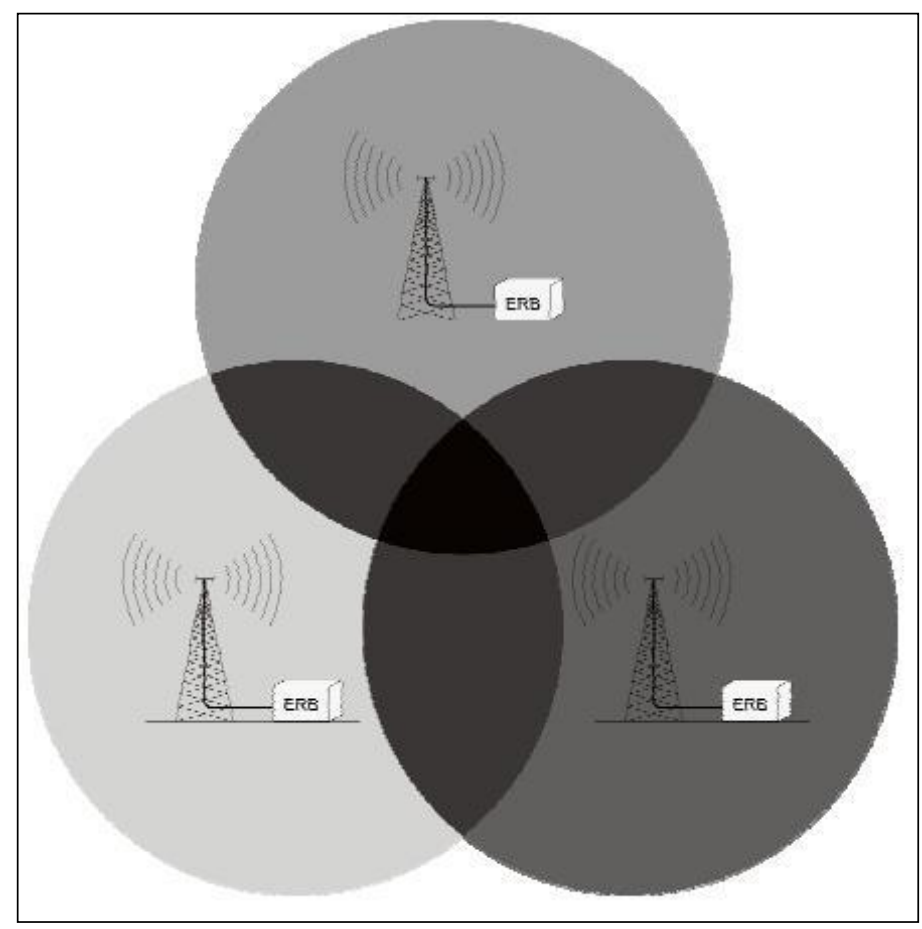

Figura 15 - Cobertura da rede com conexão GSM realizada por 3 célulasvizinhas. Esquema circular realista utilizado como segunda aproximação.

Fonte: Pivaro (2008) 


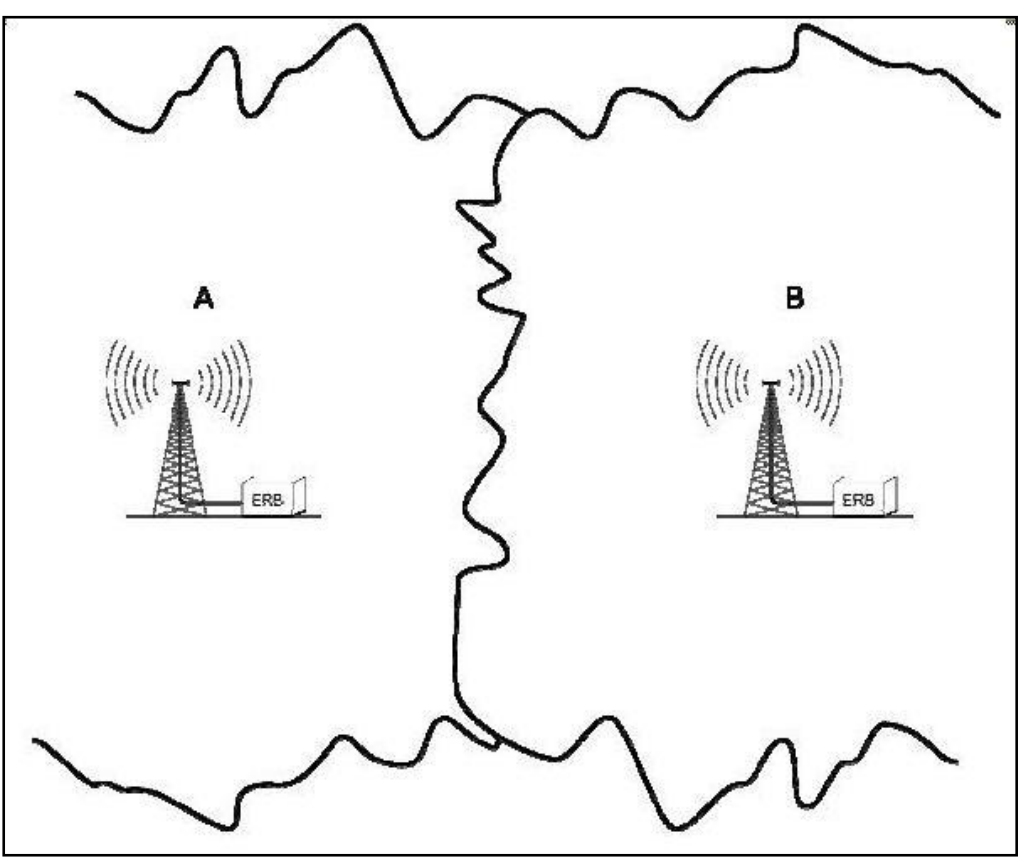

Figura 16 - Borda de cobertura de 2 células vizinhas numa terceira aproximação onde existe a influência do relevo.

Fonte: Pivaro (2008)

A comunicação na telefonia móvel ocorre em duas direções, que são: comunicação da ERB para a EM (enlace de descida, downlink, ou seja, a recepção de chamada ou de mensagem) e vice-versa (enlace de subida, uplink, ou seja, a realização de uma chamada ou o envio de uma mensagem), utilizando as bandas de frequência de 800, 900, 1800 e $1900 \mathrm{MHz}$. Para cada uma delas existe uma quantidade limitada de bandas de frequência que podem ser utilizadas. Um exemplo é apresentado na tabela 6 , em que é utilizada a frequência de $900 \mathrm{MHz}$ na conexão GSM, sendo esta dividida em bandas ou intervalos. Dessa forma, a primeira banda de frequência é $890 \mathrm{MHz}$ e a última, $960 \mathrm{MHz}$, configurando uma largura de banda de $70 \mathrm{MHz}$. Além disso, existe um espaçamento de $20 \mathrm{MHz}$, entre a última frequência portadora do uplink e a primeira do downlink, evitando com isso a interferência. A largura da banda uplink é de $25 \mathrm{MHz}(890-915 \mathrm{MHz})$ e cada portadora tem largura de banda de $200 \mathrm{kHz}$, resultando em 125 portadoras (igualmente no downlink). Novamente, para evitar problemas de interferência com outros sistemas celulares, os primeiros $200 \mathrm{kHz}$ da banda na frequência de $900 \mathrm{MHz}$ não são utilizados, restando 124 portadoras (124 canais) para o transporte de informações nos dois sentidos (downlink e uplink) (PIVARO, 2008). 
Tabela 6 - Divisão da banda de 900 MHz na conexão GSM.

\begin{tabular}{|l|l|}
\hline $890-915 \mathrm{MHz}$ & uplink \\
\hline $935-960 \mathrm{MHz}$ & downlink \\
\hline
\end{tabular}

Fonte: Pivaro (2008).

Conclui-se que, quando é estabelecida uma comunicação entre uma EM e uma ERB, a EM tem disponíveis 124 canais. Isto é, se a EM transmite no canal 35 no uplink, a ERB deverá utilizar este mesmo canal no downlink (PIVARO, 2008). As frequências do canal 35 serão:

- No uplink: 890,2 MHz +0,2*(34-1) $=897 \mathrm{MHz}$

- No downlink: $897 \mathrm{MHz}+45 \mathrm{MHz}=942 \mathrm{MHz}$

Essa separação de $45 \mathrm{MHz}$ garante que não haja interferência entre o uplink e o downlink (PIVARO, 2008). Outro aspecto importante, conforme relata o mesmo autor, ainda com respeito à comunicação entre a $E M$ e a ERB, refere-se ao planejamento de cobertura e ao reuso das frequências.

Segundo Pivaro (2009), a CERB é outro componente relacionado à conexão GSM, que tem como função principal o controle das ERBs. As ERBs possuem contadores de tráfego que coletam as informações sobre o mesmo e o comportamento das EMs. Para entender melhor como a ERB funciona, o autor apresenta a figura 17, onde a região de cobertura de uma operadora possui quatro células. Nesta figura existe uma EM sob cobertura da célula A. Além disso, conexão entre a ERB e a CERB acontece mediante uma interface denominada Abis, que utiliza um ou mais canais com modulação por pulso do código (PCM - Pulse Code Modulation) de 32 canais, com uma taxa de 2,048 Mbps. Já a conexão entre a CERB e o SMC (Serviço Móvel de Comutação) é realizada pela interface $A$, a qual se utiliza também da interface Abis. 


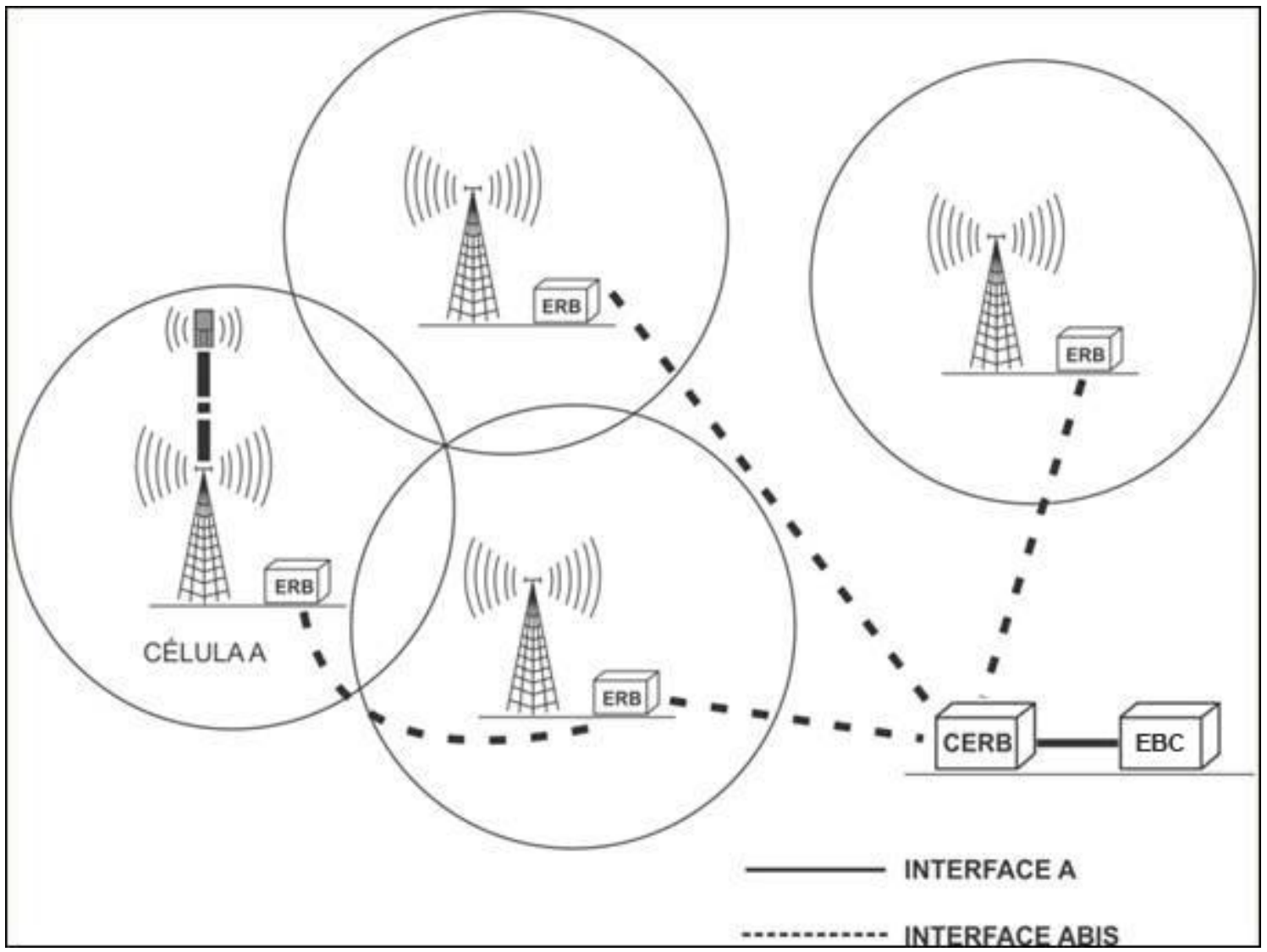

Figura 17 Destaque para as interfaces de ligação dos elementos de rede. Fonte: Pivaro (2008).

Finalmente, o último elemento vinculado à codificação na conexão GSM são os SC, os quais se assemelham ao que é utilizado na telefonia fixa. Este tem como função a conexão ao SEB (Sistema de Estação Base), cujos elementos são as ERBs e a EBC (Estação Base de Comutação). A figura 18 apresenta a arquitetura da conexão GSM com o SEB e o SC. As SCCs (Sistema Central de Comutação) têm a função de comutar as chamadas notando-se na figura que estão conectadas diretamente às EBCs. 


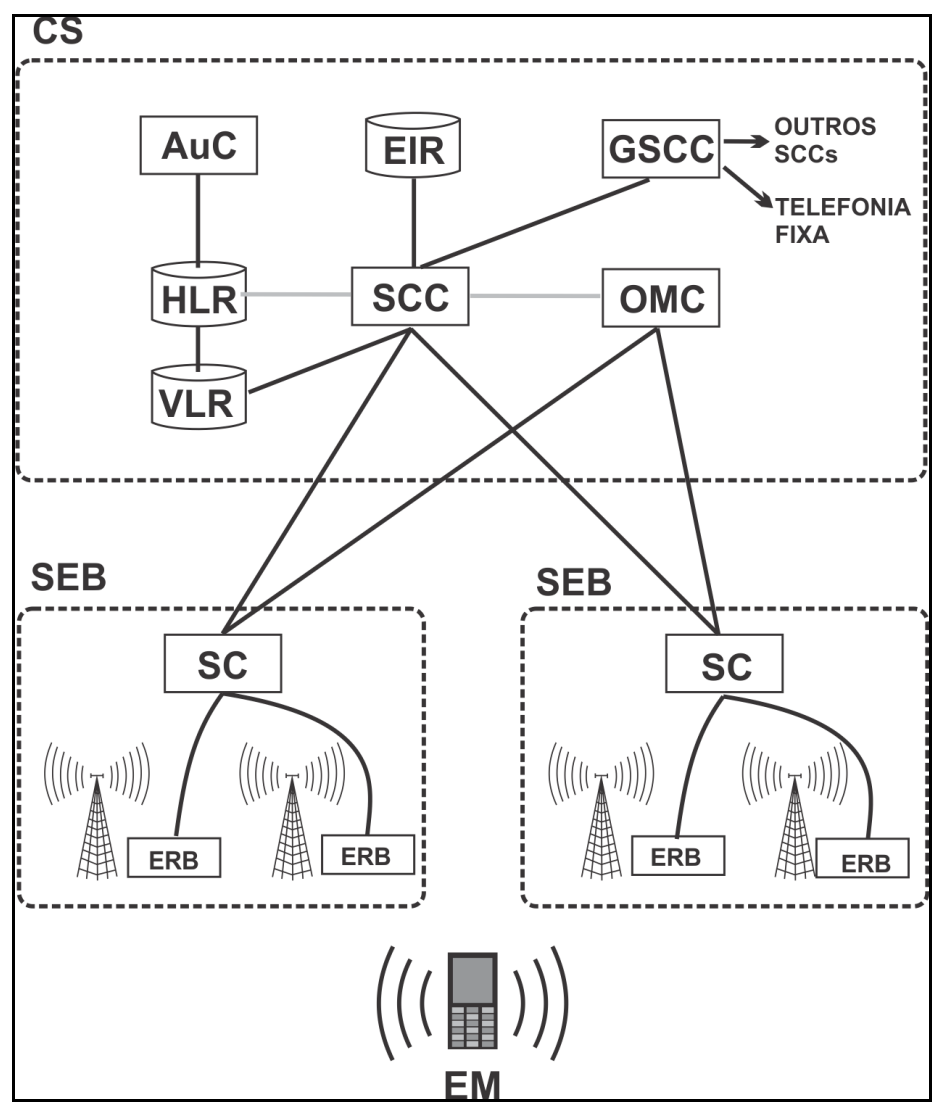

Figura 18 - Arquitetura de rede com conexão GSM mostrandoo SEB e na parte superior, o SC. Fonte: Pivaro (2008).

Conforme Pivaro (2008), os elementos da figura 18 são os seguintes:

- HLR (Home Location Recorder): corresponde à base de dados centralizada na rede que armazena e gerencia todas as assinaturas da rede móvel pertencentes à operadora. Assim, armazena informações do assinante, tais como a identidade (número do celular), perfil de serviços disponíveis (caixa postal, Internet, entre outros), informação da localização (a SCC e a EM) e informação de autenticação (chaves digitais utilizadas na identificação do assinante);

- VLR (Visitor Location Recorder): corresponde ao registrador de localização de visitante e armazena parte dos dados de assinantes que estão presentes naquele instante sob a área de cobertura da SCC;

- AUC (Autentification Center): tem como função principal autenticar um assinante que queira utilizar a rede. Evita o problema de fraude e corresponde a uma base de dados conectada a uma HLR, que fornece os parâmetros de 
autenticação e chaves de proteção utilizadas para garantir a segurança da rede;

- EIR (Equipment Identity Recorder): base de dados responsável pelo armazenamento das informações da identidade da EM, que permite bloquear as chamadas de EMs perdidas, não autorizadas ou com defeito. Devido à distinção da EM e do SIM card, o bloqueio da EM não resulta no bloqueio automático de um assinante. Assim, se o celular (EM) for roubado ou perdido o usuário pode obter um novo aparelho, bem como um novo cartão SIM com os dados de assinatura e utilizar novamente o sistema;

- OMC (Operation and Monitoring Center): trata-se de um centro de monitoramento automatizado conectado aos elementos da conexão GSM. Além disso, recebe informações para controlar e monitorar uma variedade de parâmetros e alarmes.

No processo de transmissão por meio da conexão GSM/GPRS se dispõe de toda a estrutura de rede de telefonia móvel, descrita anteriormente. Para a transmissão de dados e voz, segundo Queiroz (2008), é utilizada a padronização FDMA/TDMA em intervalos conforme o esquema da figura 19. Observa-se que é possível alocar de um a oito intervalos para cada usuário. Dessa maneira, cada intervalo pode ser entendido como um canal lógico que transporta voz ou dados (no caso das aplicações de GNSS). Os intervalos lógicos para dados são distribuídos em canais físicos dedicados aos mesmos, denominados PDCH (Packet Data Channel).

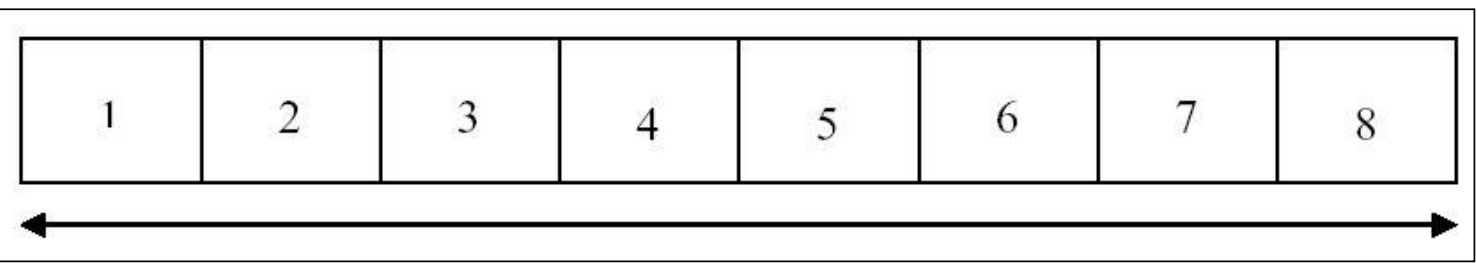

Figura 19 - Quadro com 8 slots da padronização FDMA/TDMA.

Fonte: Queiroz (2008).

Queiroz (2008) descreve a possibilidade de utilização de quatro tipos de codificações no sistema com a padronização GPRS sendo (CS1, CS2, CS3 e CS4), apresentado na tabela 7. Assim, a utilização de cada intervalo para a referida 
conexão poderá ter quatro esquemas, sendo que para cada banda possível, cada conexão poderá ter oito níveis. Por exemplo, no caso de uma conexão por meio da padronização GPRS com esquema de codificação CS4, seus níveis poderão ser 20 kbps (1 slot), 40 kbps (2 slots), 60 kbps (3 slots), 80 kbps (4 slots), 100 kbps (5 slots), $120 \mathrm{kbps}$ (6 slots), $140 \mathrm{kbps}$ (7 slots) e $160 \mathrm{kbps}$ (8 slots). A mesma metodologia pode ser atribuída para os demais esquemas de codificação, apresentado na tabela 8 .

Tabela 7 - Esquemas de codificação por meio da padronização GPRS

\begin{tabular}{|c|c|c|}
\hline Esquema de Codificação & Banda (kbps) & Sem RLC/MAC (kbps) \\
\hline CS1 & 9.05 & 8 \\
\hline CS2 & 13.4 & 12 \\
\hline CS3 & 15.6 & 14.4 \\
\hline CS4 & 21.4 & 20 \\
\hline
\end{tabular}

Fonte: Queiroz (2008).

Tabela 8 - Níveis de conexão e número de slots no sistema com conexão GSM/GPRS

\begin{tabular}{|c|c|c|c|c|}
\hline & \multicolumn{2}{|c|}{ Codificação } & \multirow[b]{2}{*}{ CS3 (kbps) } & \multirow[b]{2}{*}{ CS4 (kbps) } \\
\hline Nível ( $n^{\circ}$ slots)k & CS1 (kbps) & CS2 (kbps) & & \\
\hline Nível 8 & 64 & 96 & 115.2 & 160 \\
\hline Nível 7 & 56 & 84 & 100.8 & 140 \\
\hline Nível 6 & 48 & 72 & 86.4 & 120 \\
\hline Nível 5 & 40 & 60 & 72 & 100 \\
\hline Nível 4 & 32 & 48 & 57.6 & 80 \\
\hline Nível 3 & 24 & 36 & 43.2 & 60 \\
\hline Nível 2 & 16 & 24 & 28.8 & 40 \\
\hline Nível 1 & 8 & 12 & 14.4 & 20 \\
\hline
\end{tabular}

Fonte: Queiroz (2008).

Para um melhor entendimento da evolução nos processos de transmissão de dados via telefonia celular, com base em Yan (2005), Lenz (2008), Pivaro (2008) e Queiroz (2008), segue um resumo das padronizações:

- Conexão GSM: consiste em codificação pública de telefonia celular digital que utiliza técnicas de codificação e transmissão de dados com base numa 
frequência de $900 \mathrm{MHz}$. Nas versões mais recentes utiliza as frequências de $1.800 \mathrm{MHz}$ (na Europa);

- Padronização GPRS: alternativa da telefonia celular que aumenta a velocidade de transmissão de dados de 9.600 para 14.400 bps, realizando a compressão dos mesmos. Além disso, vale ressaltar que com a utilização da infraestrutura das estações base com conexão GSM pode-se atingir uma velocidade de transmissão de dados de até 115.000 bps;

- Conexão EDGE (Enhanced Datarate for GSM Evolution): corresponde a uma rede de telefonia celular que utiliza novo esquema de modulação mais eficiente da faixa de frequência para o emprego das redes com conexão GSM. O esquema de modulação é denominado 8PSK (8 Phase Shift Keying Modulation), que possibilita triplicar a velocidade de transmissão com relação ao emprego da conexão GPRS (atinge uma velocidade média de transmissão de dados de 384kbps);

- Conexão UMTS (Universal Mobile Telephone System): é considerada como terceira geração europeia de sistema de comunicação de rede via telefonia móvel (3G). Opera dentro das faixas de 1.900 a $2.025 \mathrm{MHz}$ e de $2.110 \mathrm{MHz}$ a $2.200 \mathrm{MHz}$. Poderá atingir a velocidade máxima de 2 Mbps).

No Brasil têm-se disponível hoje as redes de telefonia móvel com a padronização GPRS que foram a primeira evolução da conexão GSM. Corresponde ao serviço denominado "no voice" permitindo que a informação seja transmitida e recebida pela rede de telefonia móvel. Por meio da padronização GPRS se atinge uma taxa de transmissão de dados acima dos $170 \mathrm{Kbps}$, permitindo aos usuários desse tipo de conexão o acesso direto aos sites de Internet (YAN, 2005). Isso se explica, conforme relata Lenz (2008), pelo fato de que, enquanto as redes com conexão GSM se baseiam na transmissão por meio da comutação por circuitos, as redes com o uso da padronização GPRS se fundamentam na transmissão por meio da comutação de pacotes (YAN, 2005; PIVARO, 2008; QUEIROZ, 2008; LENZ, 2008). Outra característica importante das redes vinculadas à padronização GPRS é que as mesmas foram desenvolvidas para suportar os serviços de transmissão de dados (LENZ, 2008). Portanto, o serviço de transmissão é muito mais rápido com o emprego da padronização GPRS, pois a comutação por pacotes utiliza mais eficientemente esta banda de frequência, conforme reforça LENZ (2008). 
As conexões GSM e a padronização GPRS compartilham uma única base tecnológica dinâmica e flexível, com várias características semelhantes entre si, tais como bandas, frequências, técnicas de modulação, entre outras. No entanto, a cobrança dos serviços é distinta, pois no caso da padronização GPRS a mesma é feita por quantidade de dados (Kbits) transmitidos, enquanto que no da conexão GSM é feita por tempo de conexão (segundos) (LENZ, 2008).

Uma propriedade importante da padronização GPRS é a facilidade de enviar e receber dados por meio de conexões instantâneas (limitadas é claro, à área de cobertura). Assim, é viável para uma enorme gama de aplicações, utilizando a Internet através do popular "browser" (interface de diálogo no Internet Explorer da Microsoft) e chegando ao campo por aplicações em telefones celulares. Outras novas aplicações da padronização GPRS incluem arquivos, transferência de informação digital e a possibilidade de acesso remoto e de controle de aparelhos eletrodomésticos e máquinas (LENZ, 2008).

A padronização GPRS, considerando tudo o que já foi relatado neste trabalho, fornece uma solução básica de transmissão de dados por meio da comunicação IP entre estações móveis (celulares) e os computadores conectados à Internet.

Em termos práticos, para a utilização da padronização GPRS, o usuário necessita de um telefone celular, ou de um terminal que suporte a padronização GPRS, e de subscrição para rede de telefonia móvel que suporte o uso da padronização GPRS disponível (LENZ, 2008).

Considerando as aplicações de posicionamento de precisão em tempo real com o sistema GNSS, a conexão GSM/GPRS de sistemas de telefonia celular é utilizada atualmente no Brasil como ferramenta para o envio das observações de fase, método utilizado no serviço NTRIP, o qual será melhor descrito a seguir.

\subsection{SERVIÇO NTRIP}

O sistema de posicionamento por satélite, que começou no passado com o TRANSIT e que recentemente vem se aperfeiçoando com o GNSS, teve desde o início, uma tendência para o chamado método relativo de posicionamento. Este implica no uso de um receptor fixo num ponto de coordenadas conhecidas e o outro 
num ponto a determinar. As primeiras aplicações sempre envolveram o método relativo na técnica pós-processada, após um período longo de observações, não sendo necessária a transmissão dos dados entre as estações. As necessidades modernas levaram à aspiração de diminuir o intervalo típico de observação, que no início foi de duas horas. O aumento no número de satélites facilitado pelo lançamento do GLONASS trouxe um alívio aos usuários em função da melhoria na geometria das observações em função da presença de satélites bem distribuídos entorno do horizonte; isto acarretou na diminuição do intervalo de observações. No entanto, um dos objetivos principais foi o posicionamento instantâneo viabilizado pela observação de pelo menos oito satélites (perspectiva que já se tornou possível) e pelo desenvolvimento das técnicas numéricas de solução rápida das ambiguidades. Porém, este ideal implicou na necessidade imperativa de transmissão dos dados do receptor base para o móvel. O uso de ondas eletromagnéticas transmitidas e recebidas pelos equipamentos, popularmente denominados rádios (transmissores e receptores), é limitado pelas obstruções na propagação das referidas ondas.

A necessidade prática de mais flexibilidade e eficiência no envio das observações de fase do receptor base para o móvel fez com que fosse desenvolvida a tecnologia integrada ao sistema de comunicação móvel (como por exemplo, a conexão GSM, a padronização GPRS, a conexão 3G) e a Internet (ROGOWSKI et al., 2004).

A ideia original do que veio a ser denominado serviço NTRIP foi criar uma aplicação baseada em um protocolo que fosse capaz de transmitir dados GNSS pela Internet. Assim, pode-se afirmar que o serviço NTRIP nada mais é do que um serviço de adequação da transmissão de dados GNSS/GPS na internet, gerenciado por um conjunto de softwares que convertem o protocolo RTCM para a linguagem de Internet num IP. Este IP é selecionado indiretamente por meio da configuração da estação de referência, a qual é escolhida pelo usuário quando ele configura o seu equipamento móvel durante o levantamento pela técnica RTK/GSM e com uso do serviço NTRIP.

O serviço NTRIP foi projetado para disseminar as observações de fase para diversos usuários da Internet fixa ou móvel simultaneamente. Este serviço transmite o protocolo RTCM, assim como o faz a conexão de rádio convencional, diferenciando apenas pelo método de envio. 
A conexão à Internet é essencial para disponibilizar as observações da fase em um IP dedicado e posterior acesso a estas informações pelo receptor móvel em campo. Para detalhar esta conexão é importante definir, dentro desse contexto, o que é um protocolo. Segundo Kurose e Ross (2004) apud Yan (2005), o protocolo estabelece o formato das mensagens trocadas entre dois ou mais pontos, bem como as ações tomadas na transmissão e recepção. Assim, em termos do sistema GNSS, em especial nas aplicações em tempo real via Internet, podem-se relacionar os formatos RTCM (3.0, 3.1, relatados anteriormente) e TCP (Transmission Control Protocol/IP.

Com respeito aos protocolos de Internet o mesmo autor cita que os mais conhecidos são o TCP e o IP, os quais servem de base para outros importantes protocolos, tais como o HTTP (Hypertext Transfer Protocol) e o FTP (Format Transfer Protocol). Yan (2005) afirma ainda que todos constituem protocolos abertos e que podem ser utilizados para enviar e receber informações por meio de vários tipos de redes, locais (LAN - Local Area Network) ou de área ampliada (WAN Wide Area Network). Da união de utilização desses protocolos pelos utilizados pelos usuários de GNSS/GPS e da Internet é que surgiu o serviço NTRIP.

A tabela 9 faz um resumo de todos os parâmetros envolvidos no serviço NTRIP, podendo compreender a comunicação e a transmissão de dados pela internet em dois segmentos distintos: físico, lógico e softwares utilizados na configuração e utilização do serviço. No primeiro caso, entende-se conectores, cabos, "rede sem fio", computador, receptor GNSS/GPS, entre outros. O segmento lógico é constituído dos protocolos de comunicação e da rede (internet) através da qual a informação é transmitida. No caso do segmento físico a informação precisa ser codificada atendendo a um padrão definido. Por exemplo, para a transmissão dos dados GNSS, seja a correção conhecida por DGPS, que atende à navegação, ou a RTK/GSM que é a própria observação da fase, estabeleceu-se o protocolo RTCM. A rede implica no endereçamento e no transporte. Estes dois elementos da rede atendem o protocolo da Internet conhecido por TCP/IP. O TCP se encarrega do transporte da informação. O IP é um endereço constituído até agora de quatro octetos (tende a se expandir). Dettmering et al. (2007) relatam que o IP possui várias vantagens, dentre as quais se podem destacar a globalização dos dados, informações transmitidas simultaneamente para vários usuários e a padronização internacional. 
Tabela 9 - Tabela Físico X Lógico

\begin{tabular}{|c|c|c|c|c|}
\hline Tabela Físico x Logíco & Aplicação/Usuário & Softwares Utilizados & Protocolos de Comunicação & Meio Físico \\
\hline \multirow{6}{*}{ Informática } & \multirow{3}{*}{ Site de CEGAT $p$ acesso } & \multirow{6}{*}{$\begin{array}{c}\text { Software p/Gestão dos } \\
\text { Dados }\end{array}$} & Firewall & \multirow{2}{*}{ Computador } \\
\hline & & & protocolo TCP, UCP e IP & \\
\hline & & & protocolo HTTP & \multirow{2}{*}{ Portas Serial } \\
\hline & \multirow{3}{*}{ Serviço NTRIP } & & protocolo FTP & \\
\hline & & & REDE LAN & NO-BREAK \\
\hline & & & REDE WAN & Redes sem fio \\
\hline \multirow[b]{2}{*}{ Referência Geodesica } & Coordenadas Cálculadas & \multirow[b]{2}{*}{ Software GNSS Solutions } & Protocolo RTCM & \multirow[b]{2}{*}{ Relatórios de Cálculos } \\
\hline & Transporte de Coordenada & & Velocidade de Transmissão & \\
\hline \multirow{3}{*}{ Receptores GNSS } & \multirow{2}{*}{ Fast Survey } & \multirow{2}{*}{ PROFLEX WEBSERVER } & \multirow{3}{*}{ técnica RTK/GSM } & Receptor GNSS \\
\hline & & & & Antena \\
\hline & GNSS Surfer & NTRIP CLIENT & & Cabos \\
\hline \multirow{3}{*}{ Conexão GSM/GPRS } & \multirow{2}{*}{ Fast Survey } & & & Cabo de Internet \\
\hline & & & & Torres de Comunicação \\
\hline & Softwares dos telefones & & & Chip GSM \\
\hline \multirow{5}{*}{$\begin{array}{l}\text { Infra Estrutura } \\
\text { Hospedeiro }\end{array}$} & \multirow{5}{*}{ Contrato de Comodato } & NTRIP SERVER & Padronização de Instalação & Marco de Concreto \\
\hline & & Software GBSS & porta de conexão & \multirow{2}{*}{ Predio/Sala de Instalação } \\
\hline & & GPS UP-LOAD & IP maquina de origem & \\
\hline & & AHSTECH EVALUATE & porta de saída de dados & Instalação Elétrica \\
\hline & & & nome da estação & Servidor Local \\
\hline \multirow{3}{*}{ Infra Estrutura Central } & & \multirow{3}{*}{ NTRIP CASTER } & \multirow{3}{*}{ IP Servidor } & Servidor Central \\
\hline & & & & Predio/Sala de Instalação \\
\hline & & & & Instalação Elétrica \\
\hline
\end{tabular}

É importante mencionar a existência dos protocolos UCP (Universal Control Protocol) e TCP. A diferença entre eles está num sistema de controle da informação que sai e que chega para resguardar a confiabilidade. Ou seja, imagine-se dois endereços IP e uma informação que transita entre eles. Ela precisa estar dentro de um padrão de organização, por exemplo, no caso do GNSS existe o protocolo RTCM. Segundo Prieto et al. (2008), o HTTP consiste em uma aplicação tipo protocolo para distribuição de conjuntos de informação, mas pode ser usado igualmente para transmitir dados lineares de mensagem de mídia.

Finalmente, a informação pode ser transmitida na forma de fluxo contínuo (stream) ou num pacote. $O$ primeiro caso implica que, quem acessa num dado momento, recebe a informação a partir daquele ponto e passa a ter a informação em tempo real. O pacote significa receber um conjunto fechado e definido de informações.

Rogowski et al. (2004) enumera diversas vantagens do serviço NTRIP, entre elas: fácil acesso aos dados das ERAs múltiplo acesso (limitado apenas à capacidade do tronco de comunicação Internet); melhor interação e redução de 
custo para os usuários de receptores GNSS, medições rápidas e com alta acurácia para a maioria dos trabalhos geodésicos e maior alcance quando comparado com o rádio convencional para a transmissão das observações de fase do receptor base para móvel.

Conforme a tabela 9, ainda existem diversos softwares para a utilização do serviço NTRIP. O órgão alemão de Geodésia e Cartografia o BKG (Bundesamt für Kartographie und Geodäsie), desenvolveu 3 softwares para facilitar a disseminação deste conceito. O primeiro software é denominado NtripServer, o qual envia o protocolo RTCM de uma ERA para um servidor local. O segundo software é denominado NtripCaster, que é instalado em um servidor central, sendo responsável pelo gerenciamento das ERAs e pelos acessos dos receptores móveis. Já o terceiro software é denominado NtripClient, sendo o responsável pelo acesso do protocolo RTCM de um IP e pela conversão dos dados em informações de navegação para o posicionamento. A figura 20 apresenta a interação entre esses softwares e a integração com a conexão internet via HTTP (WEBER; DETTMERING, 2005 apud LIM et al., 2008).

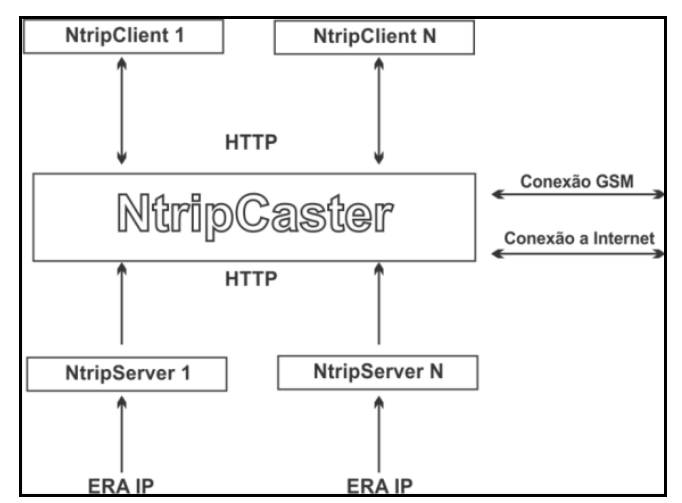

Figura 20 - Componentes do serviço NTRIP e a integração entre eles. Fonte: Weber; Dettmering (2005) apud Lim et al. (2008).

Um bom exemplo de interface de dados entre a ERA IP (Estação de Referência Ativa com IP definido), conforme citado acima pode ser observada na figura 21, que simplesmente demonstra a configuração do software NtripServer. Nesta figura a operação é realizada da seguinte forma: a partir do nome e senha gerada no software de gerenciamento para a ERA IP, se introduz, por exemplo, a porta de conexão da ERA IP ao computador (2101), a velocidade de transmissão 
dos dados (19200), o IP do servidor (200.145.185.200), a porta de entrada dos dados (COM2), o IP do servidor local (192.168.2.106), a porta de saída de dados (2101) e nome da ERA IP (por exemplo, BGAT1).

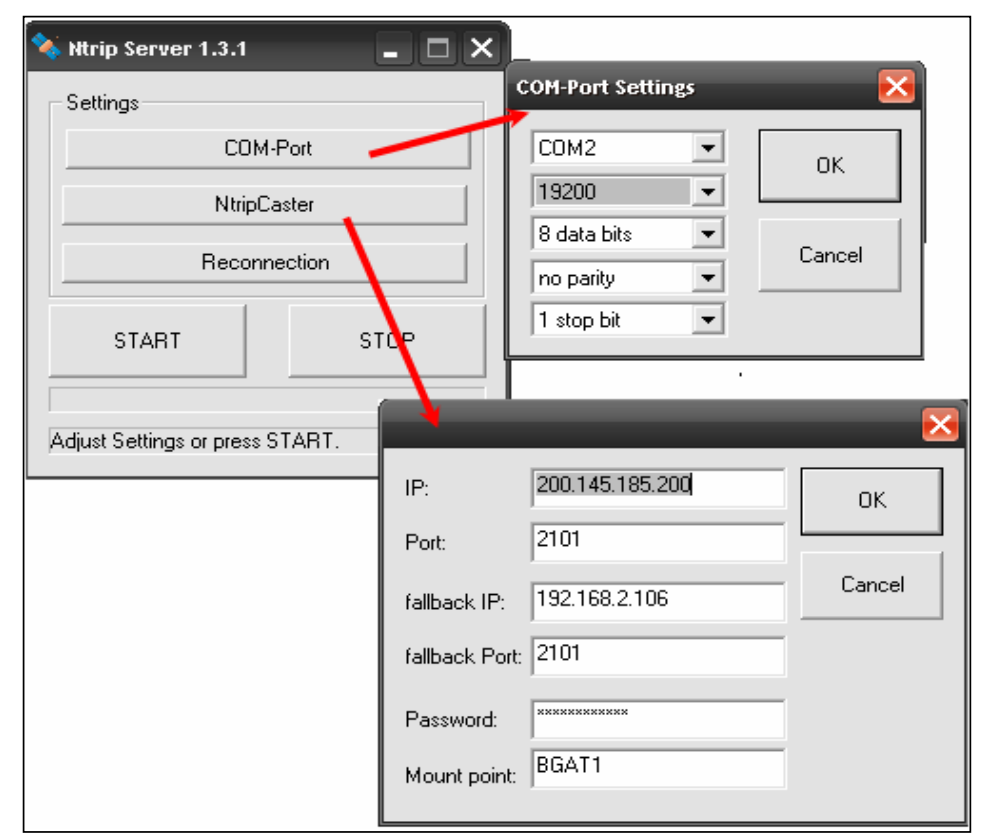

Figura 21 - Operação de configuração do software NtripServer.

Prieto et al. (2008) relata que a finalidade do software NtripCaster é multiplicar as mensagens de dados provenientes das ERAs IP (Estações de Referência Ativa com IP definido) para uma vasta gama de receptores móveis simultaneamente, de qualquer lugar no globo terrestre.

Este software gerencia as portas do firewall de entrada e saída dos dados, permitindo ao usuário configurar em uma mesma unidade, um número finito de ERAs IP. Para o acesso a esses dados, por medida de segurança, o usuário deve informar um nome e senha. Possui tecnologia similar à utilizada pelas emissoras de rádio quando disponibilizam a sua transmissão via WEB (PRIETO et al., 2008).

A ERA IP conectada ao software NtripCaster é denominada, em inglês, de MountPoint(Ponto de Conexão), sendo que o conjunto dessas ERAs IP é denominado SourceTable (Lista de Pontos). Por convenção, cada ERA IP tem a sua identificação definida por até 4 caracteres (por exemplo, ERA IP da Escola Politécnica de São Paulo é denominada POLI pelo IBGE. No software NtripCaster ainda é definida a versão de RTCM que será transmitido (RTCM 2.3, 3.0 ou 3.1), bem como as sentenças que serão habilitadas do RTCM escolhido e a velocidade de 
transmissão. Além disso, o software realiza a autenticação dos usuários com seu nome e senha, registra o uso e as interrupções que possam ocorrer nas ERAs IP vinculadas ao gerenciador, gerando um informe estatístico. As informações que podem ser vistas no NtripCaster são apresentadas na figura 22, onde o gerenciador de ERA IP de serviço NTRIP é o da FCT-UNESP de Presidente Prudente e o formato do protocolo é RTCM 3.0.

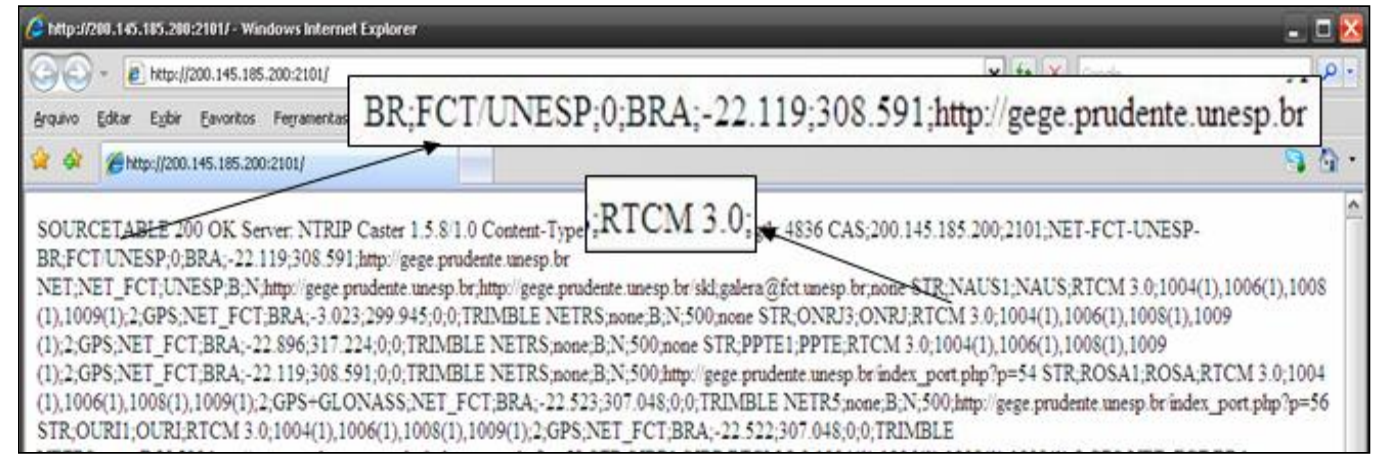

Figura 22 - Exemplo de Informações visualizadas no NtripCaster.

Finalmente, observando a figura 23, o NtripClient é o programa instalado no receptor móvel e que é utilizado para identificar qual a ERA IP irá enviar os dados para o processamento em tempo real, gerenciando e realizando o mesmo quando os parâmetros de precisão e de fixação da ambiguidade sejam atingidos. Na figura 23 é apresentado o procedimento de configuração do software NtripClient.

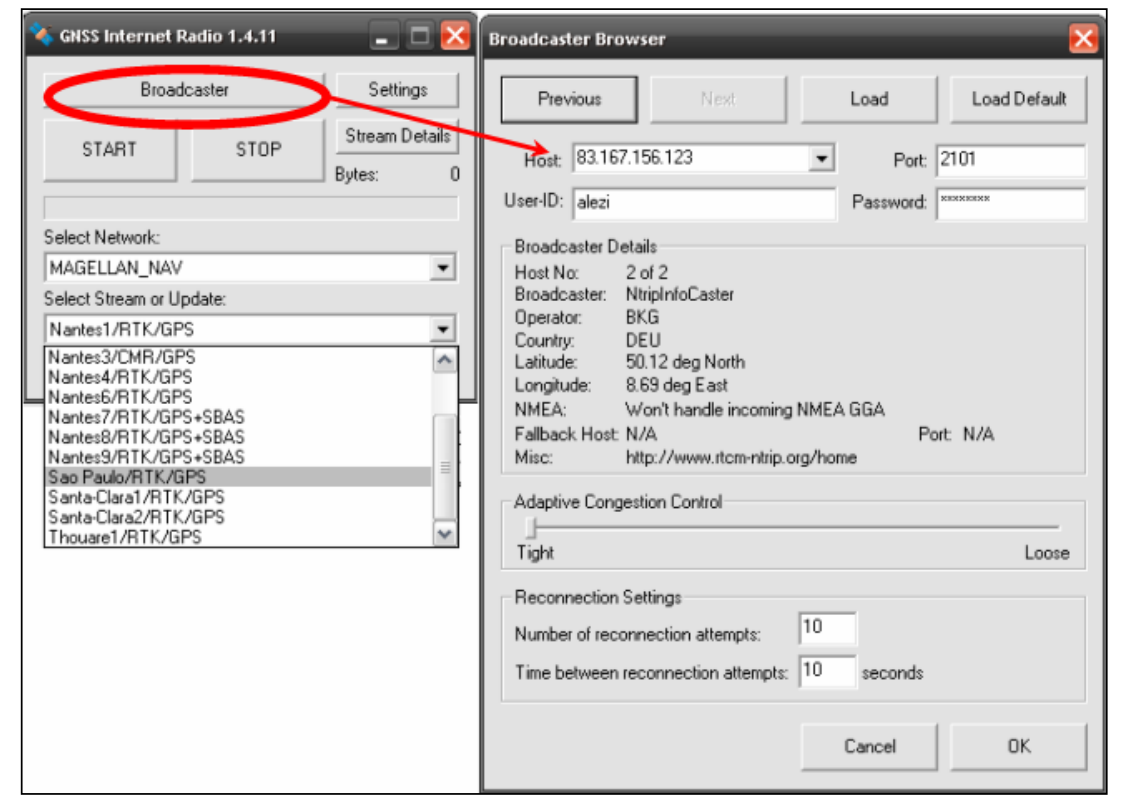

Figura 23 - Configuração do software NtripClient. 
Este programa é de domínio público, ou seja, está dentro da filosofia de software livre. Em aplicações onde são utilizados equipamentos de marcas e fabricantes específicos, costuma-se utilizar a interface própria da marca, criada por empresas para atender seus usuários. Dessa maneira, o software NtripClient já está inserido na própria aplicação, consistindo assim em uma ferramenta de conexão e não um programa isolado, como é o caso do software Fast Survey, utilizado nos receptores ProMark3 e ProMark 500 da ASHTECH, cuja interface é visualizada na figura 24.

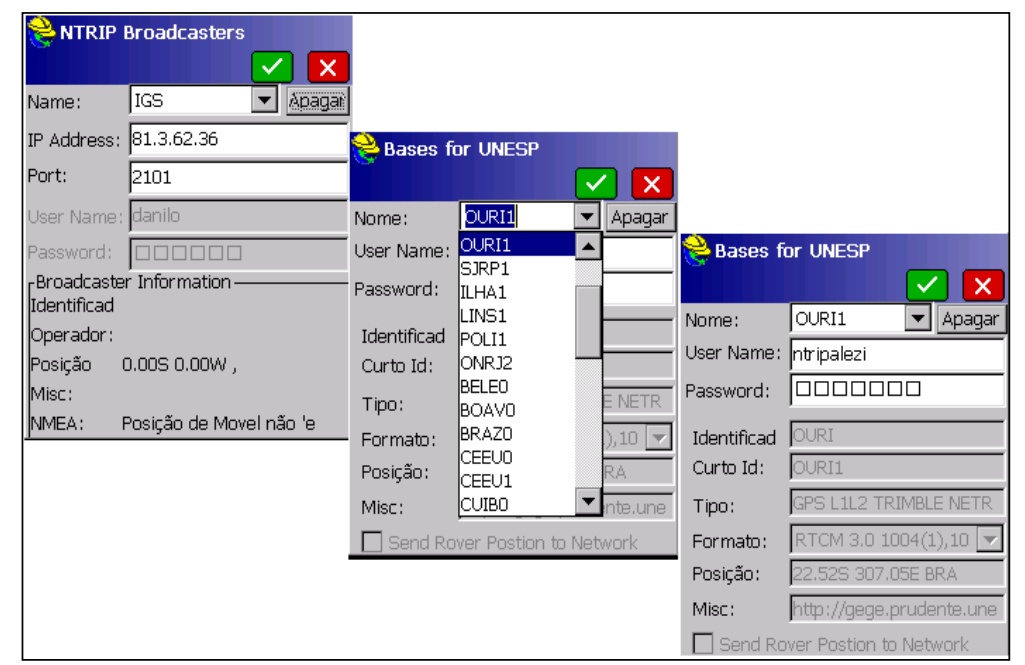

Figura 24 - Exemplo de aplicativo utilizando o software NtripClient dentro da interface própria de um fabricante específico.

Fonte: ASHTECH (2008).

Em paralelo ao avanço dos receptores GNSS e da informática, os sistemas de telefonia celular recentemente iniciaram a navegação na Internet, permitindo enviar e receber informações, utilizando a conexão GSM. É o caso da padronização GPRS, por exemplo, com emprego do protocolo TCP/IP, que foi convertido no padrão das redes de internet.

Para a comunicação deste sistema o receptor móvel deve ser capaz de realizar uma conexão GSM/GPRS, acessar um IP de uma ERA por meio de um software como o NtripCaster. Essa conexão possibilita a recepção das observações da fase através do serviço NTRIP da ERA IP de interesse. 
O uso da internet móvel, através do telefone celular, dispensa a conexão por meio de cabos (telefônico, coaxial ou fibra óptica) ou de equipamentos tradicionais, tais como os rádios transmissores tipo $\mathrm{VHF} / \mathrm{UHF}$.

Vale ressaltar ainda que existem atualmente três métodos de trabalho com a conexão GSM/GPRS, a saber: rede de serviço NTRIP, o IP direto, e a conexão GSM direta, que será detalhada a seguir (figura 25).

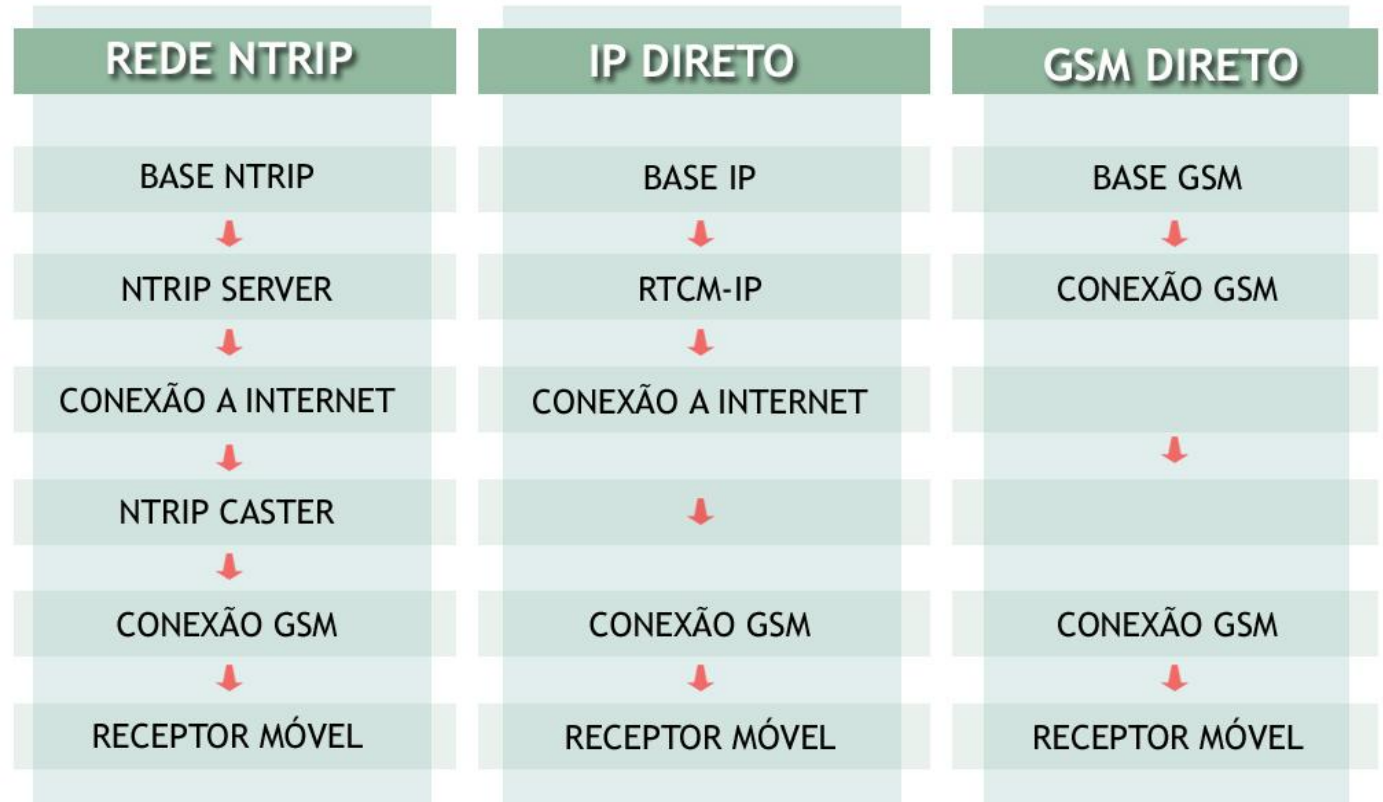

Figura 25 - Opções de uso da conexão GSM/GPRS em aplicações utilizando a técnica RTK/GSM.

A rede de serviço NTRIP se caracteriza pela utilização de um software de gerenciamento das ERAs IP e controle de acesso dos receptores móveis, como por exemplo, algo realizado pelo software NtripCaster. Poderá existir um número ilimitado de ERAs IP, que enviarão os protocolos RTCM a cada segundo para o software de gerenciamento que disponibilizará a observação de fase para o acesso de diversos usuários. Em campo os receptores móveis poderão receber as observações da fase da ERA IP mais próxima. Este método é utilizado para redes de ERAs IP permanentes, onde estão instaladas diversas ERAs IP, para um grande número de usuários.

Já no caso do IP direto existe apenas uma ERA IP, a qual disponibiliza o protocolo RTCM em um IP e o usuário em campo deve conhecer esse endereço (figura 26). Este método é usado para projetos em que a utilização da técnica 
RTK/GSM é adequada, porém, não é possível a instalação permanente de uma ERA IP, havendo a necessidade de trocá-la periodicamente.

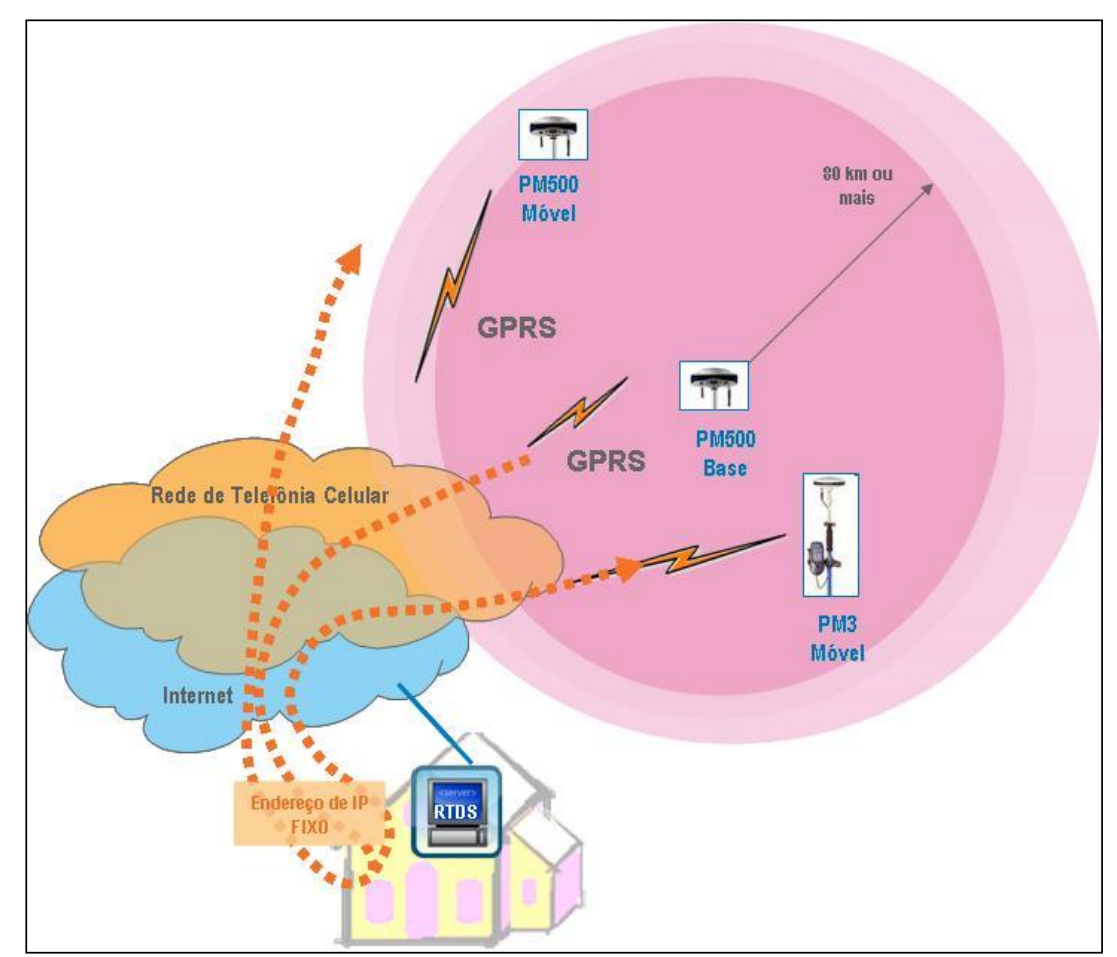

Figura 26 - Método IP direto.

Fonte: Adaptado de AHSTECH (2008).

A técnica RTK/GSM direta, é uma alternativa viável para países que ainda não dispõem de ERAs IP convenientes para uso do serviço NTRIP, consiste na utilização de dois receptores GNSS dotados da facilidade da telefonia celular. Esta configuração de conexão GSM/GPRS direta não utiliza nenhum software de gerenciamento e também não tem a necessidade de converter o protocolo RTCM para um IP. Um receptor GNSS utilizando um chip GSM e com o número telefônico conhecido é instalado num vértice de coordenadas conhecidas. E o receptor móvel com a mesma capacidade será utilizado para coleta de coordenadas dos novos pontos com a técnica RTK/GSM Direta. Como pode ser observado na figura 27, é necessário apenas iniciar o aplicativo de campo para que o chip do receptor móvel possa inicialmente realizar uma chamada telefônica utilizando a conexão GSM com o chip do receptor base e em seguida transmitir as observações de fase utilizando a padronização GPRS, não sendo necessário manter a ligação telefônica e utilizando 
apenas a transmissão de dados. Percebe-se que a metodologia é similar à utilizada na técnica RTK/UHF. No entanto, no lugar dos rádios utiliza-se o chip GSM interno para o envio da observação de fase. Neste método o usuário tem total liberdade para instalar seus equipamentos em qualquer local de trabalho. As principais vantagens em relação à técnica RTK/UHF são: aumento da distância do receptor base para o móvel, a possibilidade de trabalhar em áreas urbanas aonde existiriam grande obstrução física para a utilização de rádios e a não dependência da ERA IP.

No entanto, para qualquer uma das opções de método de levantamento com emprego de tecnologia de telefonia móvel integrada ao GNSS em tempo real a principal limitação corresponde à cobertura da mesma.

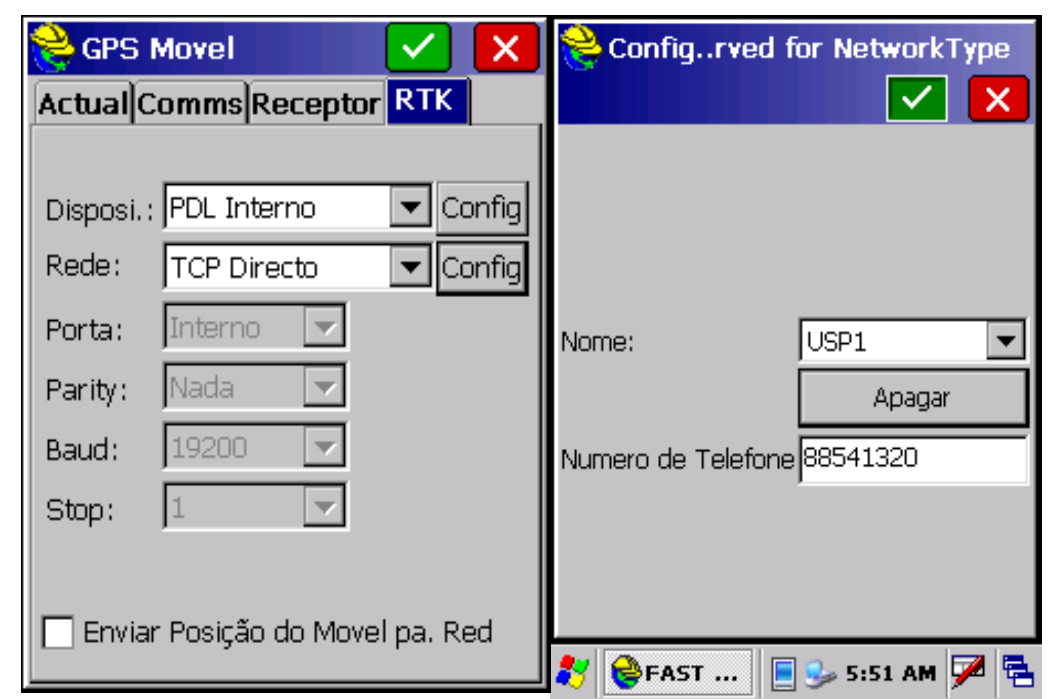

Figura 27 - Configuração do Método conexão GSM Direta.

$\mathrm{Na}$ Alemanha, o serviço NTRIP pode ser utilizado facilmente, inclusive na zona rural, devido à disponibilidade de ERAs IP em todo o território, além da disponibilidade de cobertura da telefonia celular em todo o país. No Brasil existe o serviço NTRIP através da RBMC-IP (Rede Brasileira de Monitoramento Contínuo dos Sistemas GNSS em Tempo Real), cujo servidor está no Rio de Janeiro, dependências do IBGE. Conforme IBGE (2011) a RBMC-IP corresponde a um serviço para posicionamento em tempo real, para usuários que fazem uso da técnica RTK ou DGPS nos seus levantamentos. Os dados são disponibilizados via protocolo internet conhecido por RBMC-IP, ou seja, o nome dado ao serviço NTRIP disponibilizado pelo IBGE. A transmissão dos dados é realizada da seguinte forma: um receptor GNSS realiza a conexão GSM/GPRS ao IP determinado pela RBMC-IP, 
onde será informada uma lista de ERAs IP. O usuário irá escolher a mais próxima da sua área de trabalho e receberá as observações de fase posicionando o seu receptor em tempo real. Atualmente, o servidor do IBGE recebe dados de 27 estações localizadas nas principais capitais, sendo elas: Belém (BELE), Belo Horizonte (MGBH), Boa Vista (BOAV), Brasília (BRAZ), Campo Grande (MSCG), Cuiabá (CUIB), Curitiba (UFPR), Fortaleza (CEEU), Macapá (MAPA), Manaus (NAUS), Maringá (PRMA), Natal (RNNA), Recife (RECF), Rio Branco (RIOB), Porto Alegre (POAL), Porto Velho (POVE), Presidente Prudente (PPTE), Salvador (SAVO), São Luis (SALU), Santa Maria (SMAR), São Paulo (POLI), Rio de Janeiro (ONRJ e RIOD), Palmas (TOPL), Vitória (CEFE), Imbituba (IMBT) e Campos de Goytacazes (RJCG). Essas estações são visualizadas na figura 20.

O serviço NTRIP do IBGE pode ser acessado pelo endereço IP 186.228.51.52 e opera na porta 2101, a qual é reservada para a transmissão das correções diferenciais obtidas pelo NtripClient. Acessando em qualquer navegador de internet http://186.228.51.52:2101, é possível visualizar as informações sobre as ERAs IP. O acesso ao NtripCaster do IBGE é gratuito. No entanto, o usuário precisa preencher o cadastro e se registrar como tal. A solicitação é avaliada e uma identificação e senha de acesso são enviados por e-mail. Algumas restrições de acesso se fazem necessárias visando evitar congestionamento. Entre elas estão o acesso a três ERAs IP por usuário; a identificação e a senha de acesso válidas por um período máximo de três meses; permissão de no máximo 50 acessos simultâneos ao serviço. 


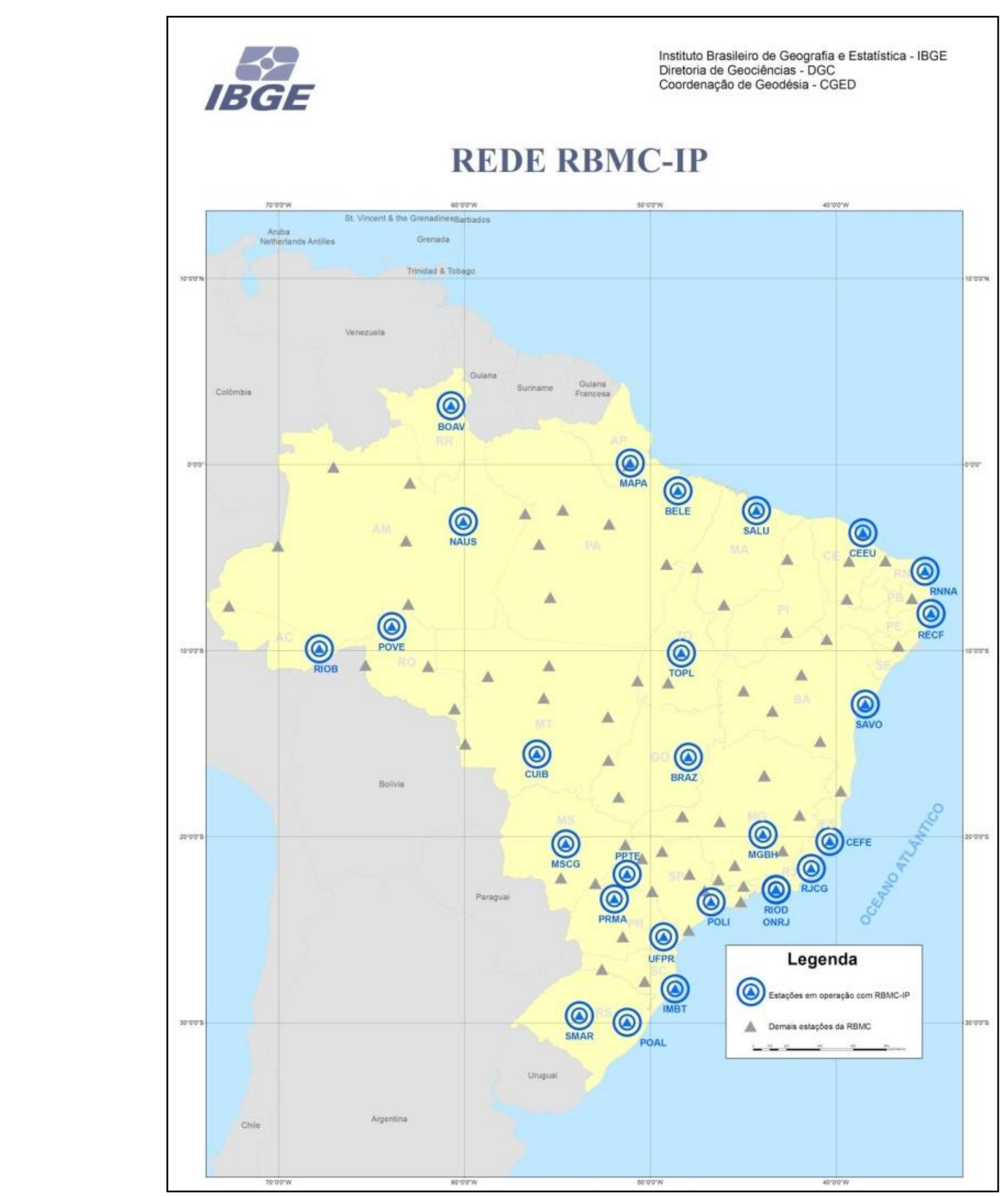

Figura 28 - Rede RBMC-IP do IBGE.

Fonte: IBGE (2011). 


\section{METODOLOGIA DA ANÁLISE DOS DADOS}

O ajustamento pelo método dos mínimos quadrados tem por objetivo a estimativa de uma solução única e consistente para problemas com um número superabundante de observações. Além disso, é essencial avaliar a qualidade da solução. Classicamente se entendia que observações estavam sujeitas a erros, ou seja, quando se repete $n$ vezes uma medida, os valores não são idênticos, mas apresentam dispersão dentro de um certo intervalo, devido a erros observacionais. Atualmente, se expressa o mesmo conceito admitindo que as observações (ou medidas) possuem uma propriedade inerente a elas, de flutuações probabilísticas ou aleatórias (DALMOLIN, 2002).

Para a análise das observações foram utilizadas estimativas intervalares. Neste tipo de análise calculam-se valores, os quais definem um intervalo de confiança. Estes contêm o parâmetro populacional estimado com certa probabilidade (1), isto é, constrói-se um intervalo $(a, b)$ em torno da estimativa por ponto $(\varepsilon)$ :

$$
P(a \leq \varepsilon \leq b)=1-\alpha
$$

O intervalo $(a \leq \varepsilon \leq b)$ é denominado intervalo de confiança relativo ao parâmetro $\varepsilon$. Os extremos desse intervalo $(\mathrm{a}, \mathrm{b})$, com função densidade de probabilidade conhecida, são chamados de limites de confiança. A probabilidade conhecida $(1-\alpha)$ é denominada nível ou grau de confiança.

Nesse trabalho, em sua parte prática, foram utilizados graus de confiança de $99 \%$.

No cálculo do intervalo de confiança para a média em função da variância amostral utiliza-se o estimador:

$$
t=\frac{(\bar{x}-\mu)}{\bar{\sigma} / \sqrt{n}}
$$


Onde:

$\bar{x}=$ média de uma amostra;

$\mu=$ média populacional;

$\widehat{\sigma}=$ desvio padrão de uma amostra;

$n=$ tamanho da amostra.

O valor do desvio padrão $\hat{\sigma}$ pode ser calculado através da seguinte expressão (3):

$$
\hat{\sigma}=\sqrt{\frac{\sum_{i=0}^{i=n}\left(\bar{x}-x_{i}\right)^{2}}{n-1}}
$$

Onde:

$x_{i}=$ valor da $i$-ésima amostra.

\subsection{TESTE DE TENDÊNCIA}

Para a aplicação do teste de tendência se utiliza como estimador a distribuição t de Student. O teste $T$ Student é baseado na distribuição normal e verifica se as observações estão isentas de erros sistemáticos. Estes erros têm causas conhecidas e podem ser evitados aplicando-se procedimentos especiais quando da observação ou eliminados posteriormente utilizando-se fórmulas teóricas (GEMAEL, 1994). Em resumo, corresponde ao erro que é quantitativamente o mesmo quando a medida se repete (VUOLO, 1992).

A probabilidade para o intervalo de confiança do estimador t (4) será:

$$
P\left(-t_{1-\alpha / 2} \leq t \leq t_{1-\alpha / 2}\right)=1-\alpha
$$


que graficamente corresponde à figura 29:

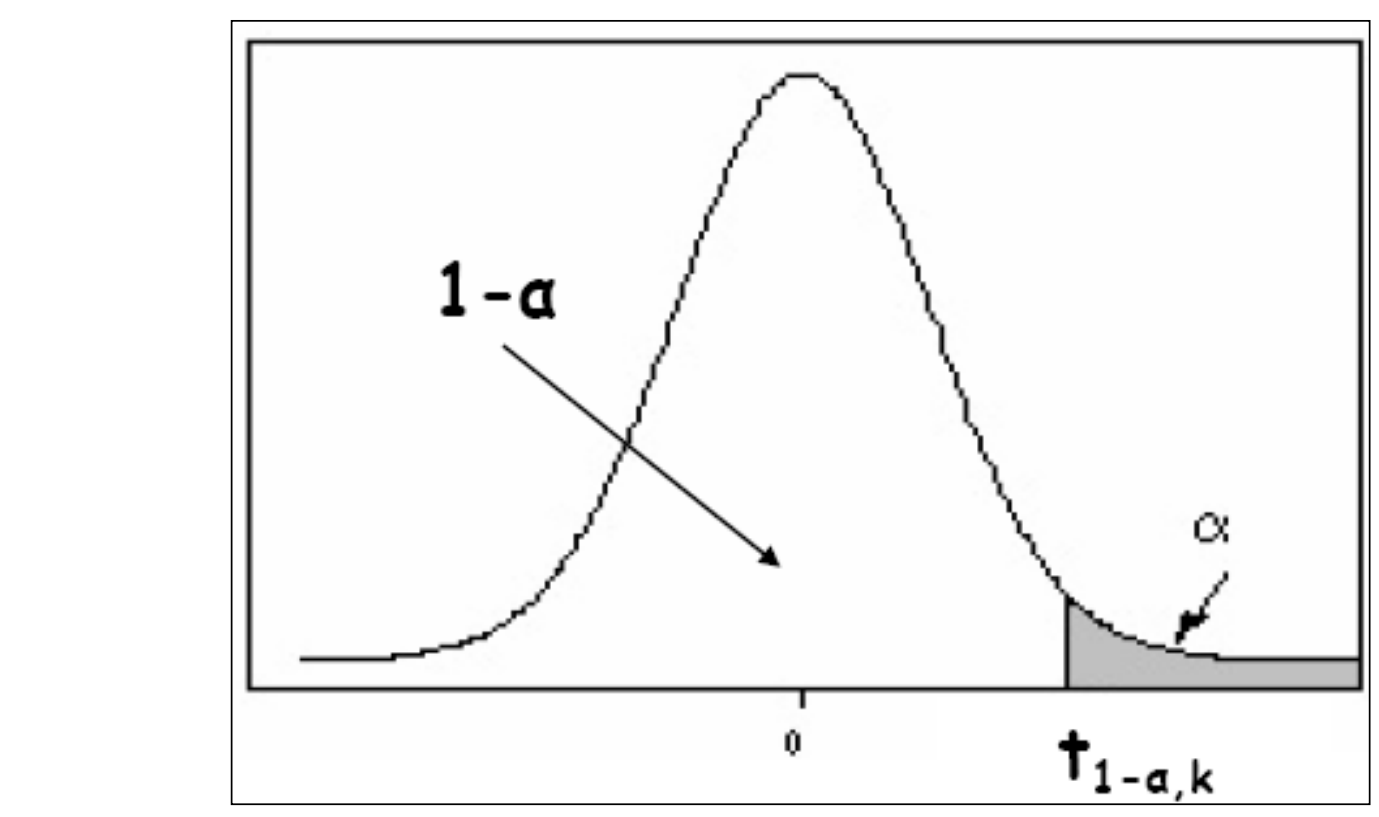

Figura 29 - Distribuição Normal.

Fonte: Gonçalez (2007).

No teste se analisa os desvios padrão das coordenadas $\mathrm{E}, \mathrm{N}$ e h (altitude geodésica). O intervalo de confiança é dado por (5) (GEMAEL, 1994):

$$
|t|<t_{1-\alpha / 2}
$$

Se essa condição não é atingida, o teste t não é aceito.

\subsection{TESTE DE PRECISÃO}

O intervalo de confiança para a variância populacional $\left(\sigma^{2}\right)$ pode ser definido utilizando-se a variância amostral $\left(\hat{\sigma}^{2}\right)$ a partir da distribuição Qui-Quadrado $\left(\chi^{2}\right)$ (6). O teste Qui-Quadrado avalia a discrepância entre o valor da variância amostral esperada $\left(\sigma^{2}\right)$ e o valor da variância amostral observada $\left(\hat{\sigma}^{2}\right)$. Seu estimador é definido pela seguinte expressão (GEMAEL, 1994): 


$$
\chi^{2}=\frac{(n-1) \bar{\sigma}^{2}}{\sigma^{2}}
$$

A probabilidade para o intervalo de confiança é dada por (7):

$$
P\left(\chi^{2}{ }_{\alpha / 2} \leq \chi^{2} \leq \chi^{2}{ }_{1-\alpha / 2}\right)=1-\alpha
$$

Esta expressão pode ser interpretada através do gráfico da figura 29:

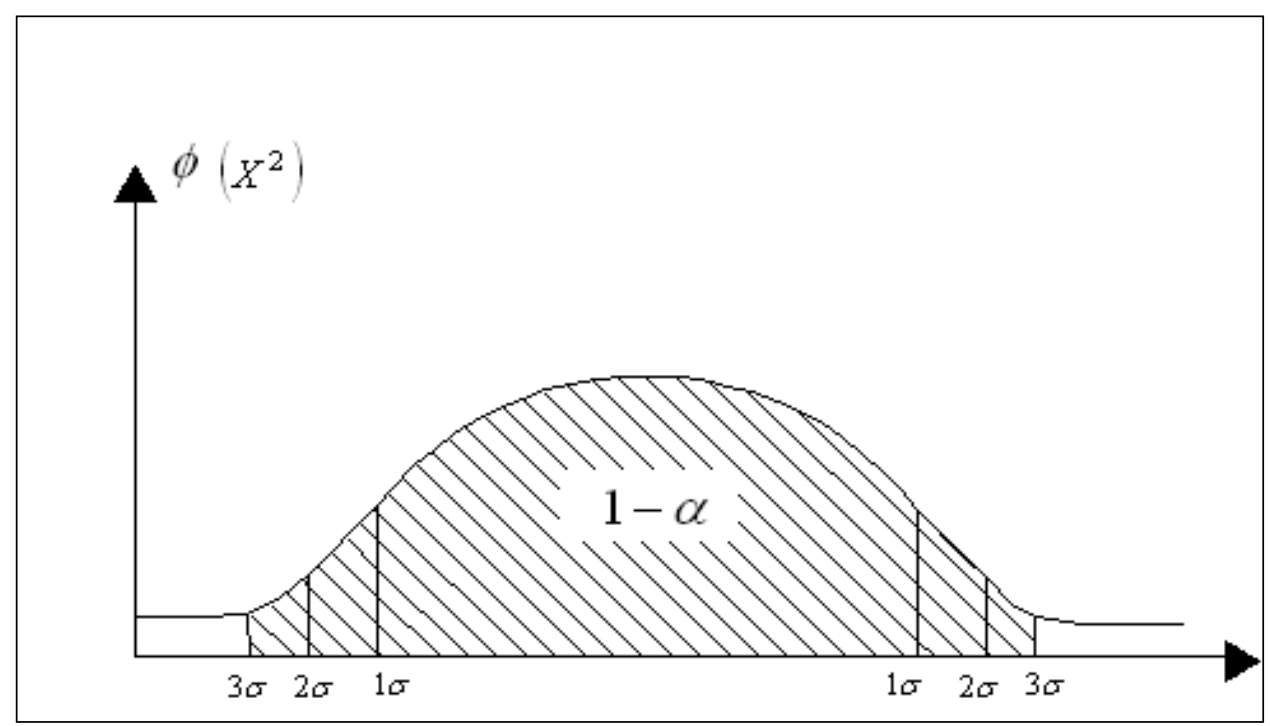

Figura 30 - Intervalos de Confiança.

Fonte: Gemael (1994).

Se $\chi^{2} \leq \chi_{n-1, \alpha}^{2}$ o teste do Qui-Quadrado passa, ou seja, é aceito, do contrário, falha, isto é, não é aceito (GEMAEL, 1994).

Conforme relata Gemael (1994), para a análise das observações utiliza-se o grau de confiança de $99 \%$. As observações são analisadas em três formas distintas: planimetricamente, planialtimetricamente e altimetricamente.

A variância esperada é calculada utilizando-se a precisão nominal do equipamento usado na observação das coordenadas. Os equipamentos utilizados são os receptores GNSS e GPS. As precisões nominais são apresentadas na tabela 10: 
Tabela 10 - Precisões nominais

\begin{tabular}{|c|c|}
\hline Tipo & Precisão Nominal \\
\hline Planimétrica & $10 \mathrm{~mm}+1 \mathrm{ppm}$ \\
\hline Planialtimétrica & $15 \mathrm{~mm}+1 \mathrm{ppm}$ \\
\hline Altimétrica & $20 \mathrm{~mm}+1 \mathrm{ppm}$ \\
\hline
\end{tabular}

Para calcular a variância esperada é usada a seguinte expressão (8):

$$
\sigma^{2}=(P N)^{2}
$$

Onde PN: precisão nominal do equipamento.

Assim, os cálculos das Variâncias Esperadas (precisão relativa do equipamento - PPM) em planimetria, planialtimetria e altimetria são apresentados nas equações (9), (10) e (11):

$$
\begin{aligned}
& \sigma_{\text {plan }}=10 \mathrm{~mm}+1 * \frac{D}{1.000 .000} \\
& \sigma_{\text {PlanAlt }}=15 \mathrm{~mm}+1 * \frac{D}{1.000 .000} \\
& \sigma_{\text {Alt }}=20 \mathrm{~mm}+1 * \frac{D}{1.000 .000}
\end{aligned}
$$

Onde: $\mathrm{D}$ = Distância entre o receptor base para o móvel.

As variâncias observadas planimétrica, planialtimétrica e altimétrica são calculadas respectivamente através das expressões (12), (13) e (14):

$$
\begin{aligned}
& \hat{\sigma}_{E N}^{2}=\widehat{\sigma}_{E}^{2}+\widehat{\sigma}_{N}^{2} \\
& \hat{\sigma}_{E N h}^{2}=\widehat{\sigma}_{E}^{2}+\widehat{\sigma}_{N}^{2}+\widehat{\sigma}_{h}^{2} \\
& \hat{\sigma}_{h}^{2}=\widehat{\sigma}_{h}^{2}
\end{aligned}
$$


As variâncias observadas, dessa maneira, devem ser calculadas para cada uma das componentes $\mathrm{E}, \mathrm{N}$ e $\mathrm{h}$, as quais são as coordenadas UTM e a altitude geométrica. Assim, essas variâncias são calculadas através das expressões (15), (16) e (17):

$$
\begin{gathered}
\hat{\sigma}_{E}^{2}=\frac{\sum_{i=0}^{i=n}\left(\bar{E}-E_{i}\right)^{2}}{n-1} \\
\hat{\sigma}_{N}^{2}=\frac{\sum_{i=0}^{i=n}\left(\bar{N}-N_{i}\right)^{2}}{n-1} \\
\widehat{\sigma}_{h}^{2}=\frac{\sum_{i=0}^{i=n}\left(\bar{h}-h_{i}\right)^{2}}{n-1}
\end{gathered}
$$

Mais dois outros parâmetros foram utilizados para a análise dos resultados obtidos neste projeto, trata-se da média das diferenças e diferença padrão.

A média das diferenças é o valor da coordenada obtida subtraída da coordenada oficial dos vértices, o cálculo deste parâmetro é realizado da seguinte maneira:

- Primeiramente calcula a diferença para cada leitura e eixo (E,N e h) através da seguinte formula:

$$
\begin{gathered}
D i_{(E)}=E(\text { oficial })-E(\text { obtido })(\mathbf{1 8}) \\
D i_{(N)}=N(\text { oficial })-N(\text { obtido })(\mathbf{1 9}) \\
D i_{(h)}=h(\text { oficial })-h(\text { obtido })
\end{gathered}
$$

- De posse dos erros médios, basta calcular o somatório para cada eixo (E,N e h) e dividir pelo número de amostras da seguinte maneira:

$$
M d_{(E)}=\sum \frac{D i_{(E)}}{n}
$$




$$
\begin{aligned}
M d_{(N)} & =\sum \frac{D i_{(N)}}{n}(22) \\
M d_{(h)} & =\sum \frac{D i_{(h)}}{n}(23)
\end{aligned}
$$

O outro parâmetro calculado será denominado de diferença padrão (df) e é baseado nas diferenças calculadas para cada amostra. Este difere do desvio padrão, convencional, porque não leva em consideração à média e sim cada leitura obtida em campo. O cálculo é realizado através das equações 24, 25 e 26, e são mostradas na sequência:

$$
\begin{aligned}
& d f_{(E)}=\sqrt{\sum \frac{D i_{(E)}^{2}}{n-1}} \text { (24) } \\
& d f_{(N)}=\sqrt{\sum \frac{D i_{(N)}^{2}}{n-1}} \text { (25) } \\
& d f_{(h)}=\sqrt{\sum \frac{D i_{(h)}^{2}}{n-1}} \text { (26) }
\end{aligned}
$$




\section{MATERIAIS E MÉTODOS}

A avaliação do levantamento no método relativo com uso da técnica RTK/GSM é aqui apresentada, a exemplo do que foi realizado recentemente em Cintra et al. (2011). Basicamente, a partir da disponibilidade dos recursos aqui listados foram realizados vários testes em vértices oficiais. A seguir, são apresentados os recursos disponíveis, a metodologia do levantamento, as distâncias com relação à ERA IP da POLI, as respectivas precisões esperadas e a descrição de cada vértice. Ao final de cada experimento foi realizada a análise detalhada da qualidade dos dados.

\subsection{RECURSOS DISPONÍVEIS}

Nos experimentos realizados foram utilizados os seguintes recursos:

- 1 notebook Intel Duo Core, 40 GB de disco rígido, 1 Gb de memória RAM.

- Receptor GNSS ProMark 500 (figura 31), habilitado com a opção de rastrear as constelações GPS e GLONASS, modem com conexão GSM integrado ao equipamento e ainda coletor de dados Mobile Mapper CX.

- Receptor GPS ProMark3 (figura 32), habilitado apenas com a constelação GPS e que utilizou um modem externo de um celular.

Visando facilitar à nomenclatura, o primeiro dos receptores é referido como Receptor GNSS L1/L2 e o segundo como Receptor GPS L1;

Figura 31 - Receptor GNSS ProMark 500.

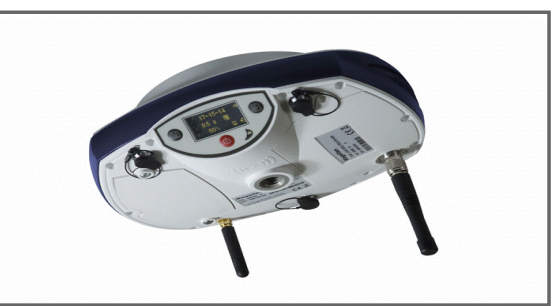


Figura 32 - Receptor GPS ProMark3.

De acordo com as informações contidas nos manuais do fabricante (ASHTECH, 2008a, 2008b) o intervalo de confiança para a determinação da precisão nominal é de $99 \%$, o que foi aplicado em todas as análises dos experimentos realizados. A precisão nominal dos equipamentos utilizados tem os seguintes valores, abaixo.

Receptor GPS ProMark3 RTK:

$$
\begin{aligned}
& \text { Horizontal: } 1 \mathrm{~cm}+1 \text { ppm (solução fixa) } \\
& \text { : } 20 \mathrm{~cm}+1 \text { ppm (solução parcial) } \\
& :<1 \mathrm{~m} \quad \text { (DGPS) } \\
& \text { Vertical }: 2 \mathrm{~cm}+2 \mathrm{ppm} \text { (solução fixa) } \\
& \text { : } 40 \mathrm{~cm}+2 \text { ppm (solução parcial) } \\
& :<3 \mathrm{~m} \quad \text { (DGPS) }
\end{aligned}
$$

Receptor GNSS ProMark 500 RTK:

Horizontal: $1 \mathrm{~cm}+1$ ppm (solução fixa)

$$
:<1 \mathrm{~m} \quad \text { (DGPS) }
$$

Vertical : $2 \mathrm{~cm}+1 \mathrm{ppm}$ (solução fixa)

$$
:<3 m \quad \text { (DGPS) }
$$

- aparelho celular NOKIA E62 para conexão bluetooth com o Receptor ProMark3;

- 1 identificador de conexão GSM TIM; 
- Programas: software de coleta de dados em campo Fast Survey 2.3.2.2., software de processamento de dados GPS GNSS Solutions 3.10.01. e Software Topográfico DataGeosis para a elaboração dos gráficos.

Uma diferença técnica importante entre os receptores ProMark3 e Promark 500 é que o primeiro não possui modem de conexão GSM integrado, sendo necessária a conexão via bluetooth com um celular externo (ver figura 33). Já o segundo possui o modem de conexão GSM integrado, facilitando o uso do mesmo (ver figura 34).

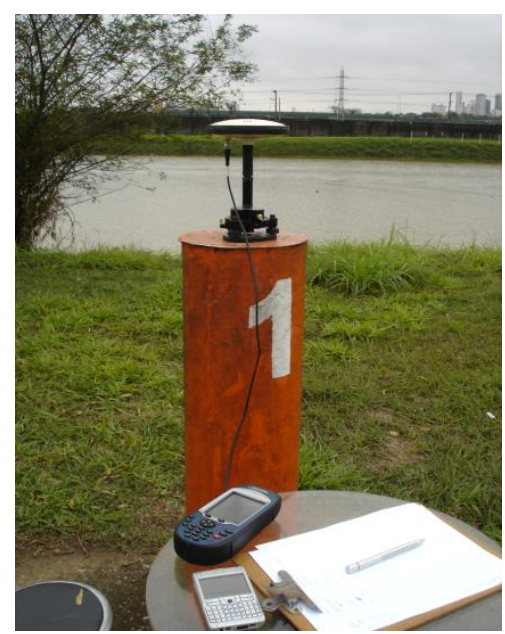

Figura 33 - Receptor GPS L1 com celular conectado via Bluetooth.

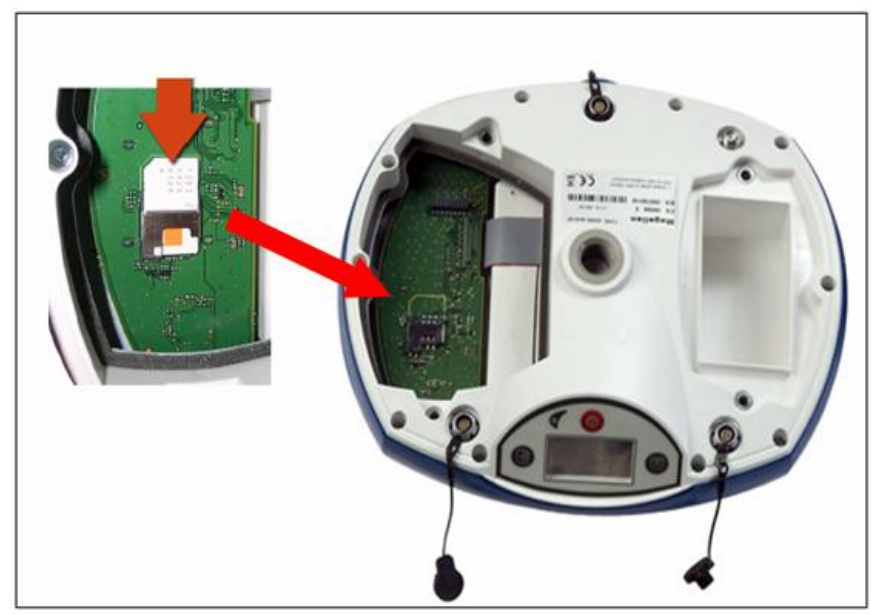

Figura 34 - Receptor GNSS L1/L2 com modem de conexão GSM integrado. 


\subsection{METODOLOGIA UTILIZADA PARA EXECUÇÃO DO LEVANTAMENTO}

Os experimentos foram realizados sobre vértices com coordenadas determinadas com tecnologia GPS e homologadas pelo IBGE ou pertencente à rede da Prefeitura Municipal de São Paulo. Foi utilizada a conexão do tipo ponto a ponto, sempre vinculando a uma ERA IP e usando um receptor GNSS móvel. Para configurar o modem do receptor GNSS móvel e definir o IP para a realização da conexão GSM/GPRS, foi necessária a configuração dos parâmetros conforme a figura 35. Na figura demonstra-se a conexão via serviço NTRIP (no campo rede), depois se define o Caster a se conectar (no caso o IBGE), o seu respectivo endereço IP (200.255.94.90), a porta (2101). Para ter o acesso se deve introduzir um usuário e a senha.

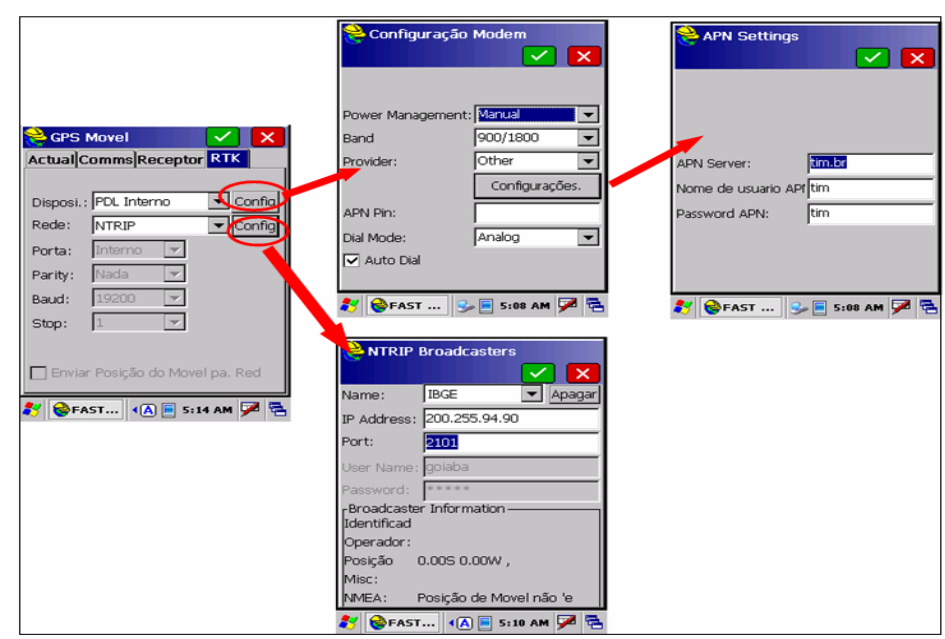

Figura 35 - Configuração dos parâmetros de conexão GSM/GPRS do receptor móvel

Realizada a conexão, são visualizadas todas as ERA IP ligadas ao servidor de origem (definido pelo IP); deve-se então selecionar a ERA IP desejada. Finalizada a operação de conexão de rede, por exemplo, para a base POLI, são mostrados através do menu do software de campo Fast Survey, os dados referentes ao rastreio. As informações que podem ser visualizadas através desta tela são as coordenadas do ponto $(E, N, h)$, número de satélites, latência, todos os DOPs (PDOP, HDOP, VDOP, TDOP e GDOP), o tipo de solução da ambiguidade no 
referido instante, a precisão do levantamento e a ERA IP. Todos os procedimentos e as informações visualizadas nas telas são ilustrados através da figura 36 .

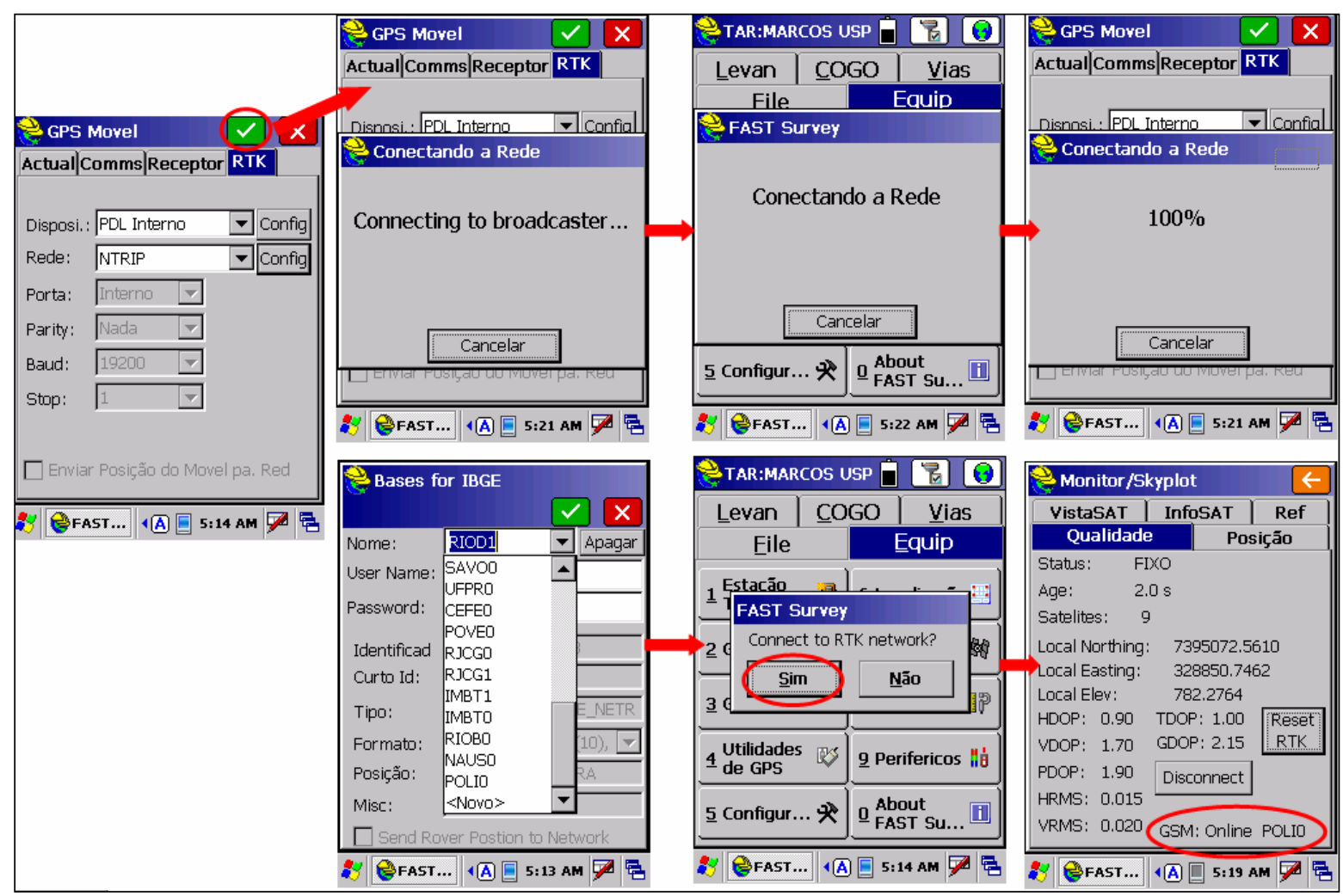

Figura 36 - Conectando ao software NtripCaster e selecionando a ERA IP POLI.

Estabeleceu-se assim o seguinte procedimento: conexão à Internet por meio de modem de conexão GSM/GPRS, localização e conexão ao servidor de dados e em sequência a ERA IP mais próxima (no caso sempre ERA IP POLI), espera pela solução da ambiguidade ou do tempo determinado como limite (GNSS L1/L2 máximo de 5 minutos e receptores GPS L1 de 22 minutos), registro de informações do número de satélites observados, latência e registro das coordenadas. Esse procedimento foi repetido até a obtenção de no mínimo 60 observações, suficiente para atender aos testes estatísticos que seriam realizados. Isso é baseado no fato de que para a Engenharia a distribuição dos erros pode configurar uma distribuição normal e que para tanto é preciso ter ao menos 30 observações. Para garantir mais segurança nos resultados optou-se por 60 observações. Nos experimentos onde se registrou solução fixa e flutuante no mesmo projeto, a análise foi feita separadamente, mesmo nos casos em que o número de observações tenha sido 
inferior a 60, visando retratar o ocorrido em campo. Com respeito ao tempo de espera para obter a solução fixa, buscou-se levar em conta a produtividade, sendo considerado inviável o tempo superior ao que foi mencionado acima e o que teoricamente seria o suficiente para a solução da ambiguidade para os respectivos tipos de receptores utilizados.

Nos seis primeiros vértices, entre os 10 estudados em função da distância para a ERA IP POLI, foram utilizados receptores de dupla e simples frequência e nos 4 últimos apenas dupla frequência, em razão dos limites de distâncias. Assim, a análise foi dividida em 16 experimentos e 20 testes, visando uma avaliação que levasse em conta as condições de trabalho, distância e tecnologia utilizada. Neste sentido, primeiro foram analisados os experimentos com o receptor GNSS L1/L2 (figura 34) e posteriormente com o receptor GPS L1 (figura 33). A seguir são apresentados a estação de referência e os vértices levantados com suas respectivas coordenadas oficiais.

\subsection{ESTAÇÃO DE REFERÊNCIA E VÉRTICES LEVANTADOS}

Com o objetivo de analisar a precisão, a acurácia e a viabilidade de uso da tecnologia de posicionamento com o emprego da técnica RTK/GSM, em trabalhos de engenharia de alta precisão, foi escolhida a ERA POLI, pertencente à Rede Brasileira de Monitoramento Contínuo e cujos dados podem ser acessados através do software NtripCaster instalado pelo IBGE.

A ERA POLI (SAT 93800) localiza-se na Escola Politécnica da USP na cidade de São Paulo, onde se encontra um receptor GNSS L1/L2 GRX 1200 Pro (fabricante Leica), denominada ERA IP POLI. As coordenadas UTM (fuso 23, Meridiano Central $45^{\circ} \mathrm{W}$, Hemisfério Sul) oficiais de referência no SIRGAS 2000 são apresentadas na tabela 11. 
Tabela 11 - Coordenadas Oficiais da ERA IP POLI

\begin{tabular}{c|c|c|c|c|c|} 
Nome & Descrição & Este $(\mathbf{m})$ & Norte $(\mathbf{m})$ & Altura da elipse $(\mathbf{m})$ & Referencial \\
\hline SAT 93800 & POLI & 323255.082 & 7393902.042 & 730.62 & Sirgas2000 \\
\hline
\end{tabular}

Fonte: IBGE (2008).

Escolhida a ERA IP POLI, foram definidos pontos conhecidos cujas coordenadas seriam determinadas e comparadas no levantamento de campo. A escolha dos mesmos levou em consideração a distância com relação à ERA IP POLI, sendo o vértice mais próximo a 500 metros e o mais distante a $108 \mathrm{Km}$. A distância limite do último ponto a ERA IP do estudo foi determinada considerando que a partir deste vértice não foi possível obter a solução fixa, desta maneira as coordenadas registradas não teriam precisão suficiente em projetos de engenharia.
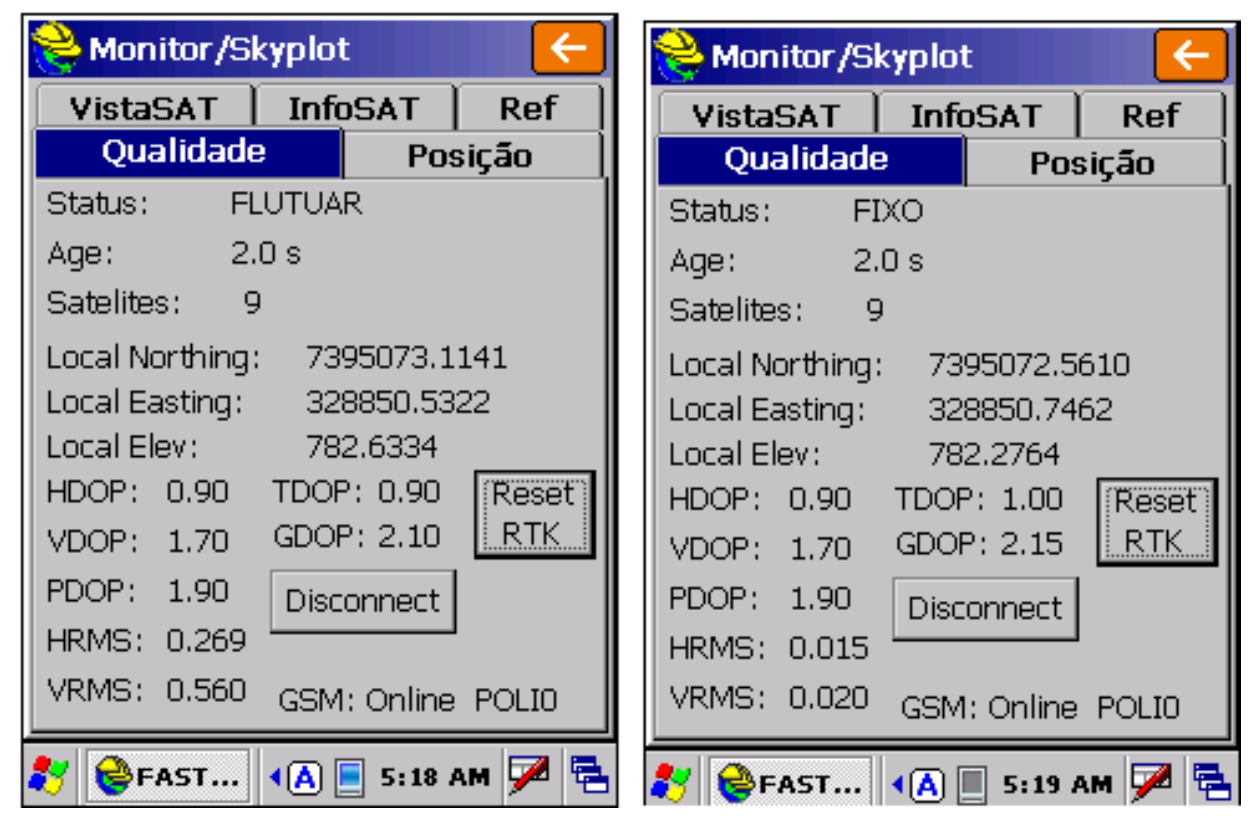

Figura 37 - Armazenando Coordenada com o emprego da técnica RTK/GSM.

A figura 37 mostra a utilização do software Fast Survey na coleta e no processamento de um ponto com o emprego da técnica RTK/GSM. Como pode ser observado, as informações de tipo de solução (Status), latência (Age), quantidade de satélites (Satellites) precisão horizontal (HRMS) e vertical (VHRMS), DOPs (HDOP, VDOP, PDOP, TDOP, GDOP), as coordenadas rastreadas e já corrigidas (Local Northing, Local Easting), além da ERA IP que está sendo conectada (nesse 
caso conexão GSM: Online POLI, ficam disponíveis para o usuário durante o levantamento.

Este critério teve como objetivo analisar a distância máxima em que pudesse ser possível obter solução fixa e consequentemente resolver as ambiguidades. Nos casos em que esta alternativa não fosse alcançada, verificou-se a precisão e a acurácia possíveis de serem atingidas mesmo com a solução flutuante.

Foram rastreados 10 vértices oficiais, cinco deles pertencentes à Rede Básica de Referência Geodésica da Prefeitura de São Paulo (prefixo V, vide figuras 39, 40, 41, 42 e 43) e outros cinco pertencentes ao Sistema Geodésico Brasileiro (prefixo SAT, vide figuras $38,44,45,46$ e 47). São vértices materializados e com diferentes características geodésicas em termos de localização e obstrução de sinal. Observou-se o PDOP médio nos diferentes vértices levantados, e considerou-se: um ponto com boa geometria os com valores inferiores a 2, um ponto com geometria média com valores entre 2 e 3 e um ponto com geometria ruim com valores superiores a 3 . Os vértices dentro da cidade de São Paulo estão em áreas urbanizadas e edificadas reproduzindo a condição de trabalho de um usuário no meio urbano e os vértices mais distantes em condições geodésicas favoráveis para analisar o erro linear em relação à distância. O sistema de Referência foi o SIRGAS 2000 para todos os vértices. Descreveu-se em cada experimento sua condição meteorológica, sendo considerada boa quando a temperatura média era superior a 24ํㅡ e sem a ocorrência de chuvas e uma condição ruim quando a temperatura era inferior a $24^{\circ} \mathrm{C}$ e com a ocorrência de chuvas. A condição ruim tem grande relevância por ter influência direta nas condições de trabalho em campo, no possível congestionamento da conexão GSM/GPRS e a sobrecarga do tráfego da internet, ocasionando uma latência maior e consequente demora na solução de ambiguidades.

A seguir as figuras 38 até a 47 apresentam as localizações, as coordenadas UTM (fuso 23, Meridiano Central 45 $\mathrm{W}$, Hemisfério Sul) e altitude geométrica, no SIRGAS 2000 e as fotos dos vértices. 


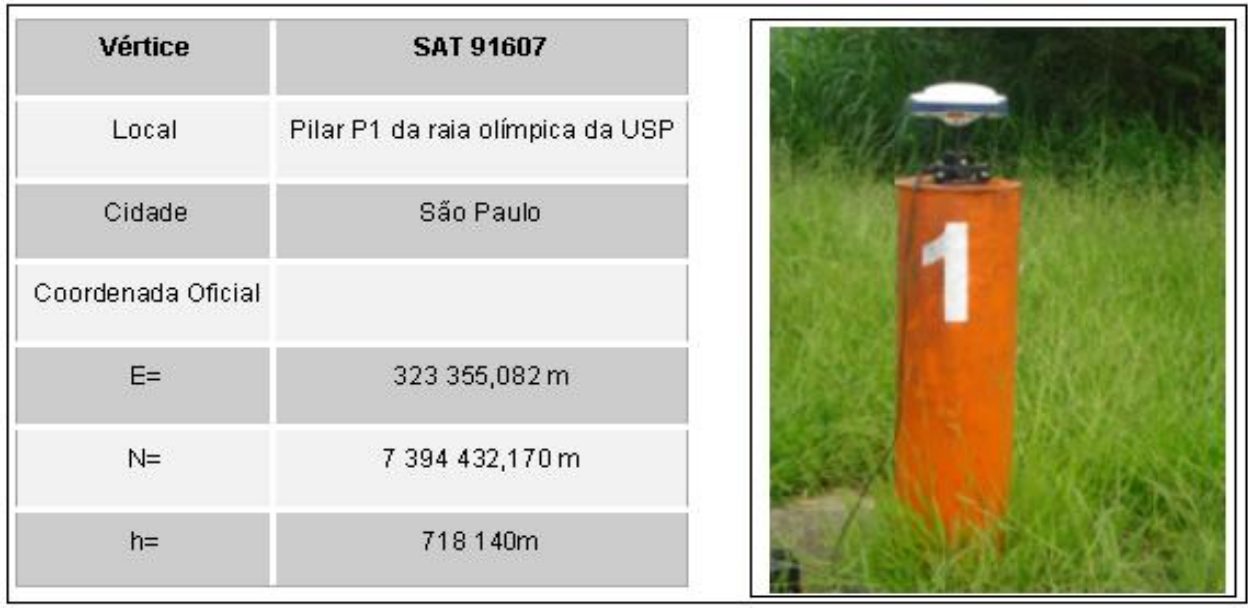

Figura 38 - Dados e foto do vértice SAT 91607.

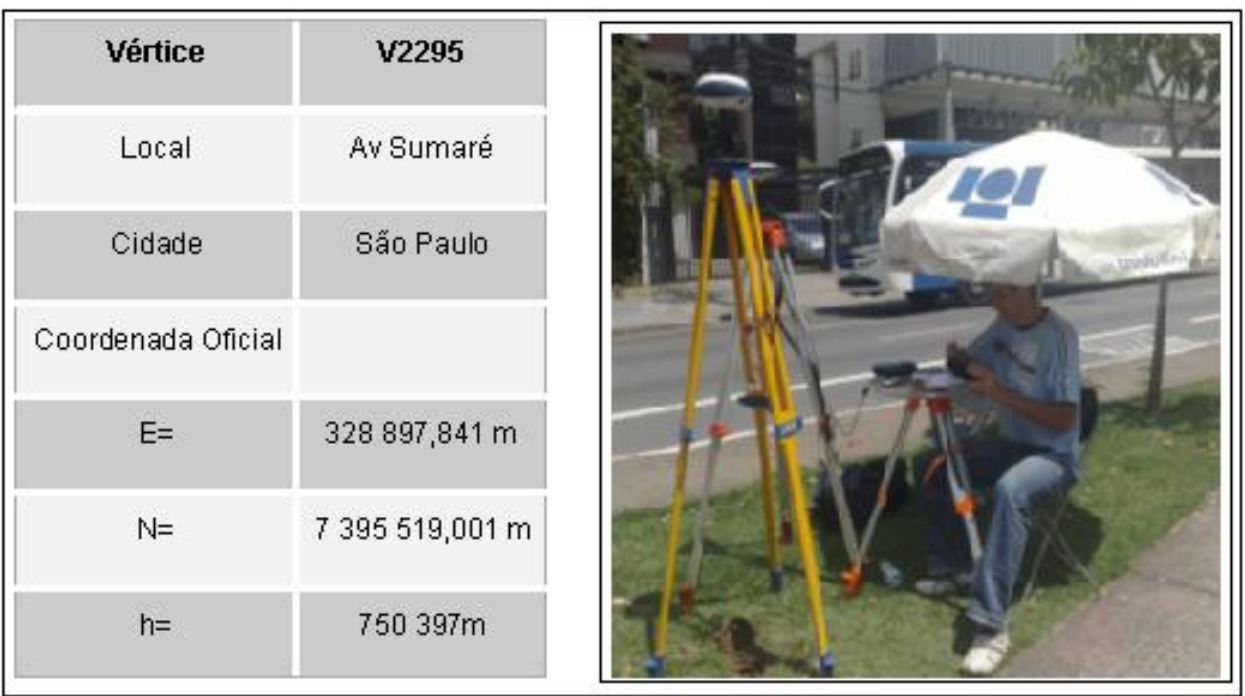

Figura 39 - Dados e foto do vértice V2295.

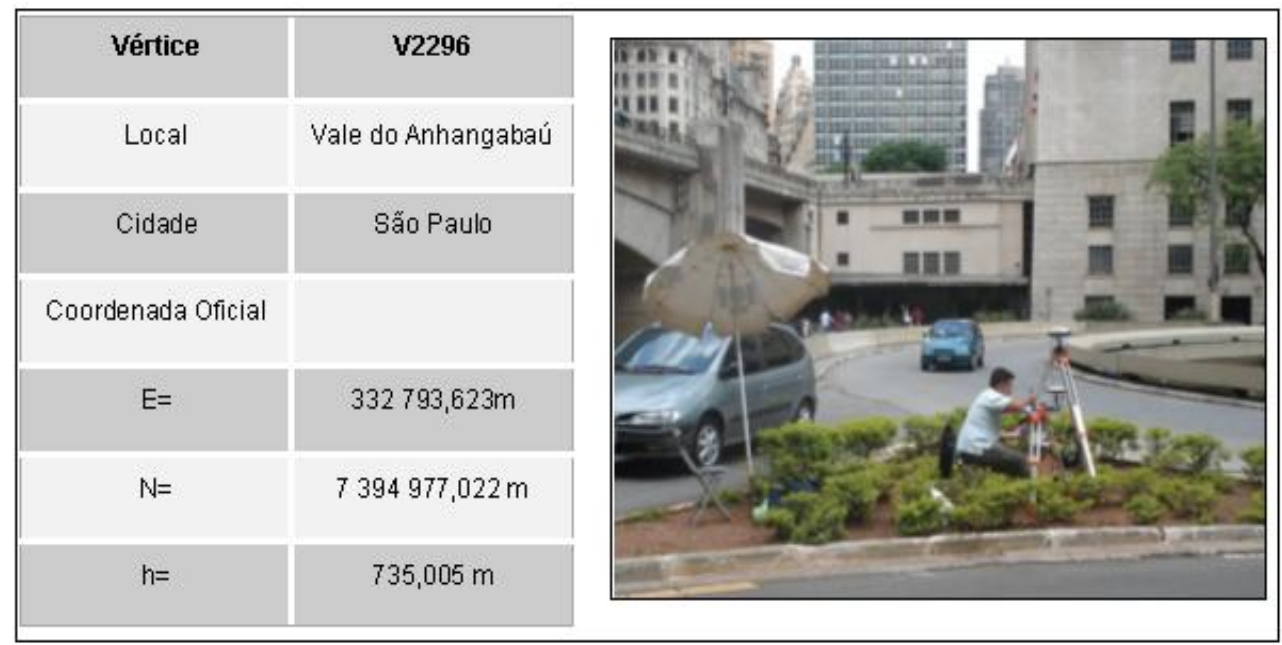

Figura 40 - Dados e foto do vértice V2296. 


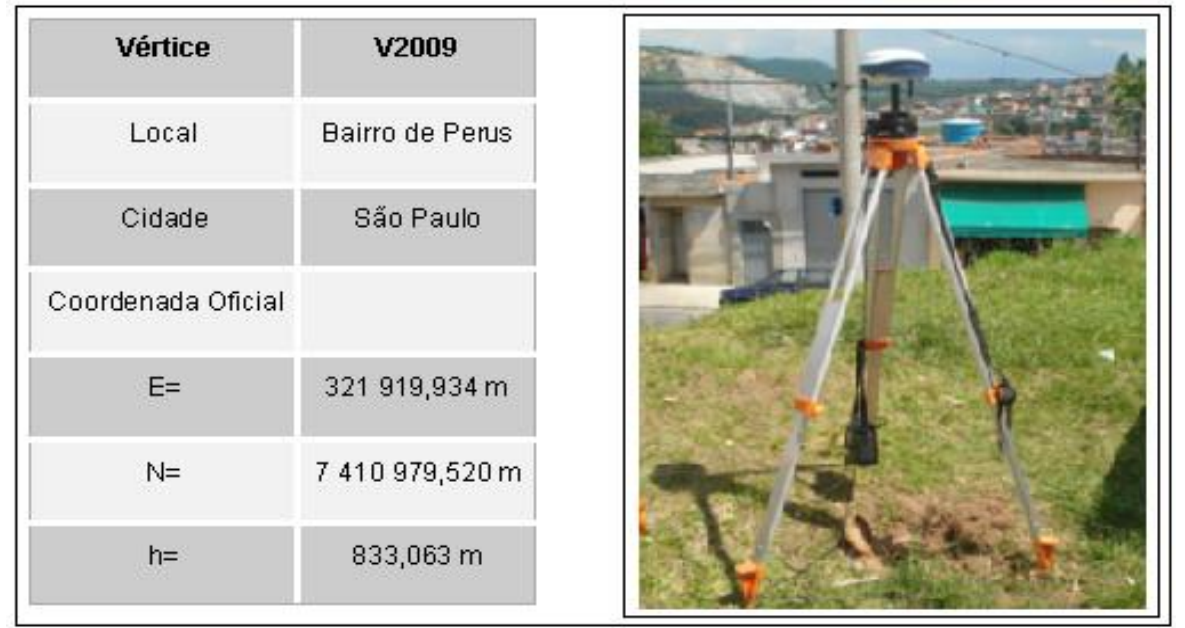

Figura 41 - Dados e foto do vértice V2009.

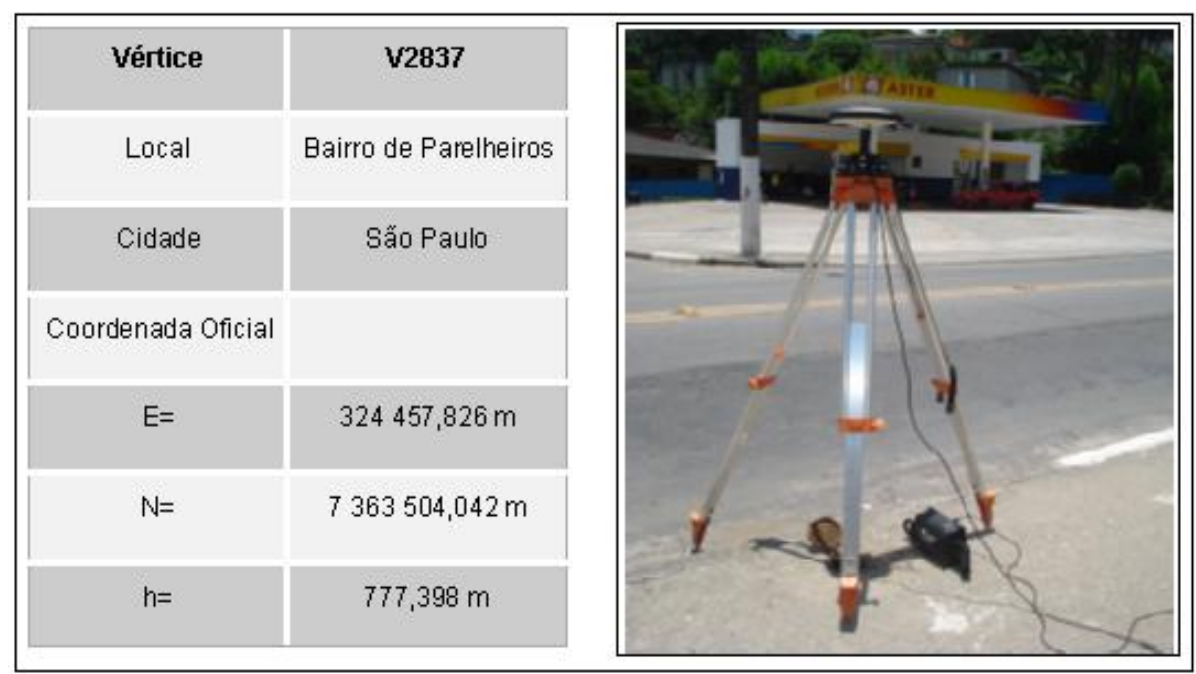

Figura 42 - Dados e foto do vértice V2837.

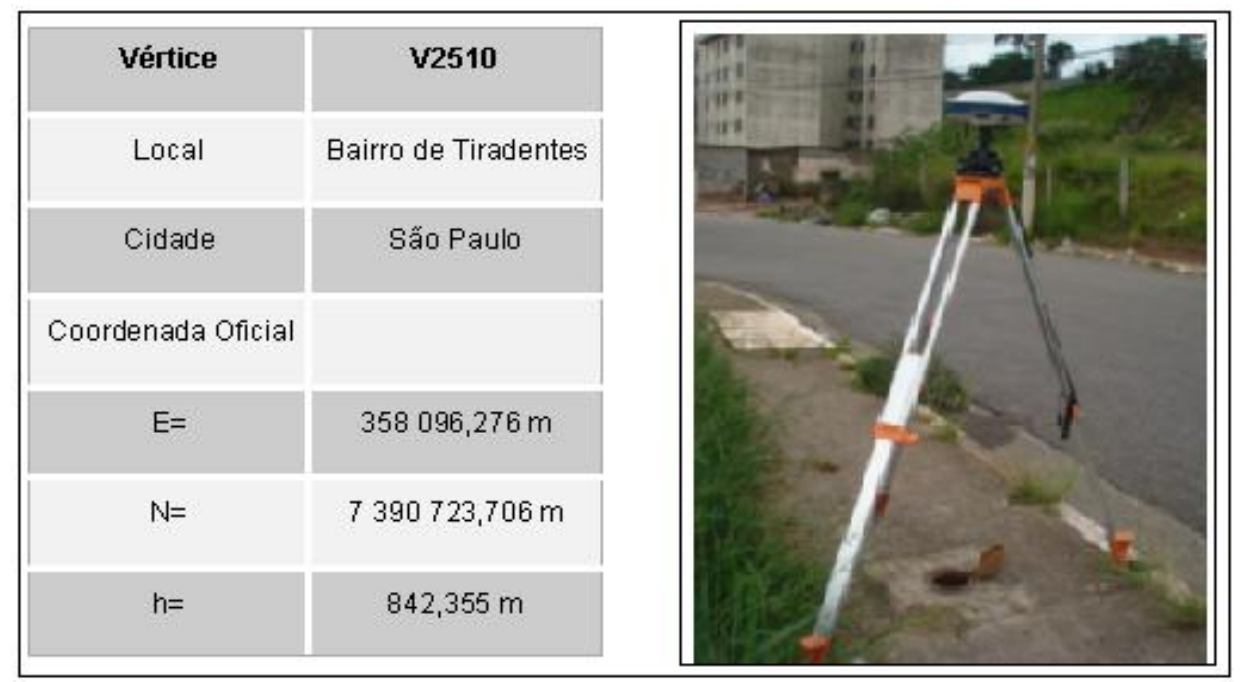

Figura 43 - Dados e foto do vértice V2510. 


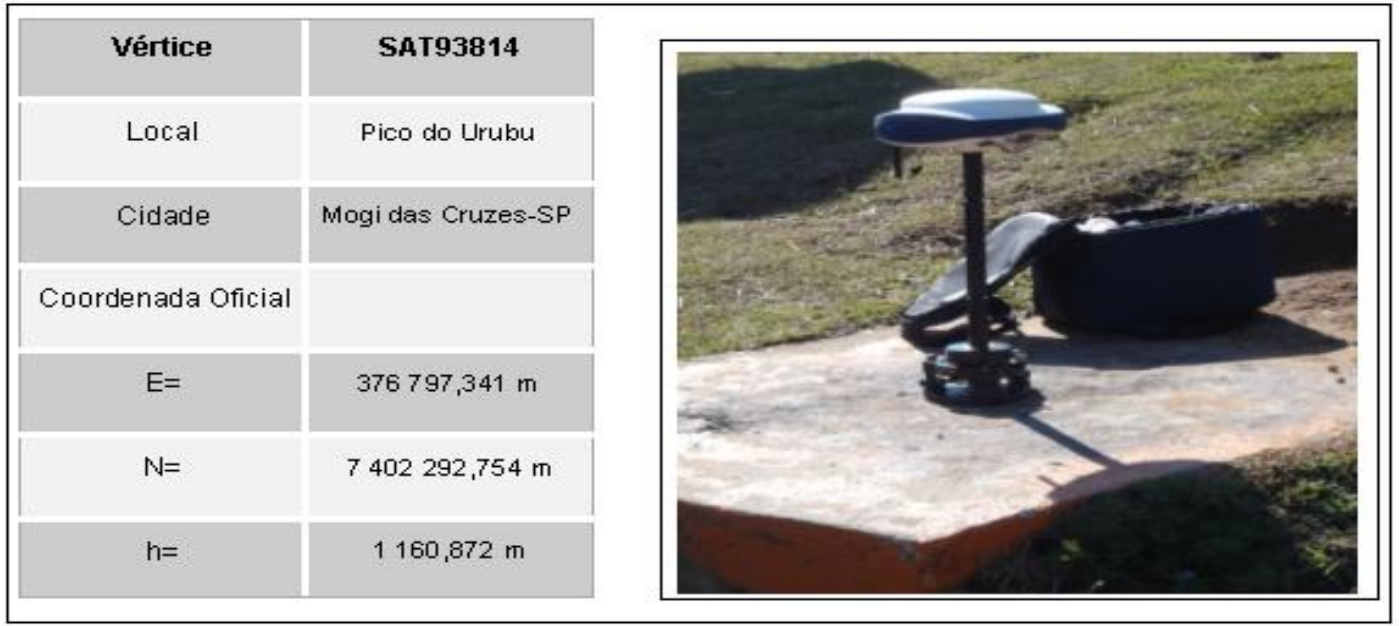

Figura 44 - Dados e foto do vértice SAT93814.

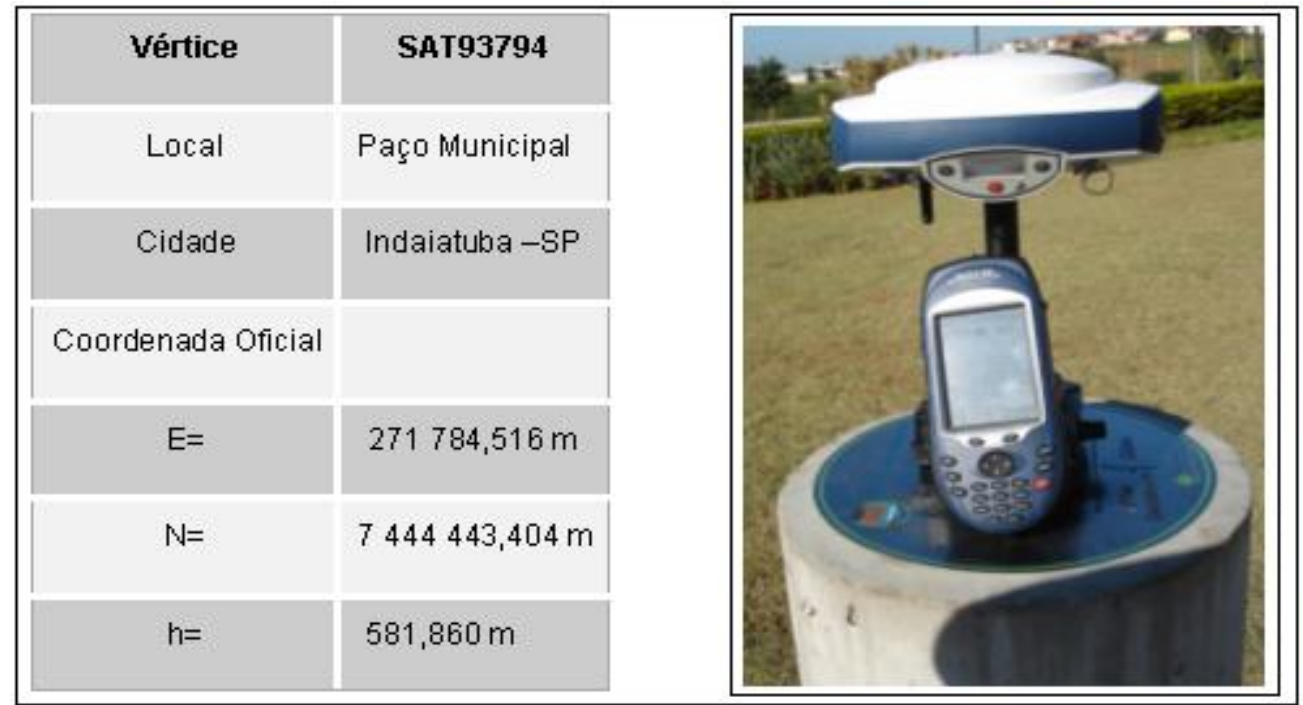

Figura 45 - Dados e foto do vértice SAT93794.

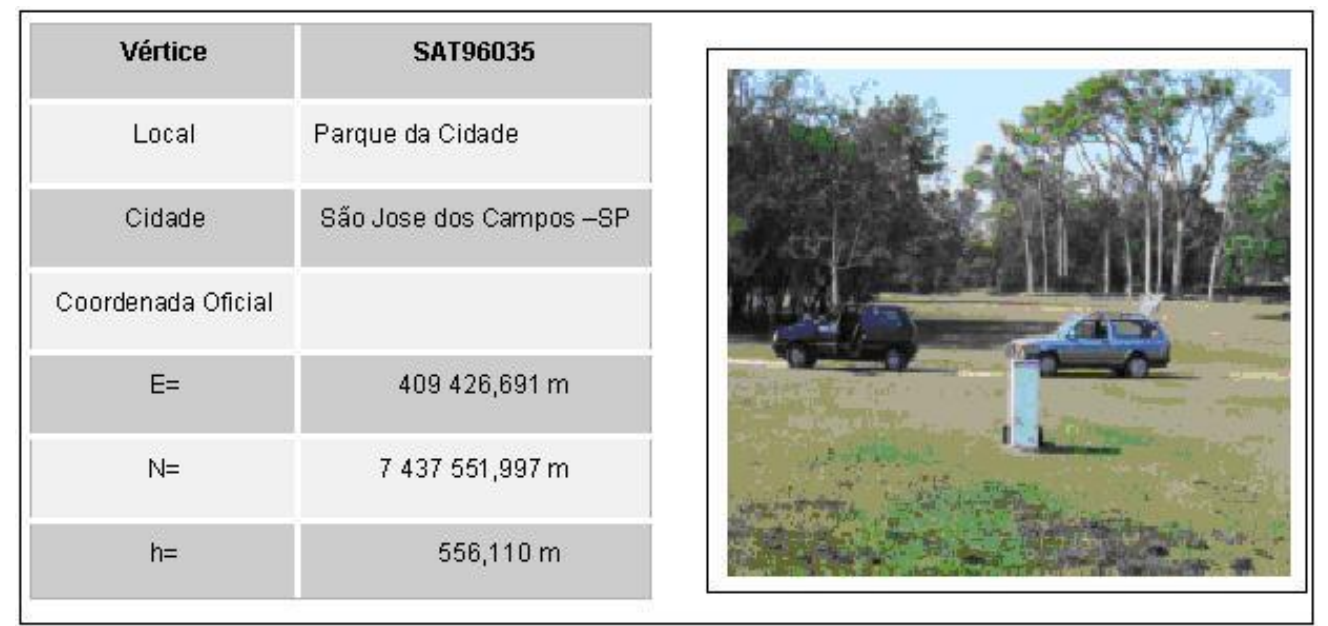

Figura 46 - Dados e foto do vértice SAT96035. 


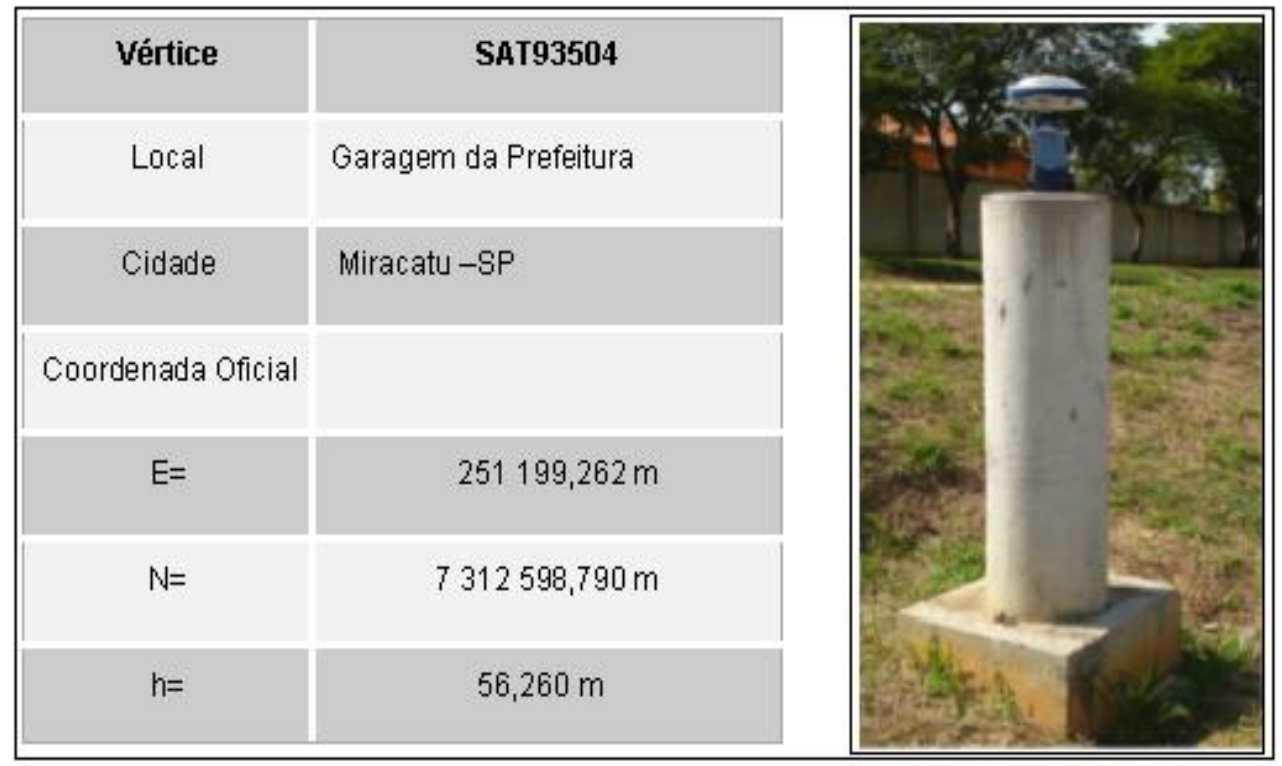

Figura 47 - Dados e foto do vértice SAT93504.

As figuras 48 e 49 apresentam a localização dos pontos e suas respectivas direções em relação à estação de referência.

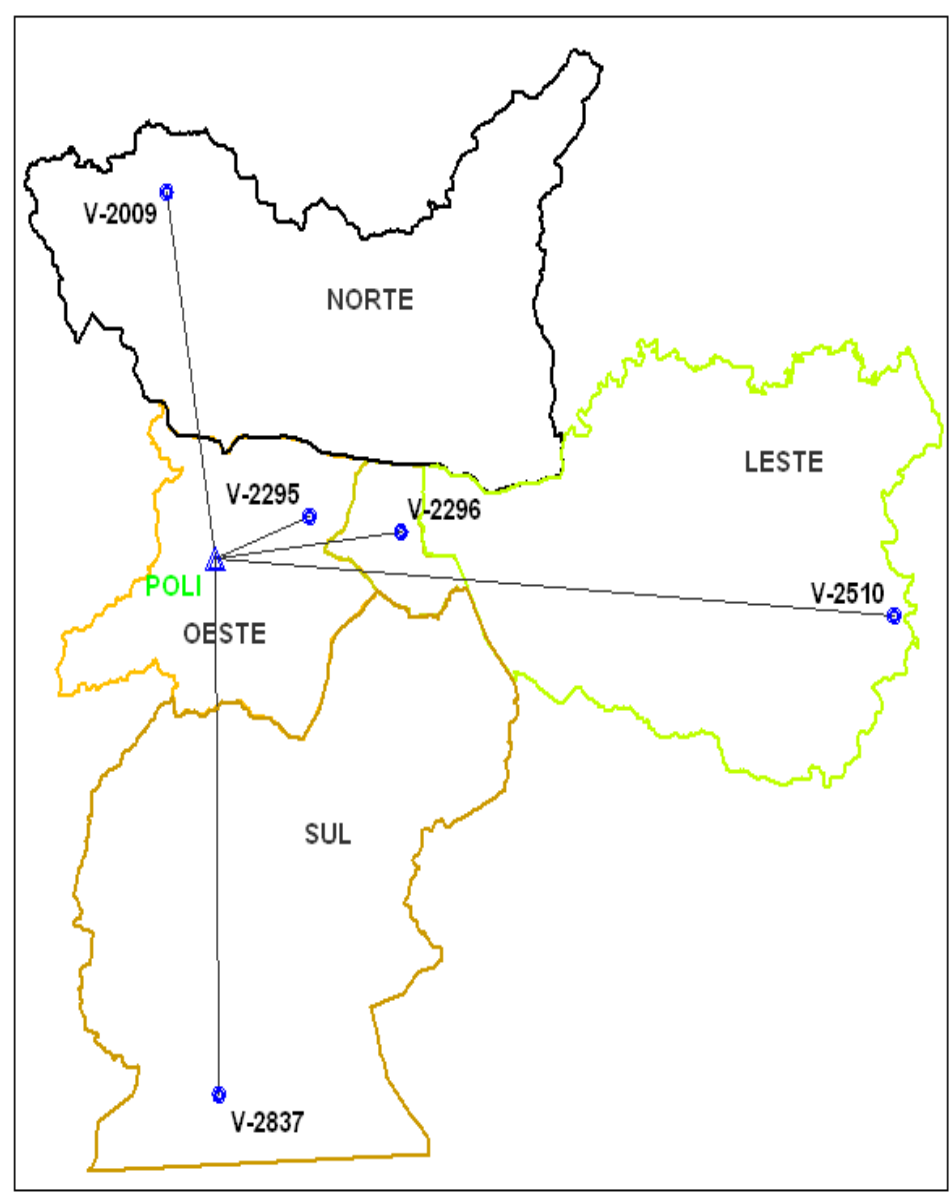

Figura 48 - Vértices utilizados da Rede Geodésica da Prefeitura de São Paulo. 


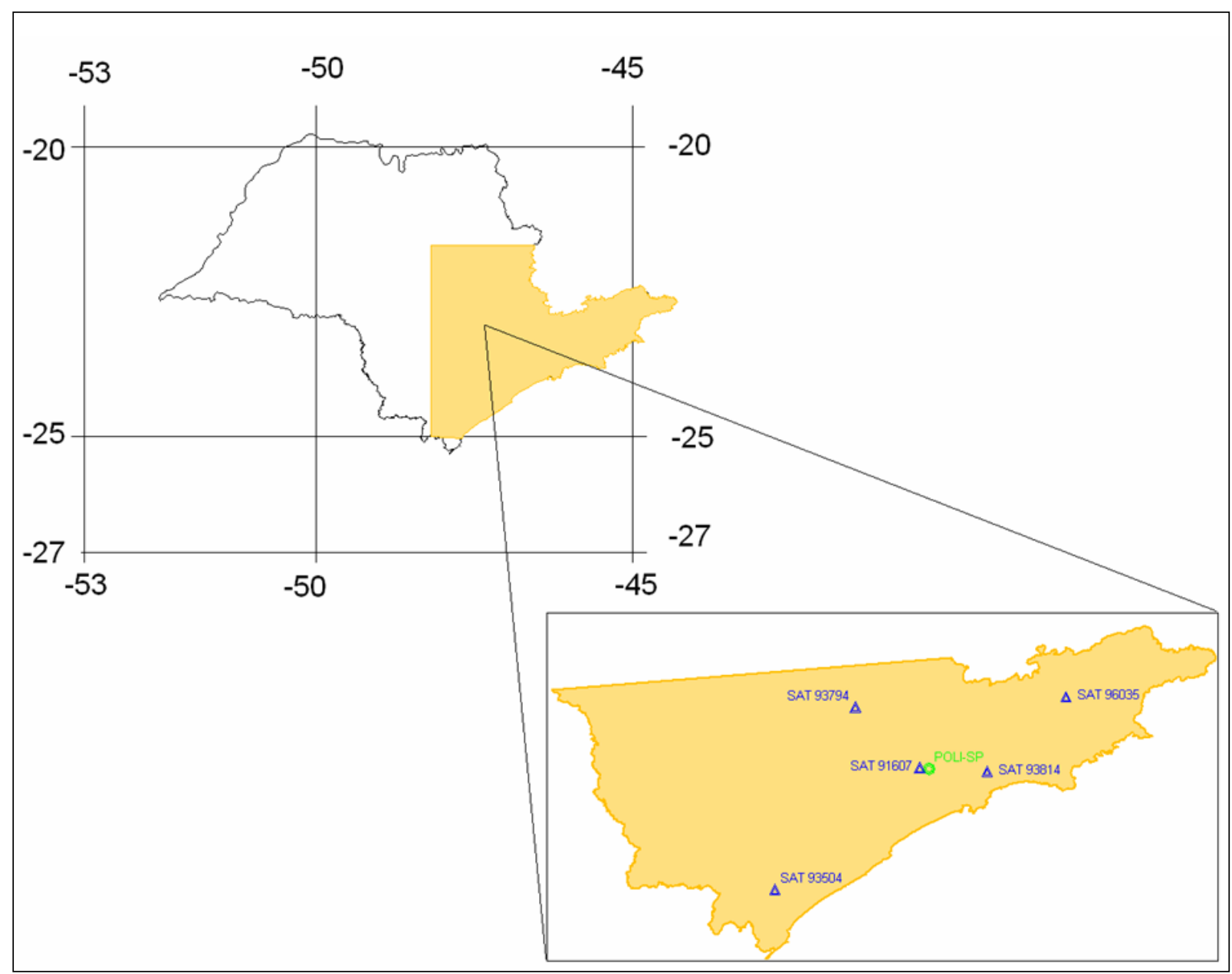

Figura 49 - Vértices utilizados do Sistema Geodésico Brasileiro.

Na tabela 12 são listados os experimentos, o vértice analisado, a distância, a precisão esperada e o tipo de receptor GNSS/GPS utilizado em cada experimento.

As informações contidas na tabela 12 foram usadas na análise estatística do resultado dos experimentos. A precisão esperada foi calculada conforme a precisão nominal dos equipamentos e em relação à distância da ERA. 
Tabela 12 - Informações dos vértices usados nos experimentos.

\begin{tabular}{|c|c|c|c|c|c|}
\hline \multirow{4}{*}{ Experimento } & \multirow{4}{*}{ Vértice } & \multirow{4}{*}{$\begin{array}{c}\text { Distância } \\
\text { (km) }\end{array}$} & \multirow{2}{*}{\multicolumn{2}{|c|}{$\begin{array}{l}\text { Precisão esperada } \\
\text { ProMark } 500 \text { (L1/L2)/ } \\
\text { ProMark3 (L1) }\end{array}$}} & \multirow{4}{*}{$\begin{array}{l}\text { Receptor } \\
\text { GNSS/GPS }\end{array}$} \\
\hline & & & & & \\
\hline & & & Horizontal & Vertical & \\
\hline & & & $10 \mathrm{~mm}+1 \mathrm{ppm}$ & $20 \mathrm{~mm}+1 \mathrm{ppm}$ & \\
\hline 1 & SAT91607 (P1-USP) & 0,547 & $0,011 \mathrm{~m}$ & $0,021 \mathrm{~m}$ & L1/L2 \\
\hline 2 & V2295 (Av. Sumaré) & 5,700 & $0,016 \mathrm{~m}$ & $0,026 \mathrm{~m}$ & L1/L2 \\
\hline 3 & V2296 (Anhangabaú) & 9,600 & $0.020 \mathrm{~m}$ & $0.030 \mathrm{~m}$ & L1/L2 \\
\hline 4 & V2009 (Perus) & 17,129 & $0.027 \mathrm{~m}$ & $0.037 \mathrm{~m}$ & L1/L2 \\
\hline 5 & V2837 (Parelheiros) & 30,422 & $0.040 \mathrm{~m}$ & $0.050 \mathrm{~m}$ & L1/L2 \\
\hline 6 & V2510 (Tiradentes) & 34,986 & $0.045 \mathrm{~m}$ & $0.055 \mathrm{~m}$ & L1/L2 \\
\hline 7 a (Fixo) & SAT93814 (Mogi das Cruzes) & 54,000 & $0,064 \mathrm{~m}$ & $0,074 \mathrm{~m}$ & L1/L2 \\
\hline 7 b (Flutuante) & SAT93814 & 54,000 & $0,064 \mathrm{~m}$ & $0,074 \mathrm{~m}$ & L1/L2 \\
\hline 8 a (Fixo) & SAT93794 (Indaiatuba) & 72,000 & $0,082 \mathrm{~m}$ & $0,092 \mathrm{~m}$ & L1/L2 \\
\hline $8 \mathrm{~b}$ (Flutuante) & SAT93794 (Indaiatuba) & 72,000 & $0,082 \mathrm{~m}$ & $0,092 \mathrm{~m}$ & L1/L2 \\
\hline 9 a (Fixo) & SAT96035 (S. J. Campos) & 96,500 & $0,106 \mathrm{~m}$ & $0,116 \mathrm{~m}$ & L1/L2 \\
\hline $9 \mathrm{~b}$ (Flutuante) & SAT96035 (S. J. Campos) & 96,500 & $0,106 \mathrm{~m}$ & $0,116 \mathrm{~m}$ & L1/L2 \\
\hline 10 a (Fixo) & SAT93504 (Miracatu) & 108,700 & $0,119 \mathrm{~m}$ & $0,129 \mathrm{~m}$ & L1/L2 \\
\hline 11 & SAT91607 (P1) & 0,547 & $0,011 \mathrm{~m}$ & $0,021 \mathrm{~m}$ & L1 \\
\hline 12 a (Fixo) & V2295 (Av. Sumaré) & 5,700 & $0,016 \mathrm{~m}$ & $0,026 \mathrm{~m}$ & L1 \\
\hline $12 \mathrm{~b}$ (Flutuante) & V2295 (Av. Sumaré) & 5,700 & $0,016 \mathrm{~m}$ & $0,026 \mathrm{~m}$ & L1 \\
\hline 13 & V2296 (Anhangabaú) & 9,600 & $0.020 \mathrm{~m}$ & $0.030 \mathrm{~m}$ & L1 \\
\hline 14 & V2009 (Perus) & 17,129 & $0.027 \mathrm{~m}$ & $0.037 \mathrm{~m}$ & L1 \\
\hline 15 & V2837 (Parelheiros) & 30,422 & $0.040 \mathrm{~m}$ & $0.050 \mathrm{~m}$ & L1 \\
\hline 16 & V2510 (Tiradentes) & 34,986 & $0.045 \mathrm{~m}$ & $0.045 \mathrm{~m}$ & L1 \\
\hline
\end{tabular}




\section{DADOS COLETADOS}

\subsection{DESCRIÇÃO DOS RESULTADOS OBTIDOS}

As informações relevantes ao trabalho de campo são descritas a seguir, tais como, coordenadas do ponto, tempo necessário para a inicialização, PDOP, número de satélites e latência média.

Para cada experimento são apresentadas as informações pertinentes para a análise, tais como, diferença entre coordenadas, percentual das amostras que atendem a precisão nominal, gráfico da dispersão dos pontos na planimetria, frequência de incidência de coordenadas, histograma de discrepâncias.

Além disso, é indicada a comparação da média das coordenadas obtidas com o valor oficial delas e apresentadas as diferenças nos três eixos $(\Delta \mathrm{E}, \Delta \mathrm{N}$ e $\Delta \mathrm{h})$. Estas foram comparadas com a precisão esperada (ver Tabela 12). Em seguida, foi realizada uma avaliação individual de cada coordenada com a oficial, determinando a porcentagem da amostra que atendeu ao experimento em planimetria e altimetria respectivamente.

Os histogramas de discrepâncias se referem às diferenças entre as coordenadas obtidas para cada eixo $(E, N$ e h) em relação às respectivas coordenadas oficiais, com intervalos adequados para as frequências.

\subsection{APRESENTAÇÃO DOS DADOS COLETADOS NOS EXPERIMENTOS}

\subsubsection{Experimento 1}

Deste experimento até o décimo experimento, foi utilizado um Receptor GNSS L1/L2. Este se refere ao vértice SAT 91607(P1-USP) com uma distância de $0,547 \mathrm{~km}$ para a ERA POLI, realizado no dia 27 de dezembro de 2008. Foram 
registradas (obtidas) 168 coordenadas com solução fixa, as quais tiveram um tempo de inicialização de 1,2 segundos, uma latência de 1,4 segundos, rastreando-se 12 satélites com um PDOP de 1,82, em média. Em termos de visibilidade dos satélites, o ponto tinha uma boa localização, conforme a figura 38 , e a condição meteorológica era ruim.

Em uma primeira análise da discrepância, levaram-se em consideração as coordenadas médias obtidas e as diferenças resultantes da comparação às coordenadas oficiais. Os valores para o caso foram os seguintes:

$$
\begin{array}{ll}
\mathrm{E}=323255,080 \mathrm{~m} ; & \Delta \mathrm{E}=|0,002 \mathrm{~m}|<0,011 \mathrm{~m}(\text { ver tabela } 12) \\
\mathrm{N}=7394432,166 \mathrm{~m} ; & \Delta \mathrm{N}=|0,004 \mathrm{~m}|<0,011 \mathrm{~m}(\text { ver tabela } 12) \\
\mathrm{h}=718,104 \mathrm{~m} ; & \Delta \mathrm{h}=|0,036 \mathrm{~m}|>0,021 \mathrm{~m}(\text { ver tabela } 12)
\end{array}
$$

Após análise de cada coordenada ( $\mathrm{E}, \mathrm{N}$ e h) obtida com o valor esperado (apresentado na tabela 12), concluiu-se que a amostra atende à planimetria em $100 \%$ e à altimetria em $91 \%$. Isto é, $100 \%$ (168) das coordenadas em E e N quando comparadas com as coordenadas oficiais $\mathrm{E}$ e $\mathrm{N}$ desse vértice tiveram discrepâncias inferiores a 0,011 m, sendo que na altimetria 91\% (153) das coordenadas em $\mathrm{h}$ quando comparadas com a coordenada oficial $\mathrm{h}$ desse vértice tiveram discrepâncias inferiores a 0,021 m,

$\mathrm{Na}$ figura 50 , pode ser vista a dispersão dos resultados das coordenadas UTM mensuradas no referido ponto, considerando-se as direções (E e N). 


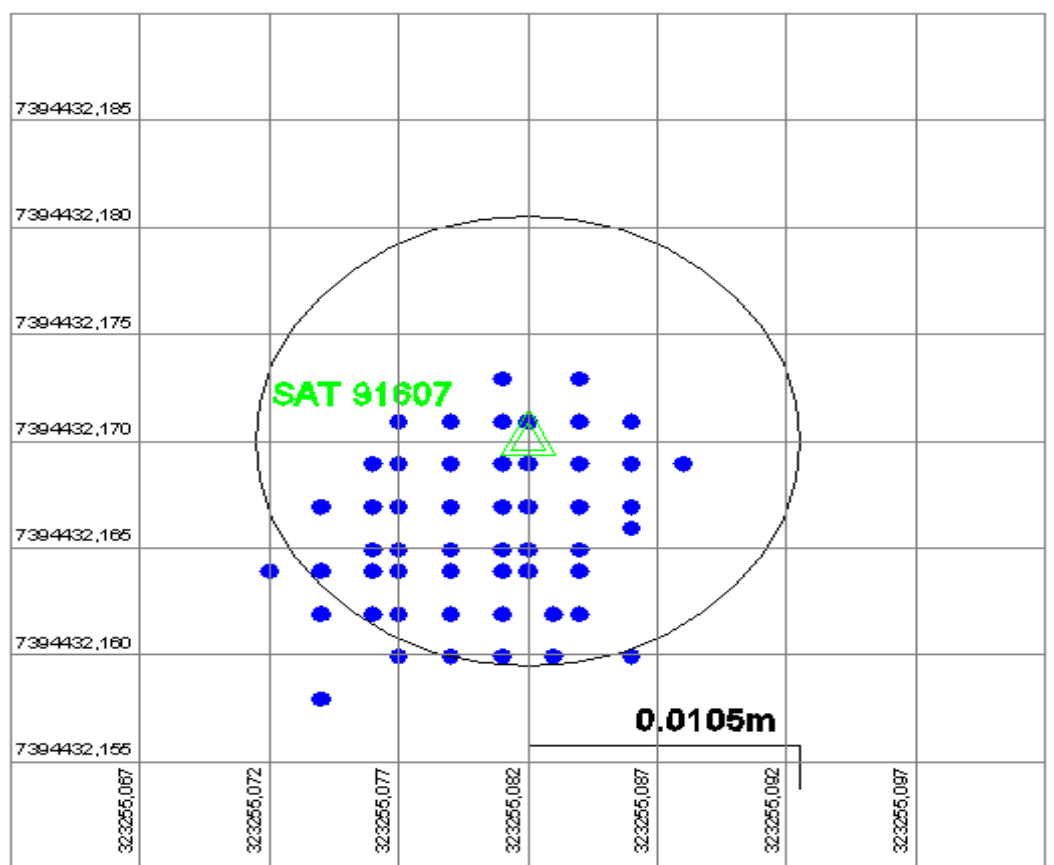

Figura 50 - Dispersão dos pontos ao redor do valor oficial, no exp. 1.

As figuras 51, 53 e 55 apresentam os gráficos das incidências relativamente às coordenadas $\mathrm{E}, \mathrm{N}$ e $\mathrm{h}$ na amostra e as figuras 52,54 e 56 os histogramas das discrepâncias em cada eixo com relação à coordenada oficial.

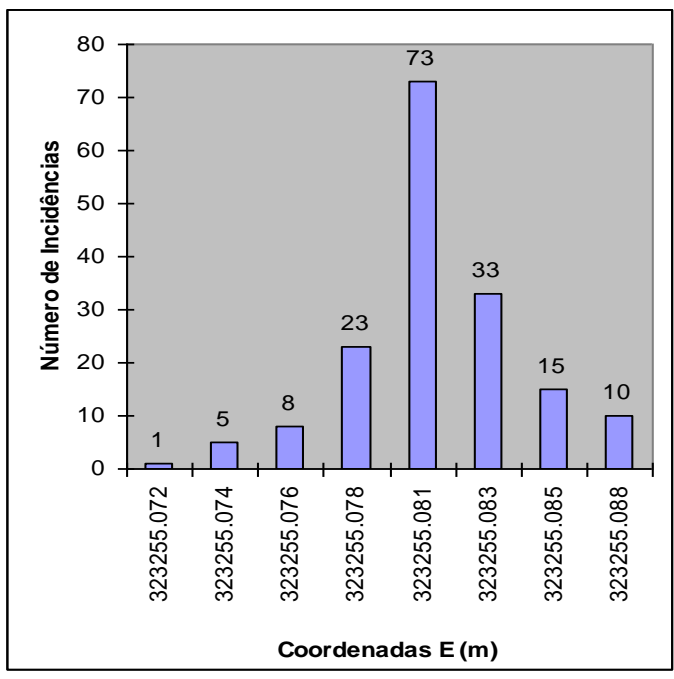

Figura 51 - Incidência da coordenada E, no exp. 1

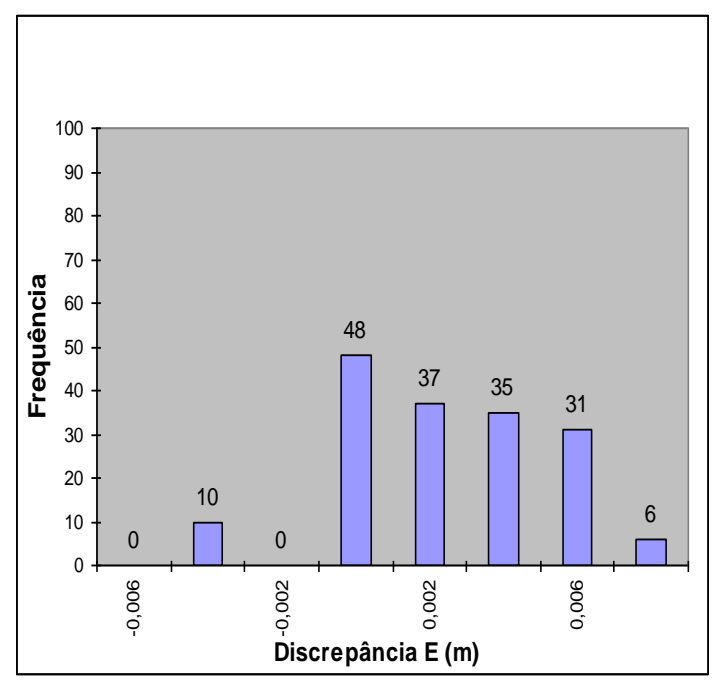

Figura 52 - Histograma Referente a E, no exp. 1. 


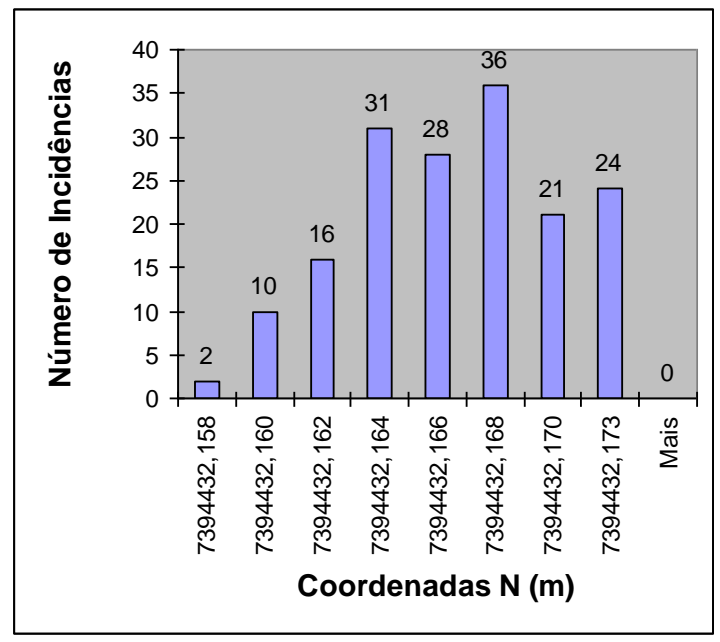

Figura 53 - Incidência da Coordenada N, no exp. 1.

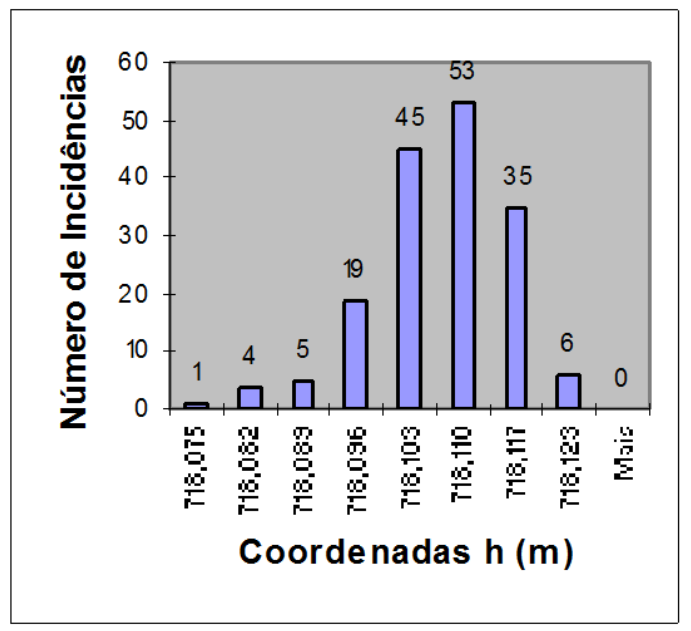

Figura 55 - Incidência da Coordenada h, no exp. 1.

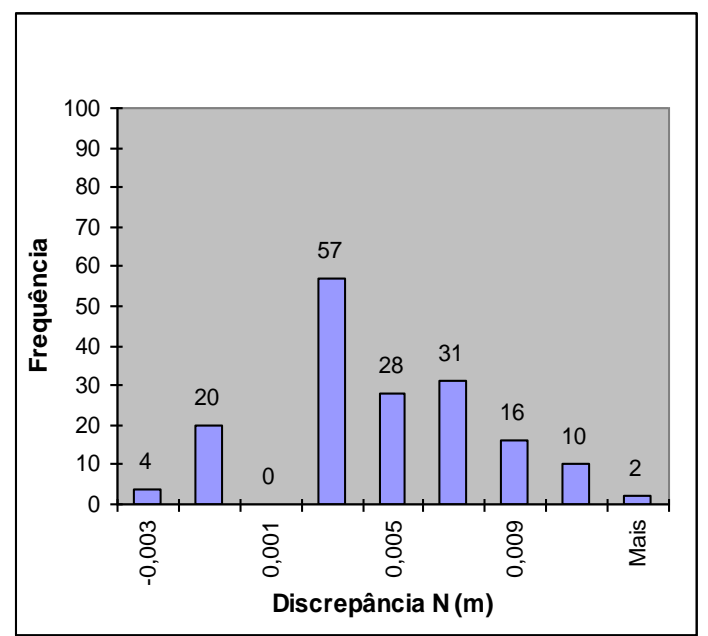

Figura 54 - Histograma Referente a $\mathrm{N}$, no exp. 1.

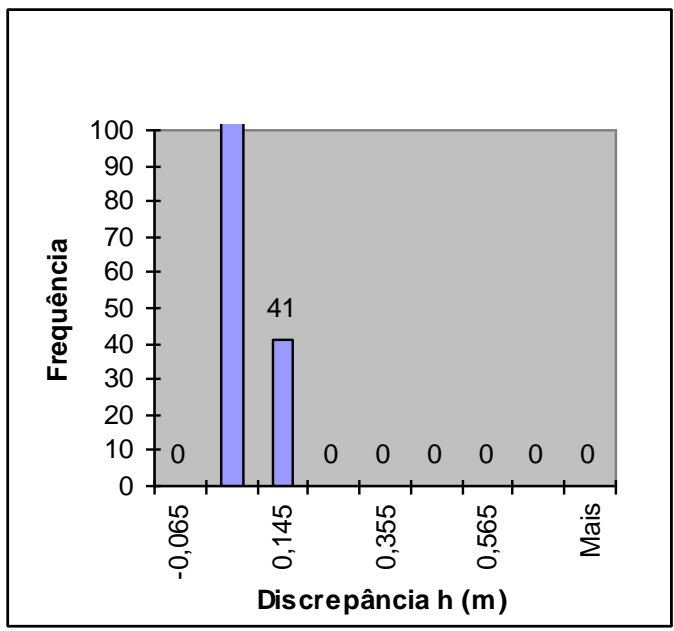

Figura 56 - Histograma Referente a $h$, no exp. 1.

\subsubsection{Experimento 2}

Este se refere ao vértice V2295 (Av. Sumaré) com distância de $5.700 \mathrm{~km}$. Foram registradas (obtidas) 64 coordenadas com uma solução fixa, as quais tiveram um tempo de inicialização de 1,4 segundos, uma latência de 1,5 segundos, rastreando-se nove satélites com um PDOP 3,4, em média, realizado no dia 28 de dezembro de 2008. Em termos de visibilidade dos satélites este ponto tem uma localização não muito favorável, pois está numa área urbana e com edificações à 
sua volta, conforme a figura 39, mas com condição meteorológica era boa no dia do levantamento.

$\mathrm{Na}$ análise da discrepância, consideraram-se as coordenadas médias obtidas e as diferenças resultantes da comparação às coordenadas oficiais. Os valores para o caso foram os seguintes:

$$
\begin{aligned}
& \mathrm{E}=328897,841 \mathrm{~m} ; \quad \Delta \mathrm{E}=|-0.014 \mathrm{~m}|<0,016 \mathrm{~m}(\text { ver tabela 12) } \\
& \mathrm{N}=7395519,001 \mathrm{~m} ; \quad \Delta \mathrm{N}=|-0.015 \mathrm{~m}|<0,016 \mathrm{~m} \text { (ver tabela 12) } \\
& \mathrm{h}=\quad 750,397 \mathrm{~m} ; \quad \Delta \mathrm{h}=|-0,041 \mathrm{~m}|>0,026 \mathrm{~m}(\text { ver tabela 12) }
\end{aligned}
$$

Depois de comparar cada coordenada com o valor esperado, conforme a Tabela 12, conclui-se que a amostra atende à precisão planimétrica em $92 \%$ e à precisão altimétrica em $54 \%$.

Na figura 57 pode ser vista a dispersão dos resultados das coordenadas UTM mensuradas no referido ponto considerando nas direções ( $E$ e $N)$.

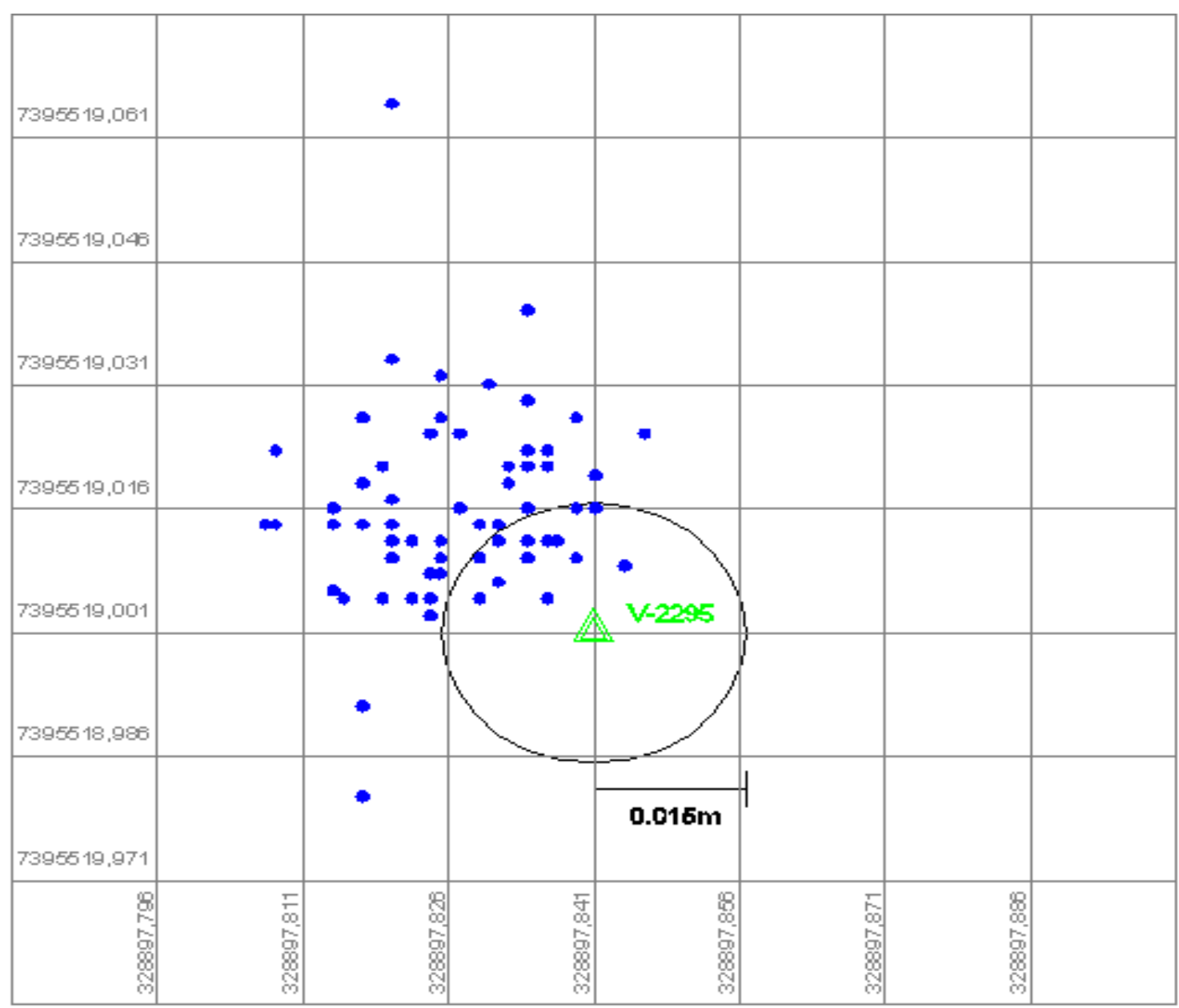

Figura 57 - Dispersão dos pontos ao redor do valor oficial, no exp. 2. 
As figuras 58, 60 e 62 apresentam os gráficos das incidências relativamente às coordenadas $\mathrm{E}, \mathrm{N}$ e h na amostra e as figuras 59, 61 e 63 o histograma das discrepâncias em cada eixo com relação às coordenadas $\mathrm{E}, \mathrm{N}$ e h oficiais.

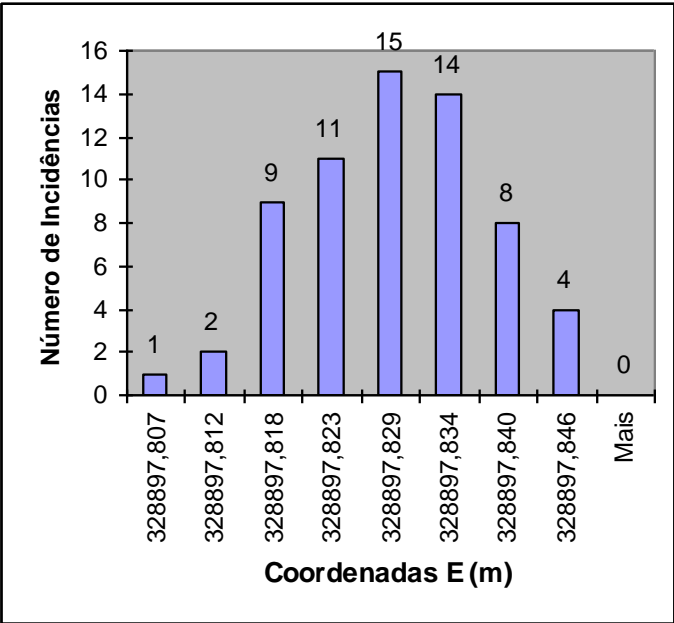

Figura 58 - Incidência da Coordenada E, no exp. 2.

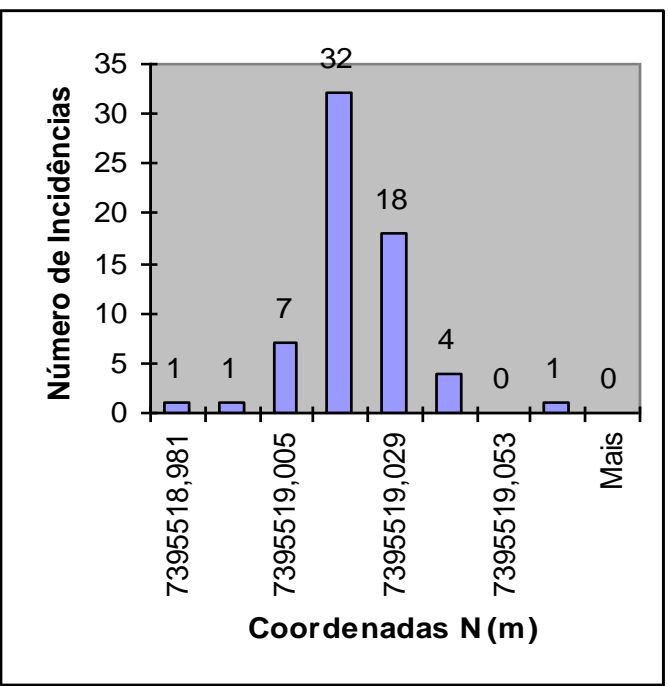

Figura 60 - Incidência da Coordenada N, no exp. 2.

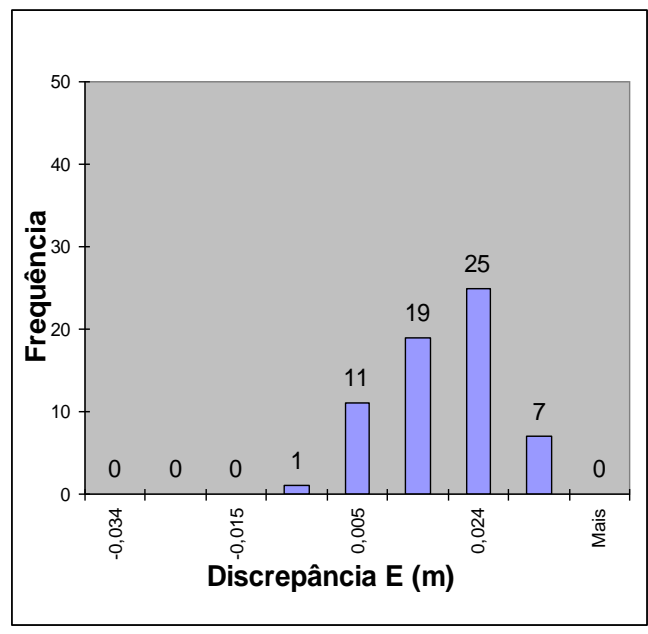

Figura 59 - Histograma referente a E, no exp. 2.

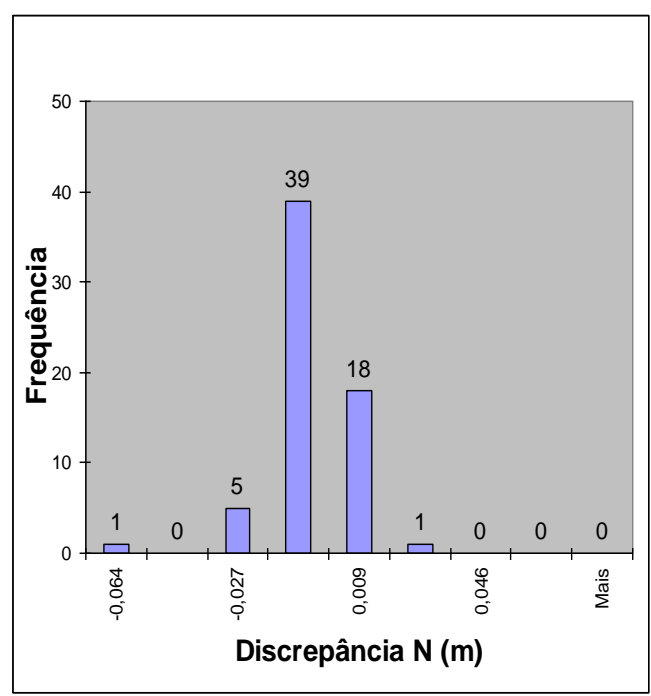

Figura 61 - Histograma referente a N, no exp. 2. 


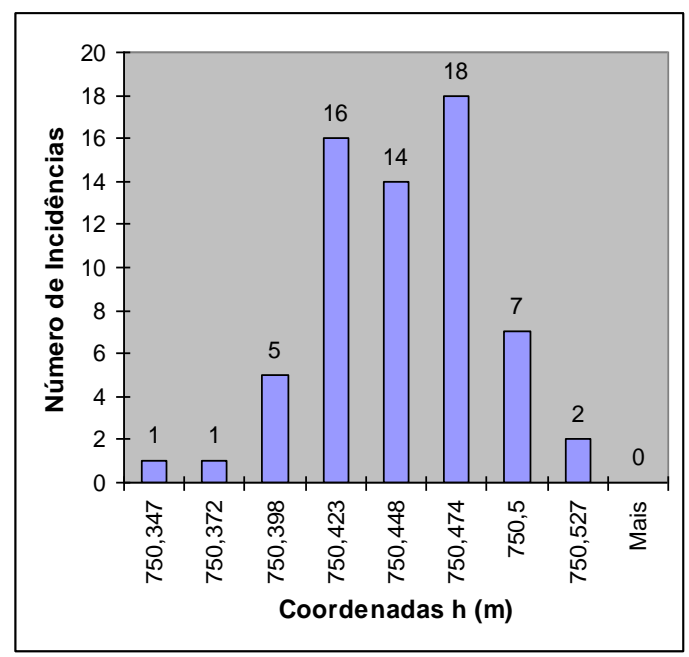

Figura 62 - Incidência da Coordenada h, no exp. 2.

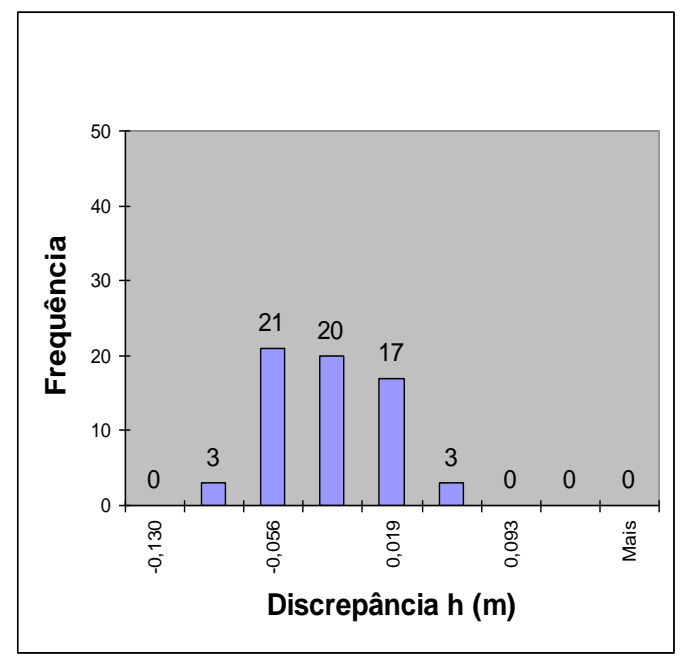

Figura 63 - Histograma referente a h, no exp. 2.

\subsubsection{Experimento 3}

Este se refere ao vértice V2296 (Anhangabaú), com uma distância de 9,468 $\mathrm{km}$. Foram registradas (obtidas) 108 coordenadas, com solução fixa, as quais tiveram um tempo de inicialização de 1,8 segundos, uma latência de 1,5 segundos, rastreando-se sete satélites com PDOP 4,7, em média, realizado no dia 22 de dezembro de 2008. Em termos de visibilidade dos satélites, esse ponto tem uma péssima localização por estar cercado por prédios, conforme Figura 40, e, no dia do levantamento, a condição meteorológica era ruim.

Em uma primeira análise da discrepância, foram consideradas as coordenadas médias obtidas $e$ as diferenças resultantes da comparação às coordenadas oficiais. Os valores para o caso foram os seguintes:

$$
\begin{array}{ll}
\mathrm{E}=332793,626 \mathrm{~m} ; & \Delta \mathrm{E}=|-0,003 \mathrm{~m}|<0.020 \mathrm{~m}(\text { ver tabela 12) } \\
\mathrm{N}=7394977,027 \mathrm{~m} ; & \Delta \mathrm{N}=|-0,005 \mathrm{~m}|<0.020 \mathrm{~m}(\text { ver tabela 12) } \\
\mathrm{h}=735,011 \mathrm{~m} ; & \Delta \mathrm{h}=|-0,006 \mathrm{~m}|>0.030 \mathrm{~m}(\text { ver tabela 12) }
\end{array}
$$


Após verificar cada coordenada obtida com o valor esperado, conforme a Tabela 12, conclui-se que a amostra atende à planimetria em $69 \%$ e a altimetria em $36 \%$.

$\mathrm{Na}$ figura 64, pode ser vista a dispersão dos resultados das coordenadas UTM mensuradas no referido ponto considerando nas direções ( $E$ e N).

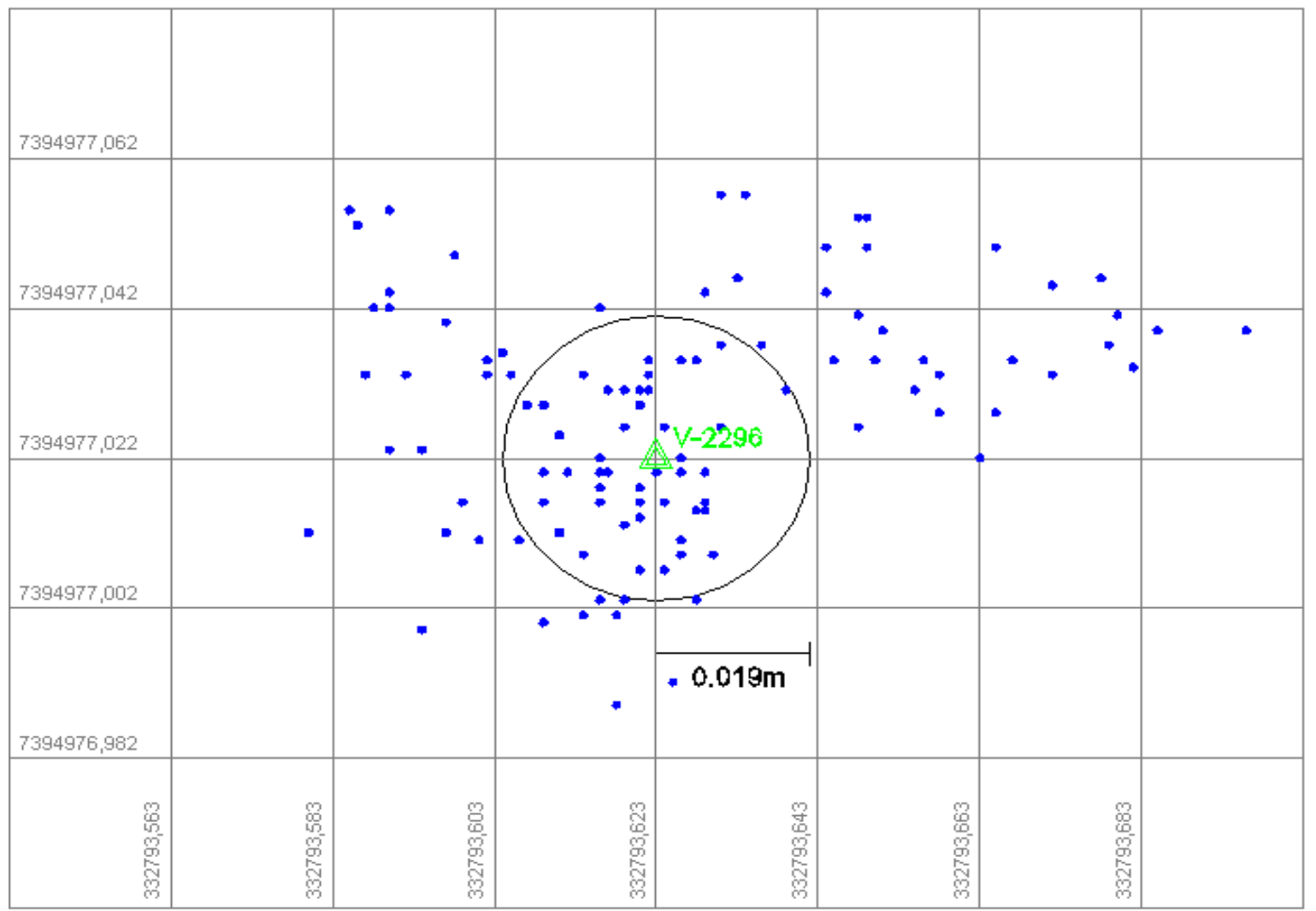

Figura 64 - Dispersão dos pontos ao redor do valor médio, exp. 3.

As Figuras 65, 67 e 69 apresentam os gráficos das incidências relativamente às coordenadas $\mathrm{E}, \mathrm{N}$ e h na amostra e as figuras 66, 68 e 70 o histograma das discrepâncias em cada eixo com relação às coordenadas $\mathrm{E}, \mathrm{N}$ e $\mathrm{h}$ oficiais. 


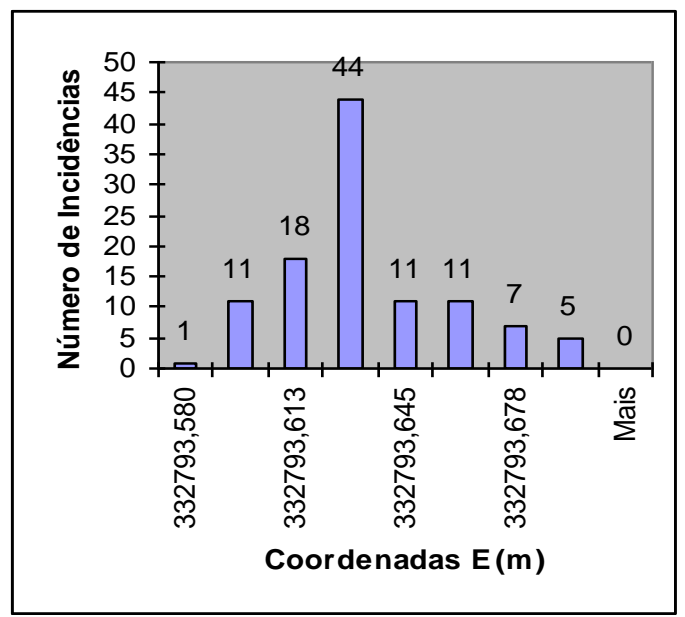

Figura 65 - Incidência da Coordenada E, no exp. 3.

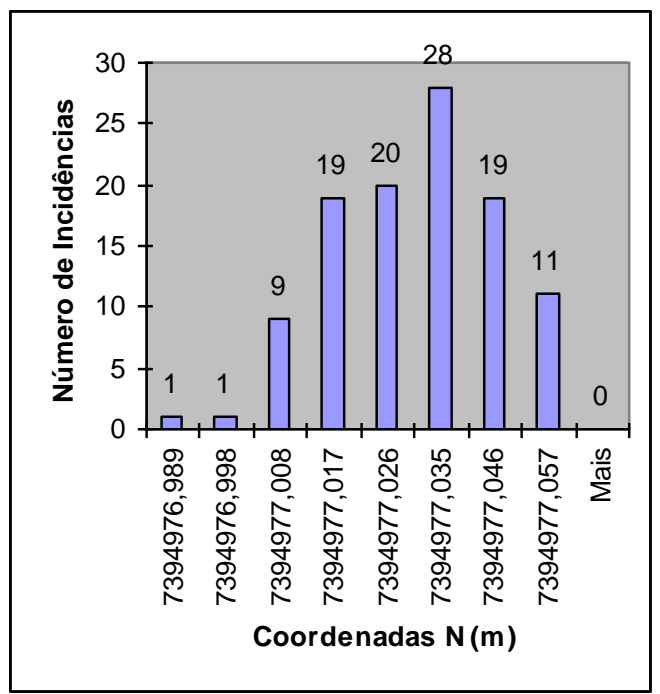

Figura 67 - Incidência da Coordenada N, no exp. 3.

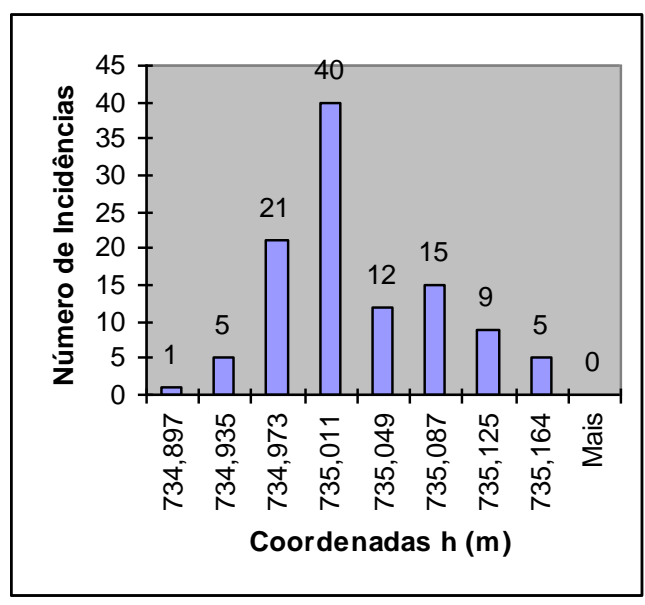

Figura 69 - Incidência da Coordenada h, no exp. 3.

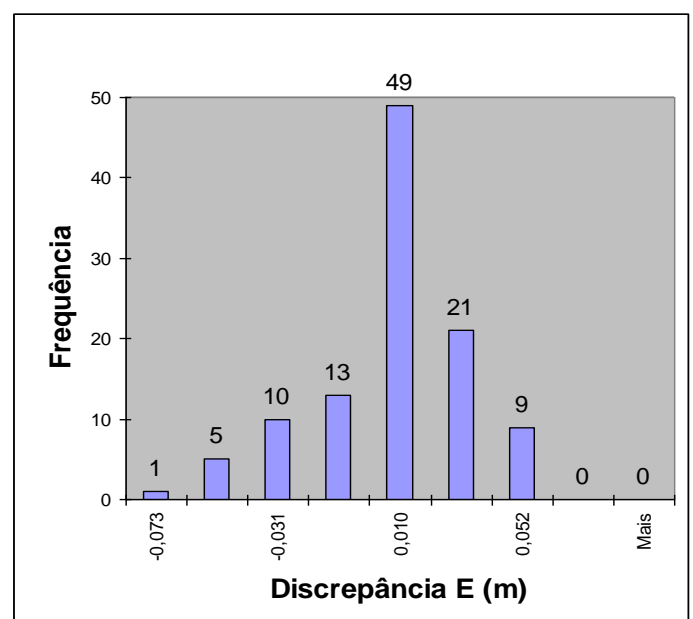

Figura 66 - Histograma referente a E, o exp. 3.

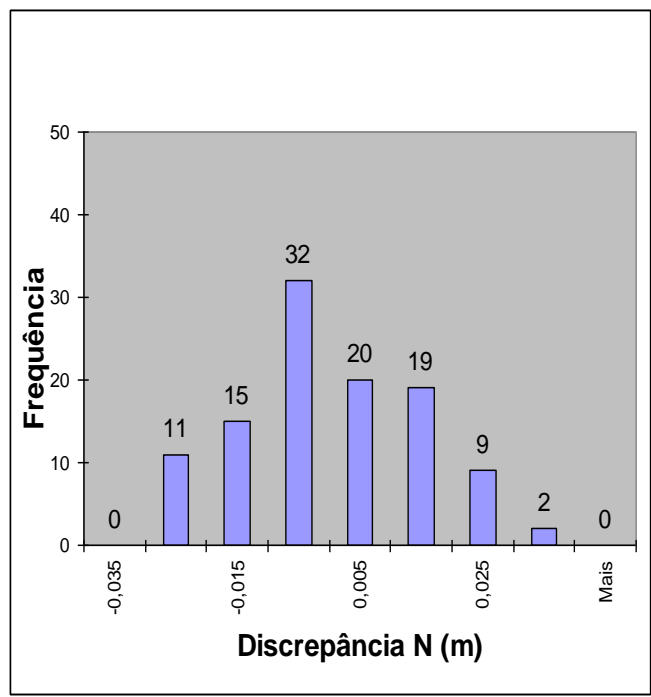

Figura 68 - Histograma referente a N, no exp. 3.

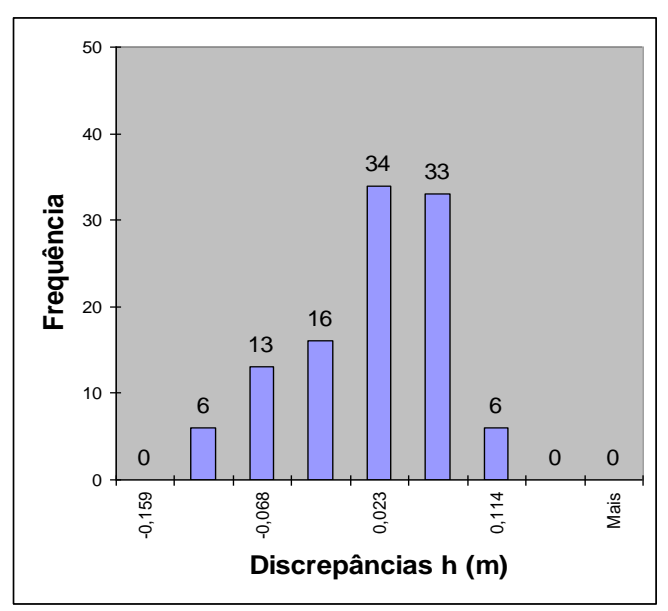

Figura 70 - Histograma referente a h, o exp. 3. 


\subsubsection{Experimento 4}

Este se refere ao vértice V2009 (Perus) com uma distância de 17,129 km. Foram registradas (obtidas) 202 coordenadas com a solução fixa, as quais tiveram um tempo de inicialização de 1,3 segundos, uma latência de 1,6 segundos, rastreando-se 11 satélites com um PDOP 2,2, em média, realizado no dia 23 de dezembro de 2008. Em termos visibilidade dos satélites, esse ponto tem uma localização ruim por estar ao lado de um prédio, de acordo com a Figura 41, e, no dia do levantamento, a condição meteorológica era boa.

$\mathrm{Na}$ análise de discrepância seguinte, foi considerada a diferença entre a coordenada média obtida com a coordenada oficial. Os valores para o caso foram os seguintes:

$$
\begin{array}{ll}
\mathrm{E}=321919,919 \mathrm{~m} ; & \Delta \mathrm{E}=|0,015 \mathrm{~m}|<0.027 \mathrm{~m}(\text { ver tabela 12) } \\
\mathrm{N}=7410979,531 \mathrm{~m} ; & \Delta \mathrm{N}=|-0,011 \mathrm{~m}|<0.027 \mathrm{~m}(\text { ver tabela 12) } \\
\mathrm{h}=833,128 \mathrm{~m} ; & \Delta \mathrm{h}=|-0,065 \mathrm{~m}|<0.037 \mathrm{~m}(\text { ver tabela 12) }
\end{array}
$$

Analisando-se cada coordenada obtida com o valor esperado, conforme a Tabela 12, tem-se que a amostra atende à planimetria em $91 \%$ e à altimetria em $70 \%$.

Na figura 71 a seguir, vê-se a dispersão dos resultados das coordenadas UTM mensuradas no referido ponto, considerando-se as direções (E e N). 


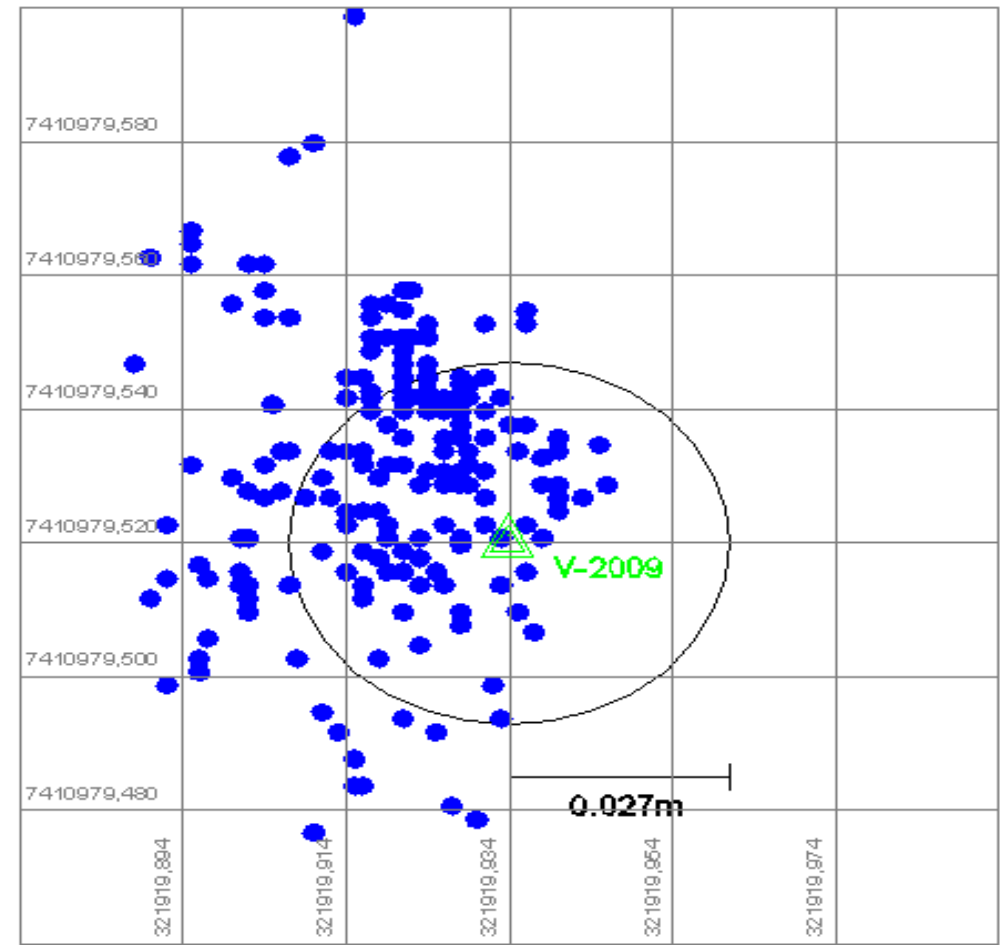

Figura 71 - Dispersão dos pontos ao redor do valor médio, exp. 4.

As figuras 72, 74 e 76 apresentam os gráficos das incidências relativamente às coordenadas $\mathrm{E}, \mathrm{N}$ e $\mathrm{h}$ na amostra e as figuras 73, 75 e 77 o histograma das discrepâncias em cada eixo com relação às coordenadas $\mathrm{E}, \mathrm{N}$ e h oficiais.

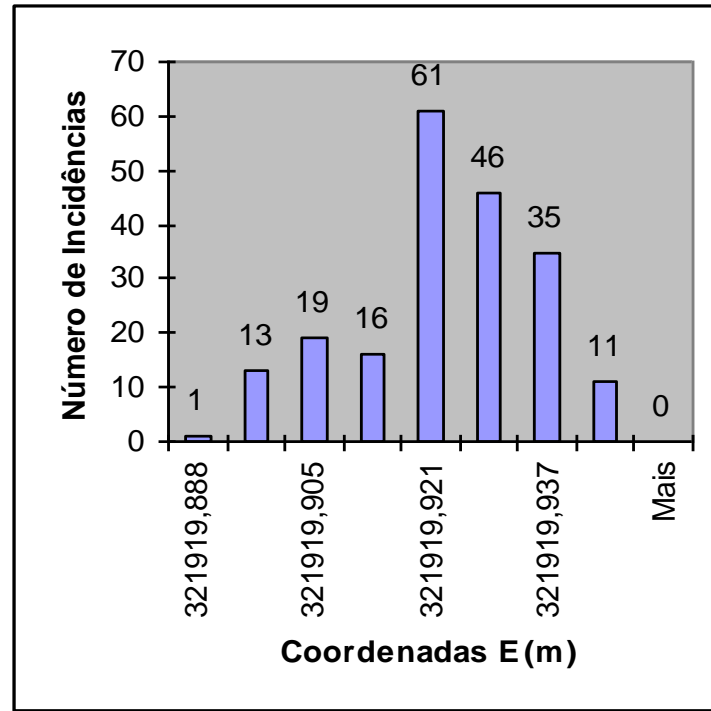

Figura 72 - Incidência da Coordenada E, no exp. 4.

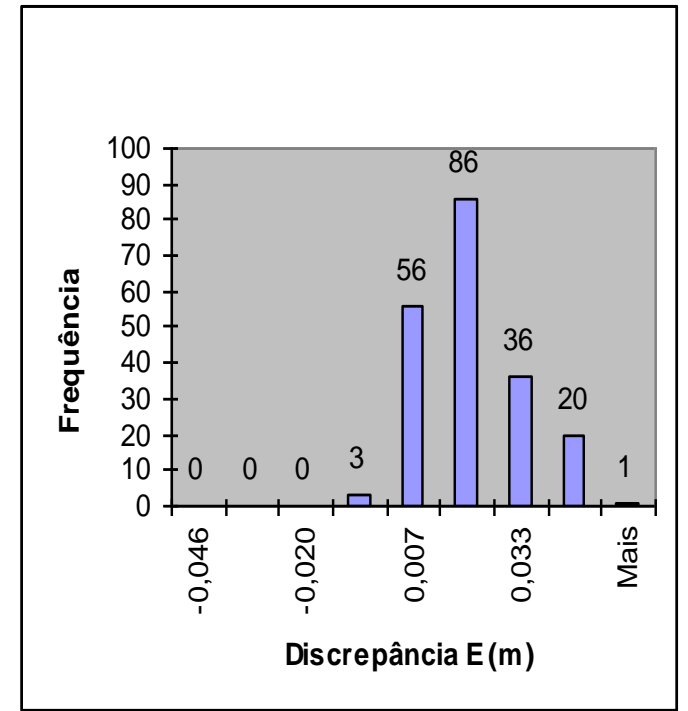

Figura 73- Histograma referente a E, no exp. 4. 


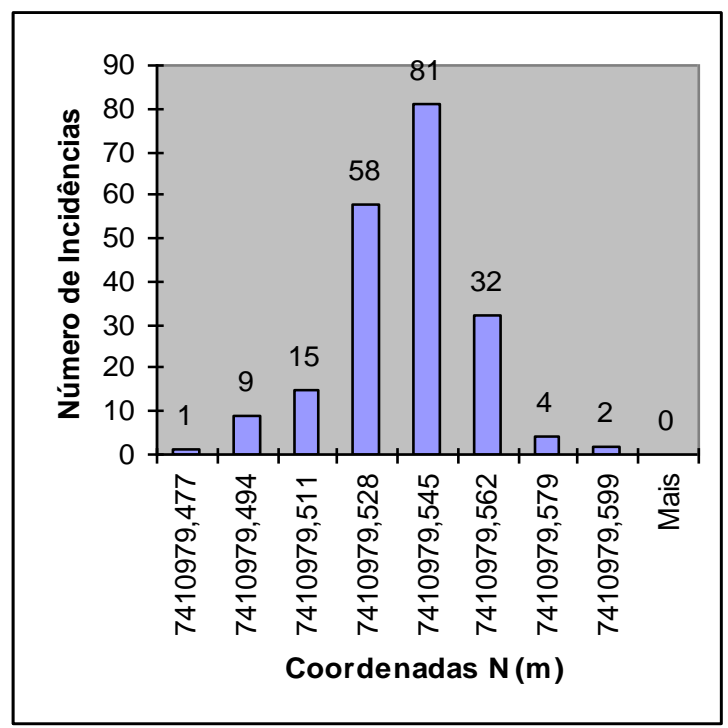

Figura 74 - Incidência da Coordenada N, no exp. 4.

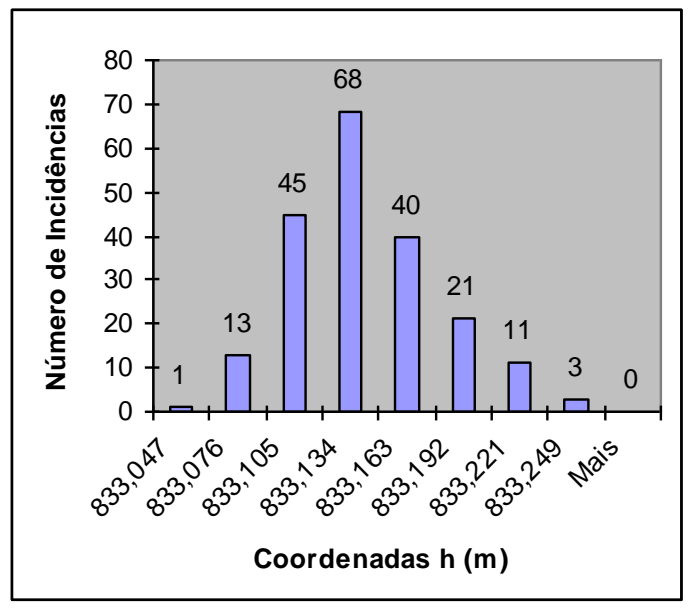

Figura 76 - Incidência da Coordenada h, no exp. 4.

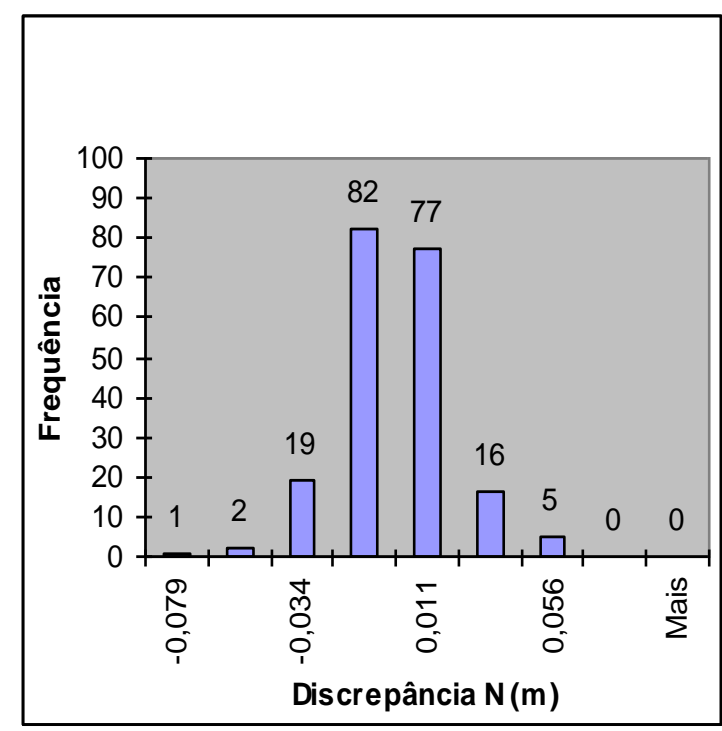

Figura 75 - Histograma referente a N, no exp. 4.

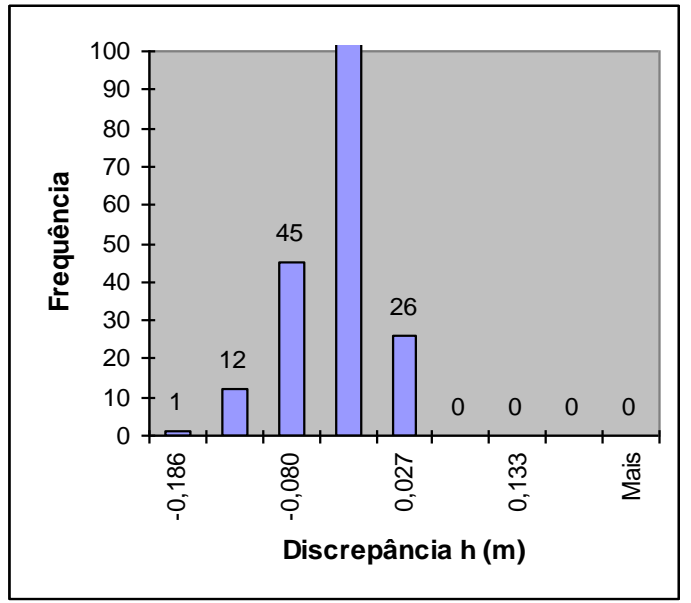

Figura 77 - Histograma referente a h, no exp. 4.

\subsubsection{Experimento 5}

Este se refere ao vértice V2837 (Parelheiros), com uma distância de 30,40 km. Foram registradas (obtidas) 200 coordenadas com solução fixa, as quais tiveram um tempo de inicialização de 1,5 segundos, latência de 1,6 segundos, rastreando-se 9 satélites com um PDOP 2,7, em média, realizado no dia 29 de dezembro de 2008. Em termos de visibilidade dos satélites, esse ponto tem uma localização com 
condições mediamente favoráveis, como pode ser visto na figura 42 , estando a condição meteorológica era boa no dia do levantamento.

Abaixo segue a análise da discrepância, considerando-se a diferença entre a coordenada média obtida e a coordenada oficial. Os valores para o caso foram os seguintes:

$$
\begin{array}{llrl}
\mathrm{E} & =324457,830 \mathrm{~m} ; & \Delta \mathrm{E}=|-0,004 \mathrm{~m}|<0,040 \mathrm{~m}(\text { ver tabela 12) } \\
\mathrm{N}=7363504,052 \mathrm{~m} ; & \Delta \mathrm{N}=|-0,010 \mathrm{~m}|<0,040 \mathrm{~m}(\text { ver tabela 12) } \\
\mathrm{h}= & 777,395 \mathrm{~m} ; & \Delta \mathrm{h}=|0,003 \mathrm{~m}|<0,050 \mathrm{~m}(\text { ver tabela 12) }
\end{array}
$$

Verificando-se as coordenadas obtidas com os valores esperados, conforme a Tabela 12, conclui-se que a amostra atende à planimetria em $84 \%$ e à altimetria em $72 \%$.

$\mathrm{Na}$ Figura 78, vê-se a dispersão dos resultados das coordenadas UTM mensuradas no referido ponto considerando-se as direções (E e N).

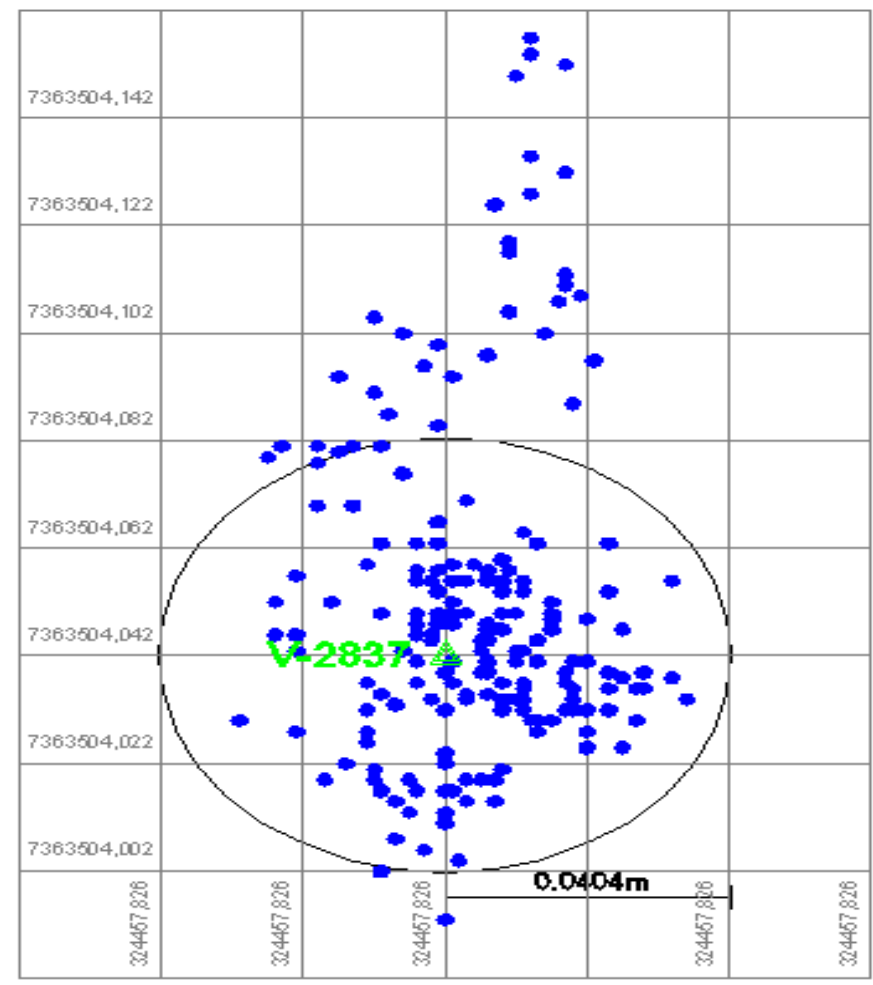

Figura 78 - Dispersão dos pontos ao redor do valor oficial, exp. 5. 
As figuras 79, 81 e 83 apresentam os gráficos das incidências relativamente às coordenadas $\mathrm{E}, \mathrm{N}$ e h na amostra e as figuras 80,82 e 840 histograma das discrepâncias em cada eixo com relação às coordenadas $\mathrm{E}, \mathrm{N}$ e h oficiais.

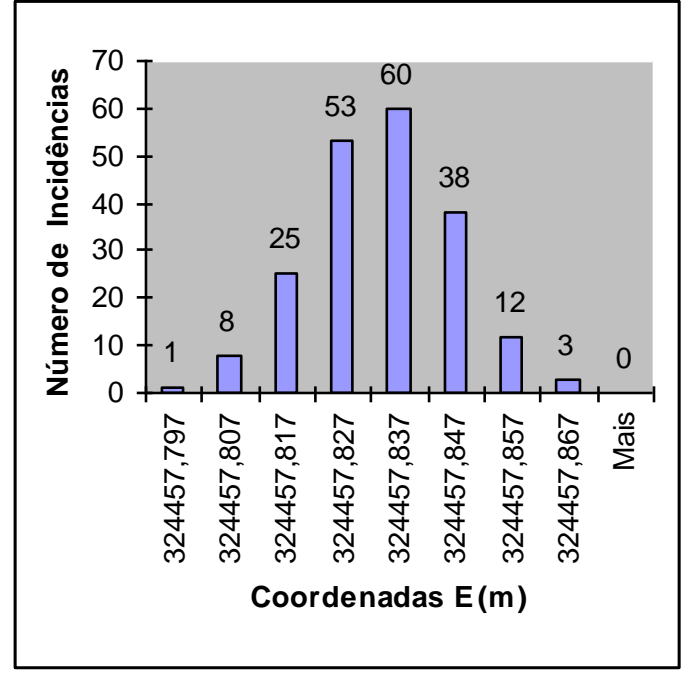

Figura 79 - Incidência da Coordenada E, no exp. 5.

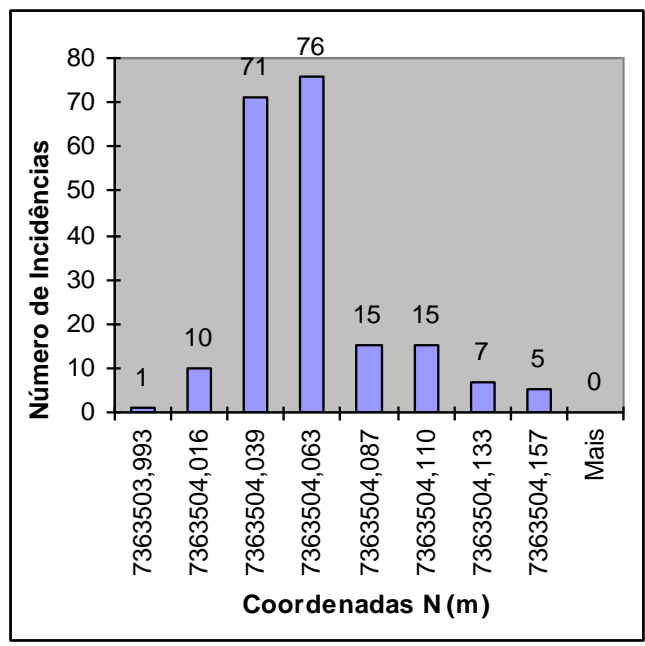

Figura 81 - Incidência da Coordenada N, no exp. 5.

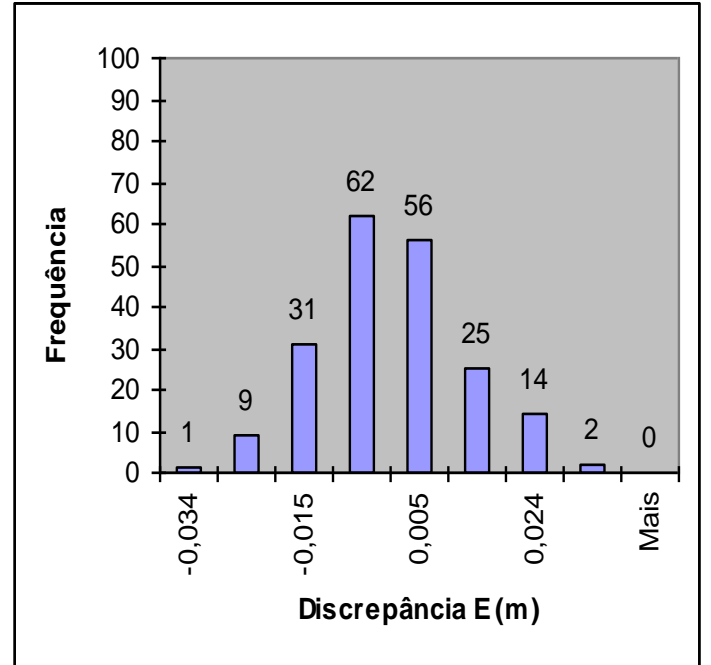

Figura 80 - Histograma referente a E, no exp. 5.

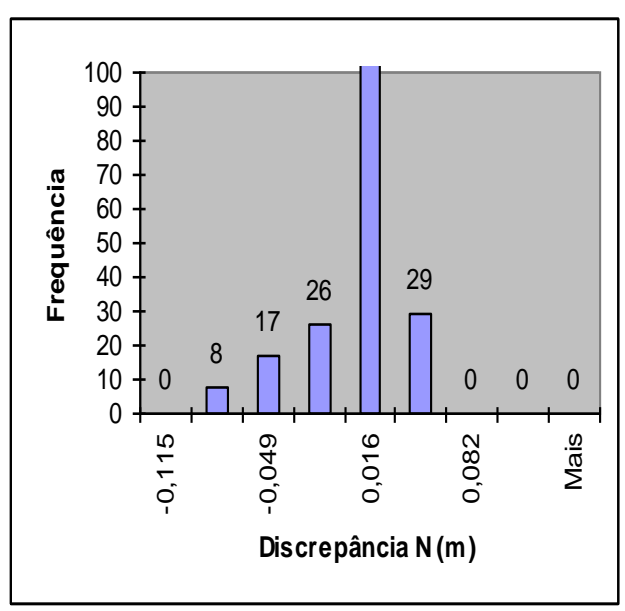

Figura 82 - Histograma referente a N, no exp. 5. 


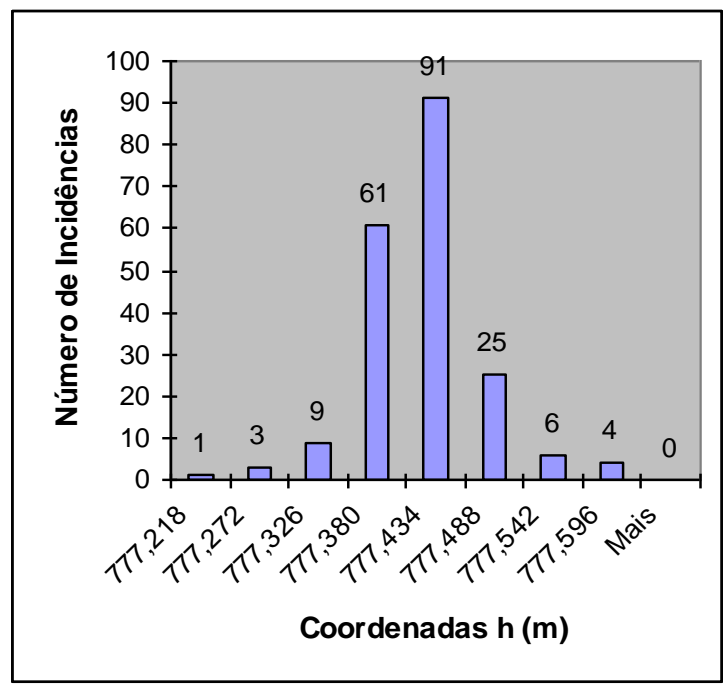

Figura 83- Incidência da Coordenada h, no exp. 5.

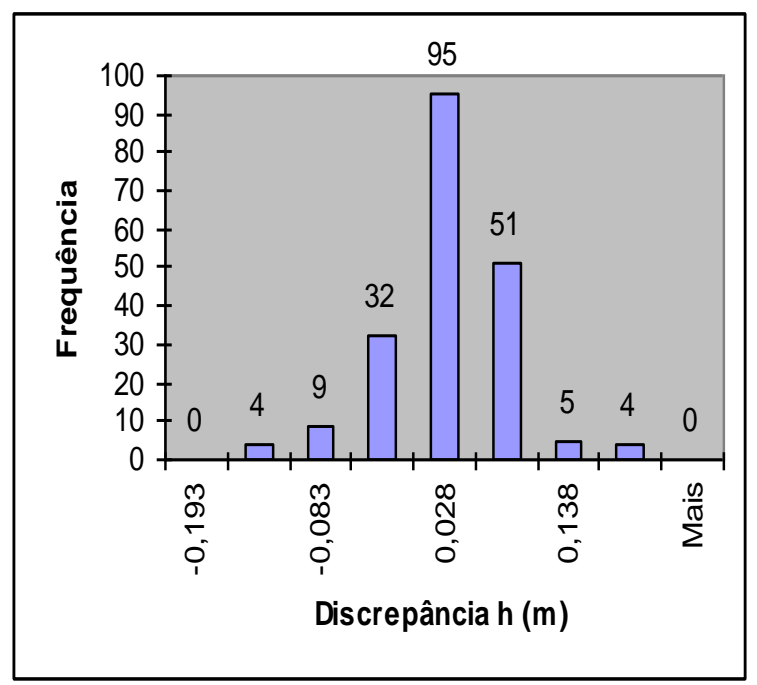

Figura 84 - Histograma referente a h, no exp. 5.

\subsubsection{Experimento 6}

Este se refere ao vértice V2510 (Tiradentes), com uma distância de 35,0 km. Foram registradas (obtidas) 157 coordenadas com solução fixa, as quais tiveram um tempo de inicialização de 1,2 segundos, latência de 1,6 segundos, rastreando-se 11 satélites com PDOP 1,89, em média, realizado no dia 26 de dezembro de 2008. Em termos de visibilidade dos satélites, o ponto tem uma localização com condições mediamente favoráveis, como pode ser visto na Figura 43, e a condição meterológica era boa no dia do levantamento.

Segue a análise da discrepância, na qual foi considerada a diferença entre a coordenada média obtida e a coordenada oficial. Os valores para o caso foram os seguintes:

$$
\begin{array}{ll}
\mathrm{E}=358096,272 \mathrm{~m} ; & \Delta \mathrm{E}=|0,004 \mathrm{~m}|<0.045 \mathrm{~m}(\text { ver tabela 12) } \\
\mathrm{N}=7390723,720 \mathrm{~m} ; & \Delta \mathrm{N}=|-0,014 \mathrm{~m}|<0.045 \mathrm{~m}(\text { ver tabela 12) } \\
\mathrm{h}=842,374 \mathrm{~m} ; & \Delta \mathrm{h}=|-0,019 \mathrm{~m}|>0.055 \mathrm{~m}(\text { ver tabela 12) }
\end{array}
$$

Verificando-se cada coordenada obtida com o valor esperado, conforme a Tabela 12, conclui-se que a amostra atende à planimetria em 100\% e à altimetria em $95 \%$. 
$\mathrm{Na}$ figura 85 observa-se dispersão dos resultados das coordenadas UTM mensuradas no referido ponto considerando-se as direções (E e N).

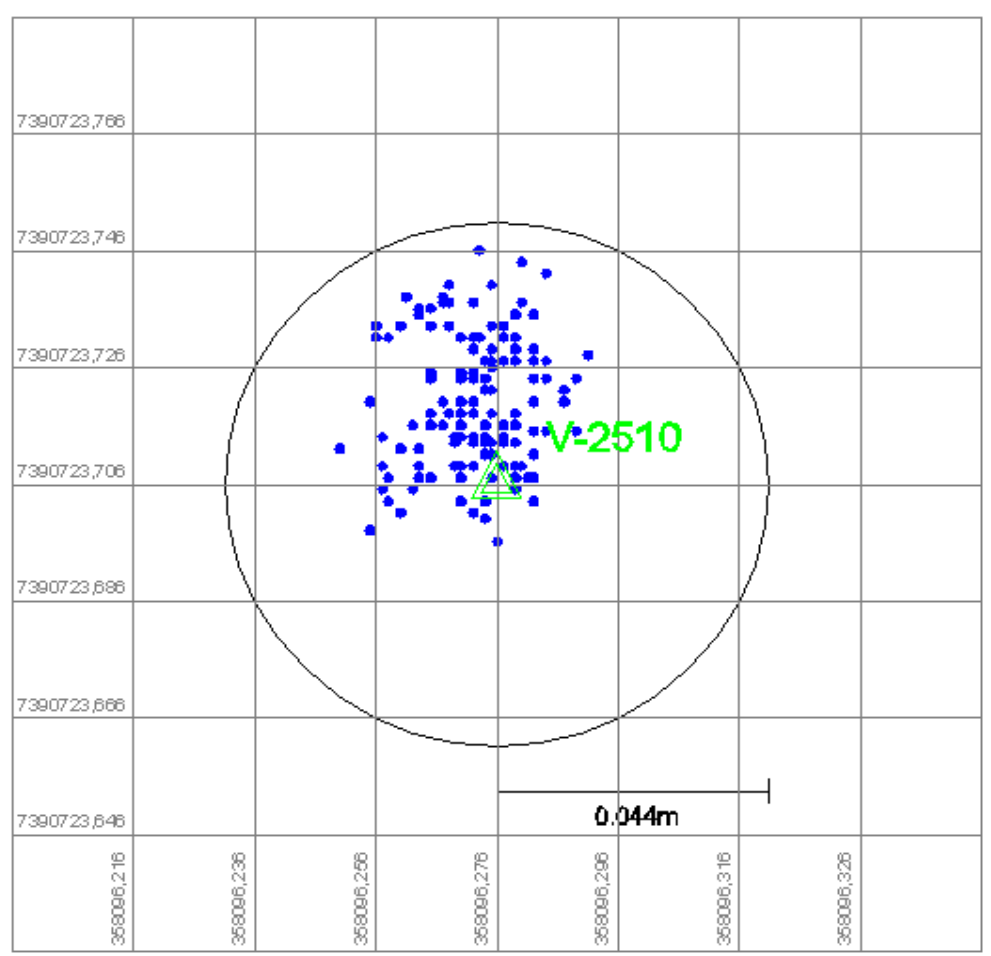

Figura 85 - Dispersão dos pontos ao redor do valor oficial, exp. 6.

As figuras 86, 88 e 90 apresentam os gráficos das incidências relativamente às coordenadas $\mathrm{E}, \mathrm{N}$ e h na amostra e as figuras 87,89 e 91 o histograma das discrepâncias em cada eixo com relação às coordenadas $\mathrm{E}, \mathrm{N}$ e $\mathrm{h}$ oficiais.

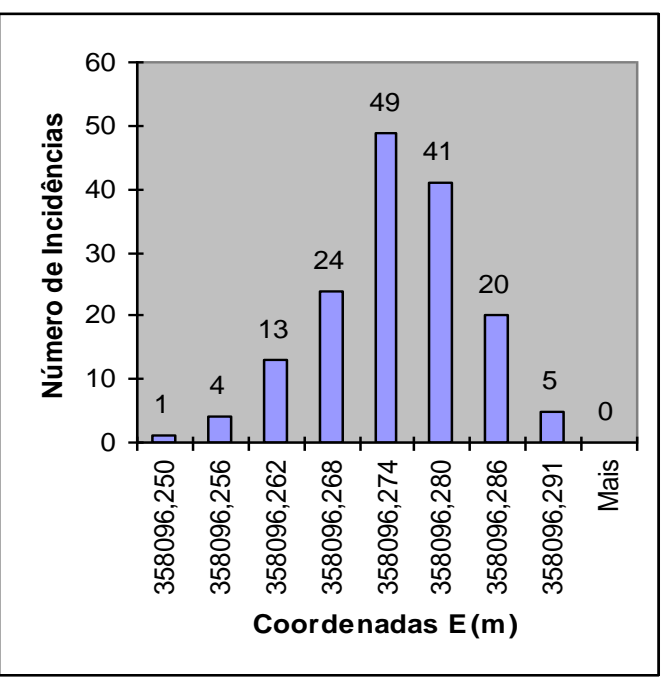

Figura 86 - Incidência da Coordenada E, no exp. 6.

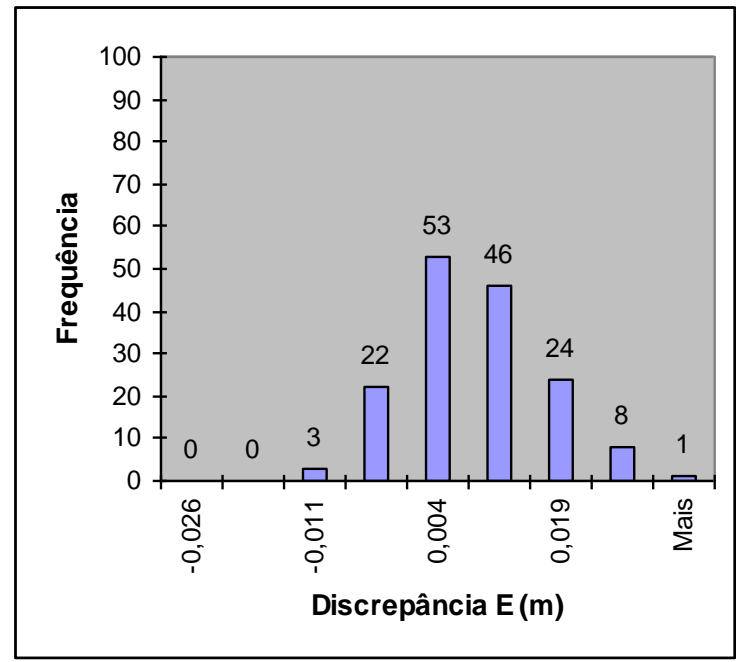

Figura 87 - Histograma referente a E, no exp. 6. 


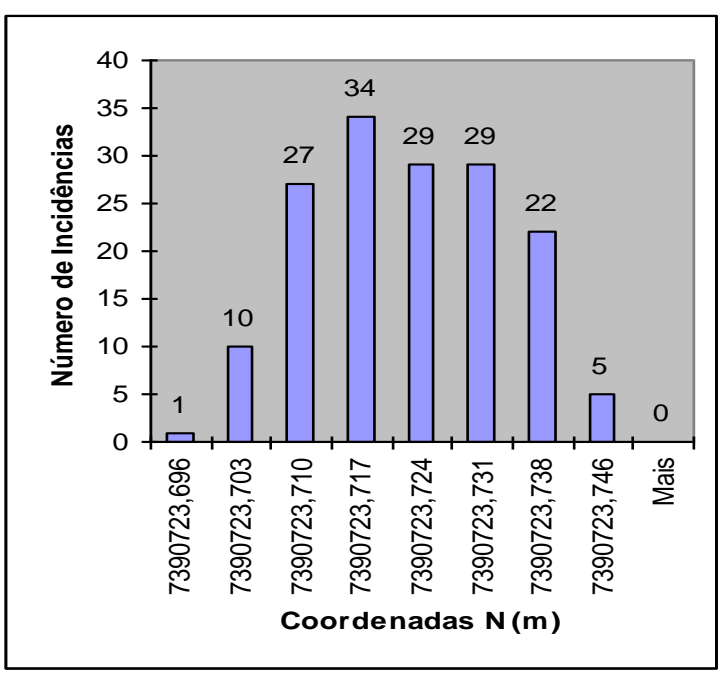

Figura 88 - Incidência da Coordenada N, no exp. 6.

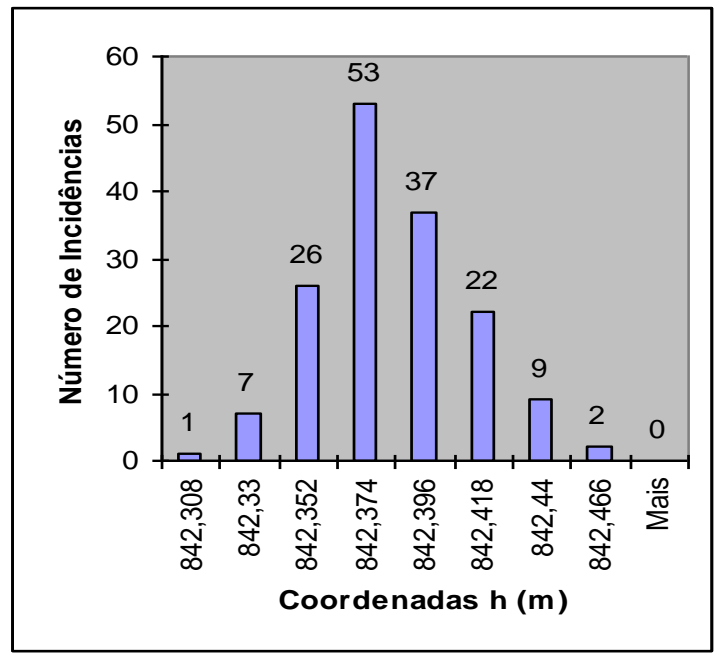

Figura 90 - Incidência da Coordenada h, no exp. 6.

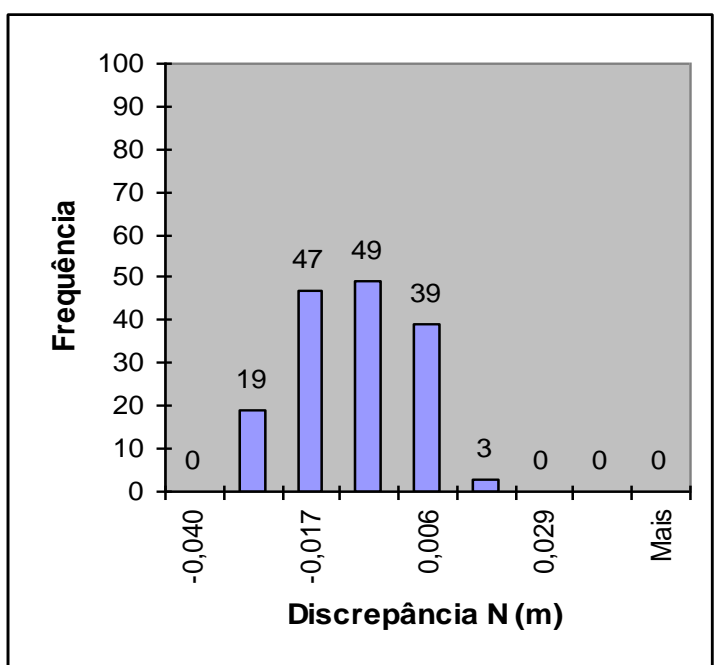

Figura 89 - Histograma referente a N, no exp. 6.

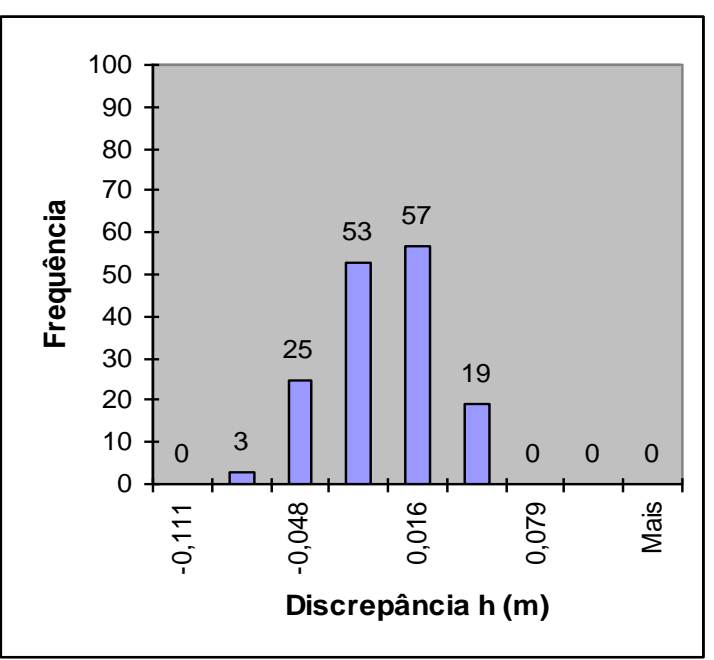

Figura 91 - Histograma referente a h, no exp. 6.

\subsubsection{Experimento 7}

Este se refere ao vértice SAT 93814 (Mogi das Cruzes) com uma distância de $54 \mathrm{~km}$. Foram registradas (obtidas) 42 coordenadas, sendo, dentre elas, $15 \mathrm{com}$ solução fixa e 27 com solução flutuante, realizado no dia 18 de novembro de 2008. Nesse experimento a análise será dividida em a e b, conforme a solução. Em termos de visibilidade dos satélites, esse ponto tinha uma localização favorável para a recepção de sinais de satélite, conforme se observa na Figura 44. No dia do 
levantamento, a condição meteorológica era ruim, por esse motivo o número total de amostra foi pequeno se comparado aos anteriores.

No teste $\mathbf{a}$, foram consideradas as 15 coordenadas fixas, as quais tiveram um tempo de inicialização de 10 segundos, uma latência de 1,9 segundos, rastreandose 12 satélites com um PDOP de 1,8, em média.

Segue a análise da discrepância, levando-se em consideração a diferença entre as coordenadas $\mathrm{E}, \mathrm{N}$ e h médias obtidas e as coordenadas $\mathrm{E}, \mathrm{N}$ e h oficiais. Os valores para esse experimento com a solução fixa foram os seguintes:

$$
\begin{array}{ll}
\mathrm{E}=376797,336 \mathrm{~m} ; & \Delta \mathrm{E}=|0,005 \mathrm{~m}|<0.064 \mathrm{~m}(\text { ver tabela 12) } \\
\mathrm{N}=7402292,751 \mathrm{~m} ; & \Delta \mathrm{N}=|0,003 \mathrm{~m}|<0.064 \mathrm{~m}(\text { ver tabela 12) } \\
\mathrm{h}=1161,069 \mathrm{~m} ; & \Delta \mathrm{h}=|-0,149 \mathrm{~m}|>0.074 \mathrm{~m}(\text { ver tabela 12) }
\end{array}
$$

Analisando-se cada coordenada obtida com o valor esperado, conforme a Tabela 12, conclui-se que a amostra atende à planimetria em $100 \%$ dos casos e à altimetria em $6,6 \%$.

$\mathrm{Na}$ figura 92, vê-se a dispersão dos resultados das coordenadas UTM mensuradas no referido ponto considerando as direções ( $\mathrm{E}$ e N). 


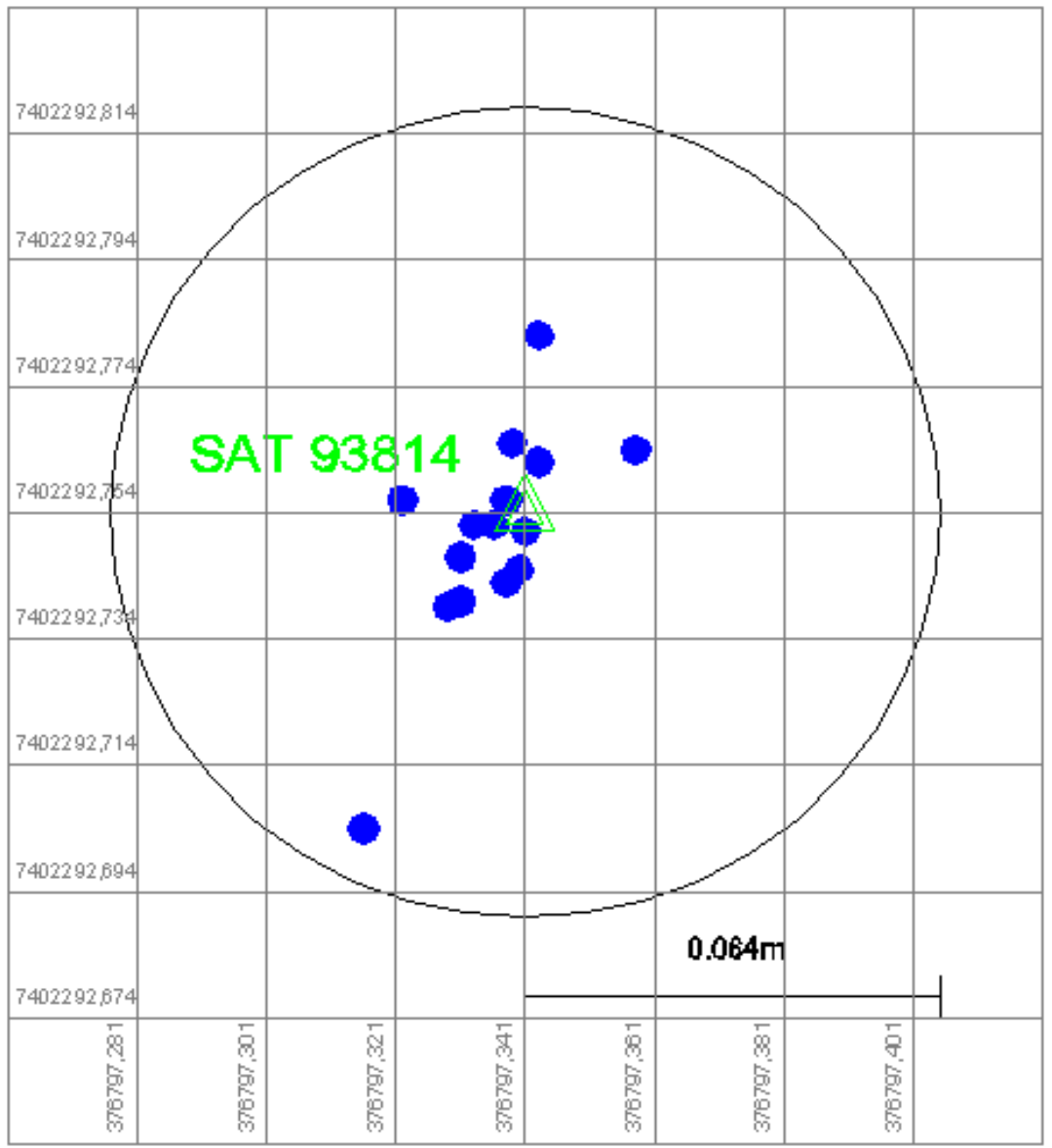

Figura 92 - Dispersão dos pontos ao redor do valor oficial, exp. 7a.

As figuras 93, 95 e 97 apresentam os gráficos das incidências relativamente às coordenadas $\mathrm{E}, \mathrm{N}$ e h na amostra e as figuras 94,96 e 98 o histograma das discrepâncias em cada eixo com relação à coordenada oficial.

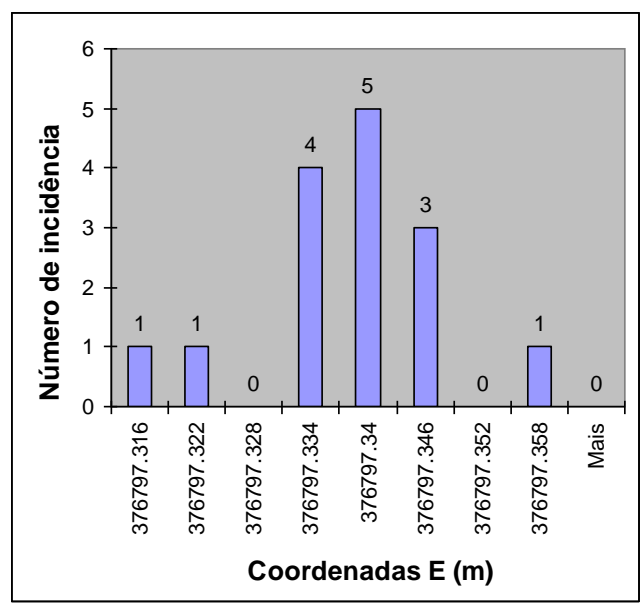

Figura 93 - Incidência da Coordenada E, no exp. 7a.

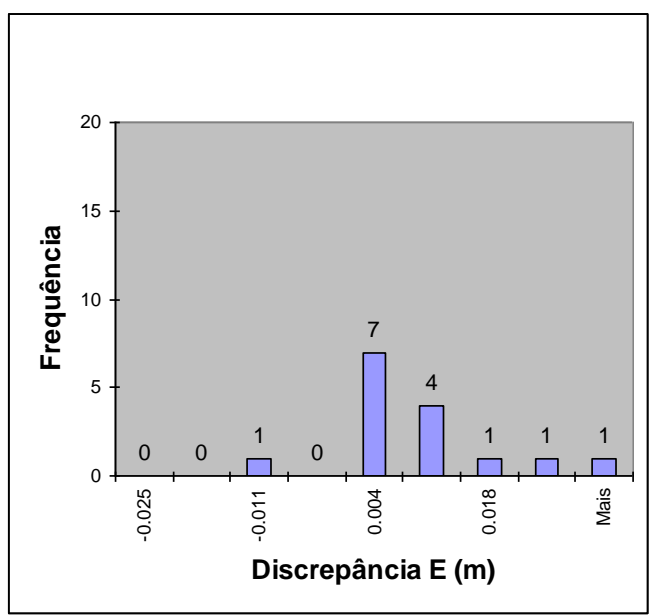

Figura 94 - Histograma referente a E, no exp. 7a. 


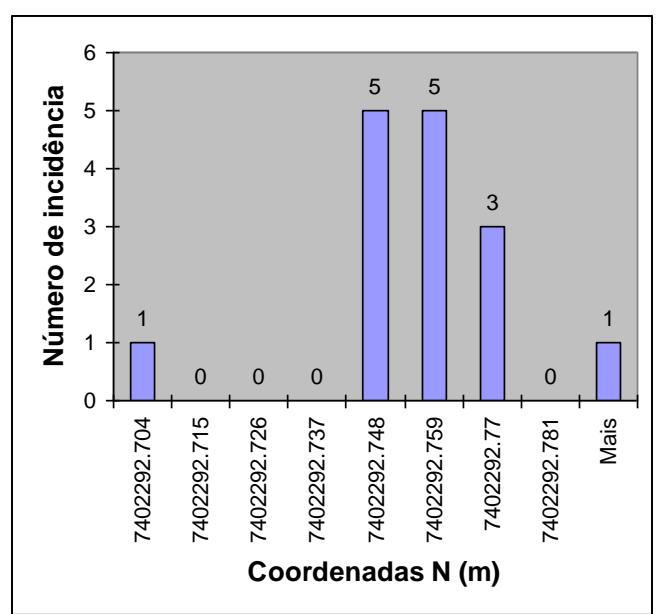

Figura 95 - Incidência da Coordenada $\mathrm{N}$, no exp. 7a.

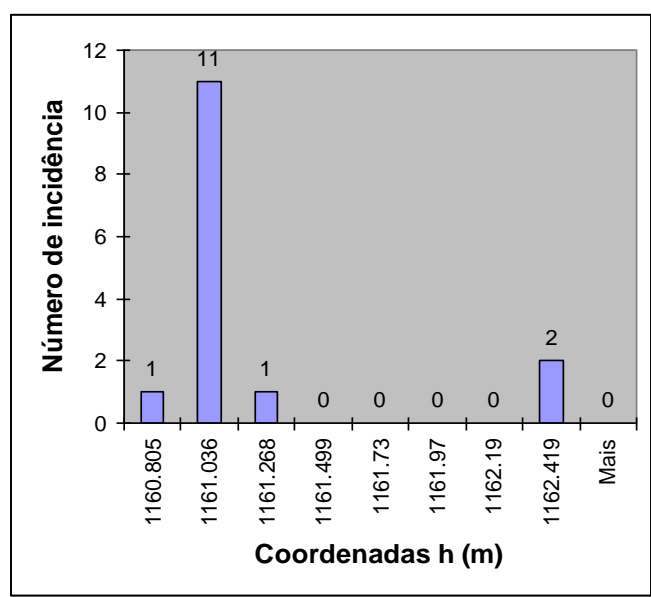

Figura 97 - Incidência de Coordenada h, no exp. $7 a$.

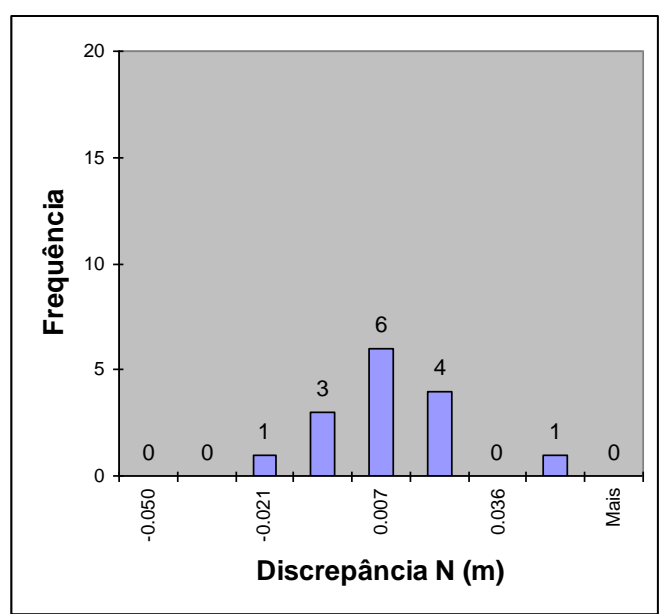

Figura 96 - Histograma referente a $\mathrm{N}$, no exp. $7 \mathrm{a}$.

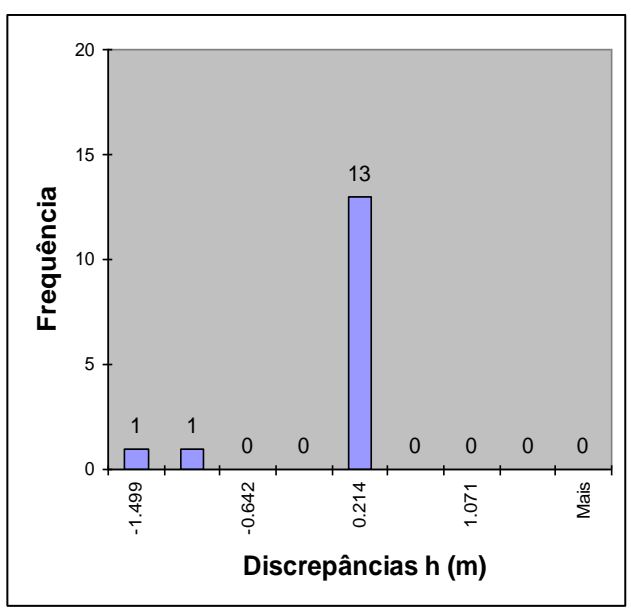

Figura 98 - Histograma referente a h, no exp. $7 a$.

No teste b, serão consideradas as 27 coordenadas flutuantes, as quais tiveram um tempo máximo de inicialização de 3 minutos, uma latência de 2 segundos, rastreando-se 14 satélites com um PDOP de 1,8, em média.

$\mathrm{Na}$ análise da discrepância seguinte, foi considerada a diferença entre a coordenada média obtida e a coordenada oficial no respectivo eixo. Os valores para o caso foram os seguintes:

$$
\begin{aligned}
& E=376797,390 \mathrm{~m} ; \\
& N=7402292,756 \mathrm{~m} ; \\
& h=1161,336 \mathrm{~m} ;
\end{aligned}
$$$$
\Delta \mathrm{E}=|-0,049 \mathrm{~m}|<0.064 \mathrm{~m}(\text { ver tabela 12) }
$$$$
\Delta \mathrm{N}=|-0,002 \mathrm{~m}|<0.064 \mathrm{~m} \text { (ver tabela 12) }
$$$$
\Delta \mathrm{h}=|-0,416 \mathrm{~m}|>0.074 \mathrm{~m}(\text { ver tabela 12) }
$$ 
Verificando-se cada coordenada com o valor esperado, conforme a Tabela 12, conclui-se que a amostra atende à planimetria em $28 \%$ e à altimetria em $14 \%$.

$\mathrm{Na}$ Figura 99, pode ser vista a dispersão dos resultados das coordenadas UTM mensuradas no referido ponto considerando-se as direções ( $E$ e N).

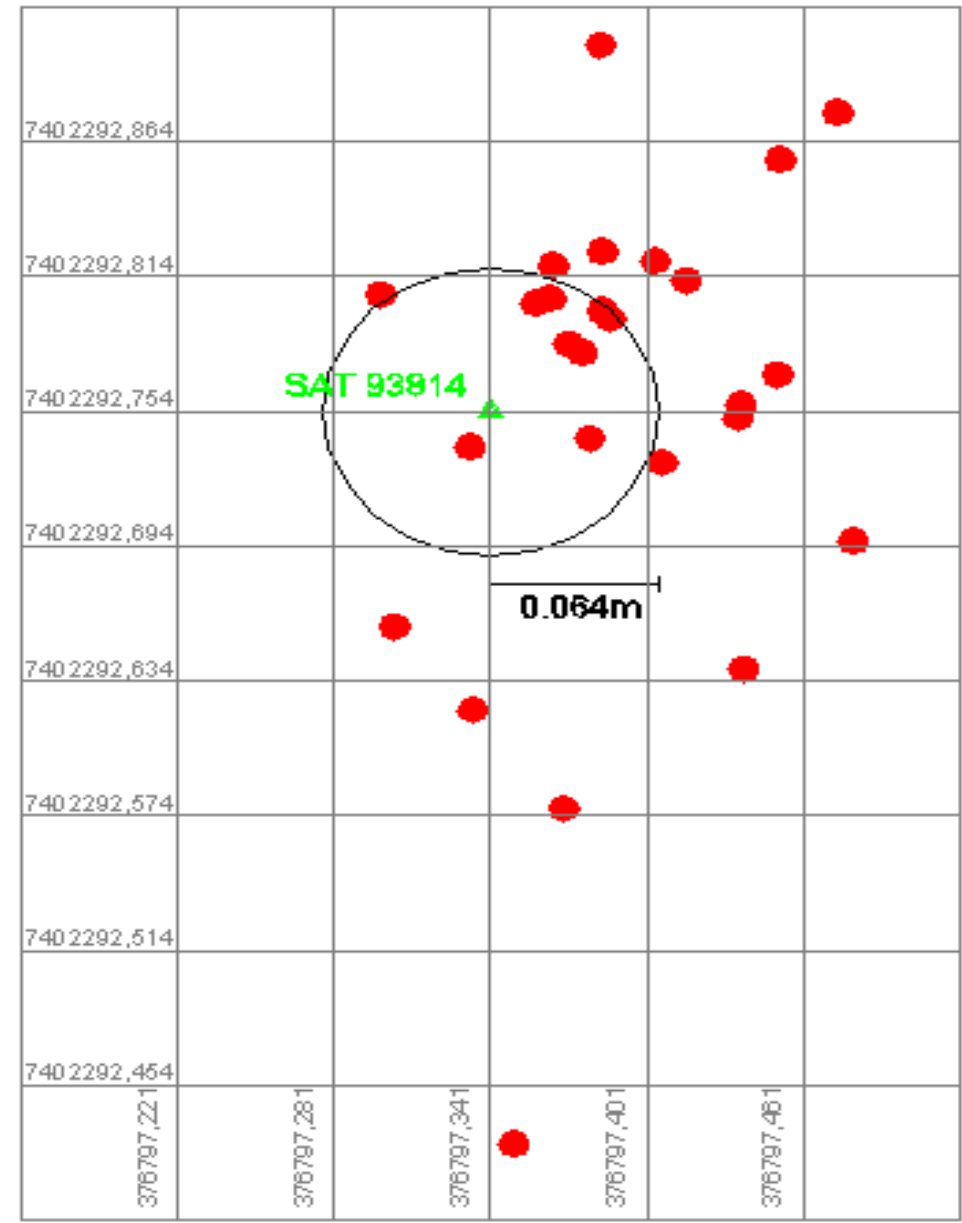

Figura 99 - Dispersão dos pontos ao redor do valor oficial, exp. 7b.

As Figuras 100, 102 e 104 apresentam os gráficos das incidências relativamente às coordenadas $\mathrm{E}, \mathrm{N}$ e $\mathrm{h}$ na amostra e as figuras 101,103 e $105 \mathrm{o}$ histograma das discrepâncias em cada eixo com relação à coordenada oficial. 


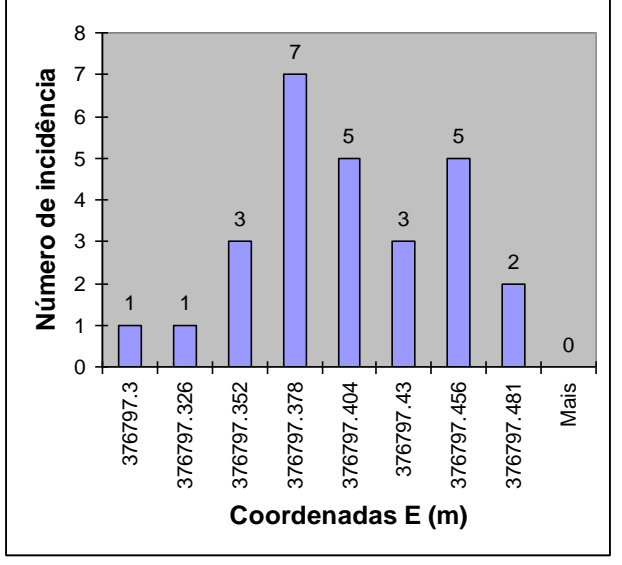

Figura 100 - Incidência da Coordenada E, no exp. $7 b$.

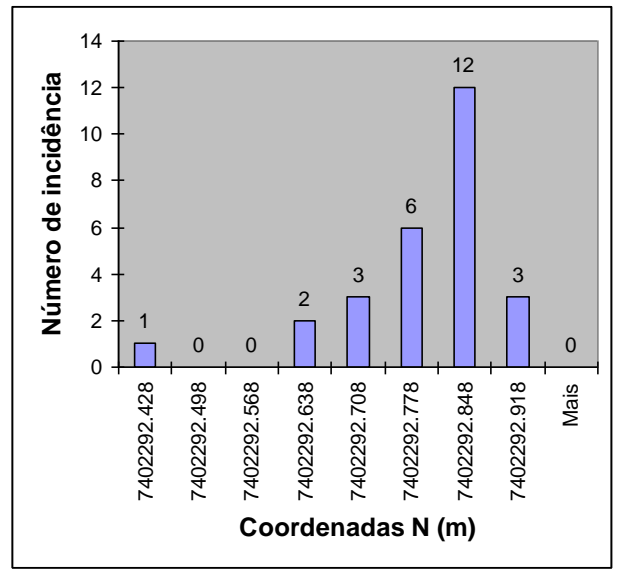

Figura 102- Incidência da Coordenada N, no exp. $7 b$.

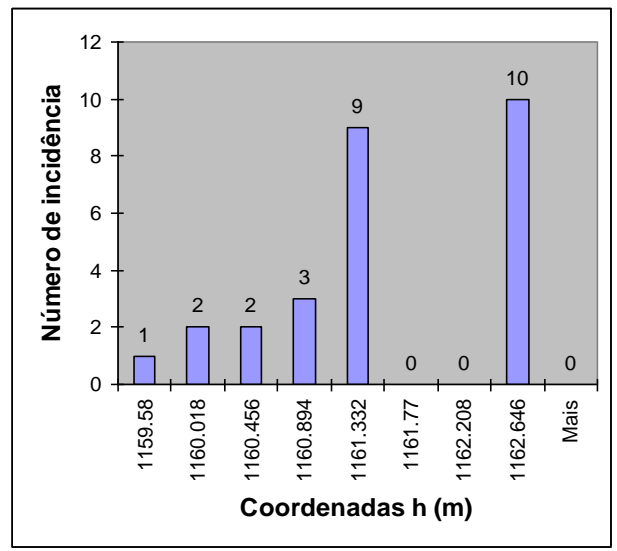

Figura 104 - Incidência da coordenada h, no exp. $7 b$.

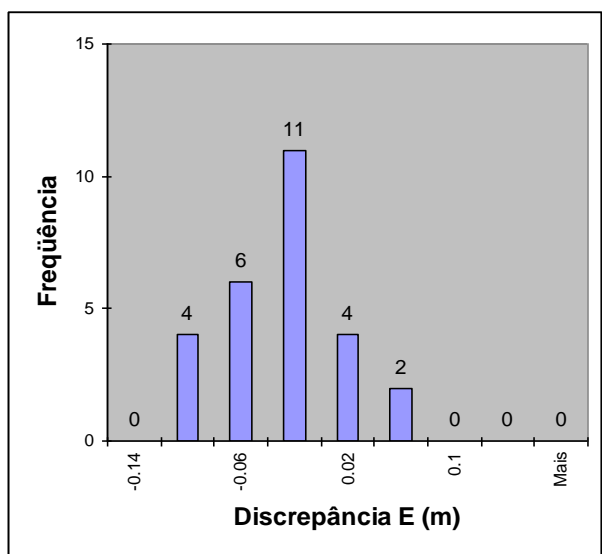

Figura 101 - Histograma Referente a E, no exp. 7b.

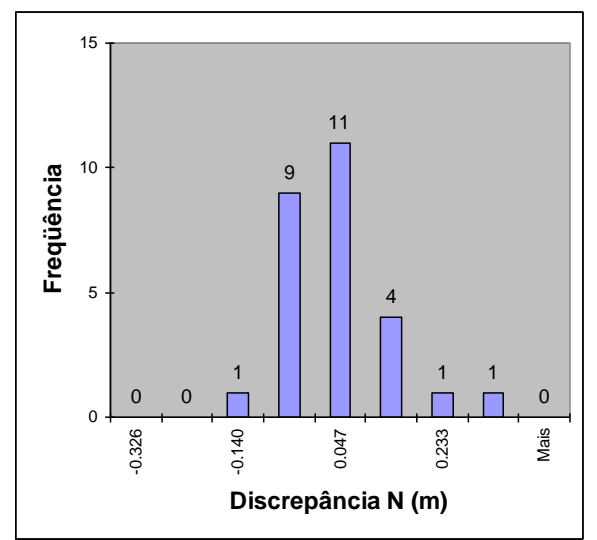

Figura 103 - Histograma Referente a $\mathrm{N}$, no exp. 7b.

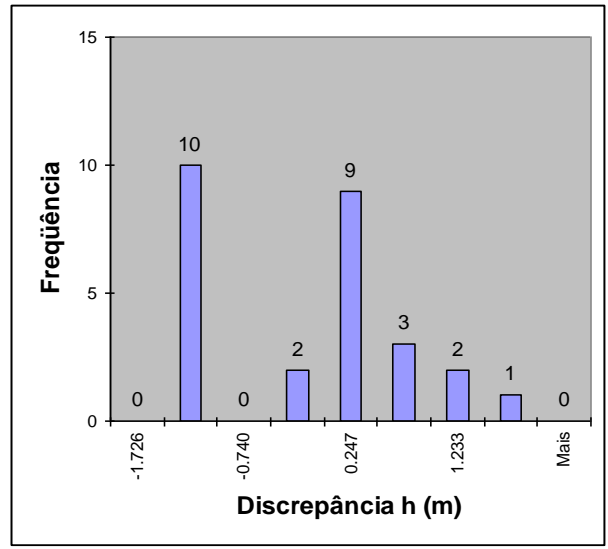

Figura 105 - Histograma Referente a h, no exp. $7 b$. 


\subsubsection{Experimento 8}

Este se refere ao vértice SAT 93794 (Indaiatuba) com distância de 72,0 km. Foram registradas (obtidas) 84 coordenadas, sendo 53 com solução fixa e 31 com solução flutuante, realizado no dia 16 de fevereiro de 2009. Nesse experimento, a análise foi dividida em a e b conforme a solução. Em termos visibilidade dos satélites, esse ponto tem uma localização boa, conforme Figura 46, e a condição meteorológica, no dia do levantamento, era boa.

No teste a, serão consideradas as 53 coordenadas fixas, as quais tiveram um tempo de inicialização de 15 segundos, uma latência de 1,6 segundos, rastreandose 12 satélites com um PDOP de 1,6, em média.

$\mathrm{Na}$ análise da discrepância que segue, levou-se em consideração a diferença entre a coordenada média obtida e a coordenada oficial. Os valores para o caso foram os seguintes:

$$
\begin{array}{ll}
\mathrm{E}=271784,518 \mathrm{~m} ; & \Delta \mathrm{E}=|0,002 \mathrm{~m}|<0.064 \mathrm{~m}(\text { ver tabela 12) } \\
\mathrm{N}=7444443,401 \mathrm{~m} ; & \Delta \mathrm{N}=|-0,003 \mathrm{~m}|<0.064 \mathrm{~m}(\text { ver tabela 12) } \\
\mathrm{h}=581,807 \mathrm{~m} ; & \Delta \mathrm{h}=|-0,053 \mathrm{~m}|>0.074 \mathrm{~m}(\text { ver tabela 12) }
\end{array}
$$

Analisando-se cada coordenada obtida com o valor esperado, conforme a Tabela 12, conclui-se que a amostra atende à planimetria em $96 \%$ e à altimetria em $90 \%$.

Na Figura 106, observa-se a dispersão dos resultados das coordenadas UTM mensuradas no referido ponto considerando as direções ( $E$ e N). 


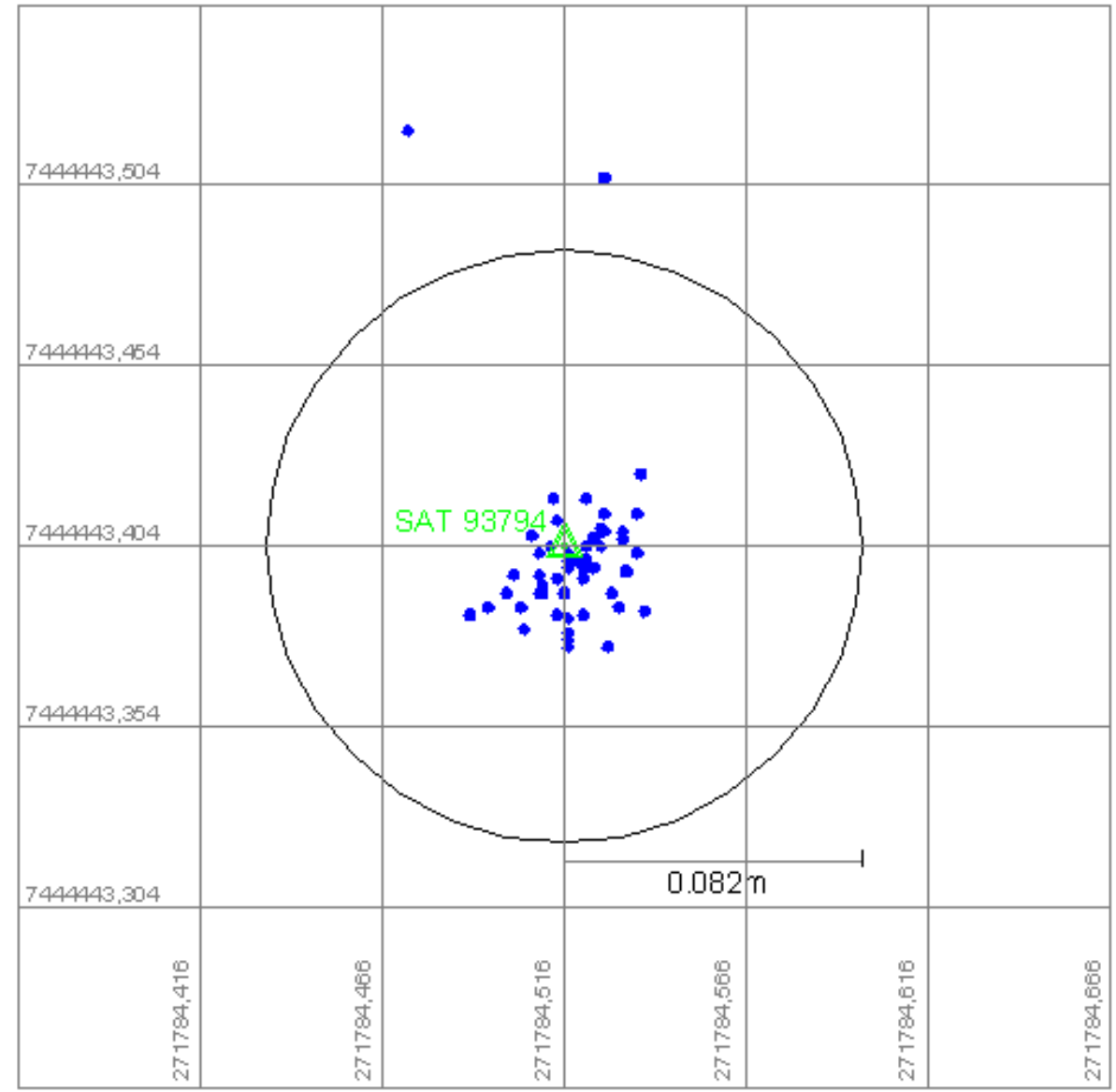

Figura 106 - Dispersão dos pontos ao redor do valor oficial, exp.8a.

As Figuras 107, 109 e 111 apresentam os gráficos das incidências relativamente às coordenadas $\mathrm{E}, \mathrm{N}$ e h na amostra e as Figuras 108, 110 e 112 o histograma das discrepâncias em cada eixo com relação à coordenada oficial.

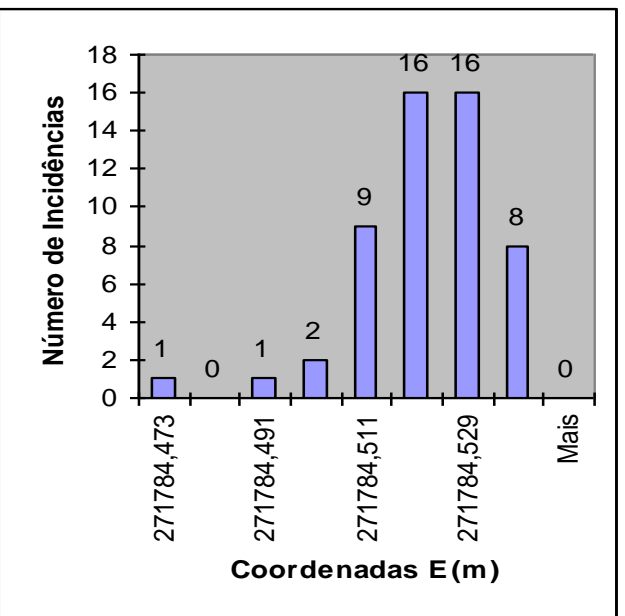

Figura 107 - Incidência da Coordenada E, no exp. 8a.

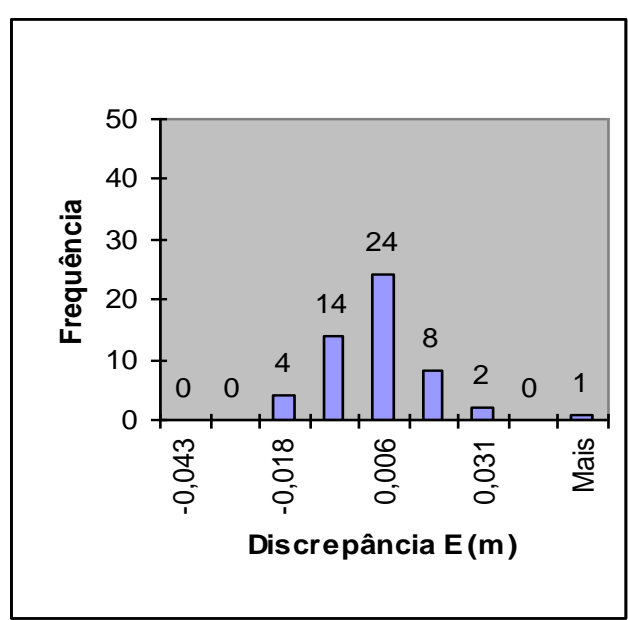

Figura 108 - Histograma referente a E, no exp. 8a. 


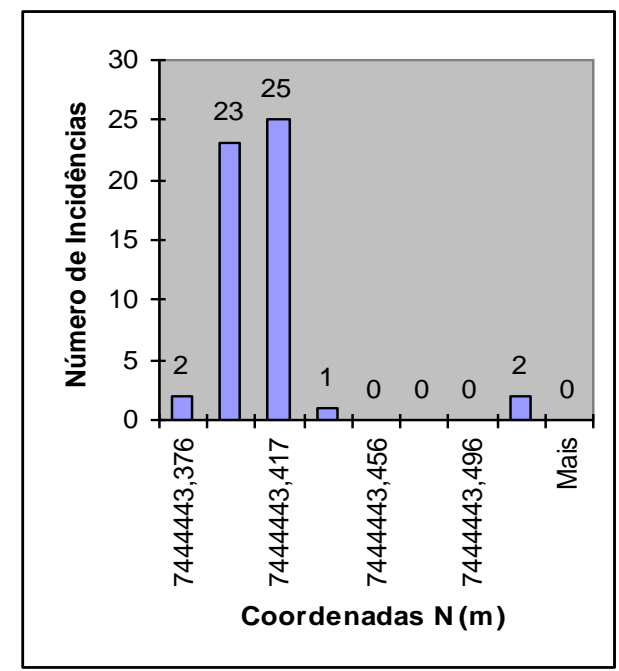

Figura 109 - Incidência da Coordenada $\mathrm{N}$, no exp. 8a.

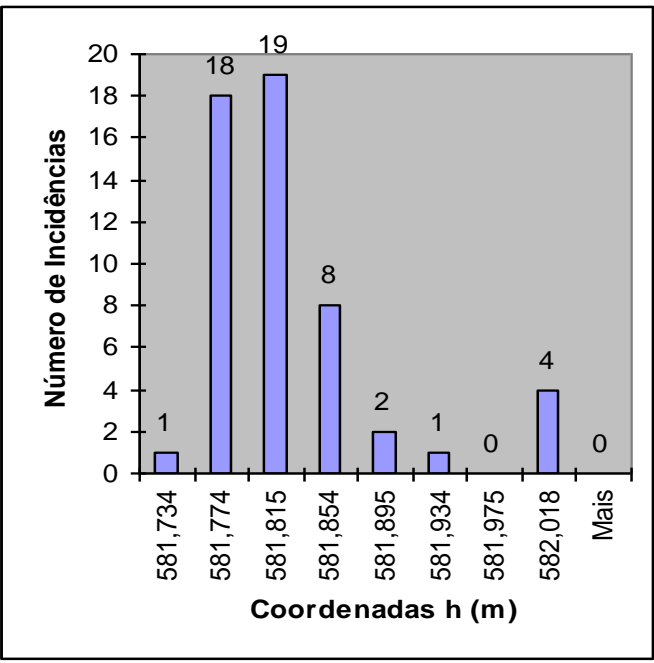

Figura 111 - Incidência da Coordenada h, no exp. 8 a.

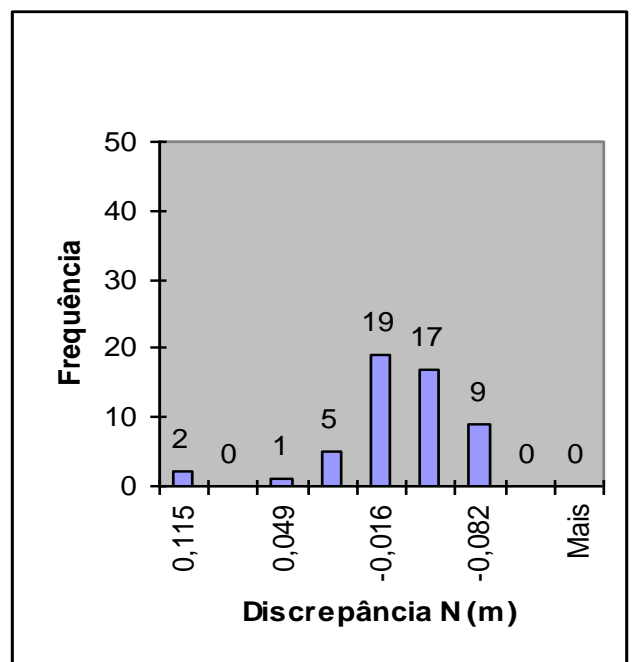

Figura 110 - Histograma referente a N, no exp. 8 a.

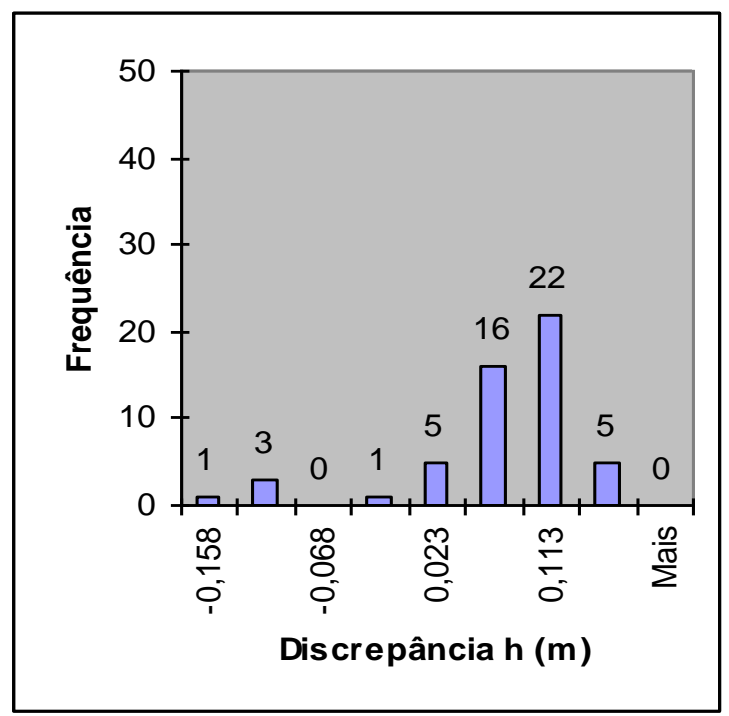

Figura 112 - Histograma referente a $h$, no exp. $8 a$.

No teste b, serão consideradas as 31 coordenadas flutuantes, as quais tiveram um tempo de inicialização de 3 minutos, uma latência de 1,6 segundos, rastreando-se 13 satélites com um PDOP de 1,9, em média.

$\mathrm{Na}$ análise da discrepância que segue, leva-se em consideração a diferença entre a coordenada média obtida e a coordenada oficial. Os valores para o caso foram os seguintes: 


$$
\begin{array}{ll}
\mathrm{E}=271784,482 \mathrm{~m} ; & \Delta \mathrm{E}=|0,034 \mathrm{~m}|<0.064 \mathrm{~m}(\text { ver tabela 12) } \\
\mathrm{N}=7444443,421 \mathrm{~m} ; & \Delta \mathrm{N}=|-0,017 \mathrm{~m}|<0.064 \mathrm{~m}(\text { ver tabela 12) } \\
\mathrm{h}=581,845 \mathrm{~m} ; & \Delta \mathrm{h}=|0,015 \mathrm{~m}|>0.074 \mathrm{~m}(\text { ver tabela 12) }
\end{array}
$$

Verificando-se cada coordenada com o valor esperado, conforme a tabela 12, conclui-se que a amostra atende à planimetria em $28 \%$ e à altimetrica em $14 \%$.

Na Figura 113, vê-se a dispersão dos resultados das coordenadas UTM mensuradas no referido ponto considerando as direções ( $\mathrm{E}$ e $\mathrm{N}$ ).

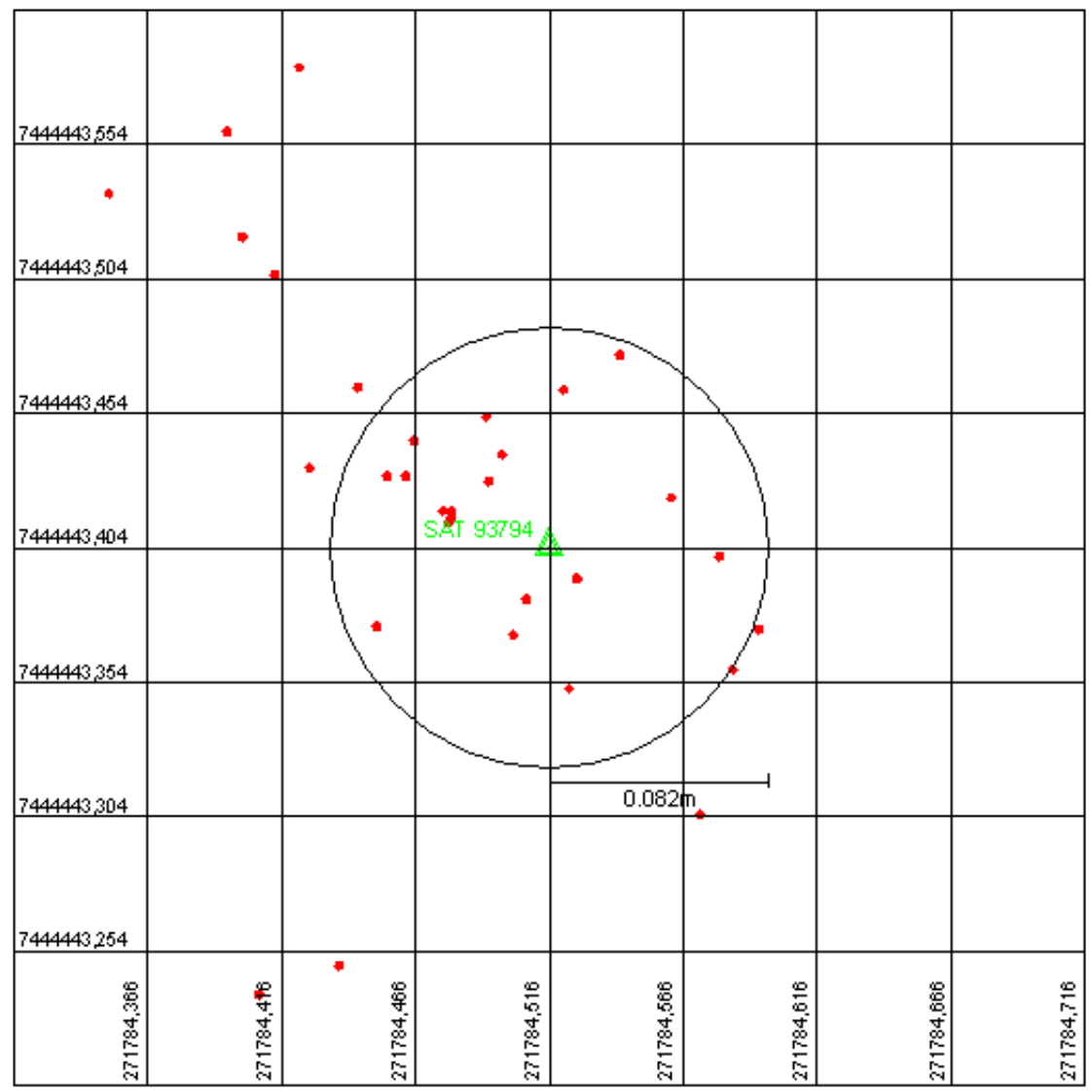

Figura 113 - Dispersão dos pontos ao redor do valor oficial, exp. 8b.

As Figuras 114, 116 e 118 apresentam os gráficos das incidências relativamente às coordenadas $\mathrm{E}, \mathrm{N}$ e $\mathrm{h}$ na amostra e as figuras 115,117 e 119 o histograma das discrepâncias em cada eixo com relação à coordenada oficial. 


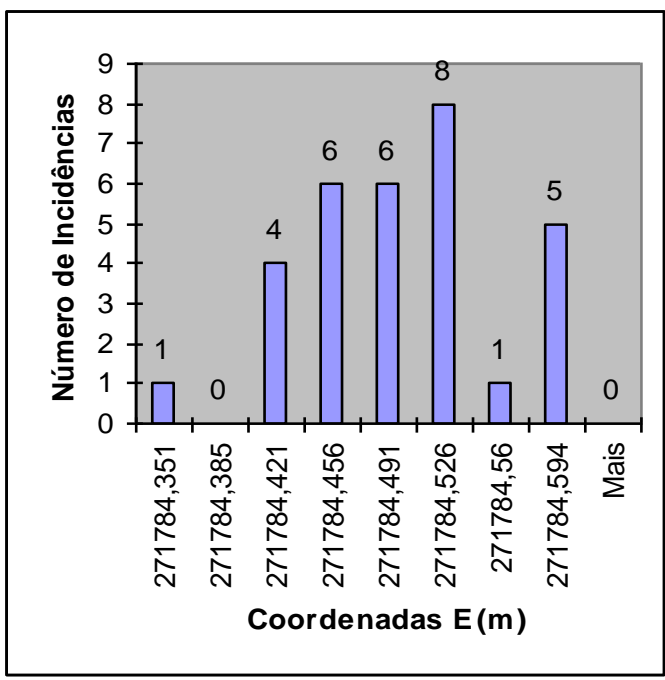

Figura 114 - Incidência da Coordenada E, no exp. 8b.

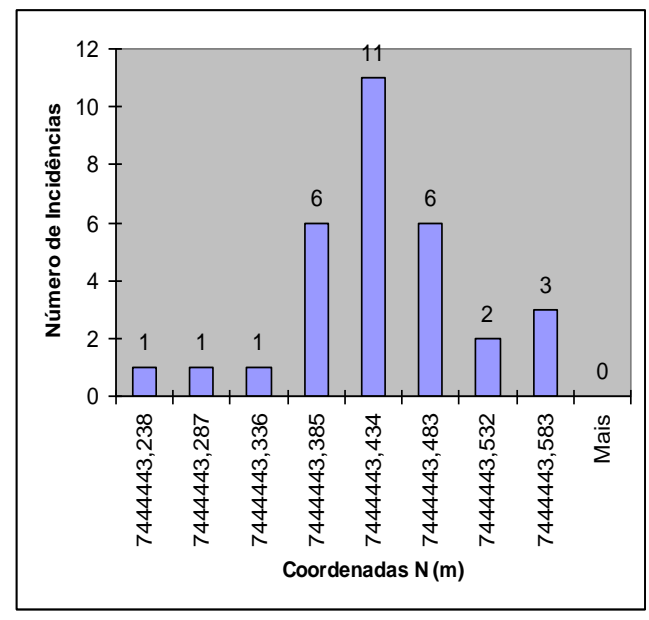

Figura 116 - Incidência da Coordenada $\mathrm{N}$, no exp. 8b.

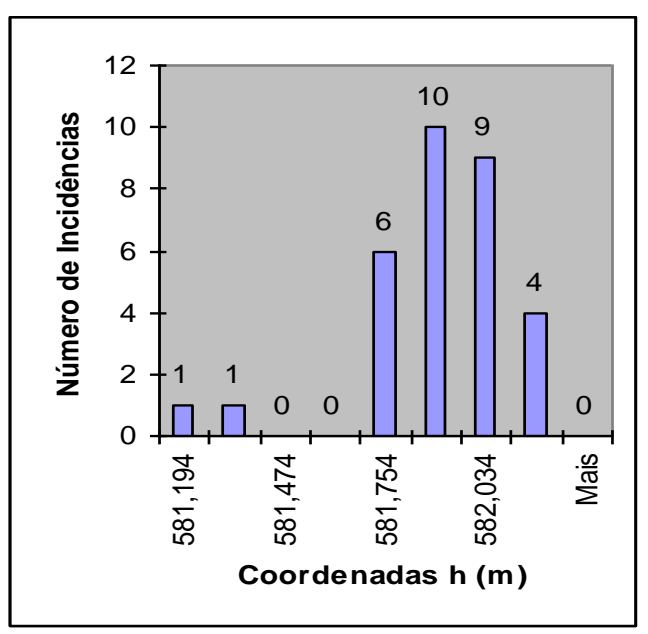

Figura 118 - Incidência da Coordenada h, no exp. $8 b$.

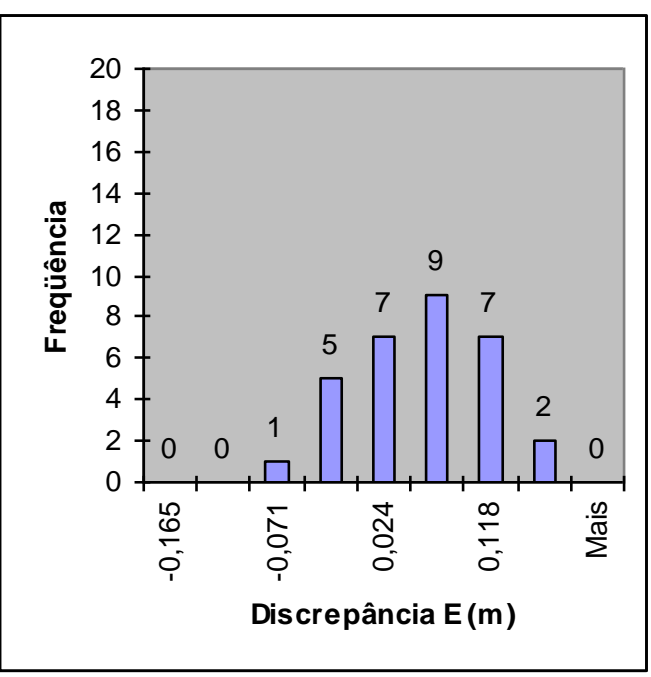

Figura 115 - Histograma referente a $\mathrm{E}$, no exp. 8b.

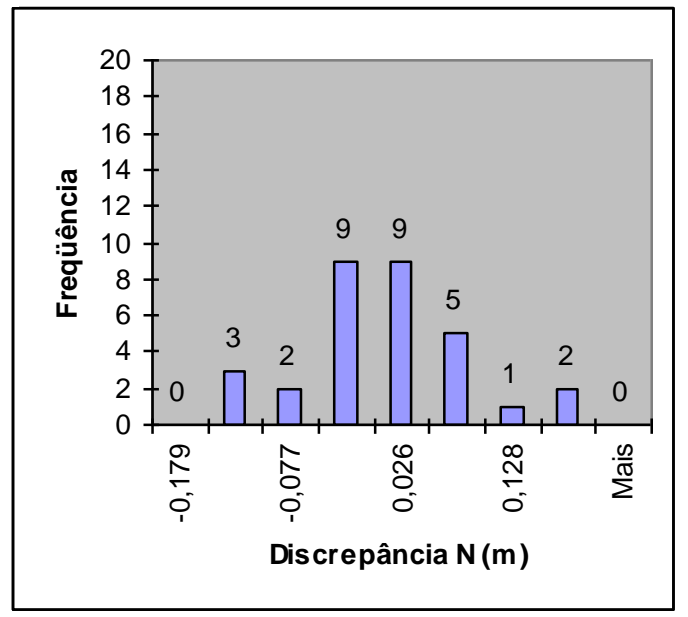

Figura 117- Histograma referente a $\mathbf{N}$, no exp. 8b.

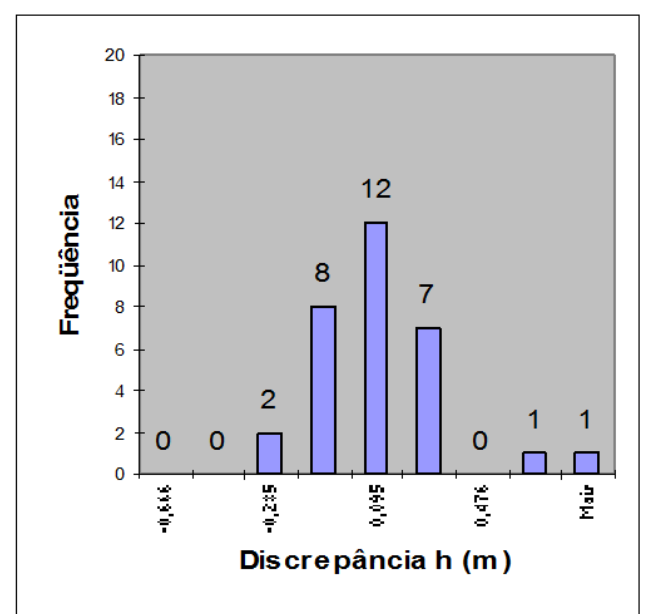

Figura 119 - Histograma referente a $h$, no exp. 8b. 


\subsubsection{Experimento 9}

Este se refere ao vértice SAT 96035 (São José dos Campos-SP) com uma distância de 96,50 km. Foram registradas (obtidas) 74 coordenadas, sendo, dentre elas, 18 com solução fixa e 56 com solução flutuante, realizado no dia 19 de novembro de 2008. Em termos de visibilidade dos satélites, este ponto tem uma boa localização, conforme figura 46. A condição meteorológica no dia do levantamento era boa. $A$ análise será dividida em a e b, conforme a solução.

No teste a, serão consideradas as 18 coordenadas fixas, as quais tiveram um tempo de inicialização de 15 segundos, uma latência de 1,5 segundos, rastreandose 15 satélites com um PDOP de 1,5, em média.

$\mathrm{Na}$ análise da discrepância a seguir, os valores encontrados foram os seguintes:

$$
\begin{array}{ll}
\mathrm{E}=409426,693 \mathrm{~m} ; & \Delta \mathrm{E}=|-0,002 \mathrm{~m}|<0.106 \mathrm{~m}(\text { ver tabela 12) } \\
\mathrm{N}=7437552,008 \mathrm{~m} ; & \Delta \mathrm{N}=|-0,011 \mathrm{~m}|<0.106 \mathrm{~m}(\text { ver tabela 12) } \\
\mathrm{h}=556,242 \mathrm{~m} ; & \Delta \mathrm{h}=|-0,132 \mathrm{~m}|>0.116 \mathrm{~m}(\text { ver tabela 12) }
\end{array}
$$

Verificando cada coordenada obtida com o valor esperado, conforme a tabela 12, conclui-se que a amostra atende à planimétrica em 100\% e à altimétrica em $100 \%$.

Na figura 120, observa-se a dispersão dos resultados das coordenadas UTM mensuradas no referido ponto considerando-se as direções (E e N). 


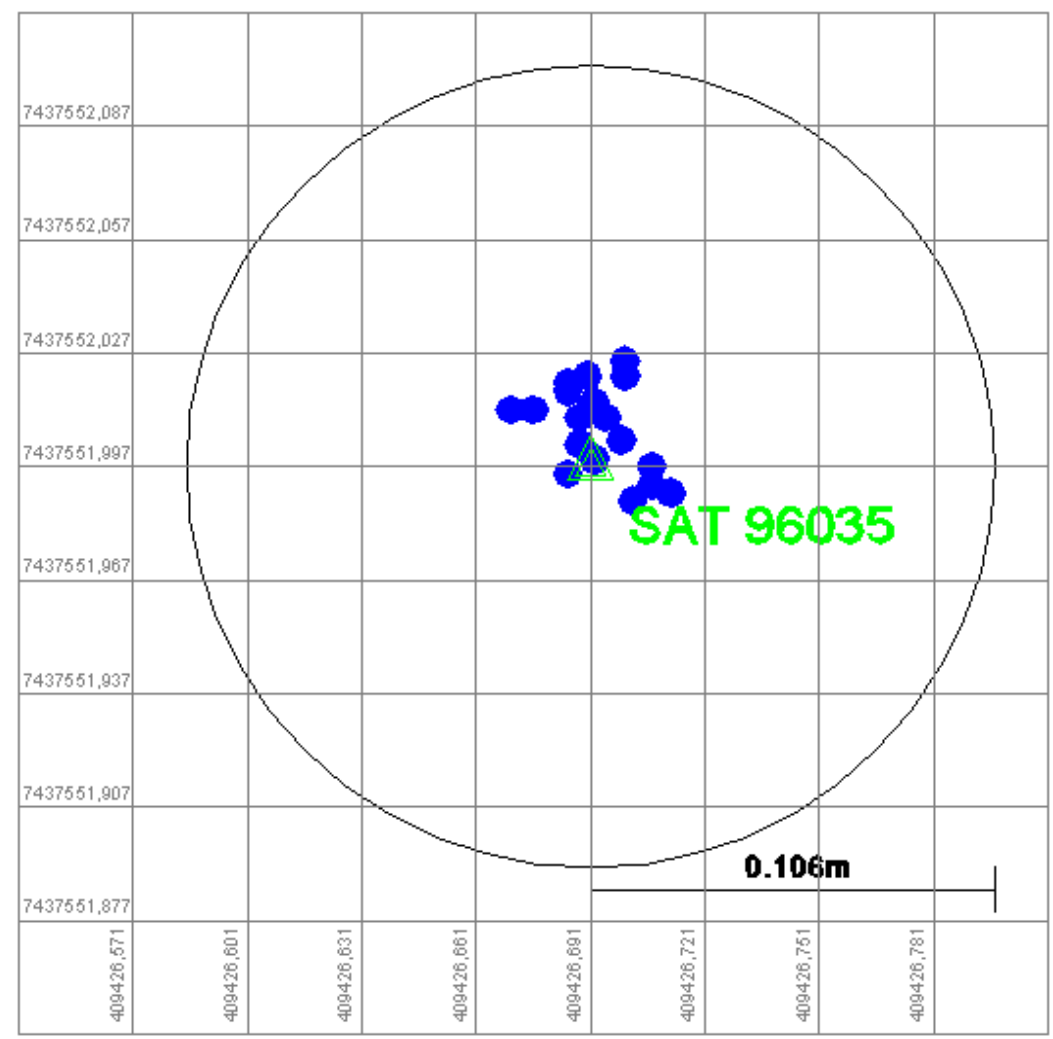

Figura 120 - Dispersão dos pontos ao redor do valor oficial, exp. 9a.

As figuras 121, 123 e 125 apresentam os gráficos das incidências relativamente às coordenadas $\mathrm{E}, \mathrm{N}$ e h na amostra e as figuras 122, 124 e 126 o histograma das discrepâncias de cada eixo com relação à coordenada oficial.

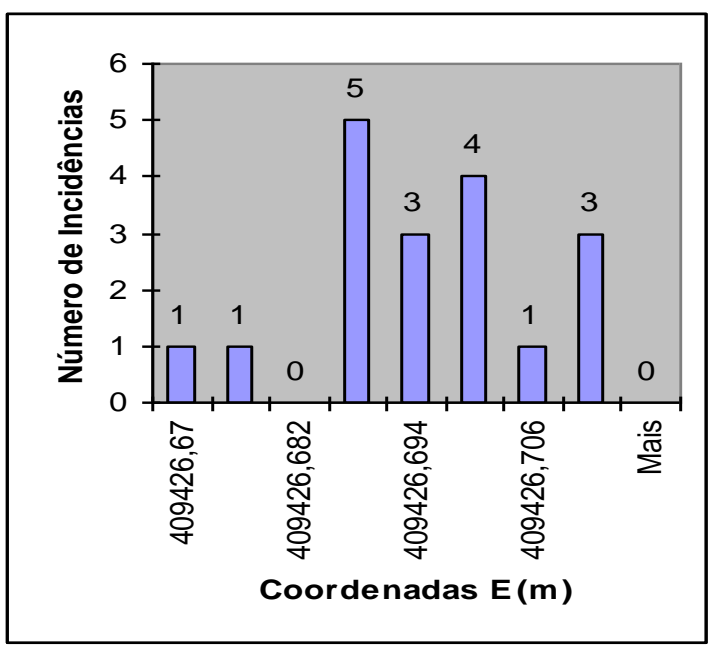

Figura 121 - Incidência da Coordenada E, no exp. 9a.

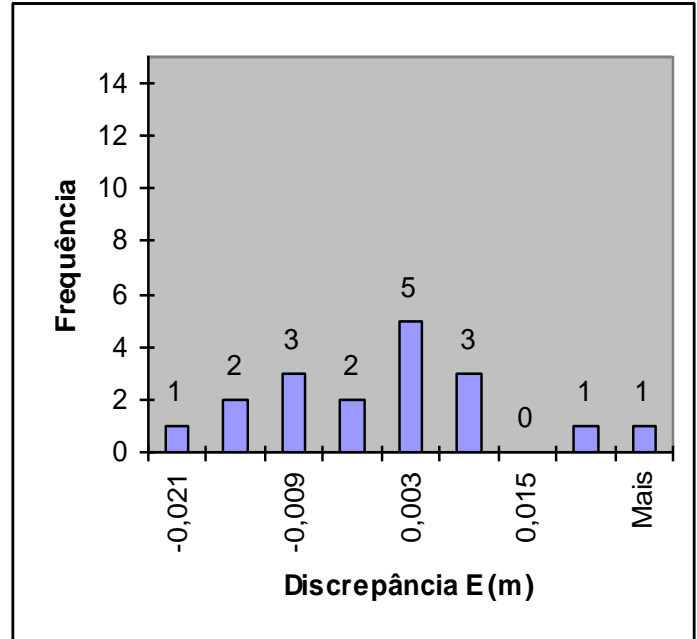

Figura 122 - Histograma Referente a E, no exp. 9a. 


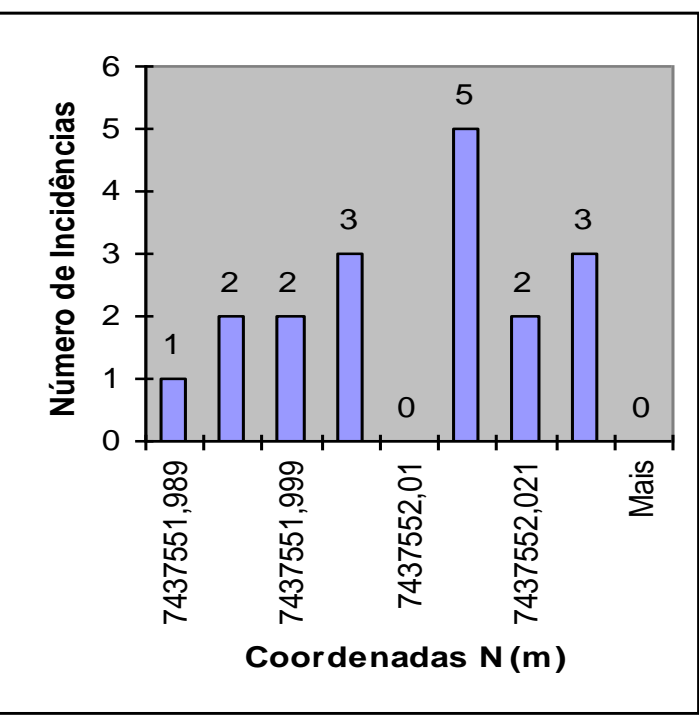

Figura 123- Incidência da Coordenada N, no exp. 9a.

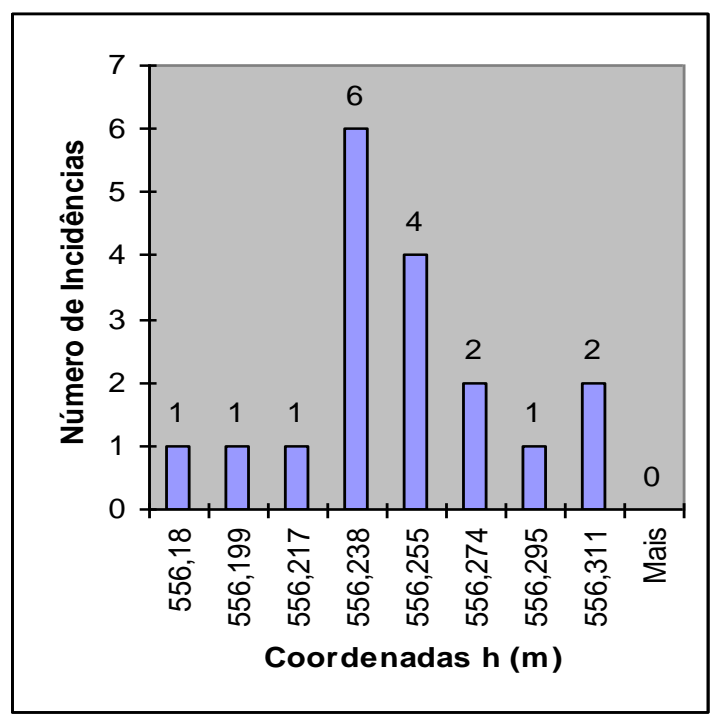

Figura 125 - Incidência da Coordenada h, no exp. 9a.

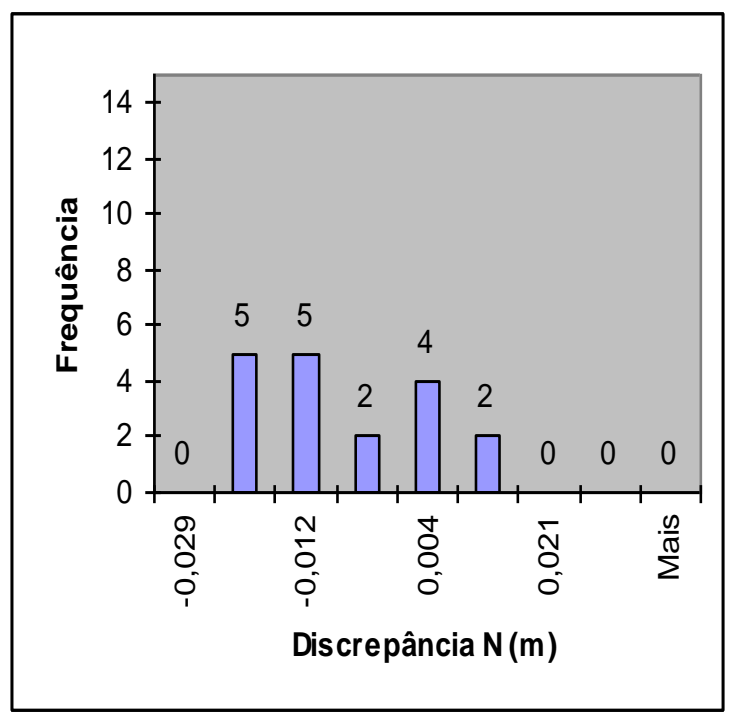

Figura 124 - Histograma Referente a N, no exp. 9a.

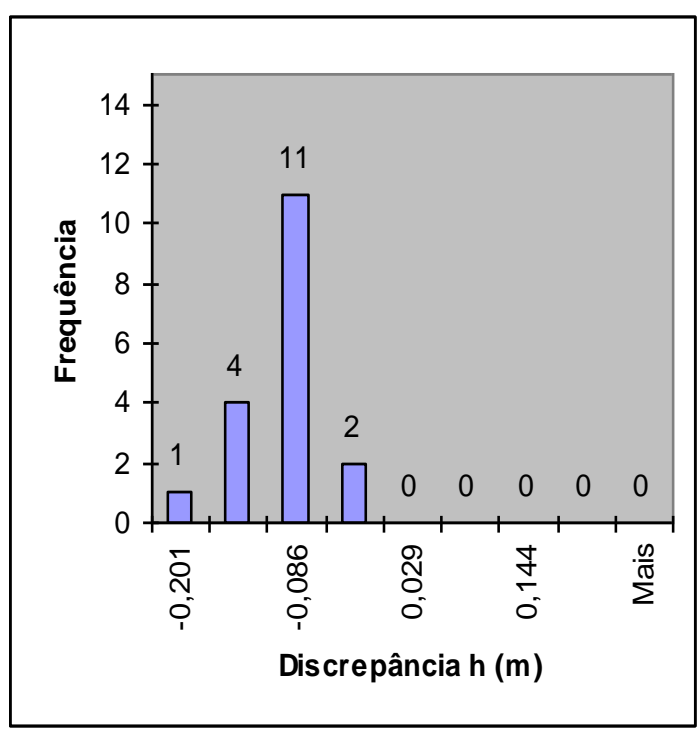

Figura 126 - Histograma Referente a h, no exp. 9a.

No teste b, serão consideradas as 56 coordenadas obtidas com solução flutuante, as quais tiveram um tempo de inicialização de três minutos, uma latência de 1,7 segundos, rastreando-se 14 satélites com um PDOP de 1,7, em média.

$\mathrm{Na}$ análise da discrepância a seguir, os valores encontrados foram os seguintes: 


$$
\begin{array}{ll}
\mathrm{E}=409426,722 \mathrm{~m} ; & \Delta \mathrm{E}=|-0,031 \mathrm{~m}|<0.064 \mathrm{~m}(\text { ver tabela 12) } \\
\mathrm{N}=7437552,031 \mathrm{~m} ; & \Delta \mathrm{N}=|-0,034 \mathrm{~m}|<0.064 \mathrm{~m}(\text { ver tabela 12) } \\
\mathrm{h}=556,196 \mathrm{~m} ; & \Delta \mathrm{h}=|-0,086 \mathrm{~m}|>0.074 \mathrm{~m}(\text { ver tabela 12) }
\end{array}
$$

Analisando-se cada coordenada obtida com o valor esperado, conforme a tabela 12 , constatou-se que a amostra atendeu à planimetria em $86 \%$ dos casos e à altimetria em $40 \%$ dos casos.

$\mathrm{Na}$ figura 127, observa-se a dispersão dos resultados das coordenadas UTM mensuradas no referido ponto considerando as direções ( $E$ e $N$ ).

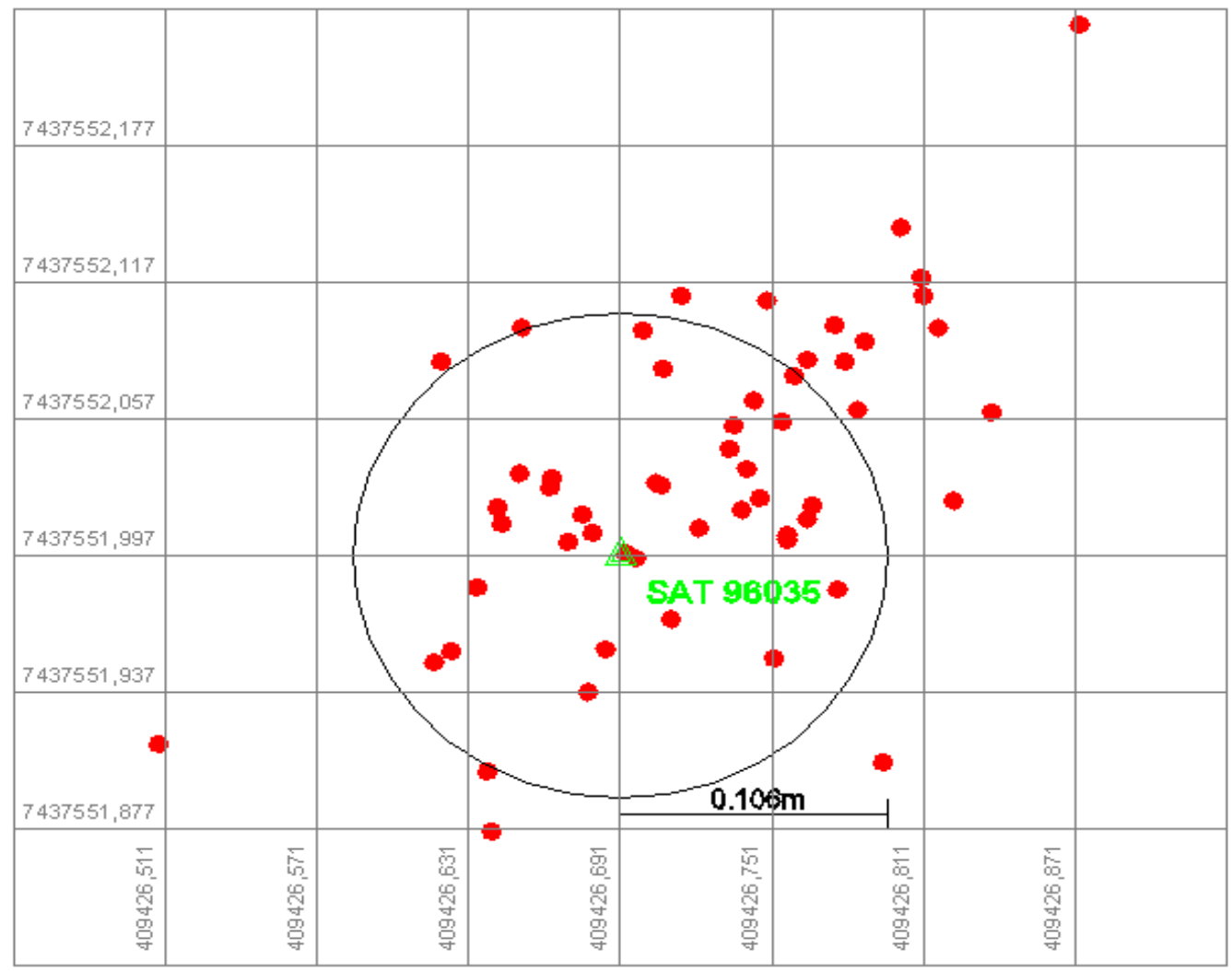

Figura 127 - Dispersão dos pontos ao redor do valor oficial, exp. 9b.

As figuras 128, 130 e 132 apresentam os gráficos das incidências relativamente às coordenadas $\mathrm{E}, \mathrm{N}$ e h na amostra e as figuras 129, 131 e $133 \mathrm{o}$ histograma das discrepâncias em cada eixo com relação à coordenada oficial. 


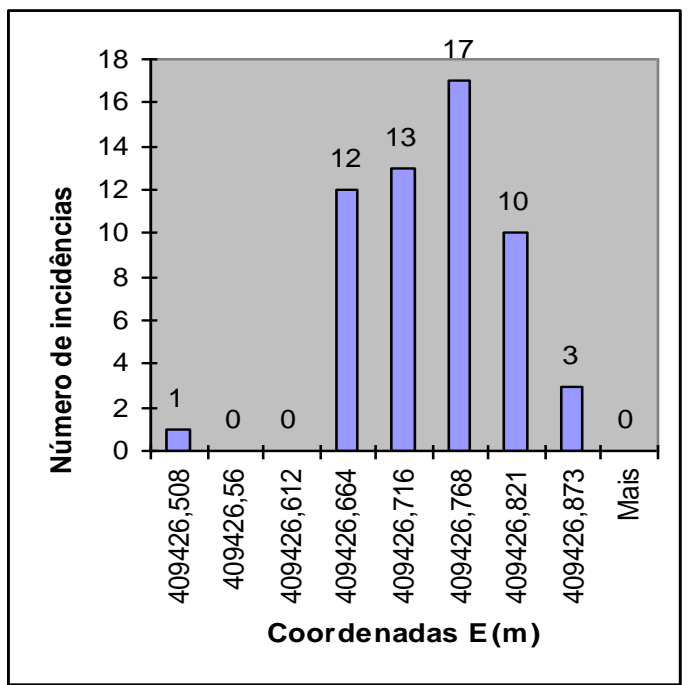

Figura 128 - Incidência da coordenada $E$, no exp. 9b.

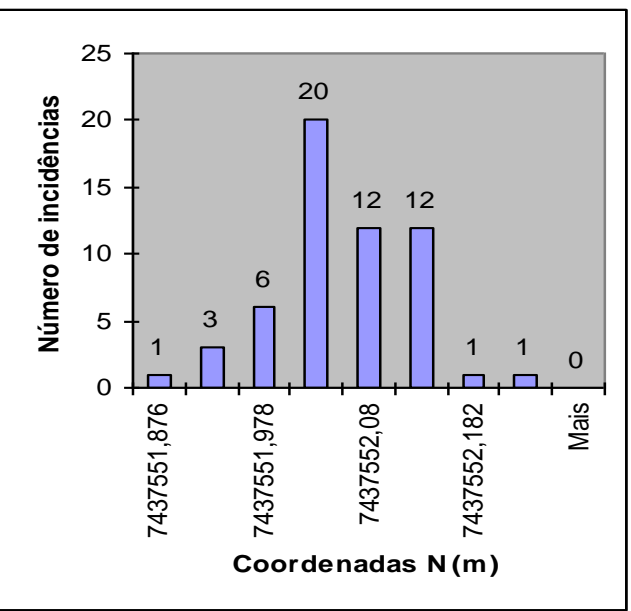

Figura 130 - Incidência da Coordenada $\mathrm{N}$, no exp. $9 b$.

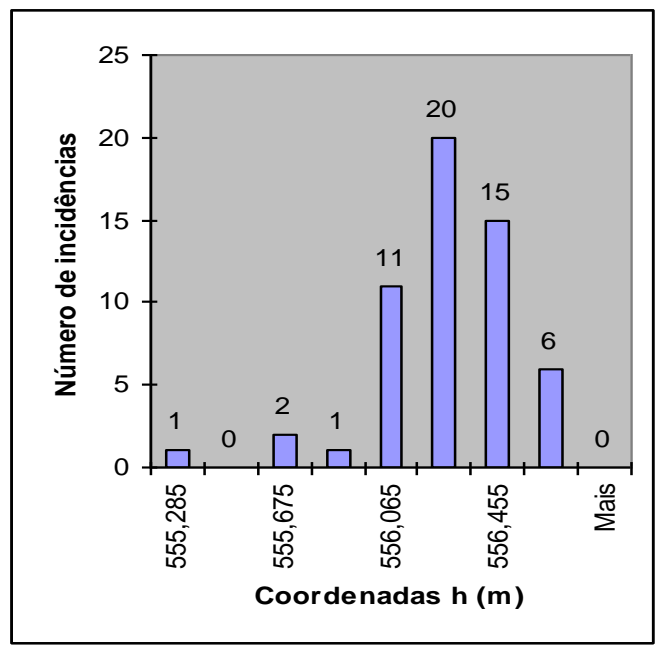

Figura 132 - Incidência da Coordenada h, no exp. 9b.

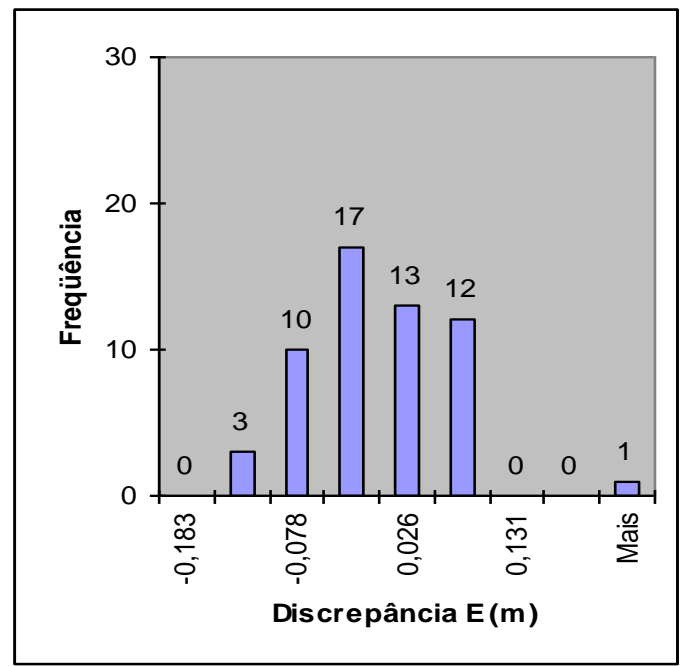

Figura 129 - Histograma Referente a E, no exp. 9b.

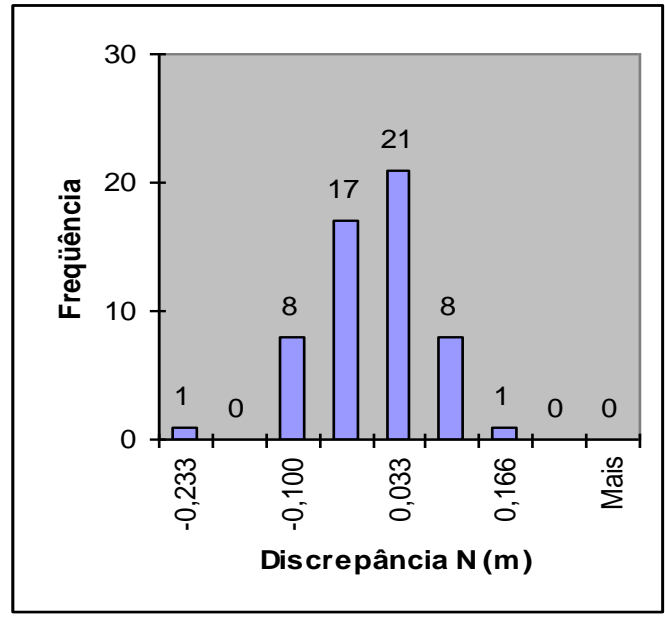

Figura 131 - Histograma Referente a $\mathrm{N}$, no exp. $9 \mathrm{~b}$.

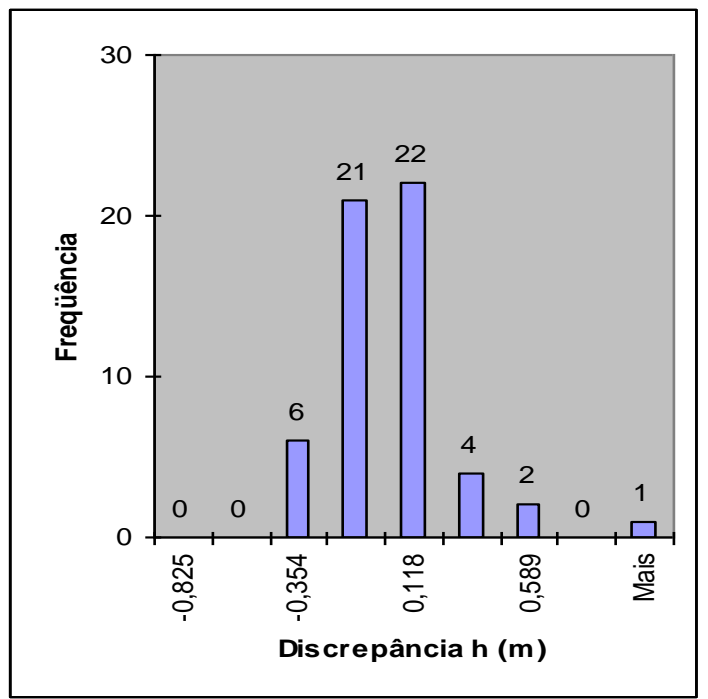

Figura 133 - Histograma referente a h, no exp. 9b. 


\subsubsection{Experimento 10}

Este se refere ao vértice SAT93794 (Miracatu) com uma distância de 108,70 $\mathrm{km}$. Foram registradas (obtidas) 64 coordenadas com a solução flutuante, as quais tiveram um tempo de inicialização de três minutos, uma latência de 1,5 segundos, rastreando-se 10 satélites, com um PDOP 2, em média, realizado no dia 21 de novembro de 2008. Em termos de visibilidade dos satélites, este ponto tem uma localização boa, conforme a figura 47. No dia do levantamento, a condição meteorológica era boa.

$\mathrm{Na}$ análise da discrepância a seguir, os valores encontrados foram os seguintes:

$$
\begin{array}{ll}
\mathrm{E}=251199,315 \mathrm{~m} ; & \Delta \mathrm{E}=|-0,053 \mathrm{~m}|<0.119 \mathrm{~m}(\text { ver tabela 12) } \\
\mathrm{N}=7312598,849 \mathrm{~m} ; & \Delta \mathrm{N}=|-0,059 \mathrm{~m}|<0.119 \mathrm{~m}(\text { ver tabela 12) } \\
\mathrm{h}=56,274 \mathrm{~m} ; & \Delta \mathrm{h}=|-0,014 \mathrm{~m}|>0.129 \mathrm{~m}(\text { ver tabela 12) }
\end{array}
$$

Após a análise de cada coordenada obtida com o valor esperado, conforme a tabela 12, constatou-se que a amostra atende à planimetria em $78 \%$ dos casos e à altimetria em $45 \%$ dos casos.

$\mathrm{Na}$ figura 134, pode ser vista a dispersão dos resultados das coordenadas UTM mensuradas no referido ponto considerando as direções (E e N); 


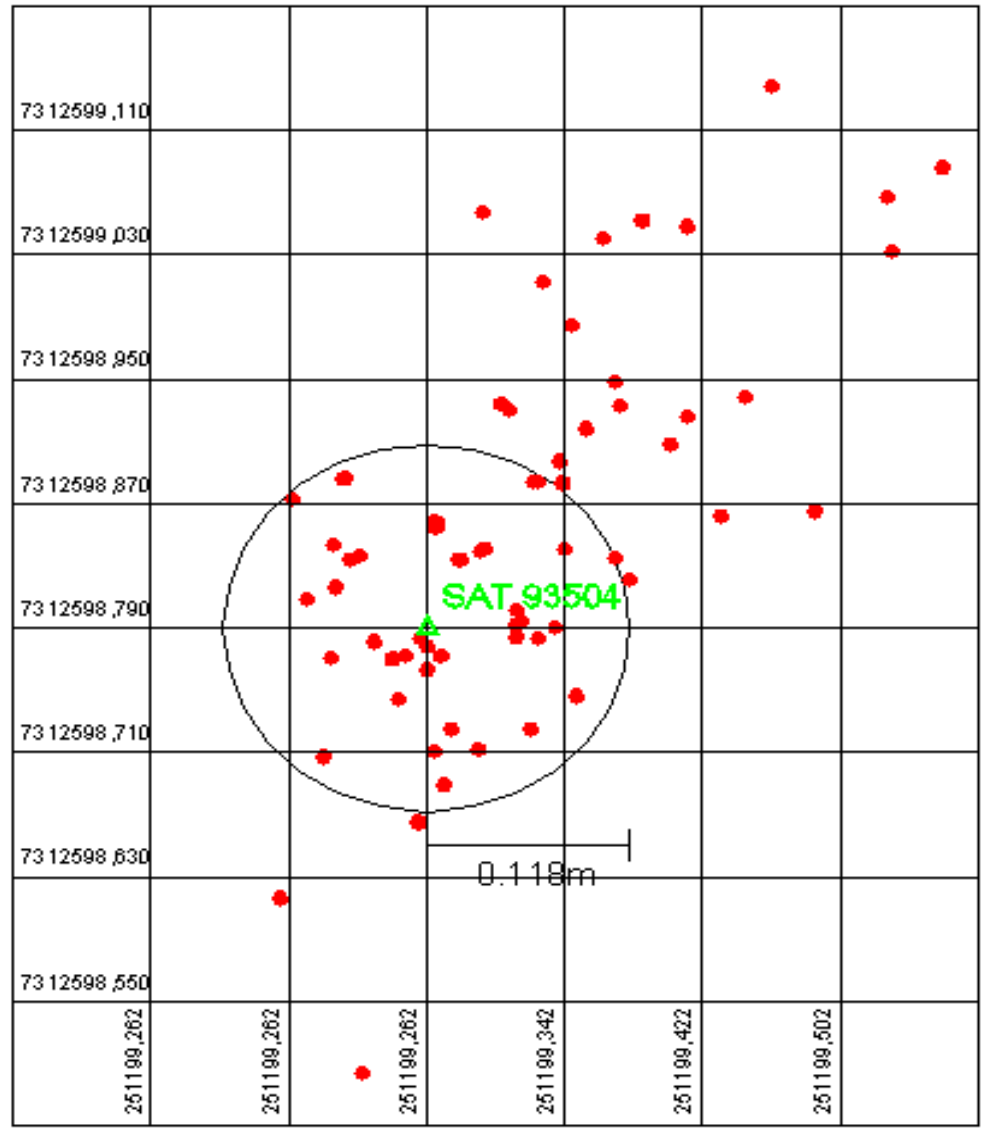

Figura 134 - Dispersão dos pontos ao redor do valor oficial, exp. 10.

As figuras 135, 137 e 139 apresentam os gráficos das incidências relativamente às coordenadas $\mathrm{E}, \mathrm{N}$ e h na amostra e as figuras 136, 138 e $140 \mathrm{o}$ histograma das discrepâncias em cada eixo com relação à coordenada oficial.

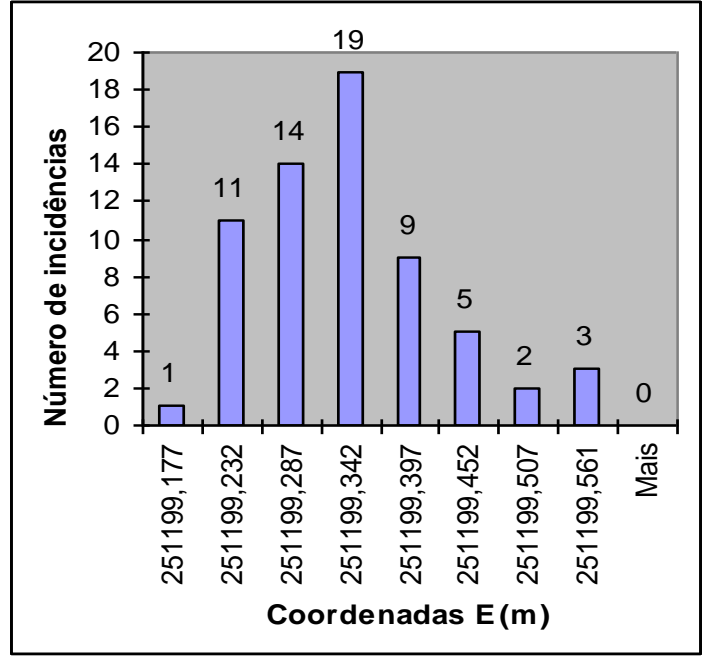

Figura 135 - Incidência da Coordenada E, no exp. 10.

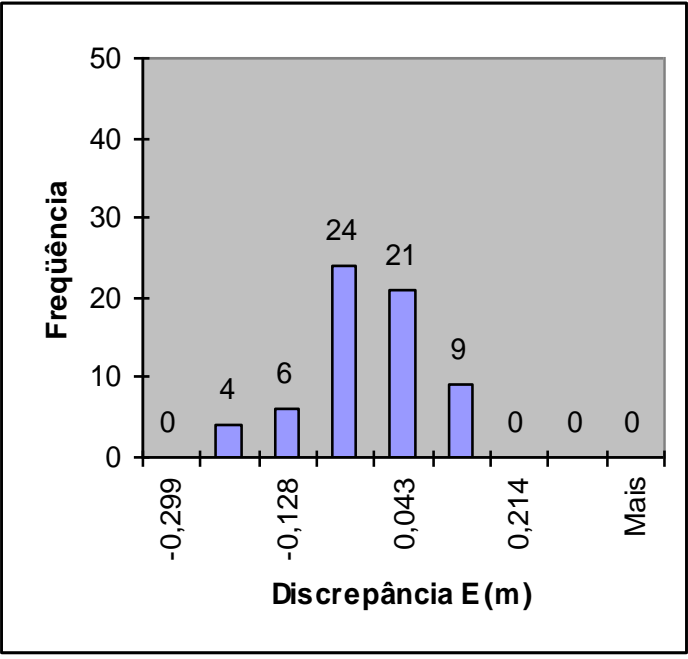

Figura 136 - Histograma Referente a E, no exp. 10. 


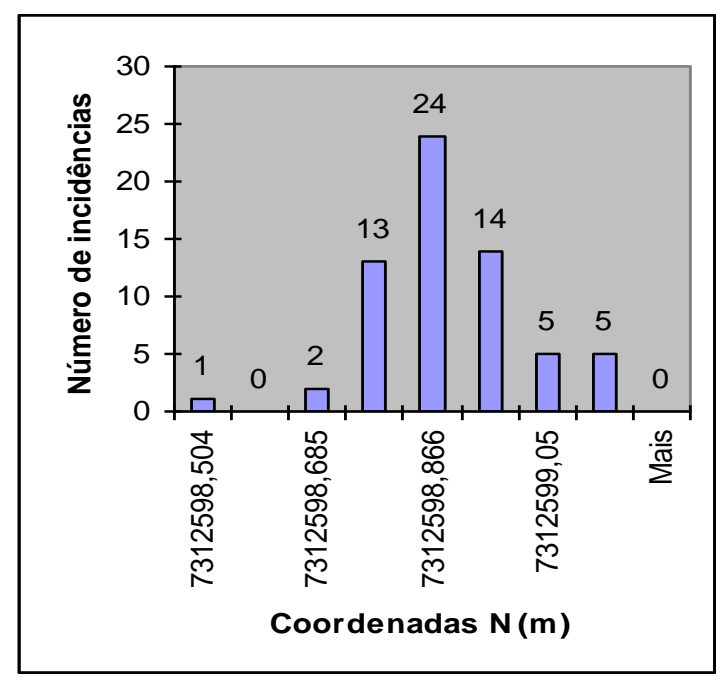

Figura 137 - Incidência da Coordenada N, no exp. 10.

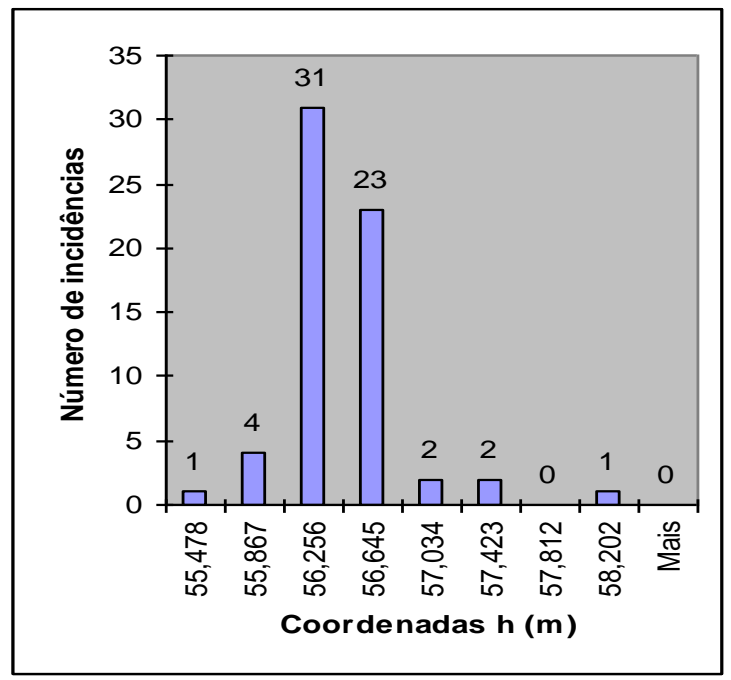

Figura 139 - Incidência da Coordenada $h$, no exp. 10.

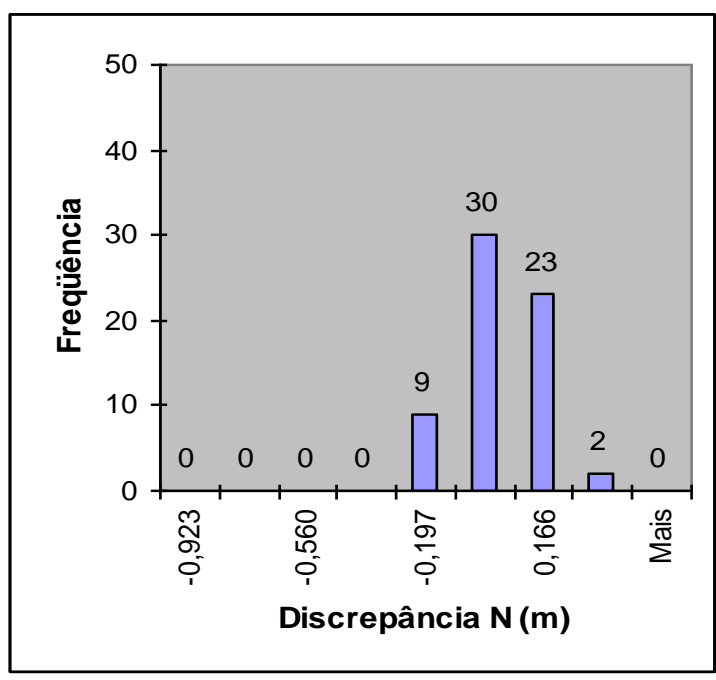

Figura 138 - Histograma Referente a N, no exn. 10

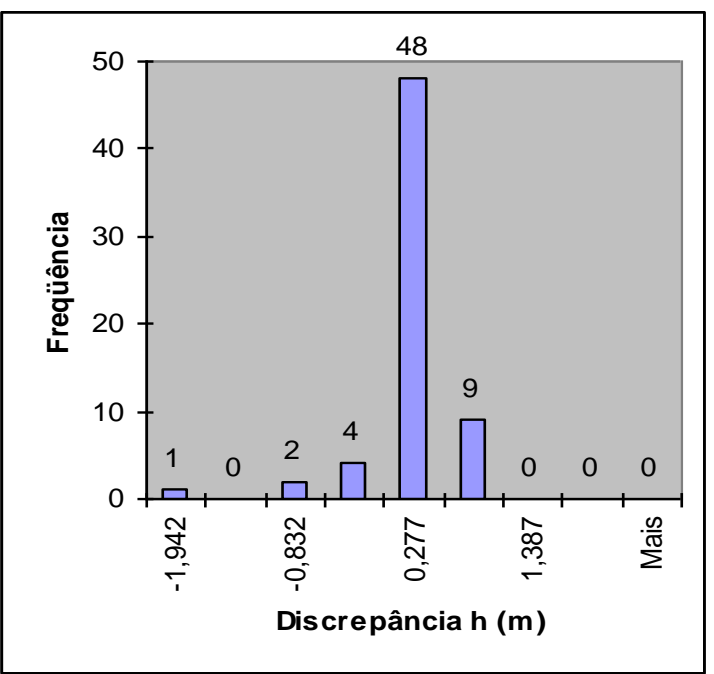

Figura 140 - Histograma Referente a h, no exp. 10.

\subsubsection{Experimento 11}

Deste experimento até o último foi utilizado um Receptor GPS de simples frequência. Este se refere ao vértice SAT 91607(P1-USP), com uma distância de $0,547 \mathrm{~km}$. Foram registradas (obtidas) 95 coordenadas com a solução fixa, as quais tiveram um tempo de inicialização de 1,17 segundos, uma latência de 1,51 segundos, rastreando-se oito satélites com um PDOP 1,87, em média, realizado no 
dia 27 de dezembro de 2008. As condições físicas e meteorológicas são as mesmas do experimento 1.

$\mathrm{Na}$ análise da discrepância a seguir, os valores encontrados foram os seguintes:

$$
\begin{array}{ll}
\mathrm{E}=323255.083 \mathrm{~m} ; & \Delta \mathrm{E}=|-0,001 \mathrm{~m}|<0.011 \mathrm{~m}(\text { ver tabela 12) } \\
\mathrm{N}=7394432.167 \mathrm{~m} ; & \Delta \mathrm{N}=|0,003 \mathrm{~m}|<0.011 \mathrm{~m}(\text { ver tabela 12) } \\
\mathrm{h}=718,159 \mathrm{~m} ; & \Delta \mathrm{h}=|-0,019 \mathrm{~m}|>0.021 \mathrm{~m}(\text { ver tabela 12) }
\end{array}
$$

Após a análise de cada coordenada obtida com o valor esperado, conforme a tabela 12 , conclui-se que a amostra atende à planimetria em $97 \%$ e à altimetria em $94 \%$.

Na figura 141, pode ser vista a dispersão dos resultados das coordenadas UTM mensuradas no referido ponto considerando as direções ( $E$ e $N)$.

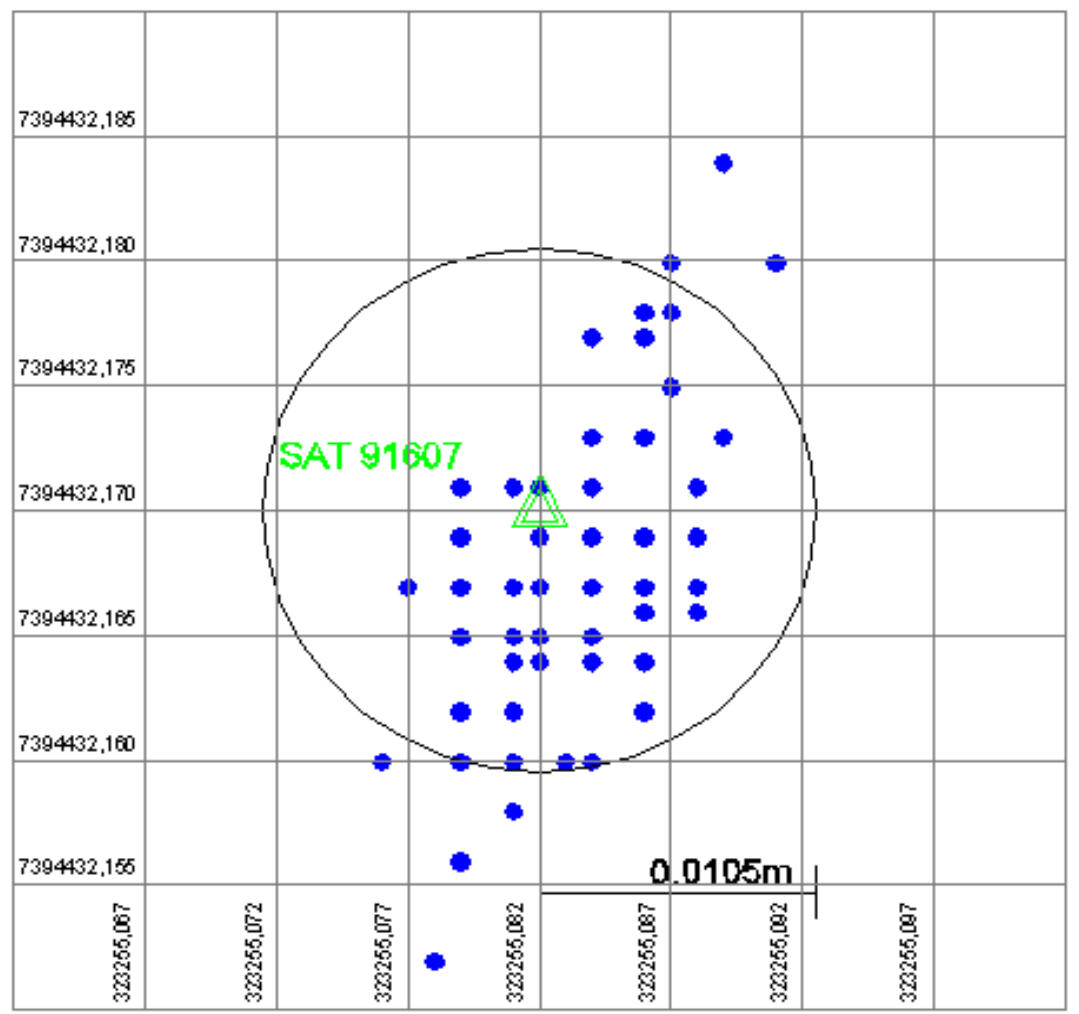

Figura 141 - Dispersão dos pontos ao redor do valor oficial, exp. 11. 
As figuras 142, 144 e 146 apresentam os gráficos das incidências relativamente às coordenadas $\mathrm{E}, \mathrm{N}$ e h na amostra e as figuras 143, 145 e 147 o histograma das discrepâncias em cada eixo com relação à coordenada oficial.

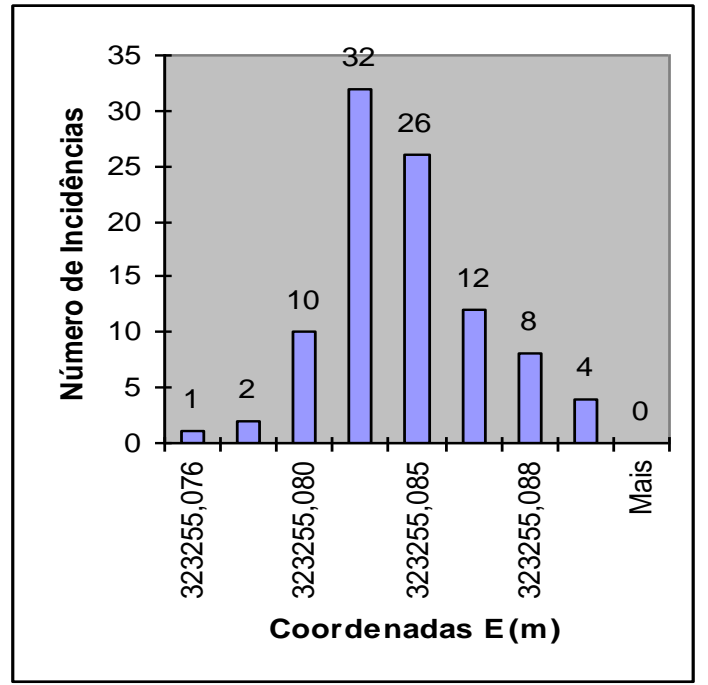

Figura 142 - Incidência da Coordenada E, no exp. 11.

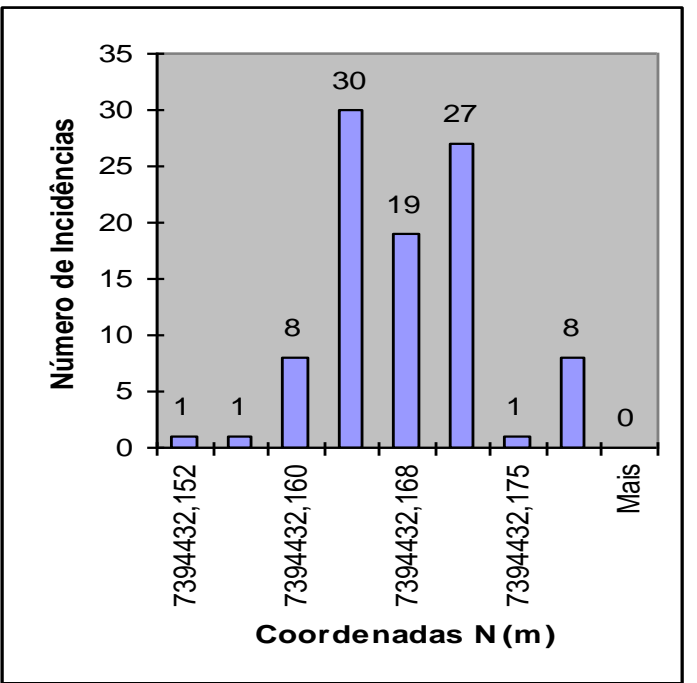

Figura 144 - Incidência da Coordenada N, no exp. 11.

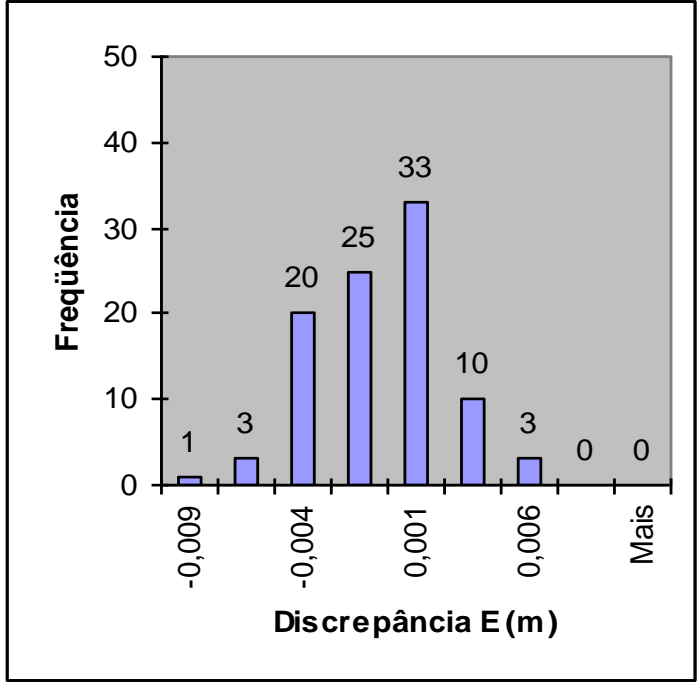

Figura 143 - Histograma referente a E, no exp. 11.

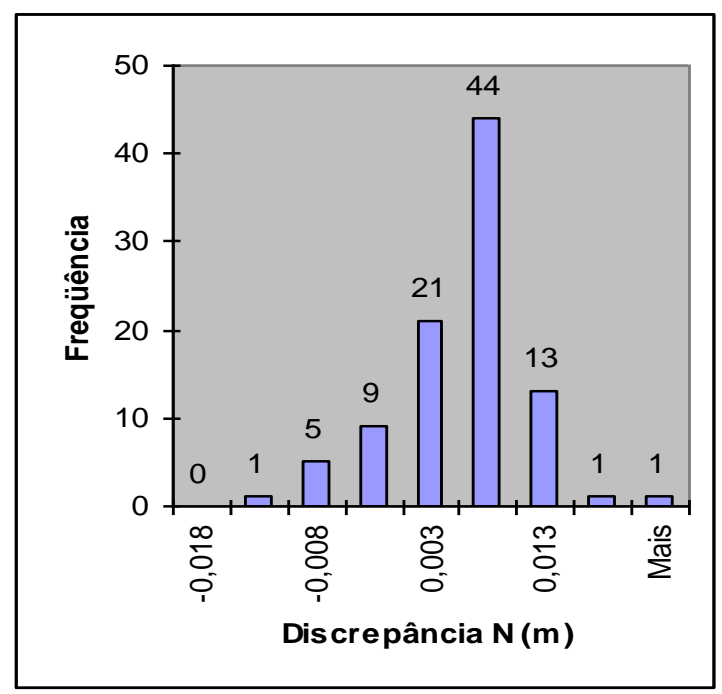

Figura 145 - Histograma Referente a N, no exp. 11. 


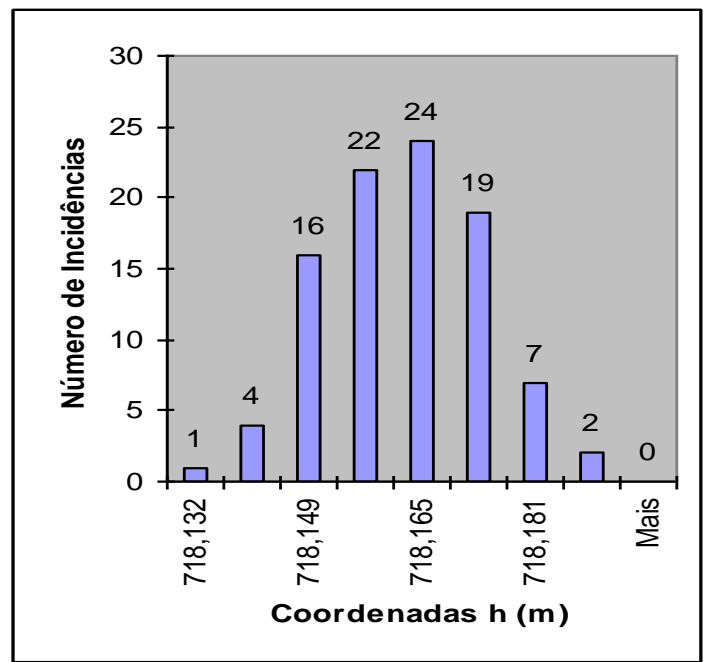

Figura 146 - Incidência da Coordenada h, no exp. 11.

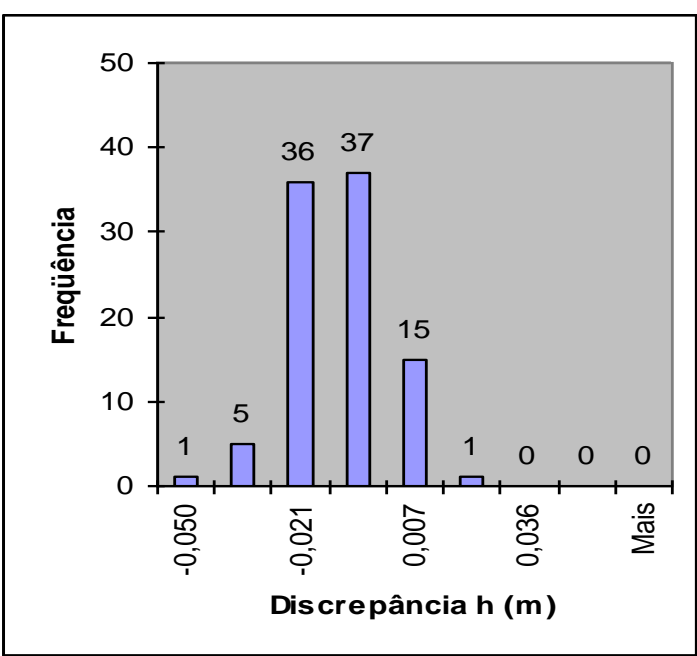

Figura 147 - Histograma Referente a $\mathrm{h}$, no exp. 11.

\subsubsection{Experimento 12}

Este refere-se ao vértice V2295 (Av. Sumaré), com distância de 5,7 km. Foram registradas (obtidas) 22 coordenadas, sendo sete com solução fixa e 15 com solução flutuante, realizado no dia 22 de fevereiro de 2009. Neste experimento a análise foi dividida em a e b conforme a solução. As condições físicas e meteorológicas são as mesmas do experimento 2.

No teste a, serão consideradas as sete coordenadas fixas, as quais tiveram um tempo de inicialização de 18 segundos, uma latência de 1,6 segundos, rastreando-se sete satélites com um PDOP 2,1, em média.

$\mathrm{Na}$ análise da discrepância a seguir, os valores encontrados foram os seguintes:

$$
\begin{array}{ll}
\mathrm{E}=328897,820 \mathrm{~m} ; & \Delta \mathrm{E}=|0,020 \mathrm{~m}|>0,016 \mathrm{~m}(\text { ver tabela 12) } \\
\mathrm{N}=7395519,010 \mathrm{~m} ; & \Delta \mathrm{N}=|-0,009 \mathrm{~m}|<0,016 \mathrm{~m}(\text { ver tabela 12) } \\
\mathrm{h}=750,463 \mathrm{~m} ; & \Delta \mathrm{h}=|-0.066 \mathrm{~m}|>0,026 \mathrm{~m}(\text { ver tabela 12) }
\end{array}
$$

Após a análise de cada coordenada com o valor esperado, conforme a tabela 12, constatou-se que a amostra atende à planimetria em $100 \%$ e à altimetria em $85,7 \%$. 
$\mathrm{Na}$ figura 148, pode ser vista a dispersão dos resultados das coordenadas UTM mensuradas no referido ponto considerando as direções ( $E$ e N) com solução fixa.

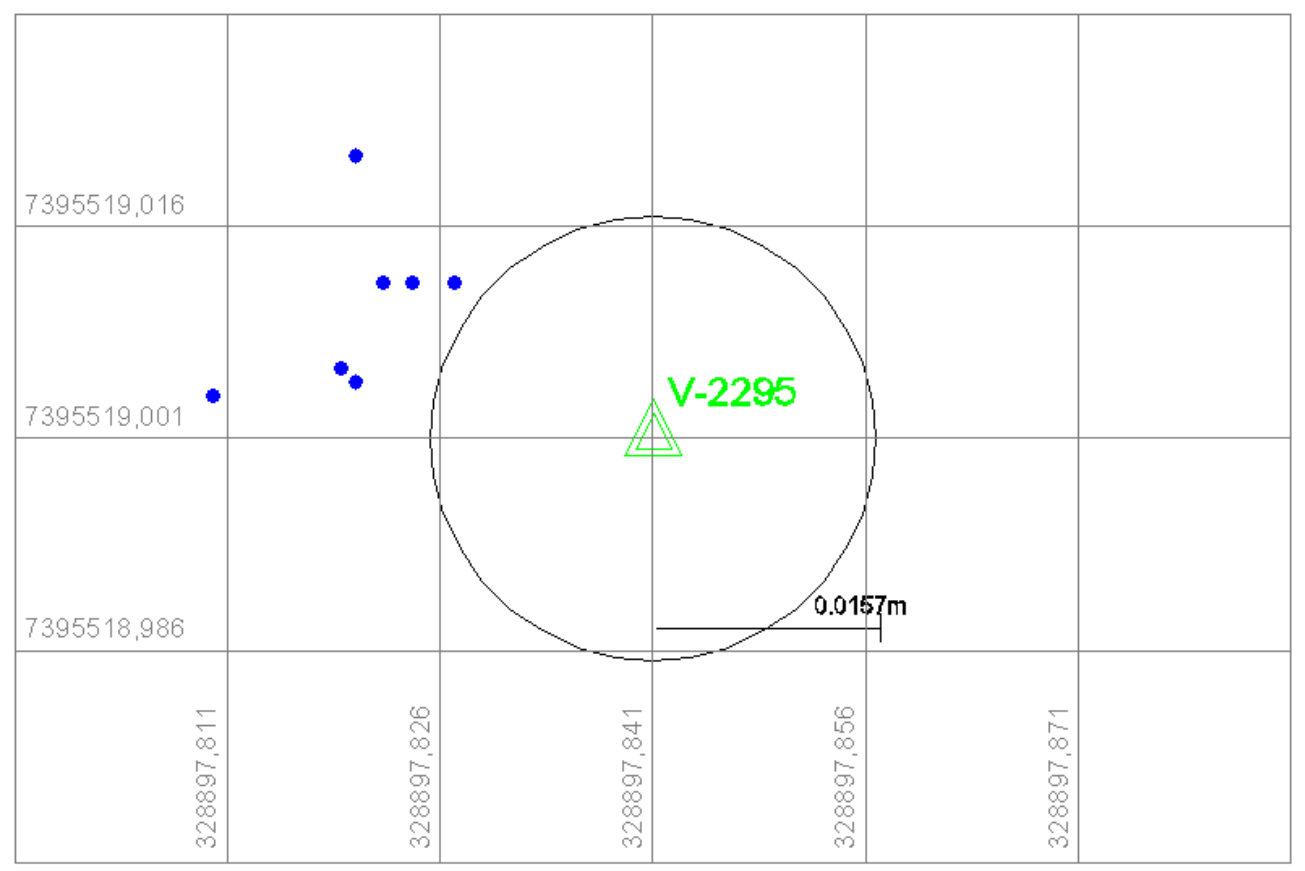

Figura 148 - Dispersão dos pontos ao redor do valor oficial, exp. 12a.

As figuras 149, 151 e 153 apresentam os gráficos das incidências relativamente às coordenadas $\mathrm{E}, \mathrm{N}$ e $\mathrm{h}$ na amostra e as figuras 150152 e 154 o histograma das discrepâncias em cada eixo com relação à coordenada oficial.

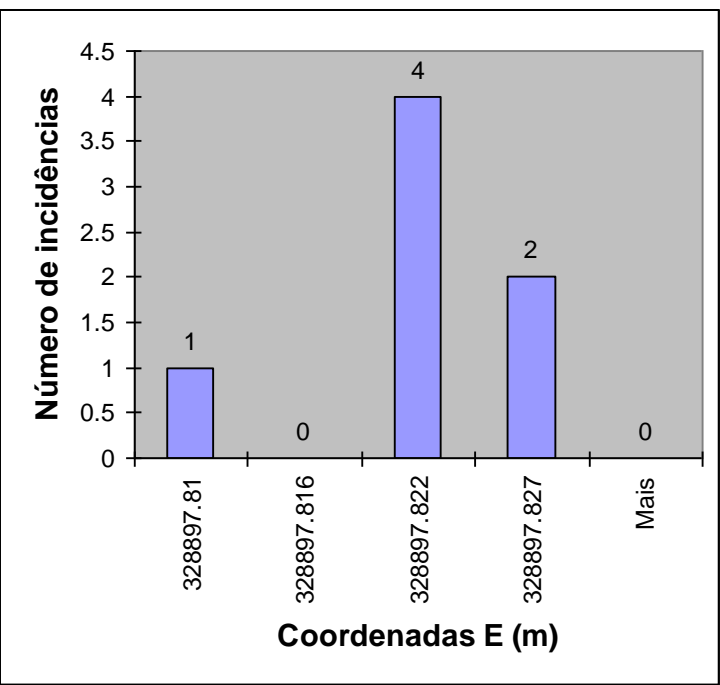

Figura 149 - Incidência da Coordenada E no exp. 12a.

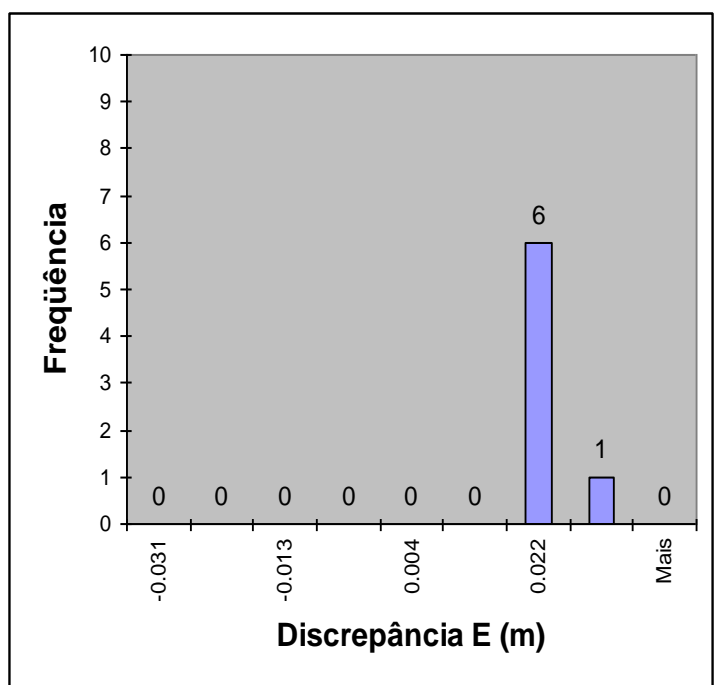

Figura 150 - Histograma Referente a E, no exp. 12a. 


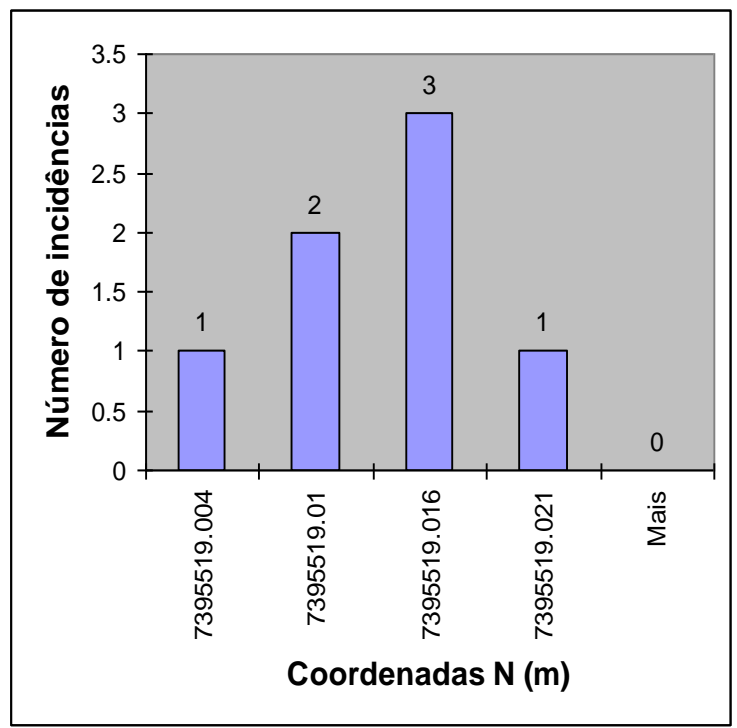

Figura 151 - Incidência da Coordenada N, no exp. 12a.

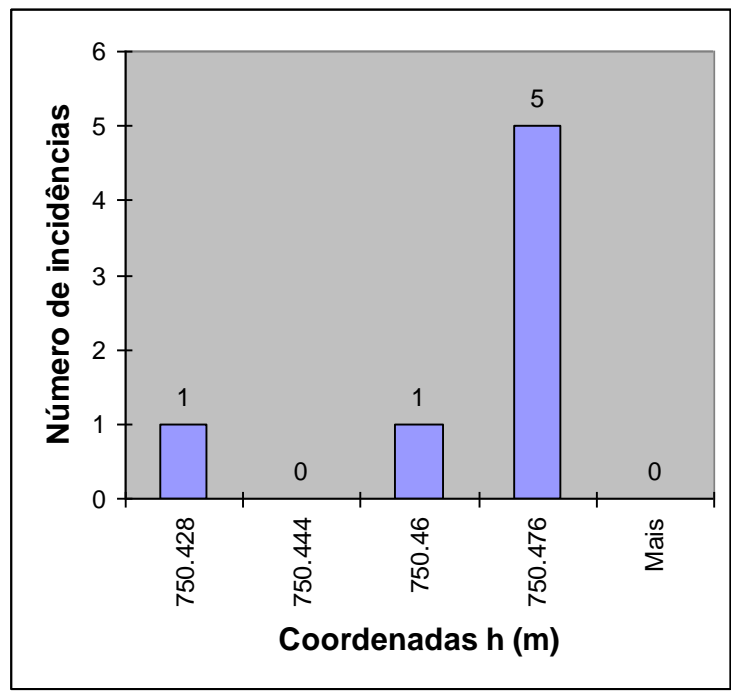

Figura 153 - Incidência da Coordenada $h$, no exp. 12a.

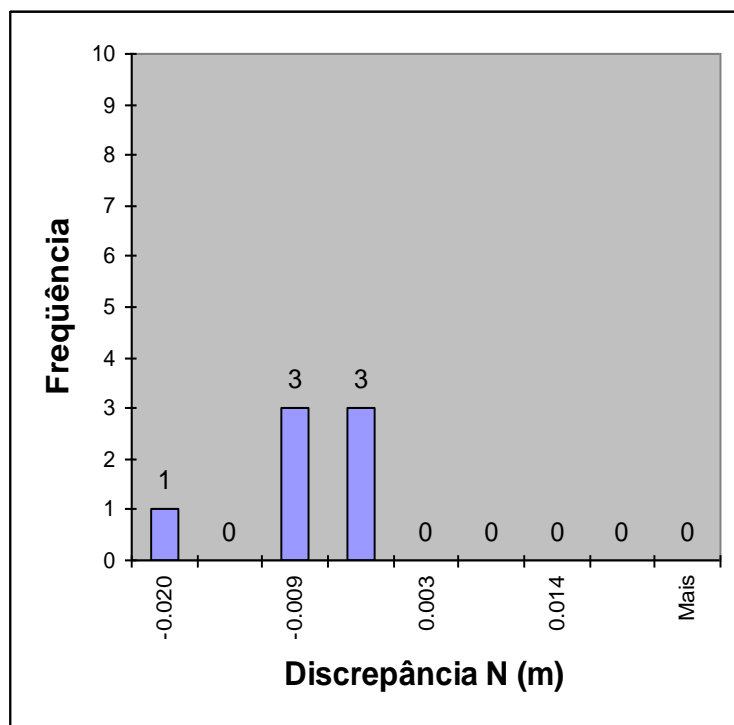

Figura 152 - Histograma Referente a N, no exp. 12a.

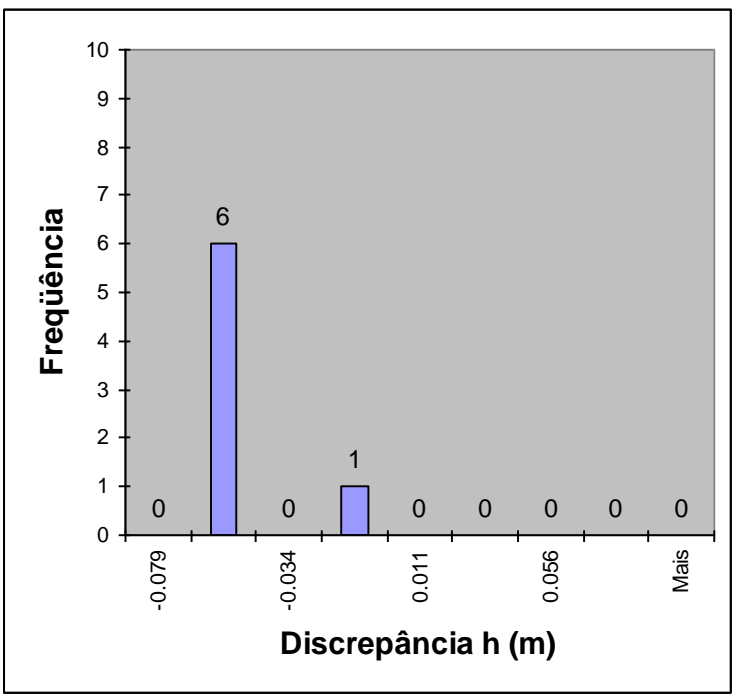

Figura 154 - Histograma Referente a $h$, no exp. 12a.

No teste $\mathbf{b}$, serão consideradas as 15 coordenadas flutuantes, uma latência de 1,6 segundos, as quais tiveram um tempo de inicialização de 3 minutos, rastreando-se sete satélites com um PDOP 2,1, em média.

$\mathrm{Na}$ análise da discrepância a seguir, os valores encontrados foram os seguintes: 


$$
\begin{array}{ll}
\mathrm{E}=328898,079 \mathrm{~m} ; & \Delta \mathrm{E}=|-0,023 \mathrm{~m}|>0,016 \mathrm{~m}(\text { ver tabela 12) } \\
\mathrm{N}=7395518,719 \mathrm{~m} ; & \Delta \mathrm{N}=|0,029 \mathrm{~m}|<0,016 \mathrm{~m}(\text { ver tabela 12) } \\
\mathrm{h}=751,066 \mathrm{~m} ; & \Delta \mathrm{h}=|-0.066 \mathrm{~m}|>0,026 \mathrm{~m}(\text { ver tabela 12) }
\end{array}
$$

Verificando-se cada coordenada com o valor esperado, conforme a tabela 12 , constatou-se que a amostra atende à planimetria em $3 \%$ e à altimetria em nenhum caso.

$\mathrm{Na}$ figura 155, pode ser vista a dispersão dos resultados das coordenadas UTM mensuradas no referido ponto considerando as direções ( $E$ e $N$ ) para as soluções flutuantes.

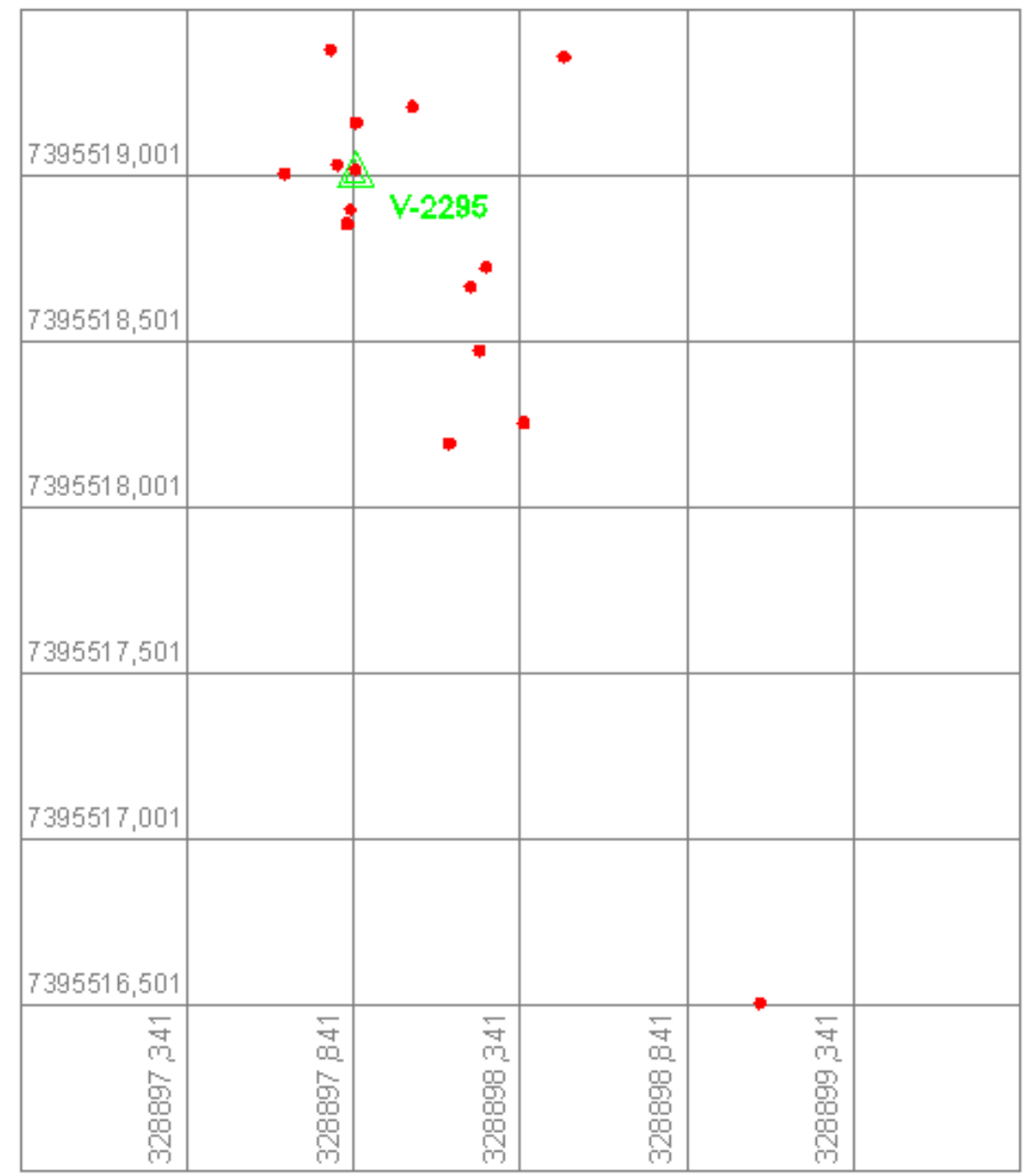

Figura 155 - Dispersão dos pontos ao redor do valor oficial, exp. 12b.

As figuras 156, 158 e 160 apresentam os gráficos das incidências relativamente às coordenadas $\mathrm{E}, \mathrm{N}$ e h na amostra e as figuras 157, 159 e 161 o histograma das discrepâncias em cada eixo com relação à coordenada oficial. 


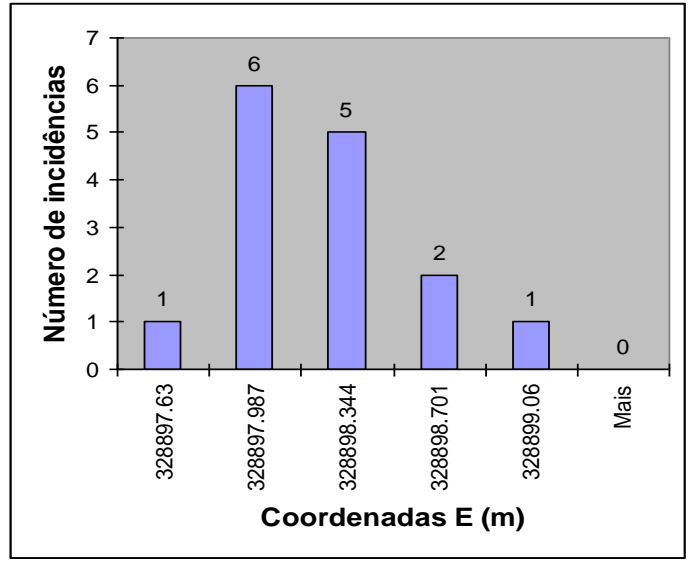

Figura 156 - Incidência da Coordenada $E$, no exp. 12b.

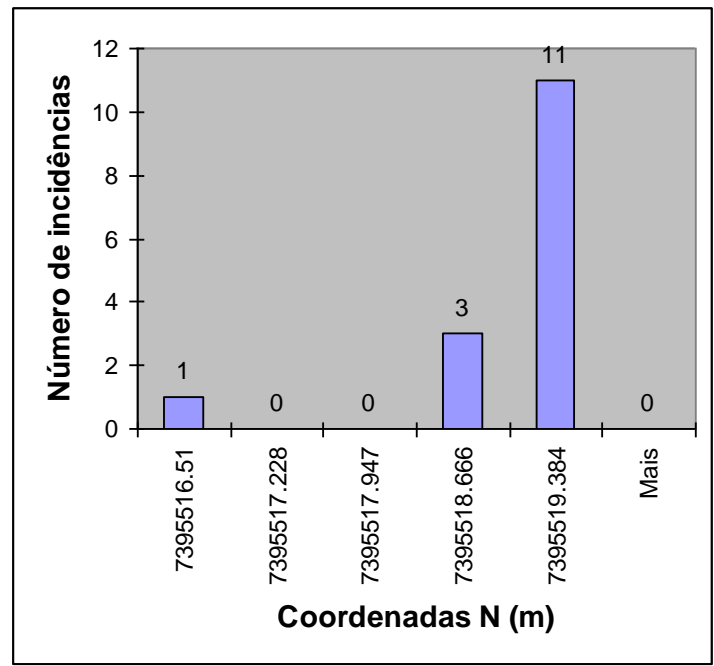

Figura 158 - Incidência da Coordenada N, no exp. $12 b$.

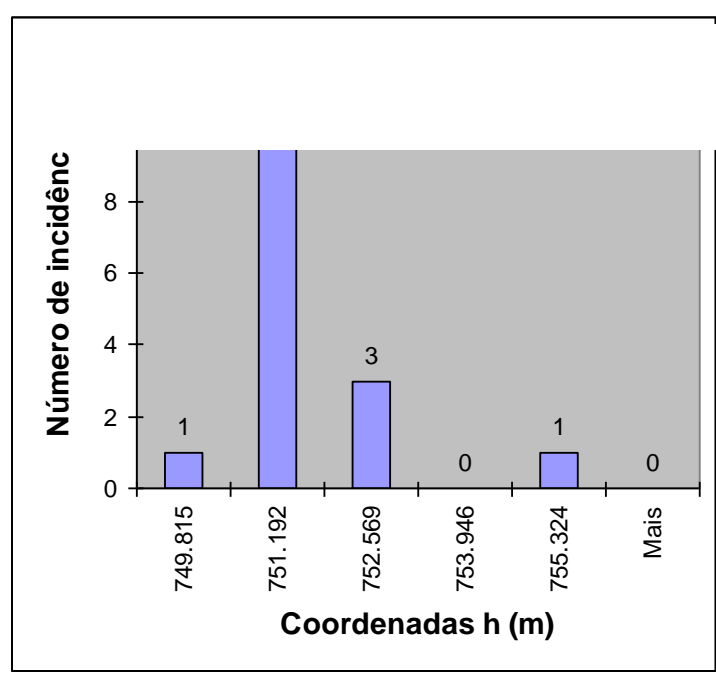

Figura 160 - Incidência da Coordenada h, no exp. $12 b$.

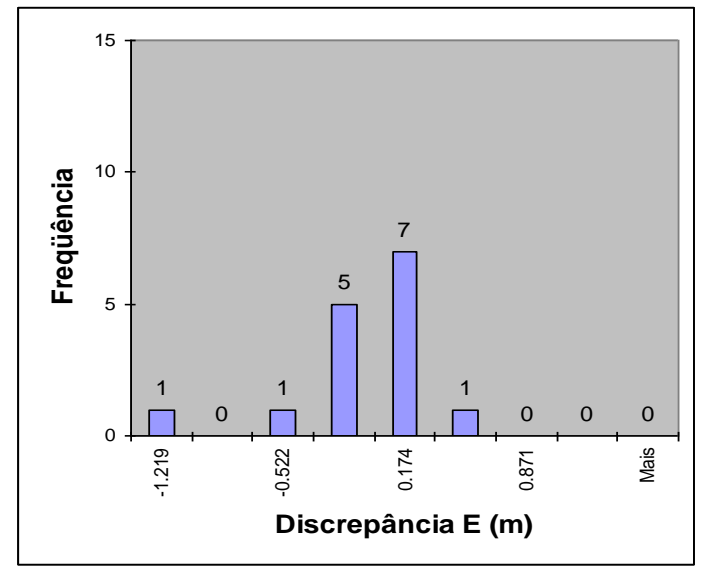

Figura 157 - Histograma Referente a E, no exp. $12 b$.

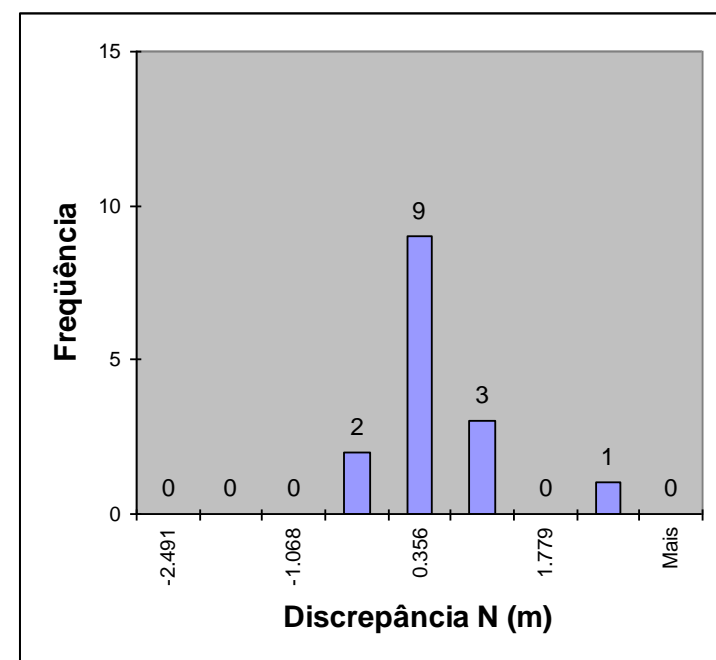

Figura 159 - Histograma Referente a N, no exp. $12 b$.

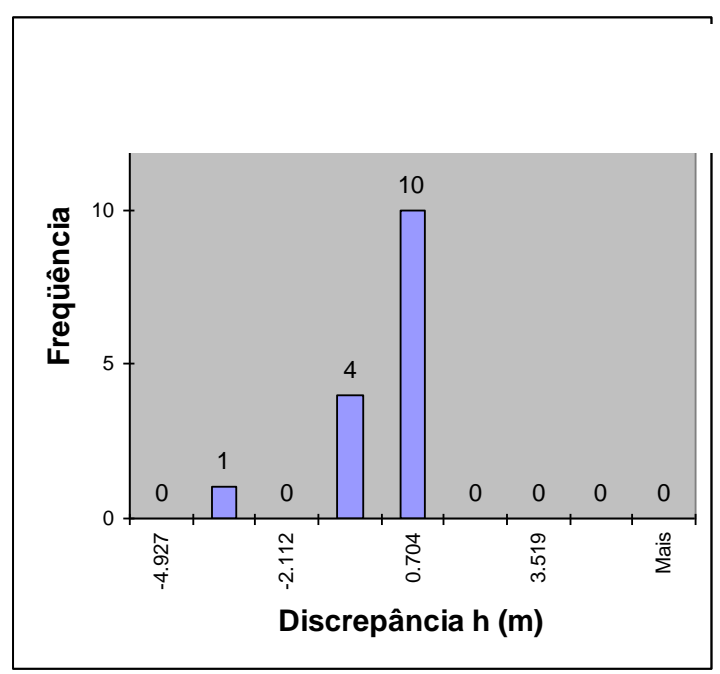

Figura 161 - Histograma Referente a h, no exp. 12b. 


\subsubsection{Experimento 13}

Este se refere ao vértice V2296 (Anhangabaú) com distância de 9,6 km. Foram registradas (obtidas) 65 coordenadas com a solução flutuante, as quais tiveram um tempo de inicialização de 3,2 minutos, uma latência de dois segundos, rastreando-se cinco a seis satélites com um PDOP 7,9 (valor alto), em média, realizado no dia 22 de dezembro de 2008. As condições físicas e meteorológicas são as mesmas do experimento 3.

$\mathrm{Na}$ análise da discrepância a seguir, os valores encontrados foram os seguintes:

$$
\begin{array}{ll}
\mathrm{E}=332793,361 \mathrm{~m} ; & \Delta \mathrm{E}=|0,262 \mathrm{~m}|>0,02 \mathrm{~m}(\text { ver tabela 12) } \\
\mathrm{N}=7394977,053 \mathrm{~m} ; & \Delta \mathrm{N}=|-0,031 \mathrm{~m}|>0,02 \mathrm{~m}(\text { ver tabela 12) } \\
\mathrm{h}=\mathrm{735,603 \textrm {m } ;} & \Delta \mathrm{h}=|-0,598 \mathrm{~m}|>0,03 \mathrm{~m}(\text { ver tabela 12) }
\end{array}
$$

Verificando cada coordenada com o valor esperado, conforme a tabela 12 , constatou-se que a amostra atende à planimetria em 14\% e à altimetria $3 \%$.

$\mathrm{Na}$ figura 162, pode ser vista a dispersão dos resultados das coordenadas UTM mensuradas no referido ponto considerando as direções ( $E$ e N). 


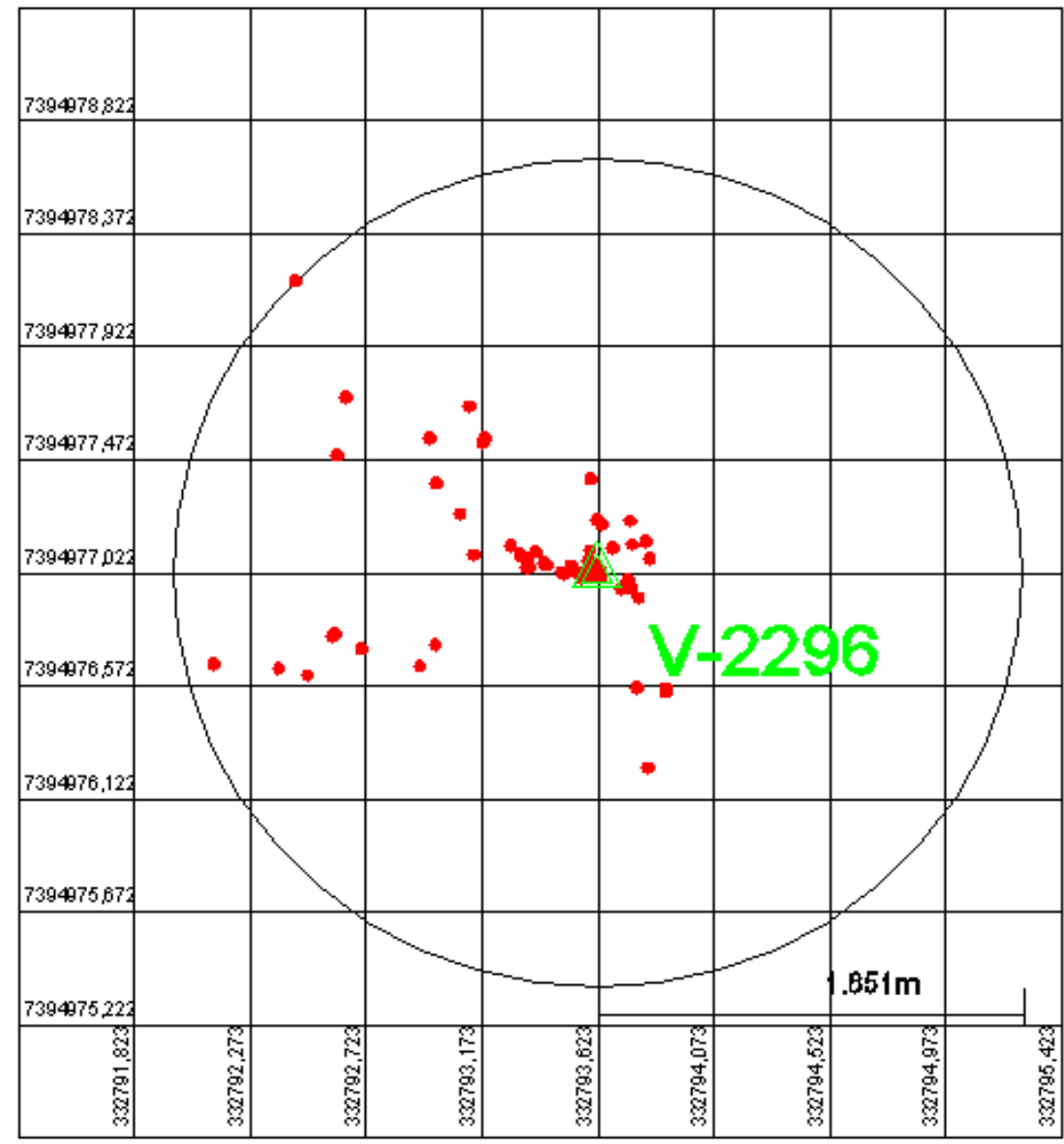

Figura 162 - Dispersão dos pontos ao redor do valor oficial, exp. 13.

As figuras 163, 165 e 167 apresentam os gráficos das incidências relativamente às coordenadas $\mathrm{E}, \mathrm{N}$ e h na amostra e as figuras 164, 166 e 168 o histograma das discrepâncias de cada eixo com relação à coordenada oficial.

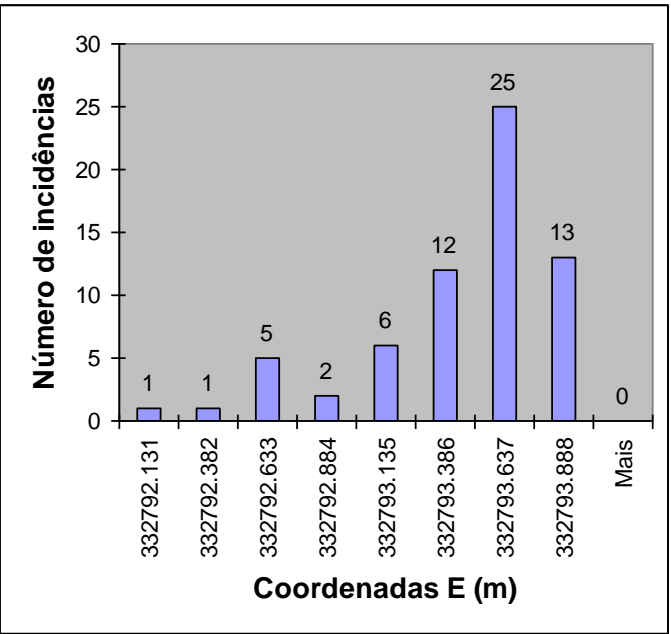

Figura 163 - Incidência da coordenada E, no exp. 13.

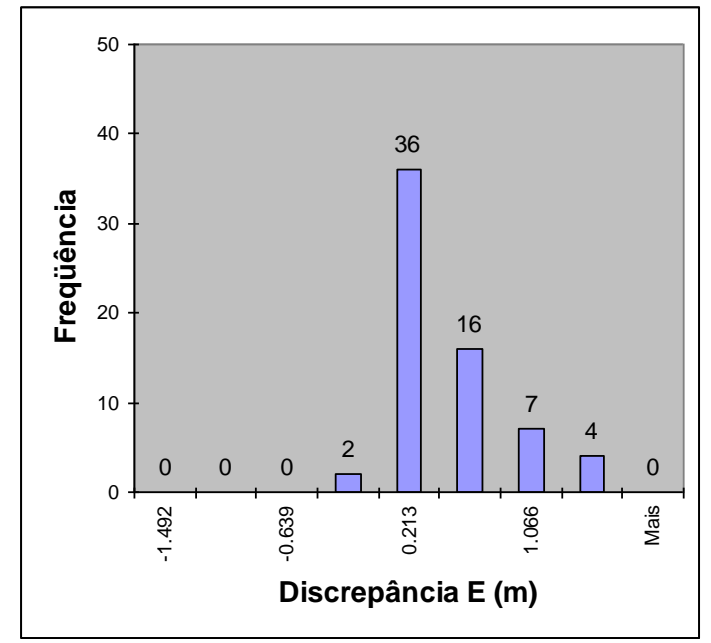

Figura 164 - Histograma referente a $\mathrm{E}$, no exp. 13. 


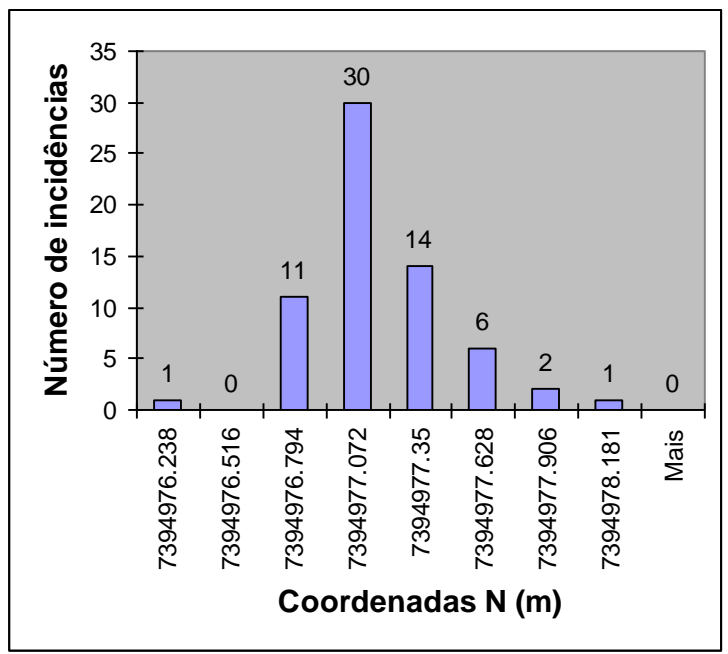

Figura 165- Incidência da Coordenada N, no exp. 13.

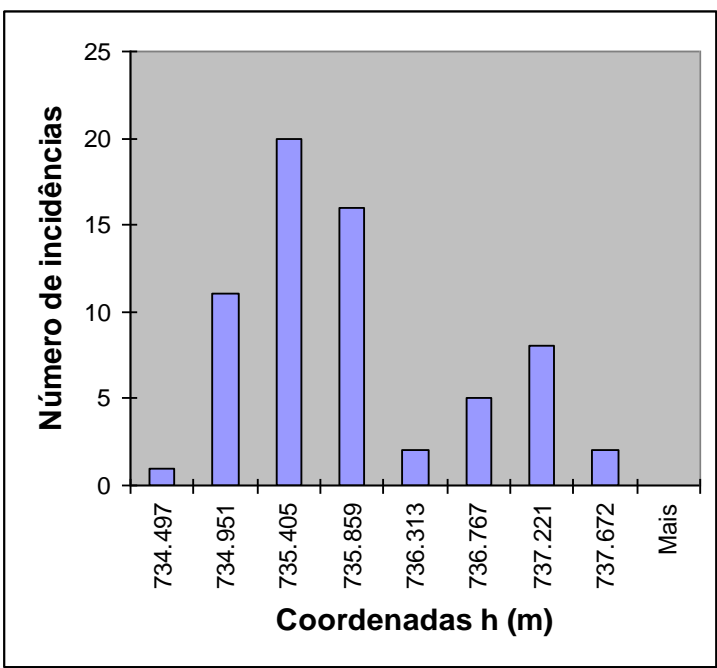

Figura 167 - Incidência da Coordenada h, no exp. 13.

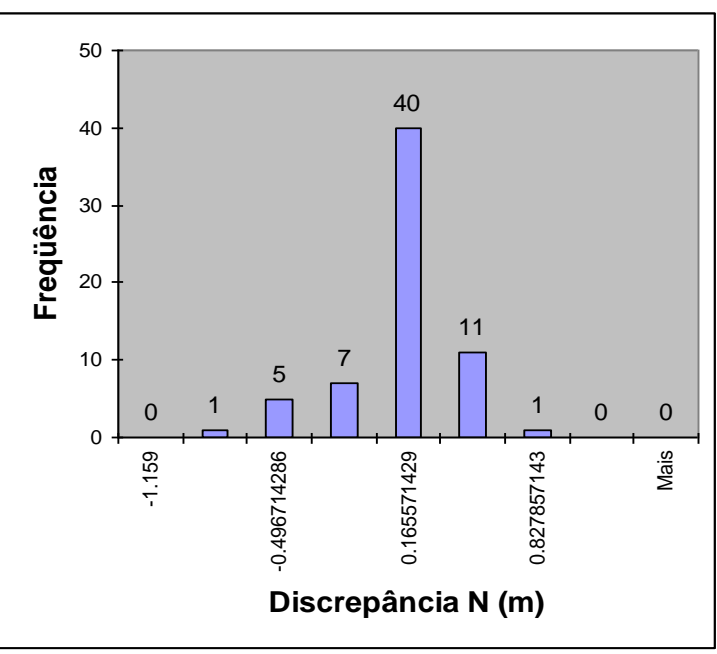

Figura 166 - Histograma referente a $\mathbf{N}$, no exp. 13.

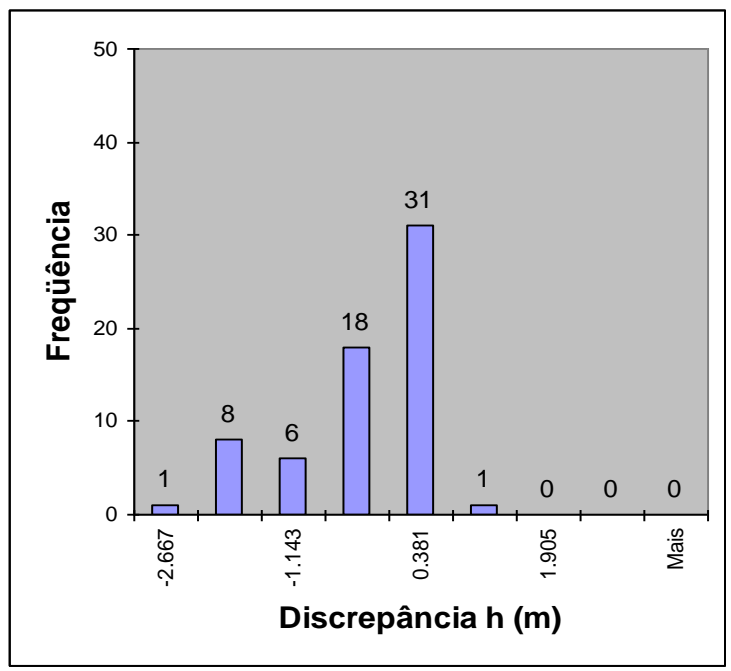

Figura 168 - Histograma referente a $h$, no exp. 13.

\subsubsection{Experimento 14}

Este se refere ao vértice V2009 (Perus) com uma distância de 17,1 km. Foram registradas (obtidas) 86 coordenadas com a solução flutuante, as quais tiveram um tempo de inicialização de 2,15 minutos, uma latência de 1,7 segundos, rastreandose oito satélites com um PDOP 2,61, em média, realizado no dia 23 de dezembro de 2008. As condições físicas e meteorológicas são as mesmas do experimento 4. 
$\mathrm{Na}$ análise da discrepância a seguir, os valores encontrados foram os seguintes:

$$
\begin{array}{lll}
\mathrm{E}=321920,140 \mathrm{~m} ; & \Delta \mathrm{E}=|-0,206 \mathrm{~m}|>0,027 \mathrm{~m}(\text { ver tabela 12) } \\
\mathrm{N}=7410979,596 \mathrm{~m} ; & \Delta \mathrm{N}=|-0.076 \mathrm{~m}|>0,027 \mathrm{~m}(\text { ver tabela 12) } \\
\mathrm{h}=833,247 \mathrm{~m} ; & \Delta \mathrm{h}=|-0.184 \mathrm{~m}|>0,037 \mathrm{~m}(\text { ver tabela 12) }
\end{array}
$$

Analisando cada coordenada com o valor esperado, conforme a tabela 12, constatou-se que a amostra atende à planimetria em $16 \%$ e na altimétrica em $13,95 \%$.

Na figura 169, pode ser vista a dispersão dos resultados das coordenadas UTM mensuradas no referido ponto considerando as direções ( $E$ e $N$ ).

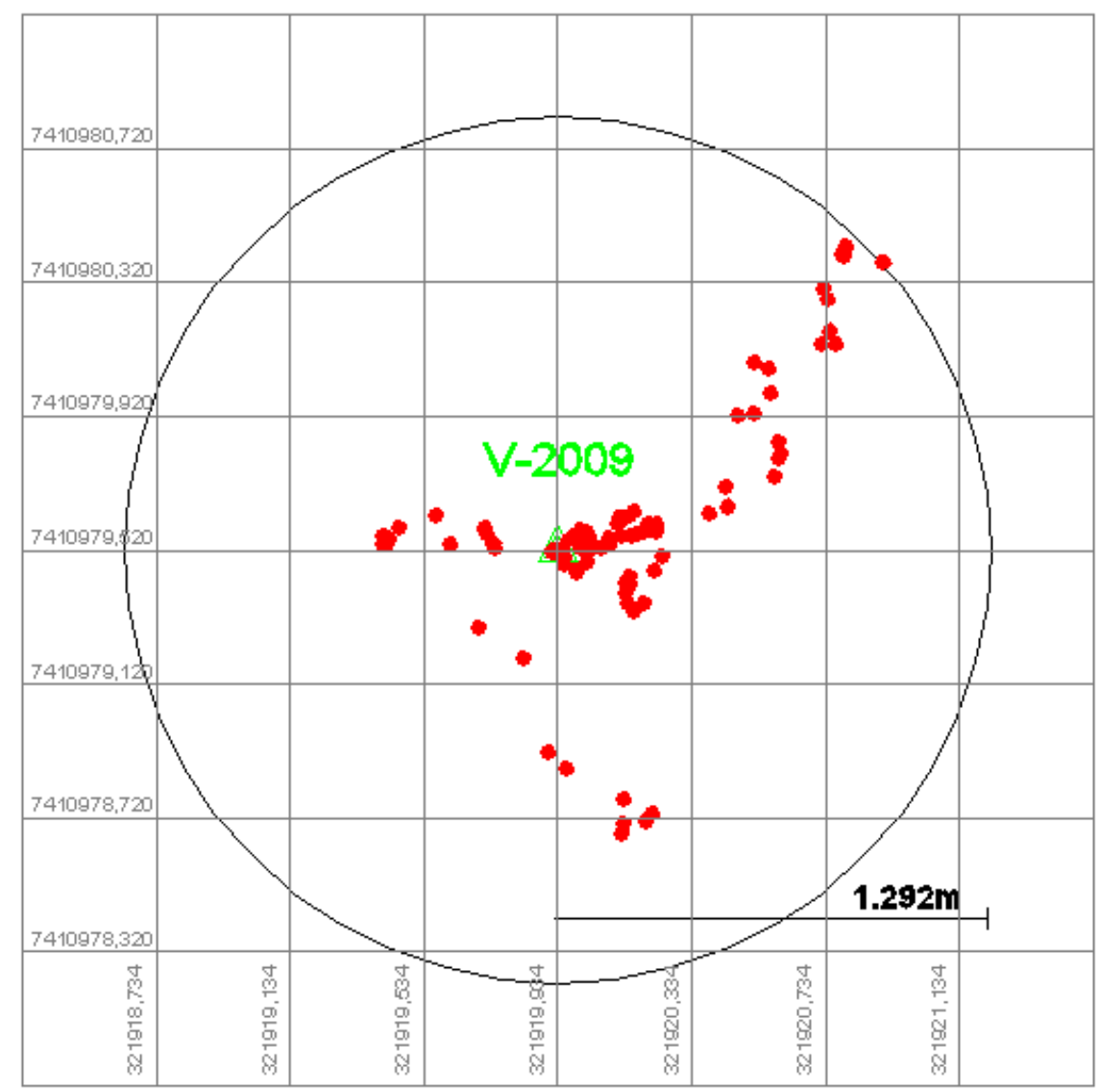

Figura 169 - Dispersão dos pontos ao redor do valor oficial, exp. 14. 
As figuras 170, 172 e 174 apresentam os gráficos das relativamente às coordenadas $\mathrm{E}, \mathrm{N}$ e h na amostra e as figuras 171, 173 e 175 o histograma das discrepâncias em cada eixo com relação à coordenada oficial.

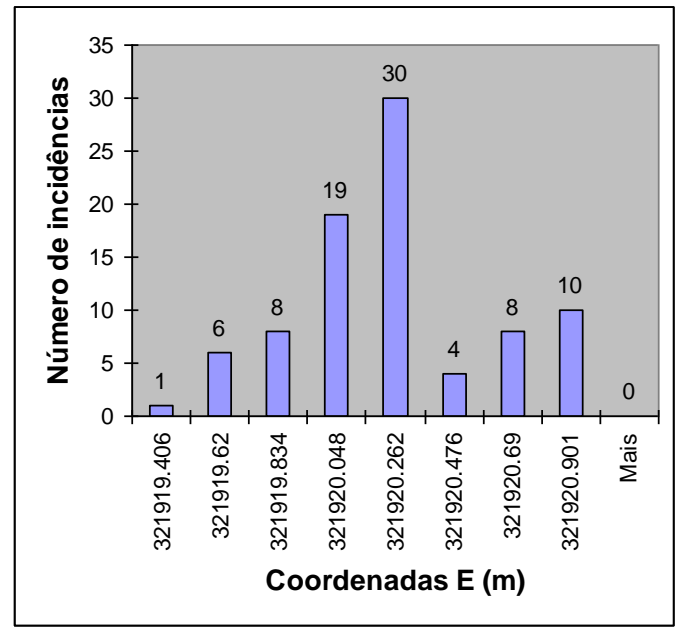

Figura 170 - Incidência da Coordenada E, no exp. 14.

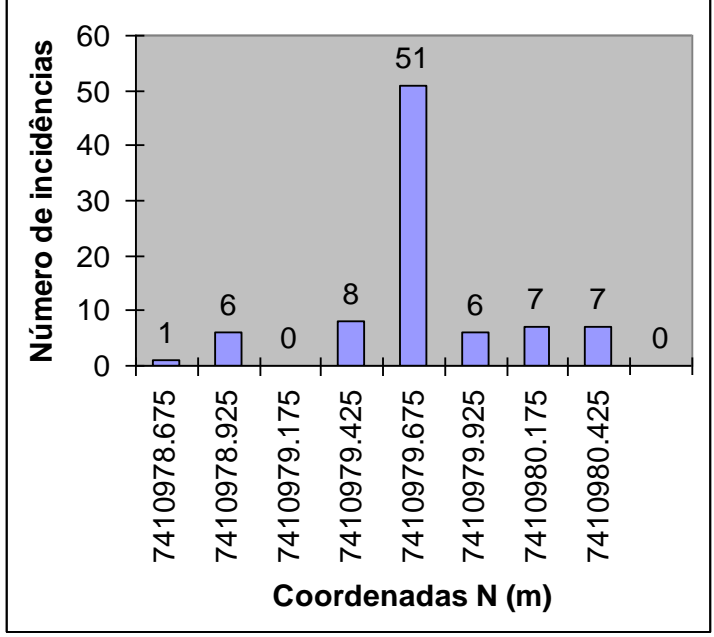

Figura 172 - Incidência da Coordenada N, no exp. 14.

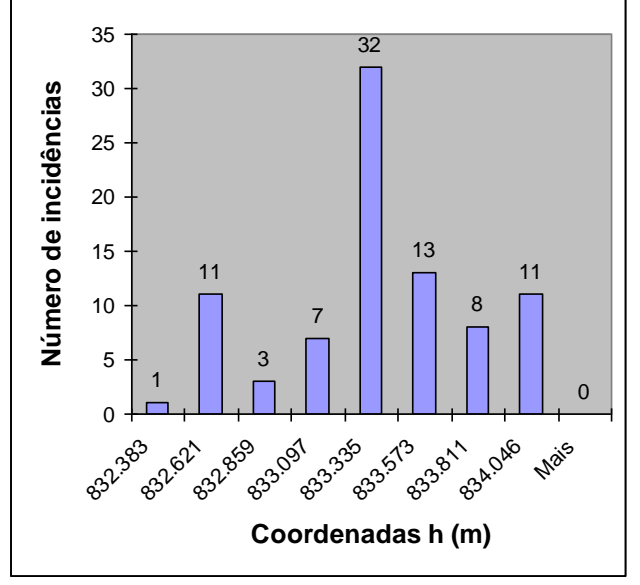

Figura 174- Incidência da Coordenada $h$, no exp. 14.

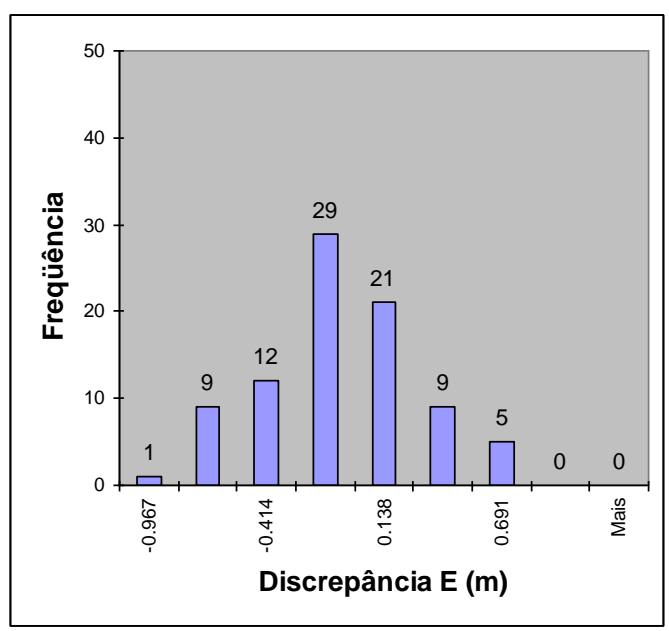

Figura 171 - Histograma Referente a E, no exp. 14.

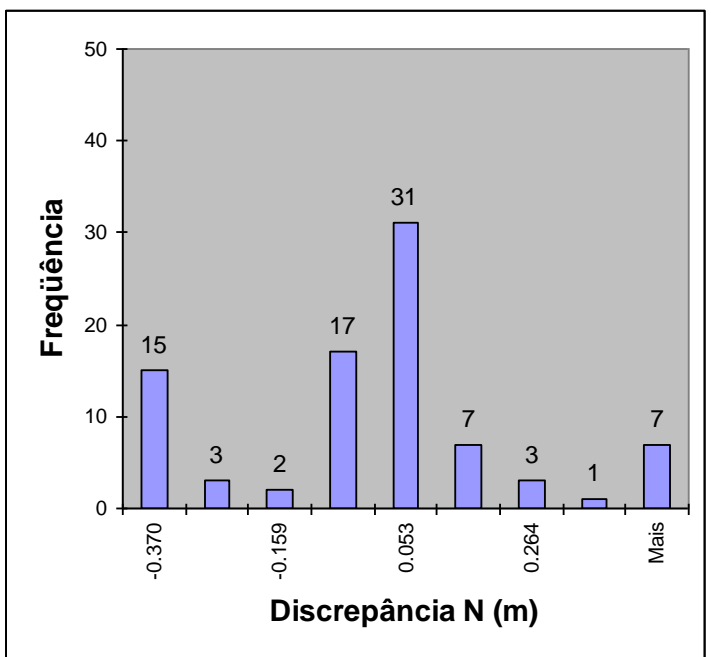

Figura 173- Histograma referente a N, no exp. 14

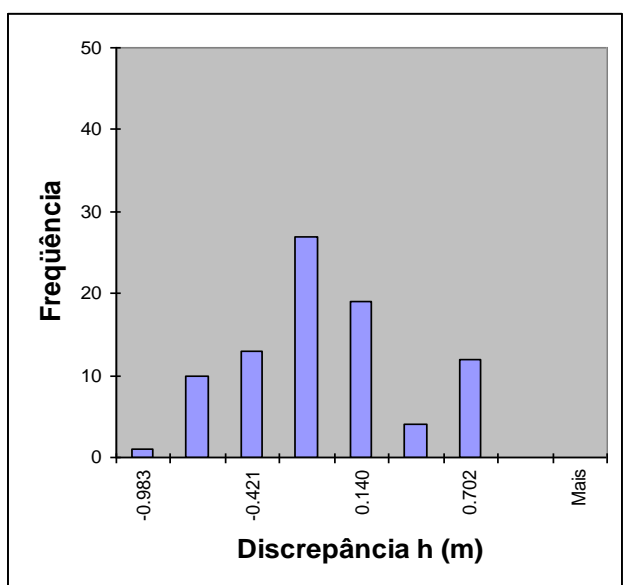

Figura 175 - Histograma Referente a h, no exp. 14. 


\subsubsection{Experimento 15}

Este se refere ao vértice V2837 (Parelheiros) com uma distância de 30,4km. Foram registradas (obtidas) 80 coordenadas com a solução flutuante, as quais tiveram um tempo de inicialização de 1,2 segundos, uma latência de 1,6 segundos, rastreando-se nove satélites com um PDOP de 2,5, em média, realizado no dia 29 de dezembro de 2008. As condições físicas e meteorológicas são as mesmas do experimento 5 .

$\mathrm{Na}$ análise da discrepância a seguir, os valores encontrados foram os seguintes:

$$
\begin{array}{ll}
\mathrm{E}=324457,765 \mathrm{~m} ; & \Delta \mathrm{E}=|0,060 \mathrm{~m}|>0,04 \mathrm{~m}(\text { ver tabela 12) } \\
\mathrm{N}=7363504,135 \mathrm{~m} ; & \Delta \mathrm{N}=|-0,093 \mathrm{~m}|>0,04 \mathrm{~m}(\text { ver tabela 12) } \\
\mathrm{h}=\mathrm{777,529 \textrm {m } ;} & \Delta \mathrm{h}=|-0,131 \mathrm{~m}|>0,05 \mathrm{~m}(\text { ver tabela 12) }
\end{array}
$$

Verificando-se a coordenada obtida com o valor esperado, conforme a Tabela 12 , conclui-se que a amostra atende à planimetria em $17 \%$ e à altimetria em $30 \%$.

$\mathrm{Na}$ figura 176, pode ser vista a dispersão dos resultados das coordenadas UTM mensuradas no referido ponto considerando as direções (E e N).

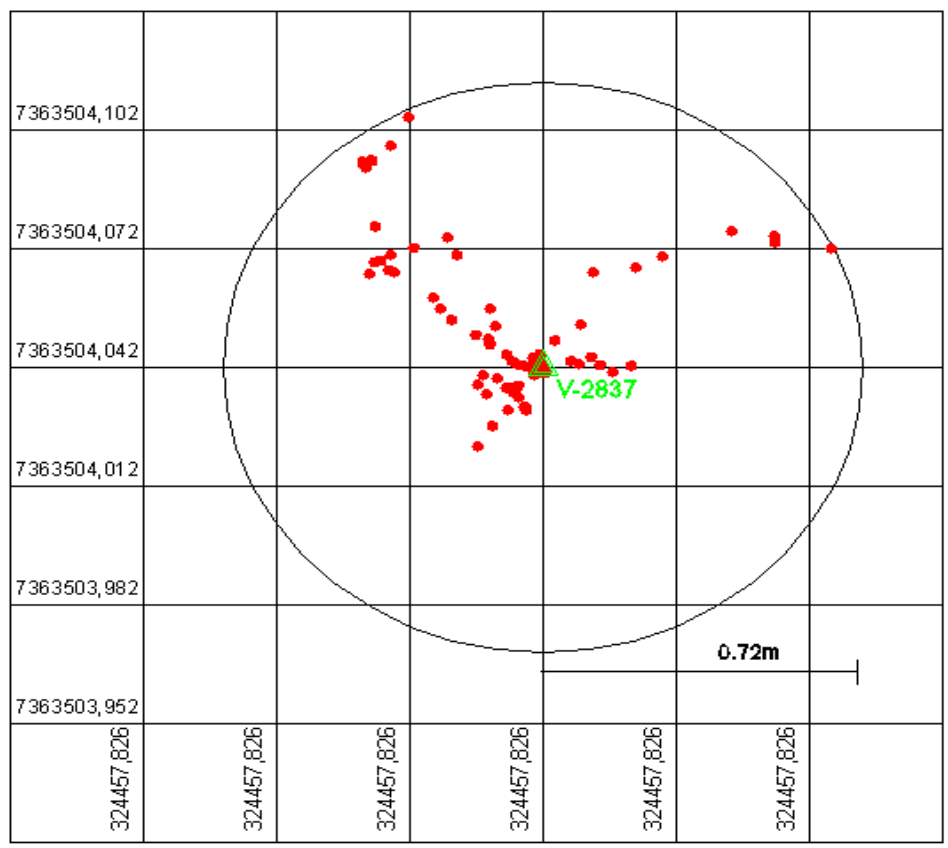

Figura 176 - Dispersão do ponto no exp. 15. 
As figuras 177, 179 e 181 apresentam os gráficos das incidências relativamente às coordenadas $\mathrm{E}, \mathrm{N}$ e h na amostra e as figuras 178,180 e $182 \mathrm{o}$ histograma das discrepâncias em cada eixo com relação à coordenada oficial.

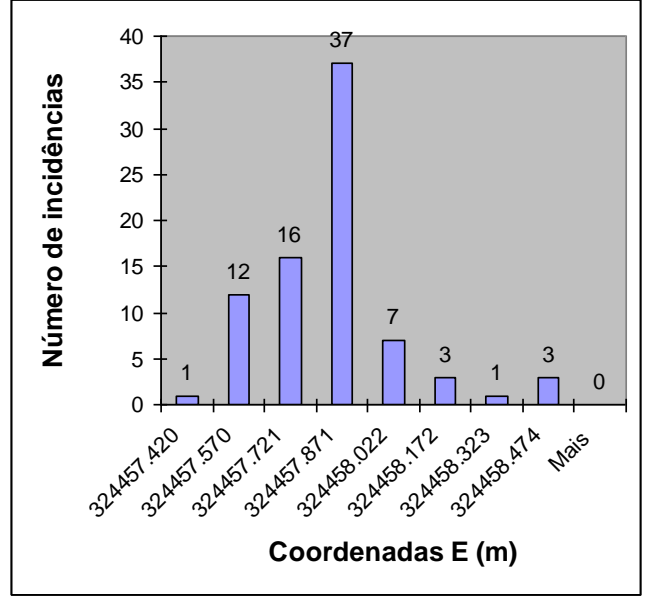

Figura 177 - Incidência da Coordenada E, no exp. 15.

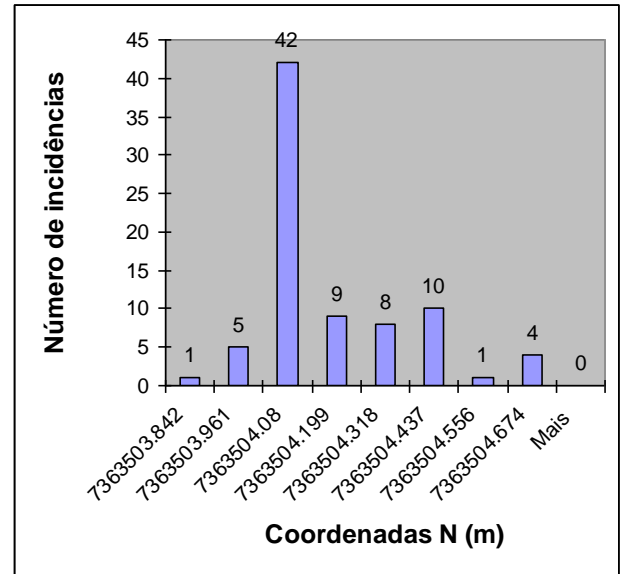

Figura 179 - Incidência da Coordenada N, no exp. 15.

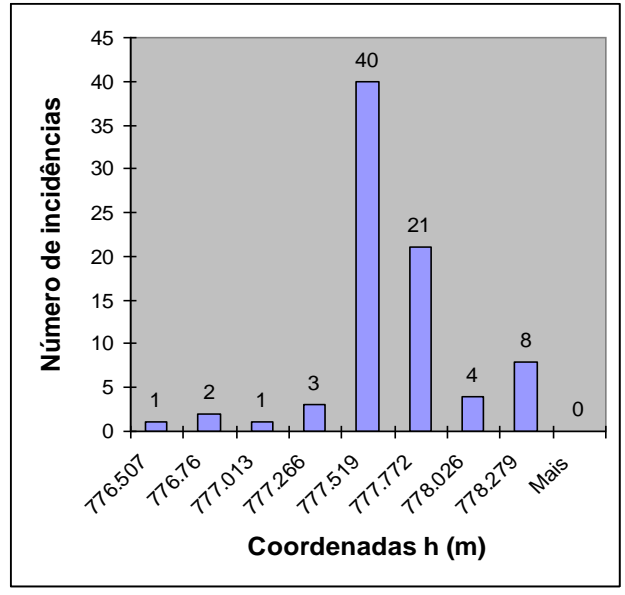

Figura 181- Incidência da Coordenada h, no exp. 15.

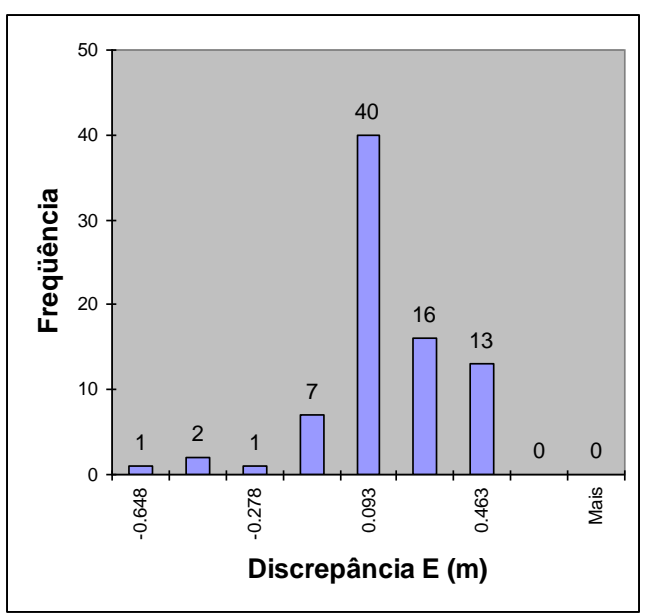

Figura 178 - Histograma Referente a E, no exp. 15.

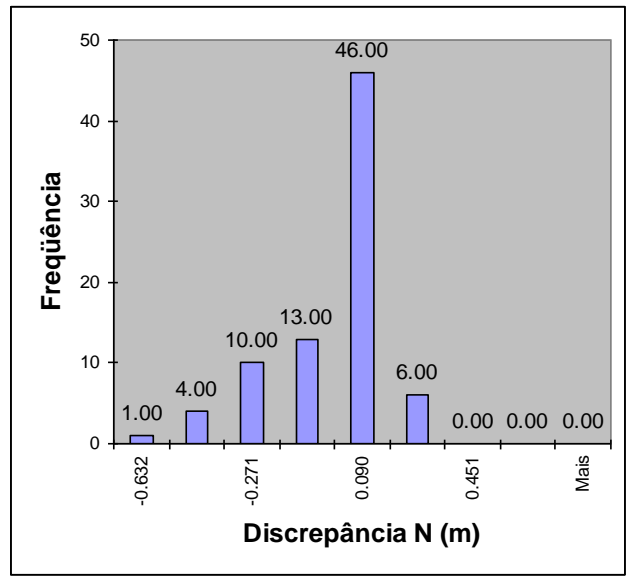

Figura 180 - Histograma Referente a N, no exp. 15.

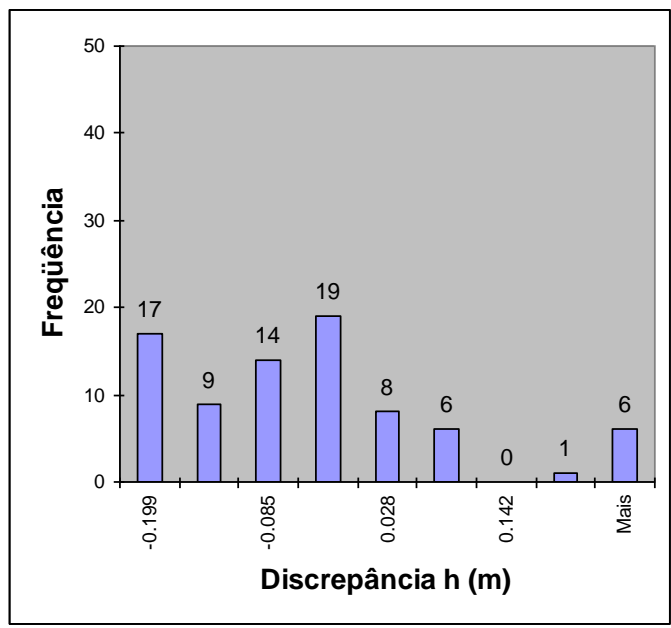

Figura 182 - Histograma Referente a $h$, no exp. 15. 


\subsubsection{Experimento 16}

Este se refere ao vértice V2510 (Tiradentes) com uma distância de $35 \mathrm{~km}$. Foram registradas (obtidas) 61 coordenadas com a solução flutuante, as quais tiveram um tempo de inicialização de 1,9 min, uma latência de 1,8 segundos, rastreando-se 7 satélites com um PDOP 3,7, em média, realizado no dia 26 de dezembro de 2008. As condições físicas e metereológicas foram as mesmas do experimento 6 .

$\mathrm{Na}$ análise da discrepância a seguir, os valores encontrados foram os seguintes:

$$
\begin{array}{ll}
\mathrm{E}=358096,268 \mathrm{~m} ; & \Delta \mathrm{E}=|0,008 \mathrm{~m}|<0,045 \mathrm{~m}(\text { ver tabela 12) } \\
\mathrm{N}=7390723,738 \mathrm{~m} ; & \Delta \mathrm{N}=|-0,032 \mathrm{~m}|<0,045 \mathrm{~m}(\text { ver tabela 12) } \\
\mathrm{h}=842,454 \mathrm{~m} ; & \Delta \mathrm{h}=|-0,099 \mathrm{~m}|>0,055 \mathrm{~m}(\text { ver tabela 12) }
\end{array}
$$

Verificando-se cada coordenada obtida e confrontando com o valor esperado (tabela 12), constatou-se que a amostra atende à planimetria em $85 \%$ e à altimetria em $62 \%$.

Na figura 183, observa-se a dispersão dos resultados das coordenadas UTM mensuradas no referido ponto considerando as direções ( $\mathrm{E}$ e N).

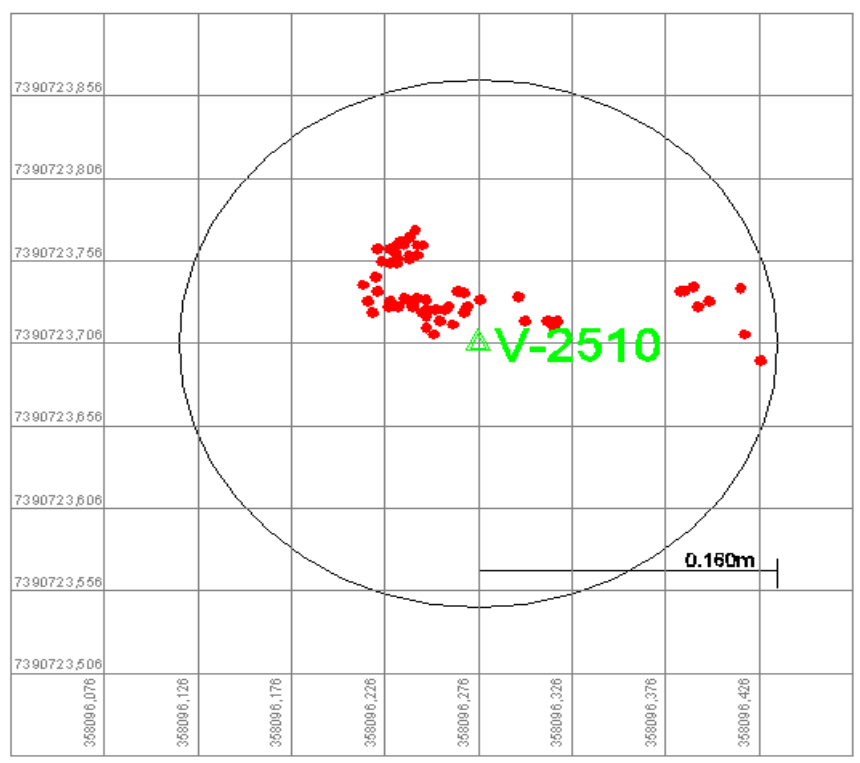

Figura 183 - Dispersão do ponto no exp. 16. 
As figuras 184, 186, 188 apresentam os gráficos das incidências relativamente às coordenadas $\mathrm{E}, \mathrm{N}$ e h na amostra e as figuras 185, 187, 189 o histograma das discrepâncias em cada eixo com relação à coordenada oficial.

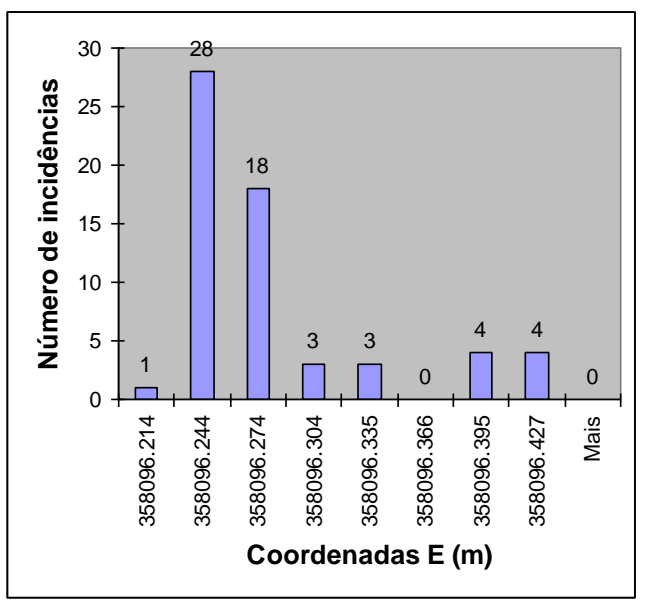

Figura 184 - Incidência da Coordenada E, no exp. 16.

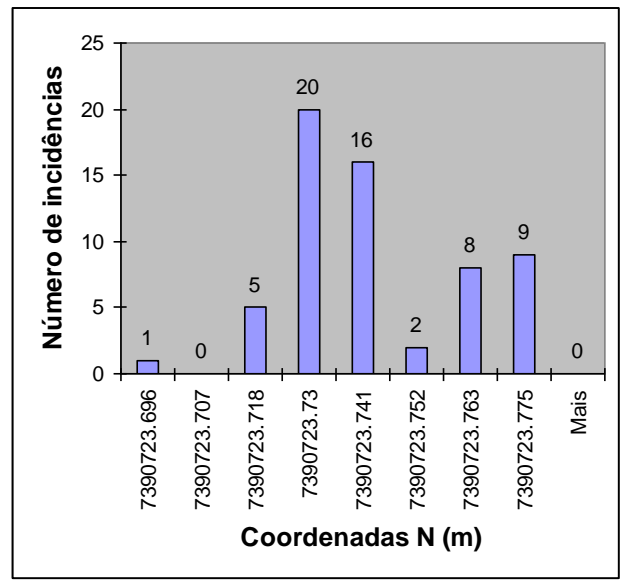

Figura 186 - Incidência da Coordenada N, no exp. 16.

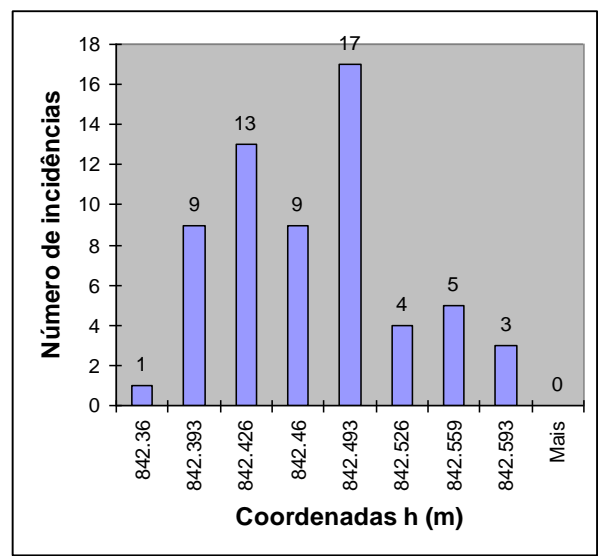

Figura 188- Incidência da Coordenada $h$, no exp. 16.

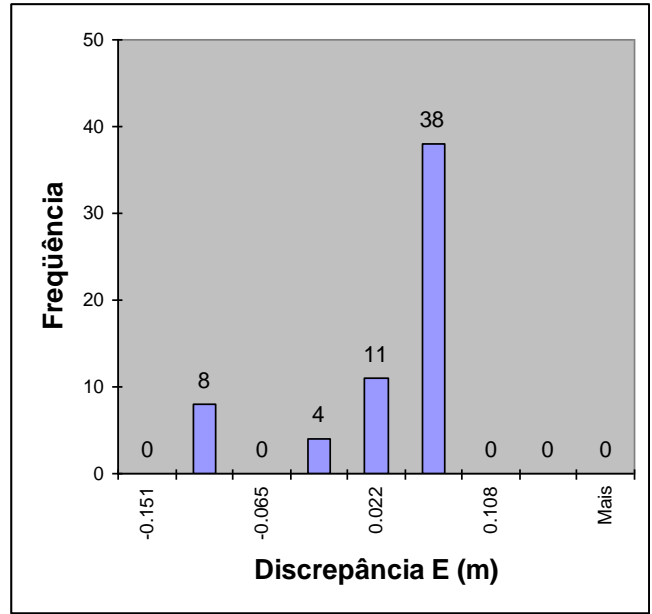

Figura 185 - Histograma Referente a E, no exp. 16.

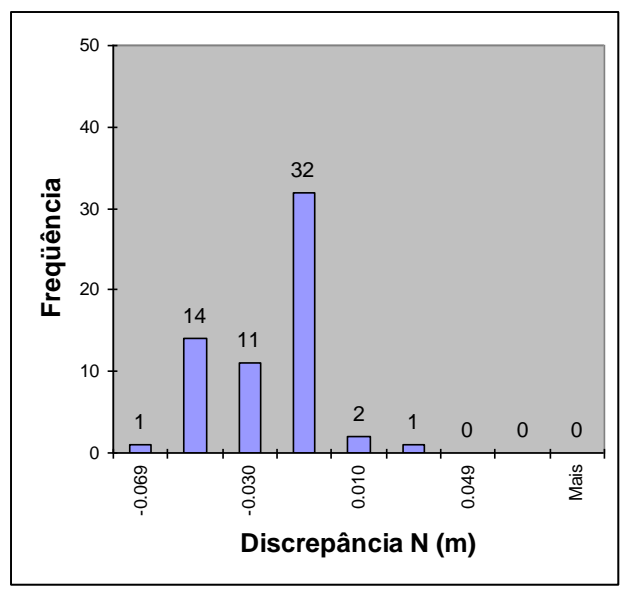

Figura 187- Histograma Referente a N, no exp. 16.

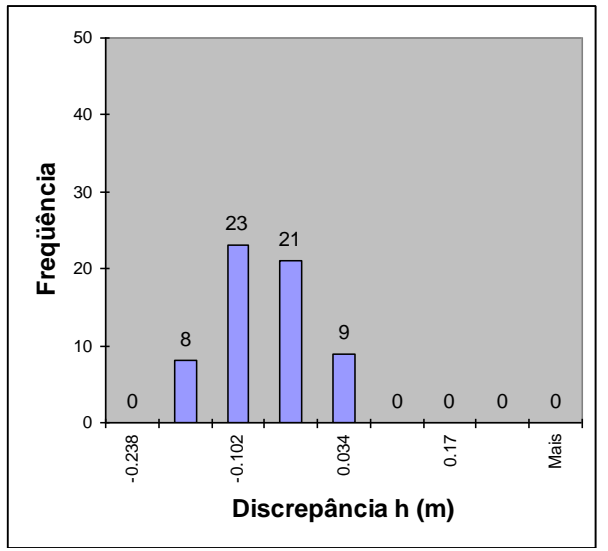

Figura 189 - Histograma referente a h, no exp. 16. 


\section{RESULTADOS OBTIDOS}

\subsection{METODOLOGIA DE ANÁLISE DOS RESULTADOS}

Os resultados parciais e suas análises relativas aos experimentos são apresentados a seguir. Contendo o teste de tendência, teste de precisão, valores máximo e mínimo das diferenças, precisão média e a diferença padrão.

$\mathrm{Na}$ análise de tendência, foi aplicado o teste T Student comparando-se o valor de $\mathrm{t}$ amostral $\left(t_{\text {calc }}\right)$ com o valor esperado analisando a existência de tendência nos eixos $\mathrm{E}, \mathrm{N}$ e h.

$\mathrm{Na}$ análise da precisão, foi aplicado o teste do Qui-Quadrado comparando-se a variância esperada com a encontrada e analisando-se os valores propostos como limite.

Utilizou-se como referência as coordenadas oficiais do vértice no experimento em questão e se comparou com as coordenadas obtidas. Assim, foi verificado o atendimento do limite do valor nominal indicado pelo fabricante e a aplicação à Engenharia.

\subsection{RESULTADOS OBTIDOS NOS EXPERIMENTOS}

\subsubsection{Experimento 1}

Os parâmetros do resultado do teste T Student, em cada componente das coordenadas, estão na Tabela 13 a seguir.

A tabela 13 mostra uma tendência sistemática nos eixos $\mathrm{N}$ e h, sendo que com base na diferença padrão, apresentada na tabela 15, concluir-se-á se é aceitável. 
$\mathrm{Na}$ análise da precisão, os resultados obtidos encontram-se na tabela 14 , onde os valores da variâncias esperadas planimétrica e altimétrica são calculadas a partir dos valores das precisões esperadas na planimetria e altimetria da tabela 12. Constata-se que $o$ teste foi aceito na planimetria e na altimetria, pois os valores de $\mathrm{X}^{2}$ calculado são inferiores ao $\mathrm{X}^{2}$ tabela.

Tabela 13 - Resultado para o Teste T Student no exp. 1. Teste T Student

\begin{tabular}{|c|c|c|c|}
\hline & Este & Norte & Altitude \\
\hline Média $(\bar{x})$ & $323255,080 \mathrm{~m}$ & $7394432,166 \mathrm{~m}$ & $718,104 \mathrm{~m}$ \\
\hline Valor Verdadeiro $(\mu)$ & $323255,082 \mathrm{~m}$ & $7394432,17 \mathrm{~m}$ & $718,14 \mathrm{~m}$ \\
\hline Precisão Nominal & $0,01100000 \mathrm{~m}$ & $0,01100000 \mathrm{~m}$ & 0,02100000 \\
\hline$\left|t_{\text {calc }}\right|$ & 1,942819045 & 4,72729032 & 22,03966182 \\
\hline$t_{(9: 0,01)}-(99 \%)$ & Intervalo de confiança $-99 \%$ & \\
\hline$\left|t_{\text {calc }}\right|<t_{1-\alpha / 2}$ & 2.6 & 2.6 & 2.6 \\
\hline
\end{tabular}

\section{Tabela 14 - Resultado do Teste Qui-Quadrado para o exp. 1} Teste de Análise de Precisão

\begin{tabular}{|c|c|c|c|c|c|}
\hline \multicolumn{5}{c|}{ Intervalo de Confiança $99 \%$} \\
\hline & $\begin{array}{c}\text { Variância Esperada } \\
\left(\mathbf{m}^{2}\right)\end{array}$ & $\begin{array}{c}\text { Variância Calculada } \\
\left(\mathbf{m}^{2}\right)\end{array}$ & $\mathbf{X}^{2}$ calculado & $\mathbf{X}_{\text {tabela }}^{2}$ & Teste \\
\hline Planimétrico & 0.00011 & 0.000019 & 5.236 & 255.300 & PASSOU \\
\hline Altimétrico & 0.00042 & 0.000081 & 5.771 & 255.300 & PASSOU \\
\hline
\end{tabular}

A tabela 15 apresenta a média das diferenças, a diferença padrão e as diferenças máximas e mínimas encontradas. Conclui-se que a "precisão média" de 4 $\mathrm{mm}$ na planimetria atende ao valor esperado na Tabela 12 e que essa metodologia pode ser utilizada no posicionamento compatível com esse nível de erro. A "precisão média" de 3,7 cm na altimetria excede o valor esperado, porém pode ser utilizada em muitos trabalhos cuja exigência seja aceitável. 
Tabela 15 - Discrepâncias das coordenadas obtidas no exp. 1

\begin{tabular}{|c|c|c|c|}
\hline Discrepâncias & $\mathbf{E}(\mathbf{m})$ & $\mathbf{N}(\mathbf{m})$ & $\mathbf{H}(\mathbf{m})$ \\
\hline Média das diferenças & 0.002 & 0.004 & 0.036 \\
\hline Diferença Padrão & 0.003 & 0.005 & 0.009 \\
\hline Diferença Máxima & 0.010 & 0.012 & 0.065 \\
\hline Diferença Mínima & -0.006 & -0.003 & 0.017 \\
\hline
\end{tabular}

\subsubsection{Experimento 2}

Os parâmetros do resultado do teste T Student apresentaram os resultados da Tabela 16, a seguir.

Tabela 16 - Resultado para o Teste T Student no exp. 2. Teste T Student

\begin{tabular}{|c|c|c|c|}
\hline & Este & Norte & Altitude \\
\hline Média $(\bar{x})$ & $328897,827 \mathrm{~m}$ & $7395519,016 \mathrm{~m}$ & $750,438 \mathrm{~m}$ \\
\hline Valor Verdadeiro $(\mu)$ & $328897,841 \mathrm{~m}$ & $7395519,001 \mathrm{~m}$ & $750,397 \mathrm{~m}$ \\
\hline Precisão Nominal & $0,016000 \mathrm{~m}$ & $0,016000 \mathrm{~m}$ & $0,026000 \mathrm{~m}$ \\
\hline$t_{\text {calc }} \mid$ & 7,076562528 & 7,573437877 & 12,5625 \\
\hline & Intervalo de confiança $-99 \%$ & \\
\hline$t_{(9: 0,01)}-(99 \%)$ & 2.6 & 2.6 & 2.6 \\
\hline$\left|t_{\text {calc }}\right|<t_{1-\alpha / 2}$ & Falhou & Falhou & Falhou \\
\hline
\end{tabular}

A tabela 16 mostra uma tendência sistemática em todos os eixos, sendo que com base na diferença padrão, conforme tabela 18, concluir-se-á se é aceitável.

$\mathrm{Na}$ análise da precisão, os resultados obtidos para esse teste estão na tabela 17. Constata-se que o teste foi aceito na planimetria e tem restrição na altimetria. 
Tabela 17 - Resultado para o Teste Qui-Quadrado para o exp. 2.

Teste de Análise de Precisão

\begin{tabular}{|c|c|c|c|c|c|}
\hline \multicolumn{5}{|c|}{ Intervalo de Confiança 99\% } \\
\hline & $\begin{array}{c}\text { Variância Esperada } \\
\left(\mathbf{m}^{\mathbf{2}}\right)\end{array}$ & $\begin{array}{c}\text { Variância Calculada } \\
\left(\mathbf{m}^{\mathbf{2}}\right)\end{array}$ & $\mathbf{X}^{2}$ calculado & $\mathbf{X}_{\text {tabela }}$ & Teste \\
\hline Planimétrico & 0.000247762 & 0.000215 & 54.57140528 & 98.110 & Passou \\
\hline Altimétrico & 0.000662571 & 0.001279 & 121.633904 & 98.110 & Falhou \\
\hline
\end{tabular}

A Tabela 18 apresenta a média das diferenças, a diferença padrão e as diferenças máximas e mínimas encontradas. Conclui-se que a "precisão média" de $1,8 \mathrm{~cm}$ na planimetria excede em $2 \mathrm{~mm}$ o valor esperado na Tabela 12, considerando-se, portanto, desprezível. Conclui-se que essa metodologia pode ser usada no posicionamento compatível com esse erro. A precisão média de $5,4 \mathrm{~cm}$ na altimetria excede o valor esperado, porém pode ser utilizada em muitos trabalhos cuja exigência seja aceitável.

Tabela 18 - Discrepâncias das coordenadas obtidas no exp. 2.

\begin{tabular}{|c|c|c|c|}
\hline Discrepâncias & $\mathbf{E}(\mathbf{m})$ & $\mathbf{N}(\mathbf{m})$ & $\mathbf{h}(\mathbf{m})$ \\
\hline Média das diferenças & 0.014 & -0.015 & -0.041 \\
\hline Diferença Padrão & 0.017 & 0.019 & 0.054 \\
\hline Diferença Máxima & 0.034 & 0.020 & 0.050 \\
\hline Diferença Mínima & -0.005 & -0.064 & -0.130 \\
\hline
\end{tabular}

\subsubsection{Experimento 3}

Os parâmetros do resultado do teste T Student apresentaram os resultados da Tabela 19, a seguir. 
Tabela 19 - Resultado para o Teste T Student no exp. 3.

Teste T Student

\begin{tabular}{c|c|c|c|}
\hline & Este & Norte & Altitude \\
\hline Média $(\bar{x})$ & $332793,626 \mathrm{~m}$ & $7394977,027 \mathrm{~m}$ & $735,011 \mathrm{~m}$ \\
\hline Valor Verdadeiro $(\mu)$ & $332793,623 \mathrm{~m}$ & $7394977,022 \mathrm{~m}$ & $735,005 \mathrm{~m}$ \\
\hline Precisão Nominal & $0,020000 \mathrm{~m}$ & $0,020000 \mathrm{~m}$ & $0,030000 \mathrm{~m}$ \\
\hline$\left|t_{\text {calc }}\right|$ & 1,522280186 & 2,762622314 & 2,05280096 \\
\hline$t_{(9: 0,01)}-(99 \%)$ & Intervalo de confiança $-99 \%$ & \\
\hline$t_{\text {calc } \mid<t_{1-\alpha / 2}}$ & 2,66 & 2,66 & 2,66 \\
\hline
\end{tabular}

A tabela acima mostra uma tendência sistemática no eixo $\mathrm{N}$, sendo que se baseando na diferença padrão, mostrada na Tabela 21, concluir-se-á se é aceitável.

$\mathrm{Na}$ análise da precisão, os resultados obtidos encontram-se na Tabela 20. Contata-se que o teste tem restrição na planimetria e na altimetria. Tabela 20 - Resultado para o Teste Qui-Quadrado para o exp. 3.
Teste de Análise de Precisão

Intervalo de Confiança 99\%

\begin{tabular}{|c|c|c|c|c|c|}
\hline & $\begin{array}{c}\text { Variância Esperada } \\
\left(\mathbf{m}^{\mathbf{2}} \mathbf{n}\right.\end{array}$ & $\begin{array}{c}\text { Variância Observada } \\
\left(\mathbf{m}^{\mathbf{2}} \mathbf{n}\right.\end{array}$ & $\mathbf{X}^{\mathbf{2}}$ calculado & $\mathbf{X}^{\mathbf{2}}$ tabela & Teste \\
\hline Planimétrico & 0.00038 & 0.00085 & 241.128 & 151.900 & FALHOU \\
\hline Altimétrico & 0.00087 & 0.00323 & 398.633 & 151.900 & FALHOU \\
\hline
\end{tabular}

A Tabela 21 apresenta a média das diferenças, diferença padrão e as diferenças máximas e mínimas encontradas. Conclui-se que a "precisão média" de 2 $\mathrm{cm}$ na planimetria atende ao valor esperado na Tabela 12 e essa metodologia pode ser utilizada no posicionamento compatível com esse erro. A "precisão média" de 5,7 $\mathrm{cm}$ na altimetria excede em 2,7 cm o valor esperado na Tabela 12. Assim, essa metodologia pode ser aplicada em muitos trabalhos cuja a exigência seja aceitável. 
Tabela 21 - Discrepâncias das coordenadas obtidas no exp. 3.

\begin{tabular}{|c|c|c|c|}
\hline Discrepâncias & $\mathbf{E}(\mathbf{m})$ & $\mathbf{N}(\mathbf{m})$ & $\mathbf{h}(\mathbf{m})$ \\
\hline Média das diferenças & -0.003 & -0.005 & -0.006 \\
\hline Diferença Padrão & 0.025 & 0.016 & 0.057 \\
\hline Diferença Máxima & 0.043 & 0.033 & 0.108 \\
\hline Diferença Mínima & -0.073 & -0.035 & -0.159 \\
\hline
\end{tabular}

\subsubsection{Experimento 4}

Os parâmetros do resultado do teste T Student, em cada componente das coordenadas, estão na Tabela 22 a seguir.

Tabela 22 - Resultado para o Teste T Student no exp. 4.

Teste T Student

\begin{tabular}{|c|c|c|c|}
\hline & Este & Norte & Altitude \\
\hline Média $(\bar{x})$ & $321919,919 \mathrm{~m}$ & $7410979,531 \mathrm{~m}$ & $833,128 \mathrm{~m}$ \\
\hline Valor Verdadeiro $(\mu)$ & $321919,934 \mathrm{~m}$ & $7410979,520 \mathrm{~m}$ & $833,063 \mathrm{~m}$ \\
\hline Precisão Nominal & $0,02700000 \mathrm{~m}$ & $0,027 \mathrm{~m}$ & $0,037000 \mathrm{~m}$ \\
\hline$\left|t_{\text {calc }}\right|$ & 7,674425136 & 5,785 & 24,98722091 \\
\hline & Intervalo de confiança $-99 \%$ & \\
\hline$t_{(9: 0,01)}-(99 \%)$ & 2,66 & 2,660 & 2,66 \\
\hline$\left|t_{\text {calc }}\right|<t_{1-\alpha / 2}$ & Falhou & Falhou & Falhou \\
\hline
\end{tabular}

A tabela acima mostra uma tendência sistemática em todos os eixos, sendo que se baseando na diferença padrão, apresentada na Tabela 24, concluir-se-á se é aceitável.

$\mathrm{Na}$ análise da precisão, os resultados obtidos encontram-se na Tabela 23, Constata-se que os testes foram aceitos para na planimetria e na altimetria. 
Tabela 23 - Resultado para o Teste Qui-Quadrado para o exp. 4.

Teste de Análise de Precisão

Intervalo de Confiança 99\%

\begin{tabular}{|c|c|c|c|c|c|}
\hline & $\begin{array}{c}\text { Variância Esperada } \\
\left(\mathbf{m}^{2}\right)\end{array}$ & $\begin{array}{c}\text { Variância Calculada } \\
\left(\mathbf{m}^{2}\right)\end{array}$ & $\mathbf{X}^{2}$ calculado & $\mathbf{X}^{2}$ tabela & Teste \\
\hline Planimétrico & 0.00074 & 0.00052 & 142.827 & 255.300 & PASSOU \\
\hline Altimétrico & 0.00138 & 0.00142 & 207.547 & 255.300 & PASSOU \\
\hline
\end{tabular}

A Tabela 24 apresenta a média das diferenças, a diferença padrão e as diferenças máximas e mínimas encontradas. Constata-se que a precisão média de 2 $\mathrm{cm}$ na planimetria atende ao valor esperado na Tabela $12 \mathrm{e}$ a metodologia pode ser utilizada no posicionamento compatível com esse erro. A "precisão média" de $7,5 \mathrm{~cm}$, na altimetria, excede em $3,8 \mathrm{~cm}$ ao valor esperado na Tabela 12 e que esta metodologia pode ser utilizada em muitos trabalhos cuja exigência seja aceitável.

Tabela 24 - Discrepâncias das coordenadas obtidas no exp. 4.

\begin{tabular}{|c|c|c|c|}
\hline Discrepâncias & $\mathbf{E}(\mathbf{m})$ & $\mathbf{N}(\mathbf{m})$ & $\mathbf{h}(\mathbf{m})$ \\
\hline Média das diferenças & 0.015 & -0.011 & -0.065 \\
\hline Diferença Padrão & 0.019 & 0.022 & 0.038 \\
\hline Diferença Máxima & 0.046 & 0.043 & 0.016 \\
\hline Diferença Mínima & -0.012 & -0.079 & -0.186 \\
\hline
\end{tabular}

\subsubsection{Experimento 5}

Os parâmetros do resultado do testeT Student, em cada componente das coordenadas, estão na tabela 25 a seguir. 
Tabela 25 - Resultado para o Teste T Student no exp. 5.

\begin{tabular}{|c|c|c|c|}
\hline \multicolumn{4}{|c|}{ Teste T Student } \\
\hline & Este & Norte & Altitude \\
\hline Média $(\bar{x})$ & $324457,830 \mathrm{~m}$ & $7363504,052 \mathrm{~m}$ & $777,395 \mathrm{~m}$ \\
\hline Valor Verdadeiro $(\mu)$ & $324457,826 \mathrm{~m}$ & $7363504,042 \mathrm{~m}$ & $777,398 \mathrm{~m}$ \\
\hline Precisão Nominal & $0,04000000 \mathrm{~m}$ & $0,04000000 \mathrm{~m}$ & $0,050 \mathrm{~m}$ \\
\hline$\left|t_{\text {calc }}\right|$ & 1,539724948 & 3,402951366 & 0,728319985 \\
\hline \multicolumn{4}{|c|}{ Intervalo de confiança - 99\% } \\
\hline$t_{(9: 0,01)}-(99 \%)$ & 2,6 & 2,6 & 2,6 \\
\hline$\left|t_{\text {calc }}\right|<t_{1-\alpha / 2}$ & Passou & Falhou & Passou \\
\hline
\end{tabular}

A tabela acima mostra tendência sistemática no eixo $\mathrm{N}$, baseando-se na diferença padrão, conforme Tabela 27, concluir-se-á se é aceitável.

$\mathrm{Na}$ análise da precisão, os resultados obtidos encontram-se na Tabela 26. Constata-se que os testes foram aceitos para na planimetria e na altimetria.

Tabela 26 - Resultado para o Teste Qui-Quadrado para o exp. 5. Teste de Análise de Precisão

\begin{tabular}{|c|c|c|c|c|c|}
\hline \multicolumn{5}{|c|}{ Intervalo de Confiança 99\% } \\
\hline & $\begin{array}{c}\text { Variância Esperada } \\
\left(\mathbf{m}^{\mathbf{2}}\right)\end{array}$ & $\begin{array}{c}\text { Variância Calculada } \\
\left(\mathbf{m}^{2}\right)\end{array}$ & $\mathbf{X}_{\text {calculado }}$ & $\mathbf{X}_{\text {tabela }}$ & \\
\hline Planimétrico & 0.001633846 & 0.001089 & 132.6742143 & 255.300 & Passou \\
\hline Altimétrico & 0.002542264 & 0.003019 & 236.3117995 & 255.300 & Passou \\
\hline
\end{tabular}

A tabela 27 apresenta a média das diferenças, a diferença padrão e as diferenças máximas e mínimas encontradas. Conclui-se que a "precisão média" de 2,2 cm na planimetria atende ao valor esperado na Tabela 12 e a metodologia pode ser utilizada no posicionamento compatível com esse erro. A "precisão média" de 5 $\mathrm{cm}$ na altimetria excede ao valor esperado na Tabela 12 e a metodologia pode ser utilizada em muitos trabalhos cuja exigência seja aceitável. 
Tabela 27 - Discrepâncias das coordenadas obtidas no exp. 5.

\begin{tabular}{|c|c|c|c|}
\hline Discrepâncias & $\mathbf{E}(\mathbf{m})$ & $\mathbf{N}(\mathbf{m})$ & $\mathbf{H}(\mathbf{m})$ \\
\hline Média das diferenças & -0.004 & -0.010 & 0.003 \\
\hline Diferença Padrão & 0.013 & 0.032 & 0.055 \\
\hline Diferença Máxima & 0.029 & 0.049 & 0.180 \\
\hline Diferença Mínima & -0.034 & -0.115 & -0.193 \\
\hline
\end{tabular}

\subsubsection{Experimento 6}

Os parâmetros do resultado do teste T Student, em cada componente das coordenadas, estão na Tabela 28 a seguir.

Tabela 28 - Resultado para o Teste T Student no exp. 6.

Teste T Student

\begin{tabular}{|l|r|r|r|}
\hline & Este & Norte & \multicolumn{1}{l|}{ Altitude } \\
\hline Média $(\bar{x})$ & $358096,272 \mathrm{~m}$ & $7390723,720 \mathrm{~m}$ & $842,374 \mathrm{~m}$ \\
\hline Valor Verdadeiro $(\mu)$ & $358096,276 \mathrm{~m}$ & $7390723,706 \mathrm{~m}$ & $842,355 \mathrm{~m}$ \\
\hline Precisão Nominal & $0,045000 \mathrm{~m}$ & $0,045000 \mathrm{~m}$ & $0,055000 \mathrm{~m}$ \\
\hline$t_{\text {calc }} \mid$ & 1,067840244 & 3,813615002 & 4,229860488 \\
\hline$t_{(9: 0,01)}-(99 \%)$ & Intervalo de confiança - 99\% & \\
\hline$t_{\text {calc }} \mid<t_{1-\alpha / 2}$ & 2,66 & 2,66 & 2,66 \\
\hline
\end{tabular}

A tabela acima mostra uma tendência sistemática nos eixos $\mathrm{N}$ e h, sendo que a diferença padrão, mostrada na Tabela 29, concluir-se-á se é aceitável.

Os resultados obtidos no teste Qui-Quadrado são mostrados na tabela 28, constatando-se que os resultados foram aceitos para a planimetria e altimetria. 
Tabela 29 - Resultado para o Teste Qui-Quadrado para o exp. 6.

Teste de Análise de Precisão

Intervalo de Confiança 99\%

\begin{tabular}{|c|c|c|c|c|c|}
\hline & $\begin{array}{l}\text { Variância Esperada } \\
\qquad\left(\mathrm{m}^{2}\right)\end{array}$ & $\begin{array}{l}\text { Variância Calculada } \\
\qquad\left(\mathrm{m}^{2}\right)\end{array}$ & $x^{2}$ calculado & $x^{2}$ tabela & Teste \\
\hline Planimétrico & 0.002012 & 0.000189 & 14.685 & 205.228 & PASSOU \\
\hline Altimétrico & 0.003009 & 0.000817 & 42.357 & 205.228 & PASSOU \\
\hline
\end{tabular}

A tabela 29 apresenta a média das diferenças, a diferença padrão e as diferenças máximas e mínimas encontradas. Conclui-se que a "precisão média" de $1,4 \mathrm{~cm}$ na planimetria atende ao valor esperado na tabela $12 \mathrm{e}$ a metodologia pode ser utilizada no posicionamento compatível com esse erro. A "precisão média" de 3,4 $\mathrm{cm}$ na altimetria atende ao valor esperado na tabela 12 e a metodologia pode ser utilizada no posicionamento compatível com esse erro.

Tabela 30 - Discrepâncias das coordenadas obtidas no exp. 6.

\begin{tabular}{|c|c|c|c|}
\hline Discrepâncias & $\mathbf{E}(\mathbf{m})$ & $\mathbf{N}(\mathbf{m})$ & $\mathbf{h}(\mathbf{m})$ \\
\hline Média das diferenças & 0.004 & -0.014 & -0.019 \\
\hline Diferença Padrão & 0.009 & 0.018 & 0.034 \\
\hline Diferença Máxima & 0.026 & 0.010 & 0.047 \\
\hline Diferença Mínima & -0.015 & -0.040 & -0.111 \\
\hline
\end{tabular}

\subsubsection{Experimento 7}

No testa a, a análise de tendência, o teste $t$ de Student, apresentou os seguintes resultados na tabela 31 . 
Tabela 31 - Resultado para o Teste T Student no exp. 7a.

Teste T Student

\begin{tabular}{|c|c|c|c|}
\hline & Este & Norte & Altitude \\
\hline Média $(\bar{x})$ & $376797,336 \mathrm{~m}$ & $7402292,751 \mathrm{~m}$ & $1161,069 \mathrm{~m}$ \\
\hline Valor Verdadeiro $(\mu)$ & $376797,341 \mathrm{~m}$ & $7402292,754 \mathrm{~m}$ & $1160,920 \mathrm{~m}$ \\
\hline Precisão Nominal & $0,064 \mathrm{~m}$ & $0,06400 \mathrm{~m}$ & $0,07400 \mathrm{~m}$ \\
\hline$\left|t_{\text {calc }}\right|$ & 0,31065 & 0,20979 & 7,78435 \\
\hline$t_{(9: 0,01)}-(99 \%)$ & Intervalo de confiança $-99 \%$ & \\
\hline$\left|t_{\text {calc }}\right|<t_{1-\alpha / 2}$ & 2.950 & 2.950 & 2.950 \\
\hline
\end{tabular}

A Tabela acima mostra a ausência de tendência sistemática nos eixos $\mathrm{E}$ e $\mathrm{N}$.

Os resultados obtidos no teste Qui-Quadrado são mostrados na Tabela 32, os resultados foram aceitos para a planimetria e não aceitos para a altimetria.

Tabela 32 - Resultado para o Teste Qui-Quadrado para o exp. 7a. Teste de Análise de Precisão

Intervalo de Confiança $99 \%$

\begin{tabular}{|c|c|c|c|c|c|}
\hline & $\begin{array}{l}\text { Variância Esperada } \\
\qquad\left(\mathrm{m}^{2}\right)\end{array}$ & $\begin{array}{l}\text { Variância Calculada } \\
\qquad\left(\mathrm{m}^{2}\right)\end{array}$ & $X^{2}$ calculado & $x^{2}$ tabela & Teste \\
\hline Planimétrico & 0.00411 & 0.00039 & 1.322 & 31.320 & PASSOU \\
\hline Altimétrico & 0.00549 & 0.29153 & 743.763 & 31.320 & FALHOU \\
\hline
\end{tabular}

A Tabela 33, a seguir, apresenta a média das diferenças, a diferença padrão e as diferenças máximas e mínimas encontradas. Conclui-se que a "precisão média" de $1,4 \mathrm{~cm}$ na planimetria atende ao valor esperado na Tabela 12 e a metodologia pode ser utilizada no posicionamento compatível com esse nível de erro. A "precisão média" de $56 \mathrm{~cm}$ na altimetria excede o valor esperado na Tabela 12 e merece restrições de uso com essa exigência. 
Tabela 33- Discrepâncias das coordenadas obtidas no exp. 7a.

\begin{tabular}{|c|c|c|c|}
\hline Discrepâncias & $\mathbf{E}(\mathbf{m})$ & $\mathbf{N}(\mathbf{m})$ & $\mathbf{h}(\mathbf{m})$ \\
\hline Erro Médio & 0.005 & 0.003 & -0.149 \\
\hline Diferença Padrão & 0.011 & 0.017 & 0.560 \\
\hline Diferença Máxima & 0.025 & 0.050 & 0.115 \\
\hline Diferença Mínima & -0.017 & -0.028 & -1.499 \\
\hline
\end{tabular}

No teste $\mathbf{b}$, a análise de tendência, o teste $\mathrm{T}$ Student apresentou os resultados da Tabela 34 a seguir.

Tabela 34- Resultado para o Teste T Student no exp. 7b. Teste T Student

\begin{tabular}{|c|c|c|c|}
\hline & Este & Norte & Altitude \\
\hline Média $(\bar{x})$ & $376797,390 \mathrm{~m}$ & $7402292,756 \mathrm{~m}$ & $1161,336 \mathrm{~m}$ \\
\hline Valor Verdadeiro $(\mu)$ & $376797,341 \mathrm{~m}$ & $7402292,754 \mathrm{~m}$ & $1160,920 \mathrm{~m}$ \\
\hline Precisão Nominal & $0,064 \mathrm{~m}$ & $0,064 \mathrm{~m}$ & $0,074 \mathrm{~m}$ \\
\hline$\left|t_{\text {calc }}\right|$ & 4,00236 & 0,14133 & 21,78795 \\
\hline & Intervalo de confiança $-99 \%$ & \\
\hline$t_{(9: 0,01)}-(99 \%)$ & 2.770 & 2.770 & 2.770 \\
\hline$\left|t_{\text {calc }}\right|<t_{1-\alpha / 2}$ & Falhou & Passou & Falhou \\
\hline
\end{tabular}

A Tabela acima mostra uma tendência sistemática nos eixos $\mathrm{E}$ e $\mathrm{h}$, sendo que baseando-se na diferença padrão, apresentada na Tabela 36, concluir-se-á se é aceitável.

$\mathrm{Na}$ análise da precisão, os resultados obtidos encontram-se na Tabela 34, constata-se que os resultados não foram aceitos tanto para a planimetria como para a altimetria. 
Tabela 35 - Resultado para o Teste Qui-Quadrado para o exp. 7b. Teste de Análise de Precisão Intervalo de Confiança 99\%

\begin{tabular}{|c|c|c|c|c|c|}
\hline \multicolumn{5}{|c|}{ Intervalo de Confiança 99\% } \\
\hline & $\begin{array}{c}\text { Variância Esperada } \\
\left(\mathbf{m}^{2}\right)\end{array}$ & $\begin{array}{c}\text { Variância Calculada } \\
\left(\mathbf{m}^{2}\right)\end{array}$ & $\mathbf{X}^{2}$ calculado & $\mathbf{X}^{2}$ tabela & \\
\hline Planimétrico & 0.00411 & 0.01260 & 79.771 & 48.290 & FALHOU \\
\hline Altimétrico & 0.00549 & 0.88643 & $4,199.940$ & 48.290 & FALHOU \\
\hline
\end{tabular}

A Tabela 36 apresenta média das diferenças, diferença padrão e as diferenças máximas e mínimas encontradas. Conclui-se que a "precisão média" na planimetria é de $8 \mathrm{~cm}$ excedendo o esperado em $1,6 \mathrm{~cm}$, e esse método de trabalho pode ser utilizado com atenção no posicionamento compatível com esse erro. A "precisão média" na altimetria é de 1 metro e não pode ser usada em trabalhos com essa exigência de precisão.

Tabela 36 - Discrepâncias das coordenadas obtidas no exp. 7b.

\begin{tabular}{|c|c|c|c|}
\hline Discrepâncias & $\mathbf{E}(\mathbf{m})$ & $\mathbf{N}(\mathbf{m})$ & $\mathbf{h}(\mathbf{m})$ \\
\hline Média das diferenças & -0.049 & -0.002 & -0.416 \\
\hline Diferença Padrão & 0.068 & 0.101 & 1.032 \\
\hline Diferença Máxima & 0.041 & 0.326 & 1.340 \\
\hline Diferença Mínima & -0.140 & -0.163 & -1.726 \\
\hline
\end{tabular}

\subsubsection{Experimento 8}

$\mathrm{Na}$ análise de tendência, o teste $\mathrm{T}$ Student apresentou os seguintes resultados da Tabela 37 . 
Tabela 37 - Resultado para o Teste T Student no exp. 8a.

Teste T Student

\begin{tabular}{|c|c|c|c|}
\hline & Este & Norte & Altitude \\
\hline Média $(\bar{x})$ & $271784,518 \mathrm{~m}$ & $7444443,401 \mathrm{~m}$ & $581,807 \mathrm{~m}$ \\
\hline Valor Verdadeiro $(\mu)$ & $271784,516 \mathrm{~m}$ & $7444443,404 \mathrm{~m}$ & $581,86 \mathrm{~m}$ \\
\hline Precisão Nominal & $0,08200000 \mathrm{~m}$ & $0,08200000 \mathrm{~m}$ & $0,092000 \mathrm{~m}$ \\
\hline$\left|t_{\text {calc }}\right|$ & 0,16081237 & 0,237868317 & 4,231302589 \\
\hline$t_{(9: 0,01)}-(99 \%)$ & Intervalo de confiança $-99 \%$ & \\
\hline$t_{\text {calc }} \mid<t_{1-\alpha / 2}$ & 2,64 & 2,64 & 2,64 \\
\hline
\end{tabular}

A Tabela acima mostra uma tendência sistemática apenas no eixo $\mathrm{h}$, com base na determinação da diferença padrão, conforme apresentado na Tabela 39, concluir-se-á se é aceitável.

$\mathrm{Na}$ análise de precisão, os resultados obtidos são mostrados na Tabela 38. Conclui-se que os testes foram aceitos para a planimetria e altimetria.

Tabela 38 - Resultado para o Teste Qui-Quadrado para o exp. 8a. Teste de Análise de Precisão

\begin{tabular}{|c|c|c|c|c|c|}
\hline & $\begin{array}{c}\text { Iariância Esperada } \\
\left(\mathbf{m}^{2}\right)\end{array}$ & $\begin{array}{c}\text { Variância Calculada } \\
\left(\mathbf{m}^{2}\right)\end{array}$ & $\mathbf{x}^{2}$ calculado & $\mathbf{x}^{2}$ tabela & \\
\hline Planimétrico & 0,00676 & 0,000770 & 5,918 & 81,994 & PASSOU \\
\hline Altimétrico & 0,00851 & 0,004575 & 27,968 & 81,994 & PASSOU \\
\hline
\end{tabular}

A Tabela 39 apresenta a média das diferenças, diferença padrão e as diferenças máximas e mínimas encontradas. Conclui-se que a "precisão média" de $1,8 \mathrm{~cm}$ na planimetria atende ao valor esperado na tabela 12 e a metodologia pode ser utilizada no posicionamento compatível com esse erro. A "precisão média" de 8,6 $\mathrm{cm}$ na altimetria excede em $1,2 \mathrm{~cm} \circ$ valor esperado na tabela 12, e essa metodologia pode ser utilizada em trabalhos cuja exigência seja aceitável. 
Tabela 39 - Discrepâncias das coordenadas obtidas no exp. $8 a$.

\begin{tabular}{|c|c|c|c|}
\hline Discrepâncias & $\mathbf{E}(\mathbf{m})$ & $\mathbf{N}(\mathbf{m})$ & $\mathbf{h}(\mathbf{m})$ \\
\hline Média das diferenças & -0.002 & 0.003 & 0.053 \\
\hline Diferença padrão & 0.012 & 0.025 & 0.086 \\
\hline Diferença Máxima & 0.043 & 0.028 & 0.126 \\
\hline Diferença Mínima & -0.022 & -0.115 & -0.158 \\
\hline
\end{tabular}

No teste $\mathbf{b}$, na análise de tendência, o teste $T$ Student apresentou os resultados que são mostrados na Tabela 40.

Tabela 40 - Resultado para o Teste T Student no exp. 8b. Teste T Student

\begin{tabular}{|c|c|c|c|}
\hline & Este & Norte & Altitude \\
\hline Média $(\bar{x})$ & $271784,482 \mathrm{~m}$ & $7444443,421 \mathrm{~m}$ & $581,845 \mathrm{~m}$ \\
\hline Valor Verdadeiro $(\mu)$ & $271784,516 \mathrm{~m}$ & $7444443,404 \mathrm{~m}$ & $581,86 \mathrm{~m}$ \\
\hline Precisão Nominal & $0,08200000 \mathrm{~m}$ & $0,08200000 \mathrm{~m}$ & $0,09200000 \mathrm{~m}$ \\
\hline$\left|t_{\text {calc }}\right|$ & 2,323917385 & 1,174005547 & 0,911692131 \\
\hline$t_{(9: 0,01)}-(99 \%)$ & Intervalo de confiança $-99 \%$ & \\
\hline$\left|t_{\text {calc }}\right|<t_{1-\alpha / 2}$ & 2,75 & 2,75 & 2,75 \\
\hline
\end{tabular}

A Tabela acima mostra que não existe tendência sistemática em nenhum dos eixos.

$\mathrm{Na}$ análise da precisão, os resultados obtidos para esse teste são mostrados na Tabela 41, constatando-se que os testes foram aceitos para a planimetria e têm restrição para a altimetria. 
Tabela 41- Resultado para o Teste Qui-Quadrado para o exp. 8b.

Teste de Análise de Precisão

Intervalo de Confiança 99\%

\begin{tabular}{|c|c|c|c|c|c|}
\hline & $\begin{array}{c}\text { Variância Esperada } \\
\left(\mathbf{m}^{\mathbf{2}}\right)\end{array}$ & $\begin{array}{c}\text { Variância Calculada } \\
\left(\mathbf{m}^{\mathbf{2}}\right)\end{array}$ & $\mathbf{X}^{2}$ calculado & $\mathbf{X}^{2}$ tabela & \\
\hline Planimétrico & 0,00676 & 0,009673 & 42,913 & 53,670 & PASSOU \\
\hline Altimétrico & 0,00851 & 0,044895 & 158,324 & 53,670 & FALHOU \\
\hline
\end{tabular}

A tabela 42 apresenta a média das diferenças, a diferença padrão e as diferenças máximas e mínimas encontradas. Conclui-se que a "precisão média" na planimetria é de $7,5 \mathrm{~cm}$, que atende ao valor esperado na tabela 12 e que este método de trabalho pode ser utilizado no posicionamento compatível com este erro. A "precisão média" na altimetria é de $21,2 \mathrm{~cm}$, que excede em $14 \mathrm{~cm}$ ao valor esperado na tabela 12 e que esta metodologia pode ser utilizada em alguns trabalhos que aceite este nível de erro.

Tabela 42 - Discrepâncias das coordenadas obtidas no exp. 8b.

\begin{tabular}{|c|c|c|c|}
\hline Discrepâncias & $\mathbf{E}(\mathbf{m})$ & $\mathbf{N}(\mathbf{m})$ & $\mathbf{h}(\mathbf{m})$ \\
\hline Média das diferenças & 0.034 & -0.017 & 0.015 \\
\hline Diferença padrão & 0.070 & 0.079 & 0.212 \\
\hline Diferença Máxima & 0.165 & 0.166 & 0.666 \\
\hline Diferença Mínima & -0.078 & -0.179 & -0.314 \\
\hline
\end{tabular}

\subsubsection{Experimento 9}

No teste a, os parâmetros do resultado do teste $T$ Student, em cada componente das coordenadas, estão na Tabela 43 a seguir. 
Tabela 43 - Resultado para o Teste T Student no exp. 9a.

Teste T Student

\begin{tabular}{|c|c|c|c|}
\hline & Este & Norte & Altitude \\
\hline Média $(\bar{x})$ & $409426,693 \mathrm{~m}$ & $7437552,008 \mathrm{~m}$ & $556,242 \mathrm{~m}$ \\
\hline Valor Verdadeiro $(\mu)$ & $409426,691 \mathrm{~m}$ & $7437551,997 \mathrm{~m}$ & $556,110 \mathrm{~m}$ \\
\hline Precisão Nominal & $0,10600000 \mathrm{~m}$ & $0,10600000 \mathrm{~m}$ & $0,116000 \mathrm{~m}$ \\
\hline$\left|t_{\text {calc }}\right|$ & 0,080049826 & 0,440274031 & 4,827832506 \\
\hline & Intervalo de confiança $-99 \%$ & \\
\hline$t_{(9: 0,01)}-(99 \%)$ & 2,88 & 2,88 & 2,88 \\
\hline$t_{\text {calc }} \mid<t_{1-\alpha / 2}$ & Passou & Passou & Falhou \\
\hline
\end{tabular}

A tabela acima mostra a tendência sistemática apenas no eixo $h$, sendo que a diferença padrão, mostrada na Tabela 45, concluir-se-á se é aceitável.

Os resultados obtidos no teste Qui-Quadrado são mostrados na tabela 44, constatando-se que os resultados foram aceitos para a planimetria e altimetria. Tabela 44 - Resultado para o Teste Qui-Quadrado para o exp. 9a.
Teste de Análise de Precisão

\begin{tabular}{|c|c|c|c|c|c|}
\hline \multicolumn{5}{|c|}{ Intervalo de Confiança 99\% } \\
& $\begin{array}{c}\text { Variância Esperada } \\
\left(\mathbf{m}^{2}\right)\end{array}$ & $\begin{array}{c}\text { Variância Calculada } \\
\left(\mathbf{m}^{2}\right)\end{array}$ & $\mathbf{X}^{2}$ calculado & $\mathbf{X}^{2}$ tabela & \\
\hline Planimétrico & 0.011342464 & 0.000254556 & 0.382 & 35.720 & PASSOU \\
\hline Altimétrico & 0.013572485 & 0.001284958 & 1.609 & 35.720 & PASSOU \\
\hline
\end{tabular}

A tabela 45 apresenta a média das diferenças, diferença padrão e os valores máximos e mínimos encontrados. Pode-se concluir que a "precisão média" de 1,3 $\mathrm{cm}$ na planimetria atende ao valor esperado na tabela 12 e que esta metodologia pode ser utilizada no posicionamento compatível com este erro. A "precisão média" de $14 \mathrm{~cm}$ na altimetria excede em $3 \mathrm{~cm}$ ao valor esperado na tabela 12, e que esta metodologia pode ser utilizada em trabalhos cuja exigência seja aceitável. 
Tabela 45 - Discrepâncias das coordenadas obtidas no exp. 9a.

\begin{tabular}{|c|c|c|c|}
\hline Discrepâncias & $\mathbf{E}(\mathbf{m})$ & $\mathbf{N}(\mathbf{m})$ & $\mathbf{h}(\mathbf{m})$ \\
\hline Média das diferenças & -0.002 & -0.011 & -0.132 \\
\hline Diferença Padrão & 0.011 & 0.016 & 0.141 \\
\hline Diferença Máxima & 0.021 & 0.008 & -0.070 \\
\hline Diferença Mínima & -0.021 & -0.029 & -0.201 \\
\hline
\end{tabular}

No teste $\mathbf{b}$, na análise de tendência, o teste $T$ de Student, apresentou os seguintes resultados da tabela 46 .

Tabela 46 - Resultado para o Teste T Student no exp. 9b.

Teste T Student

\begin{tabular}{|c|c|c|c|}
\hline & Este & Norte & Altitude \\
\hline Média $(\bar{x})$ & $409426,722 \mathrm{~m}$ & $7437552,031 \mathrm{~m}$ & $556,196 \mathrm{~m}$ \\
\hline Valor Verdadeiro $(\mu)$ & $409426,691 \mathrm{~m}$ & $7437551,997 \mathrm{~m}$ & $556,110 \mathrm{~m}$ \\
\hline Precisão Nominal & $0,10600000 \mathrm{~m}$ & $0,10600000 \mathrm{~m}$ & $0,116000 \mathrm{~m}$ \\
\hline$\left|t_{\text {calc }}\right|$ & 2,188516586 & 2,400308511 & 5,547974746 \\
\hline & Intervalo de confiança $-99 \%$ & \\
\hline$t_{(9: 0,01)}-(99 \%)$ & 2,66 & 2,66 & 2,66 \\
\hline$\left|t_{\text {calc }}\right|<t_{1-\alpha / 2}$ & Passou & Passou & Falhou \\
\hline
\end{tabular}

A tabela acima mostra uma tendência sistemática apenas no eixo $\mathrm{h}$, com base na determinação da diferença padrão, conforme apresentada na Tabela 48 , concluir-se-á se é aceitável.

$\mathrm{Na}$ análise de precisão, os resultados obtidos são mostrados na Tabela 47. Conclui-se que o teste foi aceito para a planimetria e tem restrição na altimetria. 
Tabela 47 - Resultado para o Teste Qui-Quadrado para o exp. 9b.

Teste de Análise de Precisão

Intervalo de Confiança 99\%

\begin{tabular}{|c|c|c|c|c|c|}
\hline & $\begin{array}{c}\text { Variância Esperada } \\
\left(\mathbf{m}^{2}\right)\end{array}$ & $\begin{array}{c}\text { Variância Calculada } \\
\left(\mathbf{m}^{2}\right)\end{array}$ & $\mathbf{x}_{\text {calculado }}^{2}$ & $\mathbf{x}_{\text {tabela }}^{2}$ & Teste \\
\hline Planimétrico & 0,011342472 & 0,008936045 & 43,331 & 86,990 & PASSOU \\
\hline Altimétrico & 0,013572493 & 0,063154281 & 255,921 & 86,990 & FALHOU \\
\hline
\end{tabular}

A tabela 48 apresenta a média das diferenças, diferença padrão e as diferenças máximas e mínimas encontradas. Pode-se concluir que a "precisão média" na planimetria é de $6,7 \mathrm{~cm}$ que atende ao valor esperado na tabela 12 e que esta metodologia pode ser utilizada no posicionamento compatível com este erro. A "precisão média" na altimetria de $25 \mathrm{~cm}$ excede o valor esperado na tabela 12 e que esta metodologia pode ser utilizada em trabalhos cuja exigência seja aceitável.

Tabela 48 - Discrepâncias das coordenadas obtidas no exp. 9b.

\begin{tabular}{|c|c|c|c|}
\hline Discrepâncias & $\mathbf{E}(\mathbf{m})$ & $\mathbf{N}(\mathbf{m})$ & $\mathbf{h}(\mathbf{m})$ \\
\hline Média das diferenças & $-0,031$ & $-0,034$ & $-0,086$ \\
\hline Diferença padrão & 0.074 & 0.073 & 0.263 \\
\hline Diferença Máxima & 0,183 & 0,121 & 0,825 \\
\hline Diferença Mínima & $-0,182$ & $-0,233$ & $-0,539$ \\
\hline
\end{tabular}

\subsubsection{Experimento 10}

Os parâmetros do resultado do teste T Student, em cada componente das coordenadas, estão na Tabela 49 a seguir. 
Tabela 49 - Resultado para o Teste T Student no exp. 10.

Teste T Student

\begin{tabular}{|c|c|c|c|}
\hline & Este & Norte & Altitude \\
\hline Média $(\bar{x})$ & $251199,315 \mathrm{~m}$ & $7312598,849 \mathrm{~m}$ & $56,274 \mathrm{~m}$ \\
\hline Valor Verdadeiro $(\mu)$ & $251199,262 \mathrm{~m}$ & $7312598,790 \mathrm{~m}$ & $56,260 \mathrm{~m}$ \\
\hline Precisão Nominal & $0,11900000 \mathrm{~m}$ & $0,11900000 \mathrm{~m}$ & $0,129000 \mathrm{~m}$ \\
\hline$\left|t_{\text {calc }}\right|$ & 3,575630249 & 3,951680823 & 0,87790698 \\
\hline & Intervalo de confiança $-99 \%$ & \\
\hline$t_{(9: 0,01)}-(99 \%)$ & 2,66 & 2,66 & 2,66 \\
\hline$t_{\text {calc }} \mid<t_{1-\alpha / 2}$ & Falhou & Falhou & Passou \\
\hline
\end{tabular}

A tabela acima mostra uma tendência sistemática nos eixos $\mathrm{E}$ e $\mathrm{N}$, sendo que a diferença padrão, mostrada na Tabela 51, concluir-se-á se é aceitável.

Os resultados obtidos no teste Qui-Quadrado são mostrados na tabela 50, constatando-se que os resultados têm restrição para a planimetria e altimetria.

\begin{tabular}{|c|c|c|c|c|c|}
\hline \multicolumn{6}{|c|}{ Intervalo de Confiança 99\% } \\
\hline & $\begin{array}{l}\text { Variância Esperada } \\
\qquad\left(\mathrm{m}^{2}\right)\end{array}$ & $\begin{array}{c}\text { Variância Calculada } \\
\qquad\left(\mathrm{m}^{2}\right)\end{array}$ & $x_{\text {calculado }}^{2}$ & $\mathrm{X}_{\text {tabela }}^{2}$ & Teste \\
\hline Planimétrico & 0,01409391 & 0,021857757 & 97,705 & 96,878 & FALHOU \\
\hline Altimétrico & 0,016568265 & 0,150796896 & 573,398 & 96,878 & FALHOU \\
\hline
\end{tabular}

A tabela 51 apresenta a média das diferenças, diferença padrão e as diferenças máximas e mínimas encontradas. Pode-se concluir que a "precisão média" de $11,5 \mathrm{~cm}$ na planimetria atende ao valor esperado na tabela 12 e que esta metodologia pode ser utilizada no posicionamento compatível com este erro. A "precisão média" de $38 \mathrm{~cm}$ na altimetria excede em $25 \mathrm{~cm}$ ao valor esperado na tabela 12, e que esta metodologia pode ser utilizada em trabalhos cuja exigência seja aceitável. 
Tabela 51 - Discrepâncias das coordenadas obtidas no exp. 10.

\begin{tabular}{|c|c|c|c|}
\hline Discrepâncias & $\mathbf{E}(\mathbf{m})$ & $\mathbf{N}(\mathbf{m})$ & $\mathbf{h}(\mathbf{m})$ \\
\hline Médias das diferenças & $-0,053$ & -0.059 & -0.014 \\
\hline Diferença Padrão & 0.102 & 0.133 & 0.388 \\
\hline Diferença Máxima & 0.085 & 0.286 & 0.782 \\
\hline Diferença Mínima & -0.299 & -0.348 & -1.942 \\
\hline
\end{tabular}

\subsubsection{Experimento 11}

Os parâmetros do resultado do teste T Student, em cada componente das coordenadas, estão na Tabela 52 a seguir.

Tabela 52 - Resultado para o Teste T Student no exp. 11.

Teste T Student

\begin{tabular}{|c|c|c|c|}
\hline & Este & Norte & Altitude \\
\hline Média $(\bar{x})$ & $323255,083 \mathrm{~m}$ & $7394432,167 \mathrm{~m}$ & 718,159 \\
\hline Valor Verdadeiro $(\mu)$ & $323255,082 \mathrm{~m}$ & $7394432,170 \mathrm{~m}$ & 718,140 \\
\hline Precisão Nominal & $0,01100000 \mathrm{~m}$ & $0,01100000 \mathrm{~m}$ & 0,021000 \\
\hline$\left|t_{\text {calc }}\right|$ & 0,886072204 & 2,65821625 & 8,81852822 \\
\hline & Intervalo de confiança $-99 \%$ & \\
\hline$t_{(9: 0,01)}-(99 \%)$ & 2,63 & 2,63 & 2,63 \\
\hline$t_{\text {calc }} \mid<t_{1-\alpha / 2}$ & Passou & Falhou & Falhou \\
\hline
\end{tabular}

A tabela acima mostra uma tendência sistemática nos eixos $\mathrm{N}$ e $\mathrm{h}$, sendo que com base na diferença padrão, conforme Tabela 54, concluir-se-á se é aceitável.

$\mathrm{Na}$ análise da precisão, os resultados obtidos para esse teste estão na tabela 52. Constata-se que o teste foi aceito na planimetria e na altimetria. 
Tabela 53 - Resultado para o Teste Qui-Quadrado para o exp. 11.

Teste de Análise de Precisão

Intervalo de Confiança 99\%

\begin{tabular}{|c|c|c|c|c|c|}
\hline & $\begin{array}{l}\text { Variância Esperada } \\
\qquad\left(\mathrm{m}^{2}\right)\end{array}$ & $\begin{array}{c}\text { Variância Calculada } \\
\qquad\left(\mathrm{m}^{2}\right)\end{array}$ & $X^{2}$ calculado & $X^{2}$ tabela & Teste \\
\hline Planimétrico & 0.00011 & 0.00004 & 68.237 & 134.200 & PASSOU \\
\hline Altimétrico & 0.00042 & 0.00013 & 62.129 & 134.200 & PASSOU \\
\hline
\end{tabular}

A tabela 54 apresenta a média das diferenças, diferença padrão e as diferenças máximas e mínimas encontradas. Pode-se concluir que a "precisão média" de 4,5 mm na planimetria atende ao valor esperado na tabela 12 e que esta metodologia pode ser utilizada no posicionamento compatível com este erro. A "precisão média" $2,1 \mathrm{~cm}$ atende ao esperado na tabela 12 e poderá ser usado em trabalhos com esta exigência.

Tabela 54 - Discrepâncias das coordenadas obtidas no exp. 11.

\begin{tabular}{|c|c|c|c|}
\hline Discrepâncias & $\mathbf{E}(\mathbf{m})$ & $\mathbf{N}(\mathbf{m})$ & $\mathbf{h}(\mathbf{m})$ \\
\hline Média das Diferenças & -0.001 & -0.003 & -0.019 \\
\hline Diferença Padrão & 0.003 & 0.006 & 0.021 \\
\hline Diferença Máxima & 0.006 & 0.018 & 0.008 \\
\hline Diferença Mínima & -0.009 & -0.014 & -0.050 \\
\hline
\end{tabular}

\subsubsection{Experimento 12}

$\mathrm{Na}$ análise de tendência, o teste $\mathrm{T}$ Student, apresentou os resultados da tabela 55 a seguir. 
Tabela 55 - Resultado para Teste de T Student no exp. 12a.

Teste T Student

\begin{tabular}{|c|c|c|c|}
\hline & Este & Norte & Altitude \\
\hline Média $(\bar{x})$ & $328897,820 \mathrm{~m}$ & $7395519,010 \mathrm{~m}$ & $750,463 \mathrm{~m}$ \\
\hline Valor Verdadeiro $(\mu)$ & $328897,841 \mathrm{~m}$ & $7395519,001 \mathrm{~m}$ & $750,397 \mathrm{~m}$ \\
\hline Precisão Nominal & $0,016000 \mathrm{~m}$ & $0,016000 \mathrm{~m}$ & $0,026000 \mathrm{~m}$ \\
\hline$\left|t_{\text {calc }}\right|$ & 3,375695199 & 1,552016467 & 6,745212134 \\
\hline$t_{(9: 0,01)}-(99 \%)$ & Intervalo de confiança $-99 \%$ & \\
\hline$t_{\text {calc }} \mid<t_{1-\alpha / 2}$ & 3,5 & 3,5 & 3,5 \\
\hline
\end{tabular}

A tabela acima mostra uma tendência sistemática no eixo $\mathrm{h}$, e a análise da diferença padrão, a qual é apresentada na Tabela 57, concluir-se-á se é aceitável.

$\mathrm{Na}$ análise da precisão, os resultados obtidos encontram-se na Tabela 56, constata-se que o resultado foi aceito para a planimetria e tem restrição na altimetria.

\begin{tabular}{|c|c|c|c|c|c|}
\hline \multicolumn{6}{|c|}{ Intervalo de Confiança 99\% } \\
\hline & $\begin{array}{l}\text { Variância Esperada } \\
\qquad\left(\mathrm{m}^{2}\right)\end{array}$ & $\begin{array}{l}\text { Variância Calculada } \\
\qquad\left(\mathrm{m}^{2}\right)\end{array}$ & $\mathrm{X}_{\text {calculado }}^{2}$ & $X^{2}$ tabela & Teste \\
\hline Planimétrico & 0.000247762 & 0.000063 & 1.529117415 & 18.550 & Falhou \\
\hline Altimétrico & 0.000662571 & 0.000268 & 2.423028374 & 18.550 & Passou \\
\hline
\end{tabular}

A tabela 57 apresenta a média das diferenças, diferença padrão e as diferenças máximas e mínimas encontradas. Pode-se concluir que a "precisão média" de $1,7 \mathrm{~cm}$ na planimetria praticamente atende ao valor esperado da tabela 12, pois a diferença de $4 \mathrm{~mm}$ é desprezível, e que esta metodologia pode ser utilizada no posicionamento com esta exigência. A "precisão média" de $7 \mathrm{~cm}$ na altimetria excede o valor esperado da tabela 12, mas pode ser utilizada em trabalhos em cuja exigência seja aceitável. 
Tabela 57 - Discrepâncias das coordenadas obtidas no exp. 12a.

\begin{tabular}{|c|c|c|c|}
\hline Discrepâncias & $\mathbf{E}(\mathbf{m})$ & $\mathbf{N}(\mathbf{m})$ & $\mathbf{h}(\mathbf{m})$ \\
\hline Média das diferenças & 0.020 & -0.009 & -0.066 \\
\hline Diferença Padrão & 0.022 & 0.012 & 0.073 \\
\hline Diferença Máxima & 0.031 & -0.003 & -0.031 \\
\hline Diferença Mínima & 0.014 & -0.020 & -0.079 \\
\hline
\end{tabular}

No teste $\mathbf{b}$, na análise de tendência, o teste $T$ Student apresentou os resultados que são mostrados na Tabela 58.

Tabela 58 - Resultado para Teste de T Student no exp. 12b. Teste T Student

\begin{tabular}{|l|c|c|c|}
\hline & Este & Norte & Altitude \\
\hline Média $(\bar{x})$ & $328898.079 \mathrm{~m}$ & $7395518.719 \mathrm{~m}$ & $751.066 \mathrm{~m}$ \\
\hline Valor Verdadeiro $(\mu)$ & $328897.841 \mathrm{~m}$ & $7395519.001 \mathrm{~m}$ & $750.397 \mathrm{~m}$ \\
\hline Diferença padrão $\left(\hat{\sigma}^{2}\right)$ & $0.365843 \mathrm{~m}$ & $0.725800 \mathrm{~m}$ & $1.355390 \mathrm{~m}$ \\
\hline$t_{\text {calc }} \mid$ & 2.524163019 & 1.504262793 & 1.911837001 \\
\hline & Intervalo de confiança $-99 \%$ & \\
\hline$t_{(9: 0,01)}-(99 \%)$ & 2.95 & 2.95 & 2.95 \\
\hline$\left|t_{\text {calc }}\right|<t_{1-\alpha / 2}$ & Passou & Passou & Passou \\
\hline
\end{tabular}

A tabela acima mostra que não existe tendência sistemática em nenhum dos eixos. $\mathrm{Na}$ análise da precisão, os resultados obtidos encontram-se na Tabela 59, constata-se que o resultado tem restrição na planimetria e na altimetria.

Tabela 59 - Resultado para o Teste Qui-Quadrado para o exp. 12b. Teste de Análise de Precisão

Intervalo de Confiança $99 \%$

\begin{tabular}{|c|c|c|c|c|c|}
\hline & \multicolumn{3}{|c|}{ Intervalo de Confiança 99\% } & Teste \\
\hline & $\begin{array}{c}\text { Variância Esperada } \\
\left(\mathbf{m}^{2}\right)\end{array}$ & $\begin{array}{c}\text { Variância Calculada } \\
\left(\mathbf{m}^{2}\right)\end{array}$ & $\mathbf{X}^{2}$ calculado & $\mathbf{X}^{2}$ tabela & \\
\hline Planimétrico & 0.000247762 & 0.637511 & 36023.12234 & 31.320 & Falhou \\
\hline Altimétrico & 0.000662571 & 1.837081 & 38817.16995 & 31.320 & Falhou \\
\hline
\end{tabular}


A tabela 60 apresenta a média das diferenças, a diferença padrão e as diferenças máximas e mínimas encontradas. Conclui-se que a "precisão média" de $60,4 \mathrm{~cm}$ na planimetria não atende ao valor esperado na tabela 12 e não pode ser utilizado em trabalhos com esta exigência. A "precisão média" de 1,5 m na altimetria também não pode ser utilizada com esta exigência.

Tabela 60 - Discrepâncias das coordenadas obtidas no exp. 12b.

\begin{tabular}{|c|c|c|c|}
\hline Discrepâncias & $\mathbf{E}(\mathbf{m})$ & $\mathbf{N}(\mathbf{m})$ & $\mathbf{h}(\mathbf{m})$ \\
\hline Média das diferenças & -0.238 & 0.282 & -0.669 \\
\hline Diferença Padrão & 0.441 & 0.767 & 1.522 \\
\hline Diferença Máxima & 0.211 & 2.491 & 0.582 \\
\hline Diferença Mínima & -1.219 & -0.383 & -4.927 \\
\hline
\end{tabular}

\subsubsection{Experimento 13}

Na análise de tendência, o teste T Student apresentou os resultados da Tabela 61 a seguir.

Tabela 61 - Resultado para o Teste T Student no exp. 13.

Teste T Student

\begin{tabular}{|c|c|c|c|}
\hline & Este & Norte & Altitude \\
\hline Média $(\bar{x})$ & $332793,361 \mathrm{~m}$ & $7394977,053 \mathrm{~m}$ & $735,603 \mathrm{~m}$ \\
\hline Valor Verdadeiro $(\mu)$ & $332793,623 \mathrm{~m}$ & $7394977,022 \mathrm{~m}$ & $735,005 \mathrm{~m}$ \\
\hline Precisão Nominal & $0,02000000 \mathrm{~m}$ & $0,020000 \mathrm{~m}$ & $0,030000 \mathrm{~m}$ \\
\hline$\left|t_{\text {calc }}\right|$ & 105,6248791 & 12,54921392 & 160,6539227 \\
\hline$t_{(9: 0,01)}-(99 \%)$ & Intervalo de confiança $-99 \%$ & \\
\hline$t_{\text {calc }} \mid<t_{1-\alpha / 2}$ & 2,66 & 2,66 & 2,66 \\
\hline
\end{tabular}

A tabela acima mostra uma tendência sistemática em todos os eixos, e a análise da diferença padrão, a qual é apresentada na Tabela 63, concluir-se-á se é aceitável. 
$\mathrm{Na}$ análise da precisão, os resultados obtidos encontram-se na Tabela 62, constatou-se que os resultados não foram aceitos tanto para a planimetria como para a altimetria.

Tabela 62- Resultado para o Teste Qui-Quadrado para o exp. 13. Teste de Análise de Precisão

\begin{tabular}{|c|c|c|c|c|c|}
\hline \multicolumn{7}{c}{ Intervalo de Confiança $99 \%$} \\
$\begin{array}{c}\text { Variância Esperada } \\
\left(\mathbf{m}^{2}\right)\end{array}$ & $\begin{array}{c}\text { Variância Calculada } \\
\left(\mathbf{m}^{2}\right)\end{array}$ & $\mathbf{x}^{2}$ calculado & $\mathbf{x}^{2}$ tabela & \\
\hline Planimétrico & 0,00038 & 0,266438 & $45,002,949$ & 148,390 & FALHOU \\
\hline Altimétrico & 0,00087 & 0,628737 & $46,346,667$ & 148,390 & FALHOU \\
\hline
\end{tabular}

A tabela 63 apresenta a média das diferenças, diferença padrão e as diferenças máximas e mínimas encontradas. Pode-se concluir que a "precisão média" de $40 \mathrm{~cm}$ na planimetria não atende ao valor esperado na tabela 12 e que esta metodologia não pode ser utilizada com esta exigência. Já na altimetria pode-se afirmar o mesmo, pois a precisão média de $1 \mathrm{~m}$ não atinge o valor esperado da tabela 12.

Tabela 63 - Discrepâncias das coordenadas obtidas no exp. 13.

\begin{tabular}{|c|c|c|c|}
\hline Discrepâncias & $\mathbf{E}(\mathbf{m})$ & $\mathbf{N}(\mathbf{m})$ & $\mathbf{h}(\mathbf{m})$ \\
\hline Média das Diferenças & 0,262 & $-0,031$ & $-0,598$ \\
\hline Diferença Padrão & 0,493 & 0,306 & 0,996 \\
\hline Diferença Máxima & 1,492 & 0,784 & 0,508 \\
\hline Diferença Mínima & $-0,265$ & $-1,159$ & $-2,667$ \\
\hline
\end{tabular}

\subsubsection{Experimento 14}

Os parâmetros do resultado do teste T Student, em cada componente das coordenadas, estão na Tabela 64 a seguir. 
Tabela 64 - Resultado para o Teste T Student no exp. 14.

Teste T Student

\begin{tabular}{|c|c|c|c|}
\hline & Este & Norte & Altitude \\
\hline Média $(\bar{x})$ & $321920,140 \mathrm{~m}$ & $7410979,596 \mathrm{~m}$ & $833,247 \mathrm{~m}$ \\
\hline Valor Verdadeiro $(\mu)$ & $321919,934 \mathrm{~m}$ & $7410979,52 \mathrm{~m}$ & $833,063 \mathrm{~m}$ \\
\hline Precisão Nominal & $0,02700000 \mathrm{~m}$ & $0,02700000 \mathrm{~m}$ & $0,037000 \mathrm{~m}$ \\
\hline$\left|t_{\text {calc }}\right|$ & 70,91402675 & 26,2512901 & 46,22820131 \\
\hline & Intervalo de confiança $-99 \%$ & \\
\hline$t_{(9: 0,01)}-(99 \%)$ & 2,64 & 2,64 & 2,64 \\
\hline$\left|t_{\text {calc }}\right|<t_{1-\alpha / 2}$ & Falhou & Falhou & Falhou \\
\hline
\end{tabular}

A tabela acima mostra uma tendência sistemática em todos os eixos, sendo que a diferença padrão, mostrada na Tabela 66, concluir-se-á se é aceitável.

$\mathrm{Na}$ análise do teste Qui-Quadrado, constata-se que os resultados têm restrição para a planimetria e na altimetria, conforme a tabela 65.

\begin{tabular}{|c|c|c|c|} 
Tabela 65 - Resultado para o Teste Qui-Quadrado para o exp. 14. \\
Teste de Análise de Precisão \\
Intervalo de Confiança 99\%
\end{tabular}

A tabela 66 apresenta a média das diferenças, diferença padrão e as diferenças máximas e mínimas encontradas. Constatou-se que a "precisão média" de $39 \mathrm{~cm}$ na planimetria não atende ao valor esperado da tabela 12 não pode ser utilizado em trabalhos com esta exigência. A "precisão média" de $46 \mathrm{~cm}$ na altimetria excede o valor esperado da tabela 12 e não pode ser utilizado em trabalhos com esta exigência. 
Tabela 66 - Discrepâncias das coordenadas obtidas no exp. 14.

\begin{tabular}{|c|c|c|c|}
\hline Discrepâncias & $\mathbf{E}(\mathbf{m})$ & $\mathbf{N}(\mathbf{m})$ & $\mathbf{h}(\mathbf{m})$ \\
\hline Média das diferenças & $-0,206$ & $-0,076$ & $-0,184$ \\
\hline Diferença Padrão & 0,416 & 0,378 & 0,468 \\
\hline Diferença Máxima & 0,528 & 0,845 & 0,680 \\
\hline Diferença Mínima & $-0,967$ & $-0,905$ & $-0,983$ \\
\hline
\end{tabular}

\subsubsection{Experimento 15}

Os parâmetros do resultado do teste $\mathrm{T}$ Student, em cada componente das coordenadas, estão na Tabela 67 a seguir.

Tabela 67 - Resultado para o Teste T Student no exp. 15.

Teste T Student

\begin{tabular}{|c|c|c|c|}
\hline & Este & Norte & Altitude \\
\hline Média $(\bar{x})$ & $324457,765 \mathrm{~m}$ & $7363504,135 \mathrm{~m}$ & $777,529 \mathrm{~m}$ \\
\hline Valor Verdadeiro $(\mu)$ & $324457,826 \mathrm{~m}$ & $7363504,042 \mathrm{~m}$ & $777,398 \mathrm{~m}$ \\
\hline Precisão Nominal & $0,04000000 \mathrm{~m}$ & $0,04000000 \mathrm{~m}$ & $0,050 \mathrm{~m}$ \\
\hline$\left|t_{\text {calc }}\right|$ & 13,51423583 & 20,83176899 & 23,44070061 \\
\hline$t_{(9: 0,01)}-(99 \%)$ & Intervalo de confiança $-99 \%$ & \\
\hline$\left|t_{\text {calc }}\right|<t_{1-\alpha / 2}$ & 2,64 & 2,64 & 2,64 \\
\hline
\end{tabular}

A tabela acima mostra uma tendência sistemática em todos os eixos, sendo que analisando diferença padrão, apresentada na Tabela 69, concluir-se-á se é aceitável.

$\mathrm{Na}$ análise da precisão, os resultados obtidos encontram-se na Tabela 68, constata-se que os testes têm restrição para planimetria e na altimetria. 
Tabela 68 - Resultado para o Teste Qui-Quadrado para o exp. 15. Teste de Análise de Precisão Intervalo de Confiança 99\%

\begin{tabular}{|c|c|c|c|c|c|}
\hline \multicolumn{6}{|c|}{ Intervalo de Confiança 99\% } \\
\hline & $\begin{array}{c}\text { Variância Esperada } \\
\qquad\left(\mathrm{m}^{2}\right)\end{array}$ & $\begin{array}{c}\text { Variância Calculada } \\
\qquad\left(\mathrm{m}^{2}\right)\end{array}$ & $\mathrm{X}^{2}$ calculado & $x^{2}$ tabela & Teste \\
\hline Planimétrico & 0,001633846 & 0,073193 & 3539,033 & 116,300 & FALHOU \\
\hline Altimétrico & 0,002542264 & 0,104573 & 3249,579 & 116,300 & FALHOU \\
\hline
\end{tabular}

A tabela 69 apresenta a média das diferenças, diferença padrão e as diferenças máximas e mínimas encontradas. Pode-se concluir que a "precisão média" de $36 \mathrm{~cm}$ na planimetria e $42 \mathrm{~cm}$ na altimetria não pode ser utilizada em trabalhos com a precisão exigida.

Tabela 69 - Discrepâncias das coordenadas obtidas no exp. 15.

\begin{tabular}{|c|c|c|c|}
\hline Discrepâncias & $\mathbf{E}(\mathbf{m})$ & $\mathbf{N}(\mathbf{m})$ & $\mathbf{h}(\mathbf{m})$ \\
\hline Média das diferenças & $-0,206$ & $-0,076$ & $-0,184$ \\
\hline Diferença Padrão & 0,361 & 0,370 & 0,429 \\
\hline Diferença Máxima & 0,528 & 0,845 & 0,680 \\
\hline Diferença Mínima & $-0,967$ & $-0,905$ & $-0,983$ \\
\hline
\end{tabular}

\subsubsection{Experimento 16}

Os parâmetros do resultado do teste T Student, em cada componente das coordenadas, estão na Tabela 70 a seguir. 
Tabela 70 - Resultado para o Teste T Student no exp. 16.

Teste T Student

\begin{tabular}{|c|c|c|c|}
\hline & Este & Norte & Altitude \\
\hline Média $(\bar{x})$ & $358096,268 \mathrm{~m}$ & $7390723,738 \mathrm{~m}$ & $842,454 \mathrm{~m}$ \\
\hline Valor Verdadeiro $(\mu)$ & $358096,2763 \mathrm{~m}$ & $7390723,706 \mathrm{~m}$ & $842,355 \mathrm{~m}$ \\
\hline Precisão Nominal & $0,04500000 \mathrm{~m}$ & $0,04500000 \mathrm{~m}$ & $0,055000 \mathrm{~m}$ \\
\hline$\left|t_{\text {calc }}\right|$ & 1,45478349 & 5,508145777 & 14,1050083 \\
\hline$t_{(9: 0,01)}-(99 \%)$ & Intervalo de confiança $-99 \%$ & \\
\hline$t_{\text {calc }} \mid<t_{1-\alpha / 2}$ & 2,66 & 2,66 & 2,66 \\
\hline
\end{tabular}

A tabela acima mostra uma tendência sistemática para as coordenadas $\mathrm{N}$ e h, sendo que a diferença padrão, mostrada na Tabela 72, concluir-se-á se é aceitável.

Constata-se na tabela 71, que os resultados do teste Qui-Quadrado, tem restrição para a planimetria e são aceitos na altimetria.

Tabela 71 - Resultado para o Teste Qui-Quadrado para o exp. 16.

Teste de Análise de Precisão

\begin{tabular}{|c|c|c|c|c|c|}
\hline \multicolumn{6}{|c|}{ Intervalo de Confiança 99\% } \\
\hline & $\begin{array}{c}\text { Variância Esperada } \\
\qquad\left(\mathrm{m}^{2}\right)\end{array}$ & $\begin{array}{c}\text { Variância Calculada } \\
\qquad\left(\mathrm{m}^{2}\right)\end{array}$ & $x^{2}$ calculado & $X^{2}$ tabela & Teste \\
\hline Planimétrico & 0,00201 & 0,003637 & 108,436 & 91,950 & FALHOU \\
\hline Altimétrico & 0,00301 & 0,003359 & 66,975 & 91,950 & PASSOU \\
\hline
\end{tabular}

A tabela 72 apresenta a média das diferenças, diferença padrão e as diferenças máximas e mínimas encontradas. Pode-se concluir que "a precisão média" de 4,7 cm na planimetria atende ao valor esperado da tabela 12 e que esta metodologia pode ser utilizada no posicionamento compatível com este erro. A "precisão média" de $11,5 \mathrm{~cm}$ na altimetria excede o valor esperado, porém pode ser utilizado em trabalhos cuja exigência seja aceitável. 
Tabela 72 - Discrepâncias das coordenadas obtidas no exp. 16.

\begin{tabular}{|c|c|c|c|}
\hline Discrepâncias & $\mathbf{E}(\mathbf{m})$ & $\mathbf{N}(\mathbf{m})$ & $\mathbf{H}(\mathbf{m})$ \\
\hline Média das diferenças & 0,008 & -0.032 & -0.099 \\
\hline Diferença Padrão & 0.058 & 0.036 & 0.115 \\
\hline Diferença Máxima & 0.062 & 0.010 & -0.005 \\
\hline Diferença Mínima & -0.151 & -0.069 & -0.238 \\
\hline
\end{tabular}

\subsection{ANÁLISE DOS RESULTADOS OBTIDOS}

\subsubsection{Comentários e resumo do trabalho de campo}

Antes da análise técnica e dos comentários dos experimentos, serão ressaltados os fatores que afetaram diretamente o trabalho em campo. Dentre eles destacam-se: conexão GSM, condições metereológicas, distância do receptor base e móvel, limite de disponibilidade de satélites, latência, os valores de PDOP, multicaminhamento e tipo de solução da ambiguidade. A obtenção da solução fixa foi consequência do somatório destes fatores em boas condições no momento da coleta, o que iria permitir concluir que o ponto considerou-se calculado e com as ambiguidades resolvidas. Padronizou-se como ideal a gravação dos pontos com esta solução; porém, quando não foi possível esta situação devido a um ou mais dos fatores acima não estarem adequados no momento da coleta, foi gravada a coordenada com a solução flutuante.

Nos experimentos com 0 uso do Receptor GNSS L1/L2, o tempo de inicialização para resolver as ambiguidades foi praticamente instantâneo sempre que as linhas de base eram inferiores a $35 \mathrm{~km}$. Apenas no experimento 10 utilizou-se apenas a solução flutuante, nos demais foi possível obter a solução fixa, com o tempo médio de inicialização de aproximadamente 15 segundos.

Utilizando o receptor GPS $L 1$, as coordenadas com a solução fixa foram obtidas até $5,7 \mathrm{~km}$; acima deste valor todas as coordenadas foram flutuantes até 36 $\mathrm{km}$. Notou-se que no uso deste tipo de receptor, os resultados foram piores quando o valor do PDOP foi alto e à baixa disponibilidade de satélites, o que ocorreu pelo equipamento utilizado só rastrear a constelação GPS. 
Nos experimentos $1,2,3,4,5,6,11,12,13,14,15$ e 16, utilizaram-se receptores do tipo GNSS L1/L2 e GPSL1, sendo rastreados vértices que se encontravam em locais edificados (Av. Sumaré, Anhangabaú e Parelheiros), afetados assim pelo multicaminhamento e pelas demais interferências. Assim, foram registrados PDOPs altos, mas os resultados finais foram todos aceitáveis usando L1/L2 e descartados para L1.

A seguir demonstra-se um resumo de todos os levantamentos realizados. $\mathrm{Na}$ tabela 73, apresentam-se os experimentos $1,2,3,4,5$ e 6 . 
Tabela 73 - Resumo dos resultados dos exp. 1, 2, 3, 4, 5 e 6 (solução Fixa).

\section{Experimento}

\begin{tabular}{|c|c|c|c|c|c|c|c|}
\hline \multicolumn{2}{|c|}{$\begin{array}{c}\text { Comprimento da } \\
\text { Linha de Base (km) }\end{array}$} & 0,547 & 5,7 & 9,5 & 17,0 & 30,4 & 35,0 \\
\hline \multicolumn{2}{|c|}{ Vértice } & SAT91607 & V2295 & V2296 & V2009 & V2837 & V2510 \\
\hline \multicolumn{2}{|l|}{ Local } & P1 & Av. Sumaré & Anhangabaú & Perus & Parelheiros & Cid. Tiradentes \\
\hline \multicolumn{2}{|c|}{ Equipamento } & GNSSL1L2 & GNSSL1L2 & GNSSL1L2 & GNSSL1L2 & GNSSL1L2 & GNSSL1L2 \\
\hline \multirow[t]{3}{*}{ Valor Oficial } & $E(m)$ & 323255,082 & 328897,841 & 332793,623 & 321919,934 & 324457,826 & 358096,276 \\
\hline & $\mathrm{N}(\mathrm{m})$ & 7394432,170 & 7395519,001 & 7394977,022 & 7410979,52 & 7363504,042 & 7390723,706 \\
\hline & $\mathrm{h}(\mathrm{m})$ & 718,140 & 750,397 & 735,005 & 833,063 & 777,398 & 842,355 \\
\hline \multirow[t]{3}{*}{ Valor Médio } & $E(m)$ & 323255,080 & 328897,827 & 332793,626 & 321919,919 & 324457,83 & 358096,272 \\
\hline & $N(m)$ & 7394432,166 & 7395519,016 & 7394977,027 & 7410979,531 & 7363504,052 & 7390723,72 \\
\hline & $\mathrm{h}(\mathrm{m})$ & 718,100 & 750,438 & 735,011 & 833,128 & 777,395 & 842,374 \\
\hline Precisão Esperada & $\mathrm{E}, \mathrm{N}(\mathrm{m})$ & 0,011 & 0,016 & 0,02 & 0,027 & 0,04 & 0,045 \\
\hline \multirow[t]{2}{*}{ Média das diferenças } & $E(m)$ & 0,002 & 0,014 & $-0,003$ & 0,015 & $-0,004$ & 0,004 \\
\hline & $\mathrm{N}(\mathrm{m})$ & 0,004 & $-0,015$ & $-0,005$ & $-0,01$ & $-0,01$ & $-0,014$ \\
\hline \multirow[t]{2}{*}{ Diferença Padrão } & $E(m)$ & 0,003 & 0,017 & 0,025 & 0,019 & 0,013 & 0,009 \\
\hline & $\mathrm{N}(\mathrm{m})$ & 0,005 & 0,019 & 0,016 & 0,022 & 0,032 & 0,018 \\
\hline Precisão Esperada & $\mathrm{h}(\mathrm{m})$ & 0,021 & 0,026 & 0,03 & 0,037 & 0,05 & 0,055 \\
\hline Média das diferenças & $\mathrm{h}(\mathrm{m})$ & 0,04 & $-0,04$ & $-0,01$ & $-0,038$ & 0,003 & $-0,02$ \\
\hline Diferença Padrão & $\mathrm{h}(\mathrm{m})$ & 0,037 & 0,054 & 0,057 & 0,075 & 0,055 & 0,034 \\
\hline \multirow[t]{3}{*}{ Teste de Tendências } & $E$ & passou & Falhou & Passou & falhou & passou & passou \\
\hline & $\mathrm{N}$ & falhou & Falhou & Falhou & falhou & falhou & falhou \\
\hline & $\mathrm{H}$ & passou & Falhou & Passou & falhou & passou & passou \\
\hline \multirow[t]{2}{*}{ Teste de Precisão } & $\mathrm{E}, \mathrm{N}$ & passou & Falhou & Falhou & passou & passou & passou \\
\hline & $\mathrm{H}$ & passou & Passou & Falhou & passou & passou & passou \\
\hline Percentual de & Planimetria & $100,00 \%$ & $92,00 \%$ & $69,00 \%$ & $91,00 \%$ & $84,00 \%$ & $100,00 \%$ \\
\hline
\end{tabular}

atendimento do limite de precisão do fabricante

\begin{tabular}{|c|c|c|c|c|c|c|c|}
\hline Altimetria & $91,00 \%$ & $54,00 \%$ & $36,00 \%$ & $70,00 \%$ & $72,00 \%$ & $95,00 \%$ \\
\hline $\begin{array}{c}\text { PDOP - } \\
\text { médio }\end{array}$ & 1,82 & 3,4 & 4,7 & 2,2 & 2,7 & 1,89 \\
\hline
\end{tabular}

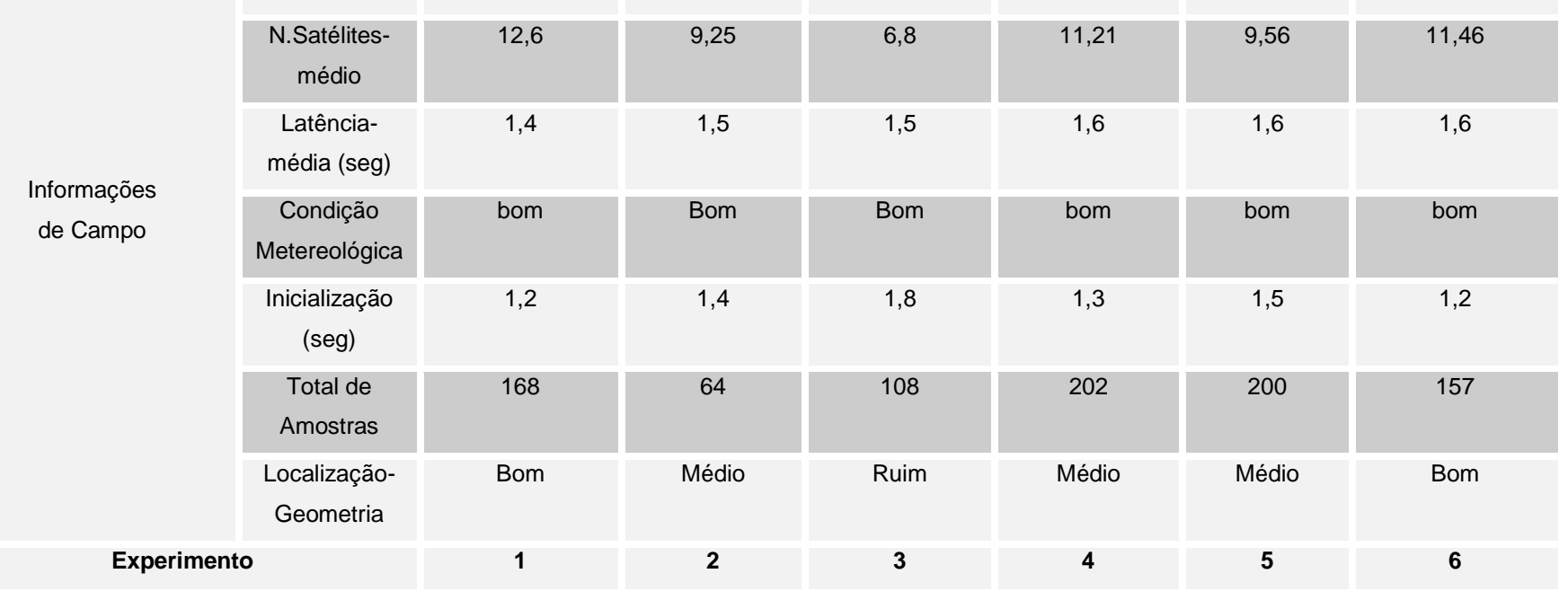

Na tabela 74, apresentam-se os experimentos 7a, 8a, 9a, 11 e 12a. 
Tabela 74 - Resumo dos resultados do exp. 7a, 8a, 9a, 11 e 12 a (solução Fixa).

Experimento

\begin{tabular}{|r|}
\hline Comprimento da Lin \\
Vértice Locaipam \\
\hline Valor Oficial \\
\hline Valor Médio \\
\hline Precisão Esperada \\
\hline Média das \\
diferenças
\end{tabular}

Diferença Padrão

Precisão Esperada

Média das
diferenças

Diferença Padrão

Teste de
Tendências

Teste de Precisão

Teste de Precisão

Percentual de atendimento da precisão nominal

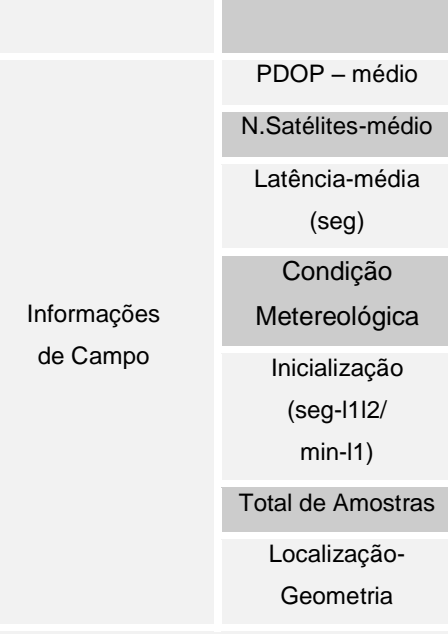

Experimento

$E(m)$
$N(m)$
$h(m)$

$E(m)$
$N(m)$

$\mathrm{h}(\mathrm{m})$

$h(m)$

\begin{tabular}{c}
\hline E \\
\hline N \\
\hline$H$ \\
\hline E,N \\
$H$
\end{tabular}

\section{$7 a \quad 8 a$}

$8 a$

Mogic

\begin{tabular}{c|}
$\mathbf{5 4 , 0}$ \\
SAT93814 \\
\hline gi das Cruzes
\end{tabular}

$\mathbf{7 2 , 0}$
SAT93794
Indaiatuba

GNSSL1L2 GNSSL1L2

\begin{tabular}{c}
$\mathbf{9 a}$ \\
$\mathbf{9 6 , 5}, \mathbf{5}$ \\
\hline SAT 96035 \\
S. J. Campos
\end{tabular}

\begin{tabular}{c}
\hline $\mathbf{1 1}$ \\
$\mathbf{0 , 5 4 7}$ \\
SAT91607 \\
P1 \\
\hline
\end{tabular}

$12 a$

5,7

376797,341

\begin{tabular}{l|l}
7402292,754 & 7444443,404 \\
\hline
\end{tabular}

GNSSL1L2

GPSL1

V2295

1160,872
376797,336

581,86
271784,518

409426,691
7437551,997

\begin{tabular}{|l|}
\hline 323355,082 \\
\hline 7394432,17 \\
\hline
\end{tabular}

GPSL1

7402292,751

556,11
409426,693

\begin{tabular}{c}
718,14 \\
323355,083 \\
\hline
\end{tabular}

328897,841

7395519,001

1161,069

7444443,401
581,807

\begin{tabular}{c}
7437552,008 \\
\hline 556,242
\end{tabular}

\begin{tabular}{c}
7394432,167 \\
718,159 \\
\hline
\end{tabular}

750,397

328897,82

7395519,01

\begin{tabular}{|c|c|}
\hline$E, N(m)$ & 0,064 \\
\hline$E(m)$ & 0,005 \\
\hline$N(m)$ & 0,003 \\
\hline
\end{tabular}

0,082

\begin{tabular}{|c|}
\hline 556,242 \\
\hline 0,106 \\
\hline$-0,002$ \\
\hline
\end{tabular}

\begin{tabular}{c}
718,159 \\
0,011 \\
$-0,001$ \\
\hline
\end{tabular}

750,463

\begin{tabular}{l}
$-0,002 \quad-0,002$ \\
\hline
\end{tabular}

$-0,001$
0,003
0,003

0,021

0,003

\begin{tabular}{|l|}
\hline$-0,011$ \\
\hline 0,011 \\
\hline 0,016 \\
\hline 0,116 \\
\hline
\end{tabular}

$\begin{array}{r}0,006 \\ 0,021 \\ -0,020 \\ \hline 0,022\end{array}$

$-0,009$
0,022

0,012
0,026

$-0,200$
0,561

0,050

$-0,130$
0,141

0,022

$-0,070$

0,073

\begin{tabular}{|c|}
\hline passou \\
\hline passou \\
\hline passou
\end{tabular}

passou

\begin{tabular}{|c|}
\hline Passou \\
\hline Passou \\
\hline Falhou \\
\hline Passou \\
\hline Passou \\
\hline
\end{tabular}

falhou passou

passou

passou
falhou

\begin{tabular}{|l|}
\hline falhou \\
passou \\
\hline passou
\end{tabular}

falhou

passou
passou

$96,00 \%$

$100,00 \%$

$97,00 \%$

$100,00 \%$

\begin{tabular}{|l|l|}
\hline Planimetria & $100,00 \%$ \\
\hline
\end{tabular}
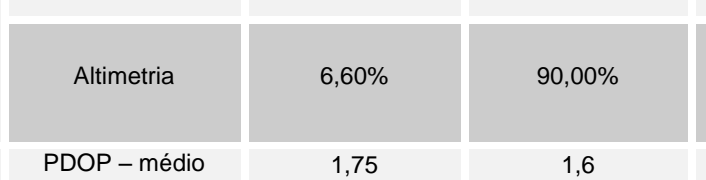

\begin{tabular}{|c|}
\hline $100,00 \%$ \\
\hline 1,5 \\
\hline 15 \\
\hline 1,5 \\
\hline
\end{tabular}

\begin{tabular}{c}
$94,00 \%$ \\
\hline 1,87 \\
8 \\
\hline 1,5
\end{tabular}

\begin{tabular}{c}
\hline $86,00 \%$ \\
\hline 2,1 \\
\hline 7 \\
\hline 1,6
\end{tabular}

\begin{tabular}{l|l}
$1,9+1,6$ \\
\hline
\end{tabular}

ruim

bom

Bom

bom bom

15

15

15

18

15

53

$8 a$

\begin{tabular}{|c|}
18 \\
\hline Bom \\
\hline $\mathbf{9}^{\mathrm{a}}$ \\
\hline
\end{tabular}

$7 a$

$9^{\mathrm{a}}$

\begin{tabular}{|c|c|}
\hline 95 & 7 \\
\hline bom & bom \\
\hline 11 & $12 a$ \\
\hline
\end{tabular}

$\mathrm{Na}$ tabela 75, apresentam-se os experimentos $7 \mathrm{~b}, 8 \mathrm{~b}, 9 \mathrm{~b}, 10$ e 12b. 
Tabela 75 - Resumo dos resultados do exp. 7b, 8b, 9b, 10 e 12b (solução flutuante).

\begin{tabular}{|c|c|c|c|c|c|c|}
\hline \multicolumn{2}{|c|}{ Experimento } & $7 \mathrm{~h}$ & oh & oh & 10 & $12 \mathrm{~h}$ \\
\hline \multirow{2}{*}{\multicolumn{2}{|c|}{ Comprimento da Linha de Base (km) }} & & & & & \\
\hline & & 54,0 & 72,0 & 96,5 & 108,7 & 5,7 \\
\hline \multicolumn{2}{|c|}{ Vértice } & SAT93814 & SAT93794 & SAT96035 & SAT93504 & V2295 \\
\hline \multicolumn{2}{|c|}{ Local } & $\begin{array}{l}\text { Mogi das } \\
\text { Cruzes }\end{array}$ & Indaiatuba & S. J. Campos & Miracatu & Av. Sumaré \\
\hline \multicolumn{2}{|c|}{ Equipamento } & GNSSL1L2 & GNSSL1L2 & GNSSL1L2 & GNSSL1L2 & GPSL1 \\
\hline \multirow{3}{*}{ Valor Oficial } & $E(m)$ & 376797,341 & 271784,516 & 409426,691 & 251199,262 & 328897,841 \\
\hline & $N(m)$ & 7402292,754 & 7444443,404 & 7437551,997 & 7312598,79 & 7395519,001 \\
\hline & $\mathrm{h}(\mathrm{m})$ & 1160,920 & 581,860 & 556,110 & 56,260 & 750,3970 \\
\hline \multirow{3}{*}{ Valor Médio } & $E(m)$ & 376797,39 & 271784,482 & 409426,722 & 251199,315 & 328898,079 \\
\hline & $N(m)$ & 7402292,756 & 7444443,421 & 7437552,031 & 7312598,849 & 7395518,719 \\
\hline & $\mathrm{h}(\mathrm{m})$ & 1161,336 & 581,845 & 556,196 & 56,274 & 751,066 \\
\hline Precisão Esperada & $\mathrm{E}, \mathrm{N}(\mathrm{m})$ & 0,064 & 0,082 & 0,106 & 0,119 & 0,016 \\
\hline \multirow{2}{*}{$\begin{array}{l}\text { Média das } \\
\text { diferenças }\end{array}$} & $E(m)$ & $-0,049$ & 0,034 & $-0,031$ & $-0,053$ & $-0,238$ \\
\hline & $N(m)$ & $-0,002$ & $-0,017$ & $-0,034$ & $-0,059$ & 0,282 \\
\hline \multirow{2}{*}{ Diferença Padrão } & $E(m)$ & 0,069 & 0,070 & 0,074 & 0,102 & 0,441 \\
\hline & $N(m)$ & 0,102 & 0,079 & 0,073 & 0,133 & 0,767 \\
\hline Precisão Esperada & $\mathrm{h}(\mathrm{m})$ & 0,074 & 0,092 & 0,116 & 0,129 & 0,026 \\
\hline $\begin{array}{l}\text { Média das } \\
\text { diferenças }\end{array}$ & $\mathrm{h}(\mathrm{m})$ & $-0,464$ & 0,015 & $-0,086$ & $-0,014$ & $-0,669$ \\
\hline Diferença Padrão & $h(m)$ & 1,032 & 0,212 & 0,263 & 0,388 & 1,522 \\
\hline \multirow{3}{*}{$\begin{array}{c}\text { Teste de } \\
\text { Tendências }\end{array}$} & $E$ & falhou & falhou & Passou & falhou & falhou \\
\hline & $\mathrm{N}$ & passou & falhou & Passou & falhou & falhou \\
\hline & $\mathrm{H}$ & falhou & passou & Falhou & passou & falhou \\
\hline \multirow{2}{*}{ Teste de Precisão } & $\mathrm{E}, \mathrm{N}$ & falhou & falhou & Passou & falhou & falhou \\
\hline & $\mathrm{H}$ & falhou & falhou & Falhou & falhou & falhou \\
\hline \multirow{2}{*}{$\begin{array}{l}\text { Percentual de } \\
\text { atendimento da } \\
\text { precisão nominal }\end{array}$} & Planimetria & $66,00 \%$ & $78,00 \%$ & $86,00 \%$ & $78,00 \%$ & $3,00 \%$ \\
\hline & Altimetria & $4,00 \%$ & $45,00 \%$ & $40,00 \%$ & $45,00 \%$ & $0,00 \%$ \\
\hline \multirow{7}{*}{$\begin{array}{l}\text { Informações } \\
\text { de Campo }\end{array}$} & PDOP - médio & 1,8 & 1,9 & 1,7 & 2,1 & 2,1 \\
\hline & N.Satélite-médio & 14,5 & 13 & 14 & 11,6 & 7 \\
\hline & $\begin{array}{l}\text { Latência-média } \\
\qquad(\text { seg) }\end{array}$ & 2 & 1,6 & 1,7 & 1,5 & 1,6 \\
\hline & $\begin{array}{c}\text { Condição } \\
\text { Metereológica }\end{array}$ & ruim & bom & Bom & Bom & Bom \\
\hline & $\begin{array}{c}\text { Inicialização } \\
\text { (seg-I112/ } \\
\text { min-l1) }\end{array}$ & 3 & 3 & 3 & 3 & 3 \\
\hline & $\begin{array}{c}\text { Total de } \\
\text { Amostras }\end{array}$ & 27 & 31 & 56 & 64 & 15 \\
\hline & $\begin{array}{l}\text { Localização- } \\
\text { Geometria }\end{array}$ & bom & bom & Bom & Bom & médio \\
\hline \multicolumn{2}{|c|}{ Experimento } & $7 b$ & $8 b$ & $9 b$ & 10 & $12 b$ \\
\hline
\end{tabular}


A análise das tabelas 73, 74 e 75 permite concluir que a média das diferenças com o emprego do receptor GNSS L1/L2 foi inferior a $2 \mathrm{~cm}$ nos eixos $E$ e N, em todos os experimentos com solução fixa e, de $10 \mathrm{~cm}$ com solução flutuante. Verificando a altimetria, não superou os $10 \mathrm{~cm}$ no caso de solução fixa e atingiu 20 $\mathrm{cm}$ no caso de solução flutuante. A média destas diferenças é o valor que o usuário visualizará no coletor de dados em campo. Ou seja, será a informação tomada como referência para um usuário menos informado, o que não poder ser considerado como exatidão do levantamento.

Ainda nas tabelas 73, 74 e 75, pela análise da diferença padrão, ou seja, o valor em que se considerou o somatório das diferenças obtidas para cada um dos pontos, valor este tomado como referência para determinar a qualidade da amostra e verificar a aceitação ou não do experimento. A diferença padrão máxima para receptores GNSS L1/L2 foi de $2 \mathrm{~cm}$ nas soluções fixas com linhas base de até $96 \mathrm{~km}$ e $12 \mathrm{~cm}$ com solução flutuante chegando a $108 \mathrm{~km}$. Nota-se ainda que se obteve para a altimetria a diferença padrão máxima de $14 \mathrm{~cm}$ com a solução fixa até $96 \mathrm{~km}$ e de 1 metro com a solução flutuante até $108 \mathrm{~km}$.

No emprego de receptores GPS L1, os resultados foram mais susceptíveis aos efeitos que geram erros na coleta de dados GPS, sendo registrados PDOP altos e a baixa disponibilidade de satélites.

A seguir, se apresenta a tabela 76, onde foi utilizado apenas o receptor GPS L1, para os experimentos 13, 14, 15 e 16. 
Tabela 76 - Resumo dos resultados do exp. 13, 14, 15 e 16 (solução flutuante). Experimento

\begin{tabular}{|c|c|c|c|c|c|}
\hline \multicolumn{2}{|c|}{ Comprimento da Linha de Base (km) } & 9,6 & 17,0 & 30,4 & 35,0 \\
\hline \multicolumn{2}{|c|}{ Vértice } & V2296 & V2009 & V2837 & V2510 \\
\hline \multicolumn{2}{|c|}{ Local } & Anhangabaú & Perus & Parelheiros & $\begin{array}{c}\text { Cid. } \\
\text { Tiradentes }\end{array}$ \\
\hline \multicolumn{2}{|c|}{ Equipamento } & GPSL1 & GPSL1 & GPSL1 & GPSL1 \\
\hline \multirow[t]{3}{*}{ Valor Oficial } & $E(m)$ & 332793,623 & 321919,934 & 324457,826 & 358096,276 \\
\hline & $N(m)$ & 7394977,022 & 7410979,52 & 7363504,042 & 7390723,706 \\
\hline & $\mathrm{h}(\mathrm{m})$ & 735,005 & 833,063 & 777,398 & 842,355 \\
\hline \multirow[t]{3}{*}{ Valor Médio } & $E(m)$ & 332793,361 & 321920,14 & 324457,765 & 358096,268 \\
\hline & $N(m)$ & 7394977,053 & 7410979,596 & 7363504,135 & 7390723,738 \\
\hline & $\mathrm{h}(\mathrm{m})$ & 735,603 & 833,247 & 777,529 & 842,454 \\
\hline Precisão Esperada & $\mathrm{E}, \mathrm{N}(\mathrm{m})$ & 0,02 & 0,027 & 0,04 & 0,045 \\
\hline \multirow[t]{2}{*}{ Média das diferenças } & $E(m)$ & 0,262 & $-0,206$ & 0,061 & 0,008 \\
\hline & $N(m)$ & $-0,031$ & $-0,076$ & $-0,093$ & $-0,032$ \\
\hline \multirow[t]{2}{*}{ Diferença Padrão } & $E(m)$ & 0,493 & 0,416 & 0,212 & 0,058 \\
\hline & $\mathrm{N}(\mathrm{m})$ & 0,306 & 0,378 & 0,201 & 0,036 \\
\hline Precisão Esperada & $\mathrm{h}(\mathrm{m})$ & 0,03 & 0,037 & 0,05 & 0,055 \\
\hline Média das diferenças & $\mathrm{h}(\mathrm{m})$ & $-0,598$ & $-0,184$ & $-0,131$ & $-0,099$ \\
\hline Diferença Padrão & $h(m)$ & 0,996 & 0,468 & 0,349 & 0,116 \\
\hline \multirow[t]{3}{*}{ Teste de Tendências } & $E$ & Falhou & falhou & falhou & passou \\
\hline & $\mathrm{N}$ & Falhou & falhou & falhou & falhou \\
\hline & $\mathrm{H}$ & Falhou & falhou & falhou & falhou \\
\hline \multirow[t]{2}{*}{ Teste de Precisão } & $\mathrm{E}, \mathrm{N}$ & Falhou & falhou & falhou & falhou \\
\hline & $\mathrm{H}$ & Falhou & falhou & falhou & passou \\
\hline \multirow{2}{*}{$\begin{array}{l}\text { Percentual de } \\
\text { atendimento do limite } \\
\text { de precisão do } \\
\text { fabricante }\end{array}$} & Planimetria & $14,00 \%$ & $16,00 \%$ & $17,00 \%$ & $85,00 \%$ \\
\hline & Altimetria & $3,00 \%$ & $13,95 \%$ & $30,00 \%$ & $62,00 \%$ \\
\hline \multirow{7}{*}{$\begin{array}{l}\text { Informações } \\
\text { de Campo }\end{array}$} & PDOP - médio & 7,9 & 2,6 & 2,5 & 3,66 \\
\hline & N.Satélite-médio & 6 & 8 & 9 & 7 \\
\hline & $\begin{array}{l}\text { Latência-média } \\
\qquad(\mathrm{seg})\end{array}$ & 2 & 1,7 & 1,6 & 1,7 \\
\hline & $\begin{array}{c}\text { Condição } \\
\text { Metereológica }\end{array}$ & Bom & Bom & Bom & Bom \\
\hline & $\begin{array}{l}\text { Inicialização } \\
\text { (min) }\end{array}$ & 3,2 & 2,15 & 1,22 & 1,9 \\
\hline & $\begin{array}{l}\text { Total de } \\
\text { Amostras }\end{array}$ & 65 & 86 & 80 & 61 \\
\hline & $\begin{array}{l}\text { Localização- } \\
\text { Geometria }\end{array}$ & Ruim & Médio & Médio & Bom \\
\hline \multicolumn{2}{|c|}{ Experimento } & 13 & 14 & 15 & 16 \\
\hline
\end{tabular}


Pela análise das tabelas 74, 75 e 76, nota-se que a média das diferenças com o emprego do receptor GPS L1 foi inferior a $2 \mathrm{~cm}$ nos eixos $E$ e $N$, para linhas base de até $5,7 \mathrm{~km}$ com solução fixa e $30 \mathrm{~cm}$ até $36 \mathrm{~km}$ com solução flutuante. A altimetria não superou os $7 \mathrm{~cm}$ com a solução fixa e atingiu $70 \mathrm{~cm}$ no caso de solução flutuante. Ou seja, pode-se afirmar que através do Receptor GPS L1, obteve-se a diferença padrão melhor do que $2 \mathrm{~cm}$ para linha base de 5,7 km com soluções fixas e melhores que $60 \mathrm{~cm}$ nas soluções flutuantes, no que diz respeito à planimetria. Para a altimetria chegou-se a $7 \mathrm{~cm}$ para linhas de base de até $5,7 \mathrm{~km}$ com soluções fixas e 1,5m até $35 \mathrm{~km}$ com solução flutuante.

Em alguns experimentos não foram aceitos os testes de tendência e precisão. Estes resultados estão diretamente ligados aos fatores citados no primeiro parágrafo desse item. Assim, algumas leituras foram afetadas e consideradas no cálculo da análise amostral, o que pode ter sido a causa desses resultados na análise estatística dos dados. Uma possibilidade estudada foi de dividir as amostras em relação a um valor significativo como o PDOP e realizar uma análise separadamente, o que foi descartado devido à necessidade da criação de um número ainda maior de experimentos. Assim, definiu-se utilizar a diferença padrão encontrada como o valor de referência para a aprovação ou não da amostra de modo a verificar se os erros sistemáticos (apontados no teste de tendência) e as baixas precisões (apontadas no teste de precisão) eram significativos, de modo a afetar a qualidade do levantamento em alguns casos.

\subsubsection{Análise técnica dos resultados obtidos e suas aplicações}

$\mathrm{Na}$ análise da utilização da técnica RTK/GSM determinou-se a precisão planimétrica média atingida em função do comprimento da linha de base, tipo de solução, isto com a utilização dos receptores GNSS L1/L2 e GPS L1. A altimetria foi apenas comentada e não analisada, exigindo um estudo mais profundo envolvendo técnicas de determinação do modelo geoidal e o emprego de gravimetria, que seriam temas para um trabalho mais extenso.

Para obter padrões de modo a estabelecer uma comparação das técnicas antigas e a proposta da técnica RTK/GSM, nas aplicações gerais da engenharia de 
agrimensura citadas na tabela 77 , serão avaliadas as precisões obtidas com as novas técnicas propostas (técnica 1: GNSS L1/L2 como solução fixa; técnica 2: GNSS L1/L2 como solução flutuante; técnica 3: GPS L1 como solução fixa; técnica 4: GPS L1 como solução flutuante) e comparadas com as precisões esperadas em cada aplicação. Após esta análise será determinada a possibilidade do uso da técnica RTK/GSM em substituição às técnicas tradicionais.

A Tabela 77 apresenta as precisões esperadas para as aplicações de levantamento topográfico, georeferenciamento de imóveis rurais, locação de obras e locação submétrica com técnicas tradicionais já consagradas e avaliadas (que serão definidas com letras.

\begin{tabular}{|c|c|c|c|c|}
\hline \multicolumn{4}{|c|}{ Tabela 77 - Aplicação x Precisão Esperada - Técnicas tradicionais. } \\
\hline $\begin{array}{c}\text { Aplicação x Precisão } \\
\text { Esperada }\end{array}$ & $\begin{array}{c}\text { Levantamento } \\
\text { Topográfico }\end{array}$ & $\begin{array}{c}\text { Georeferencimento } \\
\text { de Imóveis Rurais }\end{array}$ & $\begin{array}{c}\text { Locação } \\
\text { Obras }\end{array}$ & $\begin{array}{c}\text { Locação } \\
\text { Sub-métrica }\end{array}$ \\
\hline $\begin{array}{c}\text { Precisão esperada } \\
\text { em E,N (m) }\end{array}$ & 0,02 & 0,50 & 0,02 & 1,00 \\
\hline $\begin{array}{c}\text { Localização deste } \\
\text { tipo de Aplicação }\end{array}$ & Rural,Urbano & Rural & Rural,Urbano & Rural,Urbano \\
\hline $\begin{array}{c}\text { Técnicas Tradicionais } \\
\text { Enumeradas }\end{array}$ & Estação Total(A) & Estação Total(A) & Estação Total(A) & Banda L(D) \\
\hline
\end{tabular}

Para definir a precisão esperada (Tabela 77) foi realizada extensa pesquisa para determinar uma padronização na utilização dos receptores GNSS nas aplicações citadas. No que se refere ao georeferenciamento de imóveis rurais, destaque para as duas edições de normas do INCRA (INCRA, 2003 e INCRA, 2010). Nos casos do levantamento topográfico a pesquisa levou em conta o que é estipulado nas normas NBR 13.133 (ABNT, 1994) e NBR 14.166 (ABNT, 1998), Já em termos de locação de obras e locação submétrica, foram adotados valores baseados na experiência de profissionais da área de posicionamento.

As tabelas 78 e 79 apresentam a técnica proposta de acordo com o máximo valor das médias das diferenças e a diferença padrão máxima obtidas nos experimentos. Porém, serão utilizados os valores da tabela 78 como limites de precisão obtidos em função da distância do receptor base e móvel, da solução encontrada e do tipo de receptor utilizado. Estas precisões limites comparadas com 
as precisões esperadas determinam à qualidade dos métodos propostos e a aplicação viável.

Tabela 78 - Média das diferenças máxima de acordo com a distância, tipo solução da ambiguidade e equipamento utilizado.

\begin{tabular}{c|c|c|c|c|c|}
$\begin{array}{c}\text { Técnica } \\
\text { Proposta }\end{array}$ & Eixos & $\begin{array}{c}\text { Média das } \\
\text { Diferenças máxima }\end{array}$ & Distância $\mathbf{( k m )}$ & Solução & $\begin{array}{c}\text { Receptor } \\
\text { GNSS/GPS }\end{array}$ \\
\hline $\mathbf{1}$ & E,N & 2 & & & \\
\hline $\mathbf{2}$ & E,N & 6 & 96 & Fixa & GNSS L1/L2 \\
\hline $\mathbf{3}$ & E,N & 2 & 108 & Flutuante & GNSS L1/L2 \\
\hline $\mathbf{4}$ & E,N & 30 & 5,7 & Fixa & GPS L1 \\
\hline $\mathbf{1}$ & $\mathbf{H}$ & 7 & 35 & Flutuante & GPS L1 \\
\hline $\mathbf{2}$ & $\mathbf{H}$ & 20 & 35 & Fixa & GNSS L1/L2 \\
\hline $\mathbf{3}$ & $\mathbf{H}$ & 3 & 108 & Fixa/Flutuante & GNSS L1/L2 \\
\hline $\mathbf{4}$ & $\mathbf{H}$ & 99 & 5,7 & Fixa & GPS L1 \\
\hline
\end{tabular}

Tabela 79 - Diferença padrão máxima de acordo com a distância, tipo de solução da ambiguidade e equipamento utilizado.

\begin{tabular}{|c|c|c|c|c|c|}
$\begin{array}{c}\text { Técnica } \\
\text { Proposta }\end{array}$ & Eixos & $\begin{array}{c}\text { Diferença padrão } \\
\text { máxima (cm) }\end{array}$ & Distância(km) & Solução & $\begin{array}{c}\text { Receptor } \\
\text { GNSS/GPS }\end{array}$ \\
\hline $\mathbf{1}$ & E,N & 2 & 96 & Fixa & GNSS L1/L2 \\
\hline $\mathbf{2}$ & E,N & 12 & 108 & Flutuante & GNSS L1/L2 \\
\hline $\mathbf{3}$ & E,N & 2 & 5,7 & Fixa & GPS L1 \\
\hline $\mathbf{4}$ & E,N & 70 & 35 & Flutuante & GPS L1 \\
\hline $\mathbf{1}$ & h & 8 & 35 & Fixa & GNSS L1/L2 \\
\hline $\mathbf{2}$ & h & 60 & 108 & Fixa/Flutuante & GNSS L1/L2 \\
\hline $\mathbf{3}$ & h & 7 & 5,7 & Fixa & GPS L1 \\
\hline $\mathbf{4}$ & h & 150 & 35 & Flutuante & GPS L1 \\
\hline
\end{tabular}

Após análise da tabela acima pode-se avaliar as precisões máximas atingidas em cada uma das técnicas propostas e determinar o limite de cada uma delas.

Considerando os experimentos realizados e propondo uma alternativa às técnicas tradicionais (Tabela 77), apresenta-se a Tabela 81 onde foi relacionado o método, o tipo de solução e o comprimento de linha de base para cada aplicação utilizando a técnica RTK/GSM. Determinando a precisão obtida com a nova técnica RTK/GSM, verificou-se qual aplicação que até então era executada somente pelas técnicas tradicionais poderiam ser substituídas pelas variações do novo método. 
É demonstrado na Tabela 81 (página seguinte), que o levantamento topográfico que até então só era possível de ser realizado com a técnica tradicional $A$ e $B$, pode agora ser desenvolvido pelas técnicas propostas 1 e 3 , ou seja, com a aplicação da técnica RTK/GSM com receptores GNSS L1/L2 e GPS L1 com solução fixa da ambiguidade.

O georeferenciamento de imóveis rurais, conforme as normas do INCRA (2010), exige as seguintes precisões apresentadas na tabela 80 . Nesta tabela se apontam as classes dos pontos a serem levantados, a finalidade e a precisão final exigida.

Tabela 80- Classificação e finalidade dos vértices padrão INCRA e respectiva precisão exigida.

\begin{tabular}{|c|c|c|}
\hline Classe & Finalidade & Precisão exigida \\
\hline C1 & Apoio básico, apoio imediato, limites & Melhor que $0,10 \mathrm{~m}$ \\
\hline $\mathrm{C} 2$ & Apoio imediato, limites & Melhor que $0,20 \mathrm{~m}$ \\
\hline C3 & Desenvolvimento da poligonal, limites & Melhor que $0,40 \mathrm{~m}$ \\
\hline C4 & Limites, limites naturais & Melhor que $0,50 \mathrm{~m}$ \\
\hline C5 & Limites naturais & Melhor que 2,00 m \\
\hline
\end{tabular}

Fonte: adaptado de INCRA (2010).

Assim, a partir dos dados da tabela 80 e em comparação com o que era apenas realizado pelos métodos $A$ e $B$, considerando os padrões de precisão exigidos pelo INCRA tem-se que: a) as coordenadas planimétricas dos vértices de todas as classes (C1, C2, C3, C4 e C5) podem ser obtidas por meio das técnicas $1 \mathrm{e}$ 3 ; b) as coordenadas planimétricas dos vértices das classes ( $C 2, C 3, C 4$ e C5) podem ser obtidas por meio das técnicas 1,2 ou $3 ; \mathrm{c}$ ) as coordenadas planimétricas dos vértices da classe C5 podem ser obtidas por meio das técnicas 1, 2, 3 ou 4 .

A locação de obras, por outro lado, igualmente realizada com as técnicas tradicionais A e C, pode agora ser efetuada pelas técnicas propostas 1 e 3 , ou seja, com o levantamento com o emprego da técnica RTK/GSM L1/L2 e RTK/GSM L1 com solução fixa.

O levantamento e a locação submétrica e podem dispor atualmente das técnicas propostas 1, 2, 3 ou 4 em oposição às técnicas tradicionais $D$ (banda $L$ ) e $E$ (Oministar). Isso tudo é apresentado na tabela 81, a seguir. 
Tabela 81 -Aplicação x Precisão Esperada - técnicas propostas.

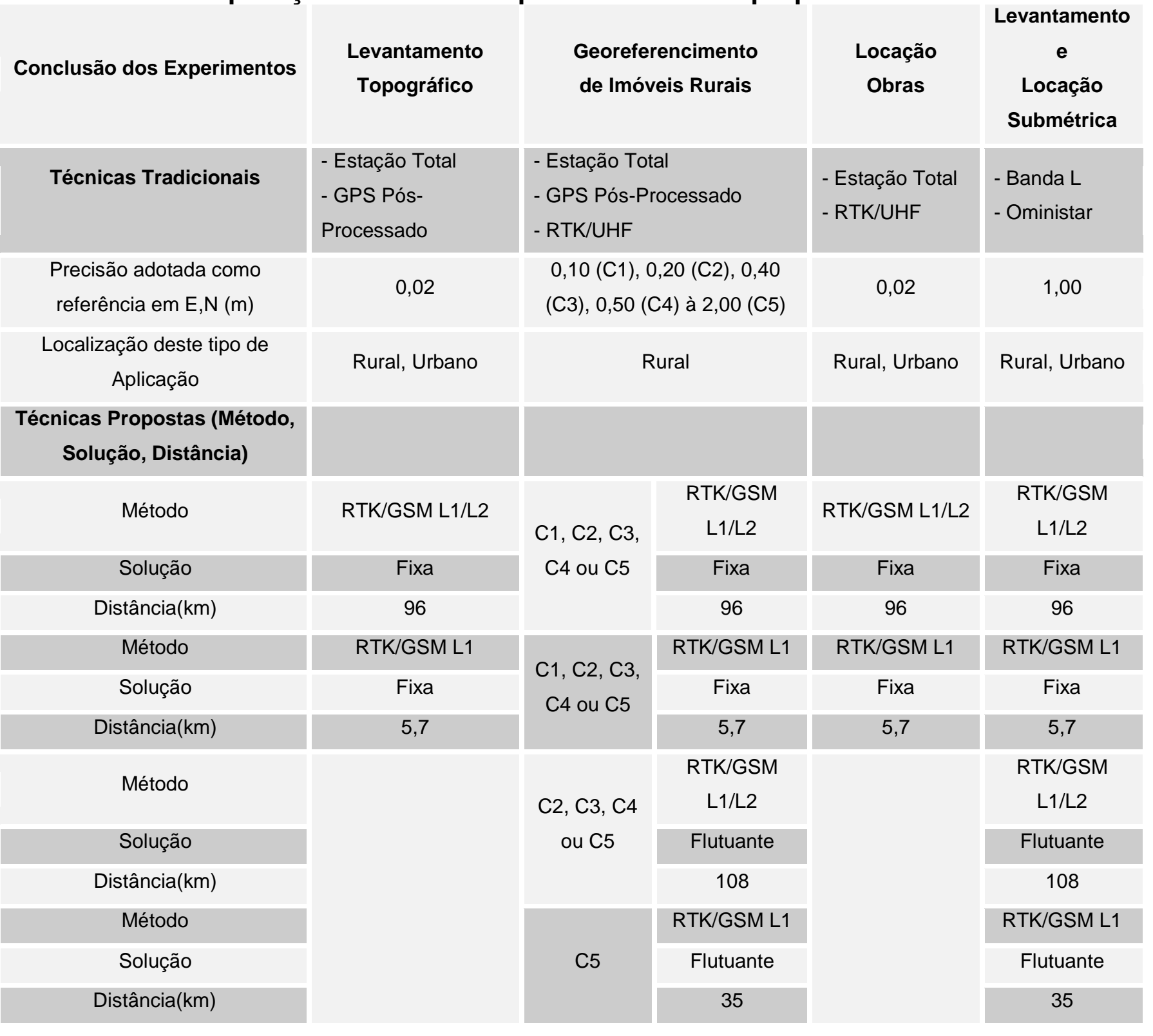

O uso do receptor GNSS L1/L2 é extremamente adequado e garante um posicionamento centimétrico mesmo para distâncias de até $1000 \mathrm{~km}$; e com vetores inferiores a $100 \mathrm{~km}$ a qualidade do cálculo chega a $2 \mathrm{~cm}$ com facilidade.

O receptor GPS L1 é capaz de rastrear apenas a constelação GPS, tornando o mais vulnerável devido ao número reduzido de satélites disponíveis decorrentes das obstruções do sinal e pelo multicaminhamento, o que será comprovado pelo aumento do PDOP. Nestas condições é possível atingir um posicionamento centimétrico com vetores de até $5,6 \mathrm{~km}$ e decimétrico para distâncias superiores a 
$100 \mathrm{~km}$, sendo que no primeiro caso recorrente de posicionamento por meio da técnica RTK e no segundo pelo levantamento por meio da técnica DGPS. Caso a constelação GLONASS soma-se a GPS em um equipamento de simples frequência, os vetores terão um resultado melhor. 


\section{CONCLUSÃO}

O novo método com o emprego da técnica RTK/GSM é tecnicamente aprovado neste trabalho para as aplicações propostas utilizando as novas técnicas RTK/GSM L1/L2 e RTK/GSM L1 em substituição às técnicas topográficas tradicionais com Estação Total ou mesmo o uso das técnicas do GPS pósprocessado, RTK/UHF e OmniSTAR.

Os resultados obtidos confirmam o uso da técnica RTK/GSM empregada em termos de precisão e acurácia, sendo esses valores quantificados de modo seguro e consistente, pois são resultantes da comparação com coordenadas oficiais.

Pode-se verificar que as coordenadas obtidas com a solução fixa, ou seja, aonde as duplas diferenças de fase foram calculadas, possuem resultados extremamente confiáveis, sendo um critério conclusivo para a validação da qualidade da precisão e acurácia do ponto medido. Desta maneira, o usuário possue uma ferramenta segura para analisar e validar seu trabalho em campo. Os resultados com a solução flutuante resultam em coordenadas com a precisão média exibida no software de coleta de dados e assim as coordenadas obtidas só poderão ser utilizadas se o projeto que esta sendo executado permite tal nível de precisão.

Os serviços topográficos tradicionais, o georeferenciamento de imóveis rurais e a locação de pontos com precisão podem empregar a técnica RTK/GSM, desde que haja a disponibilidade de sinal de telefonia celular. A grande vantagem reside na maior produtividade na realização dos trabalhos em comparação às técnicas tradicionais, o que torna a técnica RTK/GSM uma ferramenta essencial em projetos de engenharia, superando assim um paradigma na área de posicionamento com precisão.

A seguir, apresentam-se as vantagens e a viabilidade do uso da técnica RTK/GSM, bem como as perspectivas futuras. 


\subsection{VANTAGENS DA TÉCNICA RTK/GSM EM COMPARAÇÃO A TÉCNICA RTK/UHF}

A primeira e mais significativa vantagem da técnica $R T K / G S M$ em relação à técnica RTK/UHF é a consistência do sinal, pois a conexão GSM/GPRS dentro de sua área de cobertura é estável e transmite as informações com rapidez e segurança. Isso torna viável o uso da técnica RTK/GSM em locais com topografia acidentada, áreas urbanas densas ou com obstruções em geral, o que dificulta o posicionamento com o emprego da técnica RTK/UHF.

Constatou-se nesta pesquisa que é possível trabalhar num raio de até $96 \mathrm{~km}$ com receptor GNSS L1/L2, obtendo a precisão de $2 \mathrm{~cm}$, alcance nunca imaginado com o emprego da técnica RTK/UHF. Esse aspecto implica em grande economia e redução de custo operacional, por propiciar a diminuição da equipe de campo e até mesmo da quantidade de equipamentos necessários na execução de alguns projetos.

A utilização do receptor de simples frequência para o levantamento RTK foi testado neste trabalho. Na técnica RTK/GSM L1, pode-se afirmar que para distâncias de até $5,7 \mathrm{~km}$, os resultados atingem até $2 \mathrm{~cm}$ de precisão.

Por outro lado, as limitações existentes na técnica RTK/UHF, tais como PDOP e multicaminho, são as mesmas que as apresentadas na técnica RTK/GSM. No entanto, deve-se ressaltar a utilização e a consolidação da constelação GNSS, que aumentará significativamente o número de satélites disponíveis, reduzindo as limitações citadas.

\subsection{VIABILIDADE E UTILIZAÇÃO DA TÉCNICA RTK/GSM}

Para a operacionalização da técnica RTK/GSM existe a total dependência da conexão GSM/GPRS, por ser desta maneira que será transmitida a fase da onda portadora. Analisou-se neste trabalho a possibilidade de realizar a conexão GSM/GPRS de três modalidades: a rede NTRIP, o IP direto e a conexão GSM direta. 
Cada uma delas tem suas particularidades (§ 2.6), mas estão baseadas no envio da observação da fase da onda portadora por uma conexão GSM/GPRS.

O IBGE implantou oficialmente o serviço RBMC-IP por meio do estabelecimento de uma rede de serviço NTRIP. Em sua fase inicial, o serviço disponibilizou o protocolo RTCM de 25 estações de referência em um IP específico, mediante a um pré-cadastro. Este projeto tende a se expandir gradativamente com a adoção de mais ERA, vindo a cobrir uma maior área do território brasileiro, viabilizando a utilização deste serviço. Entretanto, devido à extensão territorial brasileira, seriam necessárias aproximadamente 600 ERA para a cobertura total, o que implica num alto investimento de infraestrutura e um serviço contínuo de manutenção deste sistema.

Assim, entende-se que levará vários anos para se estabelecer uma rede de serviço NTRIP com cobertura total do território brasileiro, expandindo-se a partir dos grandes centros para os médios e, posteriormente, complementando essa total cobertura. Assim, os outros 2 métodos citados -o IP direto e a técnica GSM diretaserão muito utilizados neste período inicial de implantação da rede, mesmo porque os projetos que atualmente utilizam da técnica RTK estão diretamente ligados à infra-estrutura, ou seja, distantes dos grandes centros, onde os trabalhos topográficos convencionais são os mais executados. Desta maneira, a tendência é que ocorra uma grande competição entre a utilização da técnica RTK/GSM e os instrumentos topográficos convencionais. Os mercados americano e europeu já passaram por esta etapa e a técnica RTK/GSM foi consagrada como superior quando comparada à topografia clássica (ASHTECH,2008).

Outro importante aspecto a ser debatido é a necessidade da sobreposição das ERAs. Esta possibilidade ocorre porque, devido a problemas na infraestrutura de instalação da ERA, pode haver a interrupção no funcionamento. Isto pode significar a paralisação de uma grande obra e, consequentemente, um alto custo com multas e atraso do projeto. Assim, para a consolidação do serviço NTRIP, será necessário optar pela sobreposição das ERAs ou, de alguma forma, garantir o perfeito funcionamento da existente. Outro aspecto é a própria conexão com a internet, que, se não estiver preparada para suportar este aumento de tráfego de dados, poderá sofrer uma interrupção no funcionamento.

Ao utilizar o método IP direto ( $§ 2.6$ ), passa-se a contar com a possibilidade de instalação da ERA próxima ao projeto e a eliminar o problema atual da pouca 
disponibilidade de ERA, porém, ainda existe a necessidade da cobertura para a conexão GSM/GPRS. A utilização deste método ocorrerá em paralelo à disseminação do serviço NTRIP e poderá ser implementado por empresas privadas para fornecer uma segunda opção de ERA em uma região com uma grande intensidade de uso, evitando uma possível interrupção de trabalho no caso de problemas com a operação do serviço ou viabilizar esta tecnologia em locais onde não há presença do serviço NTRIP atual. A realização desta pesquisa antecedeu à disponibilização do serviço oferecido pelo IBGE o RBMC-IP, assim todo o trabalho de campo exposto foi realizado por meio da técnica IP direto (descrito com detalhe no item 2.6). Em cidades como São Paulo, Belo Horizonte, Rio de Janeiro, Curitiba, Campo Grande, Cuiabá, Maceió e Rio Branco já existe ERA IP de empresa comercial do setor, mostrando, assim, uma tendência do mercado na cobertura mínima de mínimo 2 ERA, na mesma área de trabalho.

O método com o emprego da conexão GSM direta tem a mesma configuração do tradicional RTK/UHF, porém, não utiliza os rádios e sim os modems para a conexão GSM/GPRS. A realização desta conexão é possível e foi testada neste projeto, obtendo os mesmos resultados em relação a distâncias e precisões atingidas e viabilizando a utilização da técnica RTK/GSM.

Outro problema é a falta da infraestrutura da telefonia móvel, presente em todo o território nacional, de modo que garanta a transmissão dos dados das observações de fase em qualquer região que se realize um levantamento utilizando a técnica RTK/GSM.

\subsection{PERSPECTIVAS FUTURAS}

A evolução do serviço NTRIP é o método RTK em REDE, que é um conjunto de no mínimo 3 estações de referência ligadas a um servidor, que gerencia e disponibiliza as correções RTK, eliminando o erro linear e tornando a inicialização instantânea em campo, dentro da área de trabalho coberta.

Para o funcionamento do método RTK em REDE são necessários os seguintes componentes: no mínimo 3 ERAs IP em uma distância máxima de 100 km entre si; um software de gerenciamento das ERA que receba os dados, controle os 
acessos e crie um modelo matemático de correções geodésicas dentro da área de cobertura desta rede, e, ainda, receptores móveis com capacidade de receber e interpretar os dados.

Este método já está operacional em diversos países da Europa e as experiências demonstram que dentro desta área de cobertura a distância de linha base entre a ERA e o receptor móvel aumenta substancialmente, a qualidade do envio da observação de fase é mais estável e os trabalhos de posicionamento utilizando receptores GNSS são executados com mais eficácia e sem inicialização.

No Brasil, atualmente, o método RTK em REDE esta operacional para uso através de empresa comercial do setor. Entretanto, para a expansão, deverá ser realizado um estudo mais profundo para a respectiva conclusão dos resultados obtidos, utilizando a infraestrutura e trabalhando nas condições geográficas locais.

Espera-se por meio dessa pesquisa abrir uma discussão ampla para o desenvolvimento de novos estudos, com base em conceitos e metodologias aplicadas nos trabalhos aqui desenvolvidos. 


\section{REFERÊNCIAS}

ABNT, NBR 13.133. Execução de levantamento topográfico. ABNT, Rio de Janeiro, 1994.

ABNT, NBR 14.166. Rede de referência cadastral municipal - procedimento. ABNT, Rio de Janeiro, 1998.

ABREU, M. A. Análise da qualidade dos dados GPS: Estudo de caso da estação de Cananéia. [Dissertação de Mestrado]. Escola Politécnica da USP, São Paulo, 180 pp.

AFONSO, A. J. G. Implementação de uma rede de estações de referência GPS para posicionamento em tempo real. 2006.

ANATEL. Utilização de sistemas de transmissão de dados via telefonia móvel. 2008. Disponível em: <http://www.anatel.gov.br>. Acesso em: 23/10/2008.

ASHTECH Inc. Ashtech Z-XTREME TM GPS receiver operating manual. Maio, 2000, p. 010-052.

BENEDICTO, J.;LUDWIG, D. V Galileo system architecture and services GNSS international symposium (GNSS2001), 2001 - conferences.esa. int... Navigation Satellite Systems (GNSS-1), the EGNOS programme, to continue with the future generation of Global Navigation Satellite Systems (GNSS-2), the GALILEO. Fonte: <http://conferences.esa.int/01C14/papers/3.1.doc>. Acesso em 31/11/2008.

BRASIL. IBGE. Rede brasileira de monitoramento contínuo, 2008. Disponível em: http://www.ibge.gov.br/home/geociencias/geodesia/rbmc/rbmc_est.shtm. Acesso em: 25/11/2008.

RBMC-IP,

RBMC. Rede brasileira de monitoramento contínuo dos sistemas GNSS <http://www.ibge.com.br/home/geociencias/geodesia/rbmc/ntrip/>. Acesso em: 27/08/2011.

BRASIL. INCRA. Norma técnica para Georreferenciamento de imóveis rurais. Brasília, $2003 . \quad$ Disponível em: <http://200.252.80.5/Cartografia/download/Norma\%20Técnica.pdf>. Acesso em: 12/05/2008.

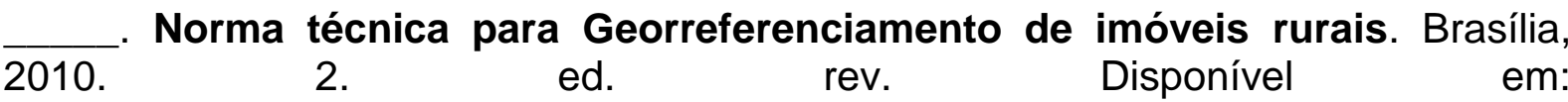
<http://www.incra.gov.br/portal/index.php?option=com_docman\&task=doc_download \&gid=755\&ltemid=295 > . Acesso em: 01/10/2011. 
BRIONES, A.B. Análise do posicionamento DGPS baseado nas ERDGPS implantadas no litoral brasileiro. Curitiba, 1999. Dissertação (Mestrado em Ciências Geodésicas), CPGCG, Universidade Federal do Paraná (UFPR).

CARROLL, J. A Survey of possible methods for mitigating the impact of radio frequency interference on satellite navigation systems used for precision approach. Center for Navigation Volpe National Transportation Systems Center Cambridge, Mass. USA, 2004. Disponível em: <http://spacecom.grc.nasa.gov/icnsconf/docs/2004/10_session_c2/C2-01Carroll.pdf>. Acesso em: 10/10/2008.

CHUJO, A. M. Tecnologias de navegação aérea por GNSS e DGNSS para operação CNS/ATM: Aplicações no Brasil. Tese (doutorado). ITA: São José dos Campos, SP, 2007.

CINTRA, J.P.; NERO, M.A.; RODRIGUES, D. GNSS/NTRIP service and technique: accuracy tests. Boletim de ciências geodésicas, V. 17. no.2, 2011. Disponível em: <http://ojs.c3sl.ufpr.br/ojs2/index.php/bcg/article/view/21896/14274>. Acesso em: 17/10/2011.

DALMOLIN, Q. Ajustamento por mínimos quadrados. Curitiba: Curso de PósGraduação em Ciências Geodésicas, 2002. V. 01.

DETTMERING, D.; SÖHNE, W.; FRANKE, P.; WEBER, G. The use of GNSS realtime data streams for geodetic applications - first results and perspectives. In: EGU General Assembly, Vienna, April 16, 2007. Disponível em: <http://bgi.cnes.fr:8110/EGU2007/02_Soehne.pdf>. Acesso em: 23/07/2008.

EISSFELLER, B. -The european satellite navigation System GALILEO. International Association of Geodesy (IAG) - dgfi2.dgfi.badw-muenchen.de Alenia, Alcatel, DornierSatellitensysteme, Matra Marconi Space: GNSS-2 Comparative System Study, Final Presentation, Noordwijk, December 7th, 1999. Disponível em: $<$ http://dgfi2.dgfi.badw-muenchen.de/dgfi/DOC/2002/cstg_vol17.pdf.page=52>. Acesso em 13/10/2008.

EL-MOWAFY, A. Performance Analysis of the RTK Technique in an Urban Environment. The Australian Surveyor, Vol.45, n.1, 2000.

ERICSON Inc., RF Guideline GSM 900 The Ericsson GSM System. 2004.

FOULKES-JONES, G.; CONSADIER, D. Utilizing a low cost receiver for centimeter to sub-meter accuracy real-time and post-processed applications. ION GPS-95, 1995.

FENG, Y. Combined Galileo and GPS: a technical perspective. Journal of Global Positioning Systems, 2003. Vol. 2, No.1: 67-72. Disponível em: <http://www.gmat.unsw.edu.au/wang/jgps/v2n1/v2n1ForumB.pdf>. Acesso em: 27/10/2008. 
FONSECA, J. S.; MARTINS, G. A. Curso de Estatística. 3. ed, São Paulo: Atlas, 1982. $286 \mathrm{pp}$.

GARCIA, D.A. Sistema GNSS (Global Navigation Satellite System). Escuela Politécnica Superior - Universidad Autônoma de Madrid, 2008. 106p. Disponível em: <http://arantxa.ii.uam.es/ jms/pfcsteleco/lecturas/20080125DavidGarcia.pdf>. Acesso em: 21/11/2008.

GEMAEL, C. Introdução ao Ajustamento de Observações: Aplicações Geodésicas. Curitiba: Editora da UFPR, 1994.

GONÇALES, R. Dispositivo de varredura laser 3D e suas aplicações na Engenharia, com ênfase em túneis. Dissertação (mestrado). EESC-USP: São Paulo, 2007.

GONZALES-MANTESANZ, F.J.; QUIROS, R.; CANO M. y DALDA. A. Posicionamiento GPS em tiempo real a través de Internet, FUREF-IP. Instituto Geográfico Nacional. VII Congresso Nacional de Topografia y Cartografia, TOPCART, 2004.

GREEN, G. Off-Road and Into the future, plenary panel session, Institute Of Navigation conference, Fort Worth, Texas, 2007.

HEIN, G. W.; GODET, J.; ISSLER, J. L.; MARTIN, J. C.; LUCAS, R. The Galileo frequency structure and signal design. In: ION GPS, 2001, Disponível em: $<$ http://www.ulg.ac.be/ipne/garnir/time/galileo/gal_stf_final_paper.pdf>. Acesso em: 21/11/2008.

HEINE, G. GSM Networks: protocols, terminology, and Implementation. Nordwood: Artech House Inc. 1999.

HENING, B. NGS Support for Real Time Networks. In: ESRI Survey \& Engineering GIS Summit, 2007. Disponível em: <ftp://ftp.ngs.noaa.gov/dist/whenning/ESRI 2007/>. Acesso em ago. 2008.

HOLDERLE, J. E.; KEEBAUGH, J. A.; LEWELLEN, J. W. Determining a predicted performance of a navigation system. US Patent App. 11/305,172, 2006 - Google Patents. Disponível em: <http://www.google.com.br/patents/pdf/Determining_a_predi cted_performance_of_a.pdf>. Acesso em: 25/10/2009.

JOOSTEN, P e IRSIGLER, M. GNSS ambiguity resolution in the presence of multipath. 2001. Disponível em: http://forschung.unibwmuenchen.de/papers/ltfxpfdymp5vtsnjondstmun8tpwad.pdf. Acesso em: 28/10/2008.

KOZLOV, D, and TKACHENKO, M, Centimeter level real-time kinematic positioning with GPS+GLONASS C/A receivers, Journal of the Institute of Navigation, Volume 45, Number 2. 
KRUEGER, C. P. Investigações sobre aplicações de alta precisão do GPS no âmbito marinho. Curitiba, 1996. Tese (Doutorado em Ciências Geodésicas), CPGCG, Universidade Federal do Paraná (UFPR).

KUROSE, J.F.; ROSS, K.W. Computer Networking a top-down approach featuring the Internet. Pearson.Addison-Wesley, Boston. 2004.

LANGLEY, R. RTK GPS. GPS World, Setembro, 1995.

LEICK, A. GPS Satellite surveying, 3. ed., New York: Wiley, 2004.

LENZ, E. et al. Networked Transport of RTCM via Internet Protocol (NTRIP): application and benefit in modern surveying systems, Raunheim, Germany, 2008.

LIM, S., HEO, Y., \& RIZOS, C., 2008. A web-based real-time monitoring system for GNSS data quality and integrity. FIG Working Week, Stockholm, Sweden, 1419 June, CD-ROM. Disponível em: $<$ http://www.gmat.unsw.edu.au/snap/publications/lim_etal2008a.pdf>. Acesso em: 23/06/08.

ASHTECH. PROMARK3/PROMARK3 RTK Reference manual. 2008a.

PROMARK 500 Reference manual. 2008b.

MCDONALD, K. Opportunity knocks: will GPS modernization open doors? GPS World 10(9):36-46. 1999.

MONICO, J. F. G. Posicionamento pelo Navistar GPS. São Paulo: Editora da UNESP, 2000.

MONICO, J. F. G. Posicionamento pelo GNSS: descrição, fundamentos e aplicações. 2. ed. São Paulo: Editora da UNESP, 2008.

NIEMANN, B.J. Improved Analytical Functionality: Modernizing Land Administration, Multipurpose Land Information Systems Guidebook, U.S. Federal Geodetic Control Committee, Section 11. 1989.

O'KEEFE, RYAN, K. S, LACHAPELLE, G. Global Availability and Reliability Assessment of the GPS and Galileo Global Navigation Satellite Systems. Canadian Aeronautics and Space Journal, v. 48. n. 2, 2002. Disponível em: <http://pubs.nrccnrc.gc.ca/casj/casj48/q02-019.pdf>. Acesso em: 23/11/2008.

PACIFICCREST (2009). Positioning Data Links For Land Surveying. (2009). Disponível em: <http://www.pacificcrest.com/products/product_wireless.shtml>. Acesso em 21/01/2009.

PAIVA, J. A. G. Efeitos da ionosfera de baixas latitudes no GPS - SBAS (Global System Positioning - Space Based Augmentation System). Dissertação (Mestrado). Pontifícia Universidade Católica. Rio de Janeiro, 2004. 
PIVARO, G. F. Redução de taxa de queda de chamada em rede de celular GSM por meio de ajustes de parâmetros de cobertura. Dissertação (mestrado). EESCUSP: São Carlos, 2008.

POLISCHUK, G. M.; KOZLOV, V.I.; ILITCHOV, V.V.; KOZLOV, A. G. The Global Navigation Satellite System GLONASS: Development and usage In: the $21^{\text {st }}$ Century. In: 34 th Annual Precise Time and Time Interval (PTTI) Meeting. 2006. Disponível em: <http://tycho.usno.navy.mil/ptti/ptti2002/paper13.pdf>. Acesso em: 25/01/2009.

PRADO, A. Análise da acurácia e da correlação espacial nas técnicas DGPS e RTK. Curitiba, 2001. Dissertação (Mestrado em Ciências Geodésicas), CPGCG, Universidade Federal do Paraná (UFPR).

PRIETO, M.A; SANABRIA, L.C; SANABRIA, P.M.M et al. NTRIP Herramienta indispensable para la cartografia y el catastro. Resumo. Chacao/Caracas, 2008. QUEIROZ, E. M. G. Algoritmo de alocação dinâmica de largura de faixa para redes de comunicação móvel celular. Dissertação (Mestrado). Escola de Engenharia de São Carlos - USP. São Carlos, 2008.

RIZOS, C.; HIGGINS, M.; HEWITSON, S. New GNSS Developments and their Impact on CORS Service Providers. In: Proceedings of SSC2005 Spatial Intelligence, Innovation and GNSS, 2005. Disponível em: <http://www.gmat.unsw.edu.au/snap/publications/rizos_etal2005b.pdf>. Acesso em: 23/11/2008.

ROGOWSKI, J.B.; KUJAWA, L.; LESZCZYNSKI, M.; ROGOWSKI, A. Some experiences in RTK and DGPS measurements using Internet and GSM mobilephone some experiences in RTK and DGPS measurements using Internet and GSM mobile. In: The EUREF 2004 Symposium of the IAG 2004 Bratislava, Slovakia. Disponível em: <http://www.euref-iag.net/symposia/book2004/P-10.pdf>. Acesso em: 20/09/2008.

ROTACHER, M.; MERVART, L. Bernese GPS Software V4.0. Astronomical Institute University of Berne, 1996.

RTCM V2.2 Radio Technical for Maritime Services: RTCM recommended standards for differential GNSS service V2.2. Alexandria (EUA), 1998. Recebido em 15 de maio de 2003 - Aceito para publicação em 23 de outubro de 2003.

RTK. Curitiba, 2001. Dissertação (Mestrado em Ciências Geodésicas), CPGCG, Universidade Federal do Paraná (UFPR).

SASS, J. Low cost, high accuracy, GNSS survey and mapping. 2008. Disponível em: <http://www.magellanjoe.comlarticles/Low_Cost_L1RTK_BLADE_2007.pdf>. Acesso em: 20/10/08.

SEEBER, G. Satellite Geodesy: fundations, methods and applications. Berlin; New York, 1993. 
SEEBER, G. Satellite Geodesy: fundations, methods and applications. 2. ed. Berlin; New York, 2003.

SEGANTINI, P. C. L. GPS: Sistema de posicionamento global. Escola de Engenharia de São Carlos - USP. São Carlos, 2005.

TIMO, H.; ROMERO, J.; MELERO, J. GSM, GPRS and EDGE performance evolution towards 3G/UTMS, Editora John Wiley \& Sons, 2002.

TORAN-MARTI, F.; VENTURA-TRAVESET J. The ESA EGNOS Project: The First Step of the European Contribution to the Global Navigation Satellite System (GNSS) In: GNSS-1 Project Office, 2004. Disponível em: $<$ http://esamultimedia.esa.int/docs/egnos/estb/Publications/NAVIGARE_EGNOS_Fin al.pdf>. Acesso em: 25/11/2008.

TSUJINO, T. Effectiveness of the Quasi-Zenith Satellite System in Ubiquitous Positioning, Science \& Technology Trends, Quarterly Review No. 16, Disponível em: $\quad<$ http://www.nistep.go.jp/achiev/ftx/eng/stfc/stt016e/qr16pdf/STTqr1607.pdf>. Acesso em: 29/07/2005.

VUOLO, J. H. Fundamentos da teoria dos erros. São Paulo: Edgard Blucher Ltda., 1992.

WEBER, G.; DETTMERING, D. (2005). Networked Transport of RTCM via Internet Protocol (Ntrip): IP-Streaming for Real-Time GNSS Applications, 18th International Technical Meeting of the Satellite Division of the U.S. Institute of Navigation, 13-16 September, Long Beach, CA, 2243-2247.

YAN, T. Benefits of telecommunications technology to GPS Users. Journal of Global Positioning Systems (2005), Vol. 4, No. 1-2: 240-244. Disponível em: $<$ http://www.gmat.unsw.edu.au/wang/jgps/v4n12/v4n12p30.pdf>. Acesso em: 20/09/2008.

ZANDONADI JR, D E WALTER, F. Pseudo-satélite transmissor/codificador de sinais GPS para aplicações GBAS: descrição, projeto e implementação. ITA, São José dos Campos, 2003. Disponível em: $<$ http://www.bibl.ita.br/ixencita/artigos/ele_DurvalZandonadiJr.pdf>. Acesso em: 23/12/2008.

ZHANG, K. et al., An Investigation of future GNSS in Support of research and development of positioning technology international in Symposium on GPS/GNSS, $2005 \quad-\quad$ user.gs.rmit.edu.au. Disponível em: $<$ http://user.gs.rmit.edu.au/falin/english/publications/proceedings/Zhangetal2005GPSGNSS.pdf>. 


\section{GLOSSÁRIO}

1- Geodésia

a. Observações de fase de batimento da onda portadora, simplificado para : observações de fase.

b. Protocolo RTCM.

c. Sistema GNSS, GPS, GALILEO.

d. Receptor GNSS: contempla os receptores que rastreiam as constelações GPS, GLONASS e demais.

e. Receptor GPS : contempla os receptores que rastreiam apenas a constelação GPS.

f. Distância do receptor base e móvel ou linha base.

g. ARP : Ponto de Referência da Antena.

h. ERA : Estação de Referência Ativa.

2- Telefonia

a. Conexão GSM.

b. Padronização GPRS.

c. Chip SIM : É um dispositivo microeletrônico que consiste de muitos transistores e outros componentes interligados capazes de desempenhar muitas funções.

d. Slot : Conector responsável por ligar os periféricos ao respectivo barramento.

3- Serviço NTRIP

a. ERA IP : Estação de referência ativa que disponibiliza as observações de fase num determinado I.P. . Será citada esta sigla quando o contexto abordar o protocolo IP.

b. MountPoint : Ponto de Conexão.

c. Source Table: Lista de Pontos.

4- Método Relativo

a. Técnica RTK.

b. Técnica RTK/GSM.

c. Técnica RTK/UHF.

d. Técnica Pós-Processada.

e. Solução Fixa - indica que todas as ambiguidades foram solucionadas.

f. Solução Flutuante - indica que menos de $50 \%$ das ambiguidades foram solucionadas.

g. Envio da observação de fase do receptor base para o móvel.

5- Definições

a. Padrão : Característica técnica entre os fabricantes.

b. Protocolo : Conjunto de Regras.

c. Firewall: é o nome dado ao dispositivo de uma rede de computadores que tem por objetivo aplicar uma política de segurança a um 
determinado ponto de controle da rede. Sua função consiste em regular o tráfego de dados entre redes distintas e impedir a transmissão e/ou recepção de acessos nocivos ou não autorizados de uma rede para outra.

d. Link : ligação entre uma fonte emissora e outra receptora. 